2. To: (Receiving Organization) Distribution

5. Proj./Prog./Dept./Div.:

TWRS Nuclear Safety and Licensing

8. Originator Remarks:

Authorization Basis upgrade plan for miscellaneous TWRS Facilities, Tanks and Components.

3. From: (originating Organization)

Operations and Projects

Safety Support

6. Design Authority/ Design Agent/Cog. Engr.:

E. J. Lipke and

R. G. Stickney
4. Related EDT No.:

$\mathrm{N} / \mathrm{A}$

7. Purchase order No.:

$N / A$

9. Equip./Component No.:

$\mathrm{N} / \mathrm{A}$

10. System/Bldg./Facility:

11. Receiver Remarks: 11A. Design Basel ine Document? [ ] Yes [X] No For Release.
TWRS
12. Major Assm. DWg. No.:
N/A

13. Permit/Permit Application No.: $N / A$

14. Required Response Date: $4 / 27 / 98$

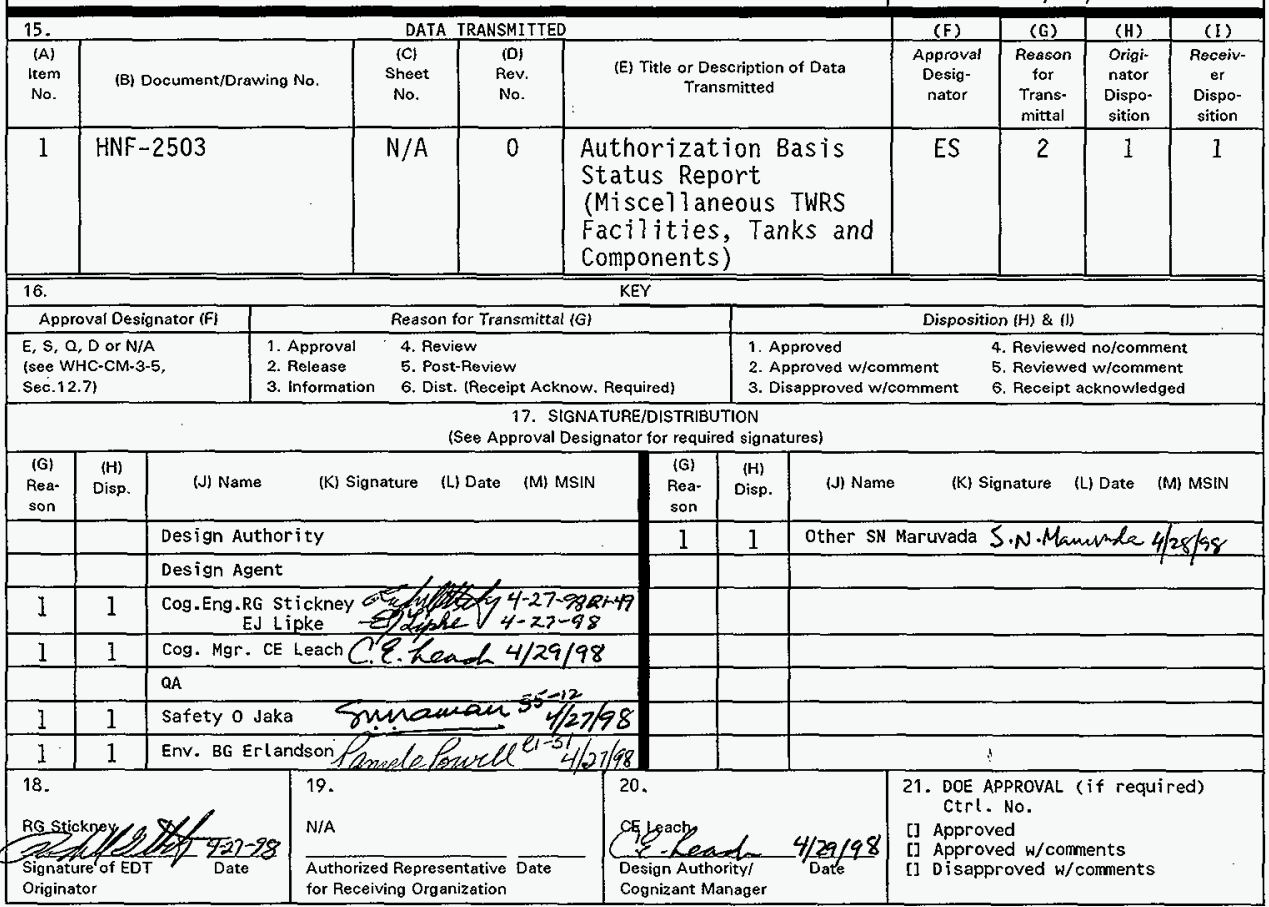




\section{Authorization Basis Status Report (Miscellaneous TWRS Facilities, Tanks and Components)}

Randall G. Stickney and Edward J. Lipke Duke Engineering and Services Hanford, Inc., Richland, WA 99352 U.S. Department of Energy Contract DE-AC06-96RL13200

EDT/ECN: EDT 624392

Org Code: 2 N140

B\&R Code: EW 3120072
UC: $\quad 2070$

Charge Code: N2GME

Total Pages: 248266

xite $4 / 24 / 48$

Key Words: Authorization Basis, IMUST, Status Report, TWRS miscellaneous facilities

Abstract: This report presents the results of a systematic evaluation conducted to identify miscellaneous TWRS facilities, tanks and components with potential needed authorization basis upgrades. It provides the Authorization Basis upgrade plan for those miscellaneous TWRS facilities, tanks and components identified.

TRADEMARK DISCLAIMER. Reference herein to any specific commercial product, process, or service by trade name, trademark, manufacturer, or otherwise, does not necessarily constitute or imply its endorsement, recommendation, or favoring by the United States Government or any agency thereof or its contractors or subcontractors.

Printed in the United States of America. To obtain copies of this document, contact: Document Control Services, P.O. Box 950, Mailstop H6-08, Richland WA 99352, Phone (509) 372-2420;

Fax (509) 376-4989.
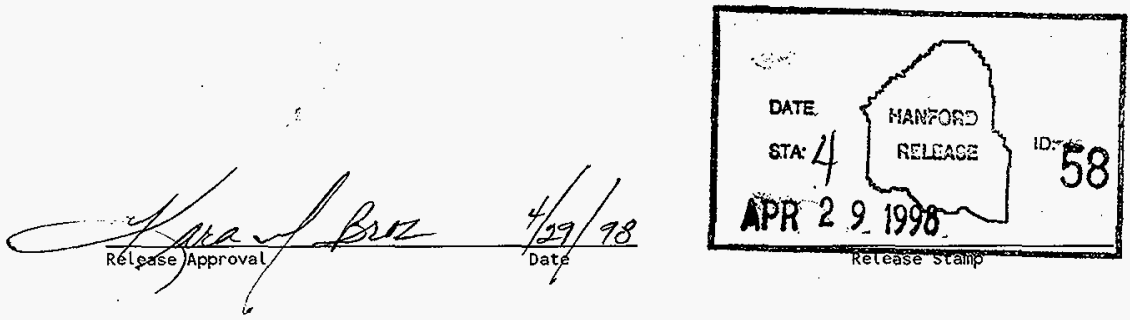

Approved for Public Release 
HNF-2503, Rev, 0

Authorization Basis Status Report

(Miscellaneous TWRS Facilities, Tanks and Components) 
This document has been prepared to satisfy the Tank Waste Remediation System (TWRS) fiscal year 1998 Performance Agreement (PA) TWR 1.2.1. The stated performance expectation is: "Prepare an Authorization Basis (AB) status report on TWRS facilities including a plan for recommended $A B$ modifications by May 1 , 1998." The documented PA contains specific expectations regarding this report. This foreword provides a reiteration of the specific expectations and summarizes how they are met.

\section{Report Expectation \#1}

"Identification of radiological and nuclear facilities, as defined in DOE-EM-STD-5502-94, clearly identified to be within the responsibility of TWRS, including major stand-alone structures and components. This shall include Inactive Miscellaneous Underground Storage Tanks (IMUSTs), the 7ist of "orphan" facjlities/structures, and any other facilities/structures identified by the Contractor during the performance of this task."

Identification of radiological and nuclear facilities. DOE-STD-EM-5502-94 provides important guidance regarding appropriate levels of safety documentation for DOE facilities based on the degree of radiological and chemical hazards posed. Chapter 3 of this report identifies all TWRS facilities, tanks and components (referred to as "FTCs" in the report) which are known or expected to fall within the DOE-STD-EM-5502-94 definition of "nuclear" and, therefore, are required to be addressed in a nuclear safety Authorization Basis per DOE Order 5480.23. Chapter 3 also identifies candidate "radiological" FTCs which may more appropriately be addressed by a lower "grade" of safety documentation. Appendix A contains detailed listings of the FTCs which are the focus of this effort to identify the remaining TWRS Authorization Basis upgrade needs.

Shall include IMUSTs. A significant portion of the effort to develop this report involved sorting through, organizing, correcting, updating and investigating many past efforts related to identifying "IMUSTs" (inactive miscellaneous storage tanks). A11 of these sources of information are cited in the extensive list of references provided in Chapter 8 , while the identification process is discussed in Chapter 3 . The first step in this effort was the introduction of new and refined definitions for the various categories of TWRS facilities which had, during RL's formulation of the PA, been informally referred to as "orphans." These definitions are provided in Chapter 2. Eleven of the sections in Appendix A provide a chronicle of the IMUST identification effort. The Appendix distills and compacts a significant amount of information in a user-friendly format.

The list of "orphan" facilities/structures. One of the motivations for the RL formulation of the PA stemmed from RL management facility walk-throughs. These walk-throughs resulted in the identification of certain TWRS facilities and structures which may not have been addressed in the TWRS Authorization Basis in a manner consistent with DOE Orders and standards. These facilities and structures were informally referred to as "orphans" predominantly because their safety documentation does not meet the standards set by the majority of the TWRS Authorization Basis documented in the TWRS Basis for Interim Operation (BIO). The informal term "orphan" does not appear in this report, however. It has been dropped in favor or the more descriptive definitions in Chapter 2. Each of the TWRS "orphan" facilities, tanks and major components 
which were included in the RL management walk-throughs are a subset of those FTCs specifically addressed in Chapters 3, 4, 5, 6 and Appendices A and B. Those facilities, structures and components which were identified by RL at the time that the PA expectations were establised are:

209-E Building

242-S Evaporator

242-T Evaporator

In-Tank-Solidification (ITS) Equipment

2727-W Sodium Storage Facility

Grout Treatment Facility

244-CR Vault

244-AR Vault

241-AX Ion Exchange Column

Purge Water Facility (subsequently confirmed not to be a TWRS facility)

other facilities/structures identified by the Contractor. It was recognized by the Contractor and RL that the means to identify facilities for management walk-throughs was not systematic and identification was ijkely not complete. Therefore, the PA expectations include effort on the part of the contractor to identify additional "orphans." The results of the full identification effort are found in Chapter 3 and in Appendix $A$.

\section{Report Expectation \#2}

"Identification of the existing Authorization Bases applicable to each facility and the determination of its adequacy with respect to:

- current mission and condition;

- requirements and guidance in DOE Orders 5480.22 and 5480.23 and DOE-STD-3011;

- comprehensive hazards identification (as ascertained by reviews of existing documentation and facility walk-downs); and

- existence of acceptable controls."

Identification of existing Authorization Bases. The nuclear safety Authorization Bases for each of the TWRS facilities, tanks and components addressed in this report are identified in Chapter 5 . Chapter 5 also identifies the Authorization Bases for non-TWRS facilities which are evaluated as possible contributors to the TWRS "hazard profile." "Hazard profile" is a term used in this report to refer to the collection of hazards (e.g., hazardous materials and energy sources) which, if uncontrolled, could cause a release of hazardous materials from a TWRS facility or pose a threat to TWRS facility workers or operations. Appendix A provides a comprehensive listing of the FTCs with indication of whether or not each is addressed in the TWRS BIO.

$A B$ evaluation with respect to current mission and condition. Chapter 3 provides the descriptions of all the TWRS facilities, tanks and components addressed in this report. The descriptions include an indication of the physical condition of each FTC and its current function in the TWRS mission. Chapters 4 and 5 use this information in the evaluation of the adequacy of existing Authorization Basis documentation.

$A B$ evaluation with respect to DOE 5480.22, 5480.23 and DOE-STD-3011. As discussed in Chapter 4, a primary evaluation criterion for the risk 
prioritized ranking of $A B$ upgrades is the "AB Status." The primary evaluation standard for "AB Status" is set by the TWRS BIO. The structure of the TWRS BIO is patterned after the chapter outline in DOE-STD-3011; although, the BIO amply exceeds the minimum technical requirements of DOE-STD-3011 and approaches that of DOE Order 5480.23. The Technical Safety Requirements (TSRs) which accompany the TWRS BIO meet the requirements of DOE Order 5480.22 and serve as a primary standard for the "Controls" evaluation criterion used in this report. Editorial considerations, such as comparison of document format to particular Orders and standards, did not strongly influence the $A B$ evaluation. Instead, the evaluation focused on a the caliber of the document's technical content compared to that called for in the DOE Orders and standards.

$A B$ evaluation with respect to hazards identification. Hazards are identified and discussed throughout Chapters 3,4 and 5 and in Appendices $A$ and $B$. References are provided in Chapter 5 to existing documented hazards analyses. The balance of discussion of hazards in the report is based on review of existing documentation and observations made during field walk-downs. No structured hazards analyses were performed (e.g., Hazops). Structured hazards analyses are part of the next phase of work to be performed to upgrade the TWRS $A B$ for the facilities, tanks and components identified in this report. This is consistent with the specific documented expectations for this PA.

$A B$ evaluation with respect to acceptable controls. As documented in Chapter 4, evaluation of the adequacy of existing controls is an influential factor in risk ranking the $A B$ upgrade needs. Chapter 5 describes the controls applicable to each FTC. Chapter 4 describes the methods used to evaluate the controls and demonstrates how these evaluations were used to establish the prioritization for FTC AB upgrades.

\section{Report Expectation \#3}

"A section which contains Authorization Basis upgrade tasks, preliminary costs and estimated schedule durations. The report sha7l prioritize the tasks. The prioritization rationale shall be described and based upon, at a minimum:

- qualitative assessment of relative risk,

- TWRS mission objectives,

- cost-benefit."

Section which contains Authorization Basis Upgrade tasks, preliminary costs and estimated schedule durations. Chapter 6 is dedicated to Authorization Basis upgrade planning. It consolidates all of the upgrade and pre-upgrade activities identified throughout the report, indicates the TWRS disciplines associates with the activities, and provides cost and schedule estimates for Authorization Basis documentation upgrade tasks.

The report shall prioritize tasks. Chapter 4 is dedicated to the prioritization of the facilities, tanks and structures with respect to the need to upgrade the $A B$ documentation for each. Chapter 4 also details a collection of "risk ranking factors" which are used to assess safety risk and importance of the $A B$ upgrades to the TWRS mission. Chapter 5 identifies specific tasks, including improvement of technical bases (e.g., sampling and characterization), which lead to and accomplish the AB upgrades. Chapter 6 captures all of the major tasks and applies a final test of cost-benefit to validate or adjust the prioritization developed in Chapter 4. 
HNF-2503, Rev. 0

Prioritization rationale shall be described. Chapter 4 documents the method, criteria and rationale for prioritization based upon safety risk and mission need. Chapter 6 provides the final validation of the prioritization based upon judgement of the cost of $A B$ and technical upgrades versus the benefit. 
HNF-2503, Rev. 0

TABLE OF CONTENTS

1.0 INTRODUCTION AND BACKGROUND ................ 1-1

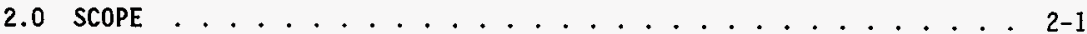

2.1 OBJECTIVE $\ldots \ldots \ldots 2-1$

2.2 FTCS WITHIN ACTIVITY SCOPE . . . . . . . . . . . . 2-1

2.3 INTERFACES ......................... 2-1

2.4 FTCS NOT WITHIN ACTIVITY SCOPE . . . . . . . $2-3$

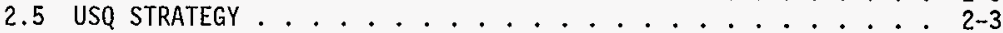

2.6 DEFINITIONS . . . . . . . . . . . . . 2-5

3.0 IDENTIFICATION OF FACILITIES, TANKS AND COMPONENTS . . . . . . . 3-1

3.1 IDENTIFICATION PROCESS . . . . . . . . . . . . 3-1

3.2 FTC INFORMATION MANAGEMENT $\ldots \ldots$

3.3 TWRS FACILITIES IDENTIFICATION AND DESCRIPTION $\ldots . . .3-7$

3.4 IMUST IDENTIFICATION AND DESCRIPTION ............ $3-41$

3.5 TWRS CHEMICAL TANKS AND FACILITIES ........... $. .5-52$

3.6 NON-TWRS FACILITIES, TANKS AND COMPONENTS ....... . . 3-52

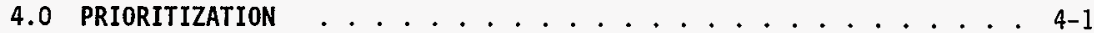

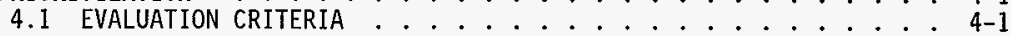

4.2 RISK RANKING RESULTS . . . . . . . . . . . . $4-5$

5.0 AUTHORIZATION BASIS STRATEGY . . . . . . . . . . . 5-1

5.1 TWRS FACILITIES .................. . . . . .

5.2 IMUST CATEGORIZATION $\ldots \ldots \ldots . \ldots .25$

5.3 FACILITIES ADJACENT TO TWRS .............. 5-31

6.0 AUTHORIZATION BASIS UPGRADE PLANNING . . . . . . . . . . 6-1

6.1 AUTHORIZATION BASIS UPGRADE TASKS ............ $6-1$

6.2 FISCAL YEAR 1998 REMAINING TASKS $\ldots \ldots \ldots$. $\ldots \ldots$

6.3 MULTI-YEAR WORK PLANNING $\ldots . \ldots 6-2$

6.4 COST-BENEFIT CRITERION FOR TASK PLANNING $\ldots . . \ldots 6-2$

7.0 CONCLUSION . . . . . . . . . . . . . . . . 7-1

8.0 REFERENCES . . . . . . . . . . . . . . . . . 8-1

Appendix A: Facilities, Tanks and Components Matrix ......... A-i

Appendix B: Hazard Profile Sheets ................ B-i 
HNF-2503, Rev. 0

\section{LIST OF TABLES}

Table 3-1. FTC Documentation and Personne1 Information Sources . . . 3-2

Table 4-1. Risk Ranking Criteria . . . . . . . . . . . 4-2

Table 4-2. Relative Risk Ranking Results . . . . . . . . . 4-6

Table 5-1. 204-AR Controls ............... 5-3

Table 5-2. 242-s Controls ................... 5-11

Table 5-3, 242-T controls . . . . . . . . . . . . . 5-13

Tab7e 5-4. 244-AR Controls . . . . . . . . . . 5-16

Table 5-5. 244-CR Controls . . . . . . . . . . . . 5-18

Table 5-6. 2727-W Controls ................ 5-21

Table 5-7. IMUST Categorization . . . . . . . . . 5-25

Table 5-8. Facilities with SARs . . . . . . 5-33

Table 5-9. Facilities with Hazardous Materials and No SAR . . 5-37

Table 6-1. Cost and Duration Estimates for Facility AB Upgrade Activities 6-4

Table 6-2. Cost and Duration Estimates for IMUST Group AB Upgrades . . 6-8 


\section{LIST OF FIGURES}

Figure $3-1$. FTC Information Management ........... 3-4

Figure 3-2. 204-AR Waste Unloading Facility ............ 3-8

Figure 3-3. 209-E Critical Mass Laboratory ............. 3-11

Figure 3-4. 213-W Dry Waste Compactor . . . . . . . . . . 3-15

Figure 3-5. 241-AX-151 Diverter Station . . . . . . . . . 3-17

Figure 3-6. 241-AX-IX Ion Exchange Column ............ 3-19

Figure 3-7. 242-S Evaporator ............... 3-20

Figure 3-8. 242-T Evaporator . . . . . . . . . . . . . . . . . . . . 3-24

Figure 3-9. 244-AR Vault . . . . . . . . . . . . 3-27

Figure 3-10. 244-BXR Vault . . . . . . . . . . . . . . . 3-30

Figure 3-11. 244-CR Vault .................. 3-31

Figure 3-12. 244-TXR Vault . . . . . . . . . . . . 3-34

Figure 3-13. 244-UR Vault ............. . 3-36

Figure 3-14. 2727-W Sodium Storage Facility . . . . . . . . . 3-37

Figure 3-15. Grout Treatment Facility ........... . 3-39

Figure 3-16. ITS-1 In-Tank Solidification System ......... 3-42

Figure 3-17. 301 Series Catch Tank . . . . . . . . . . . . . . 3-44

Figure 3-18. 302 Series Catch Tank . . . . . . . . . . . 3-45 
HNF-2503, Rev. 0

LIST OF ABBREVIATIONS, ACRONYMS, AND INITIALISMS

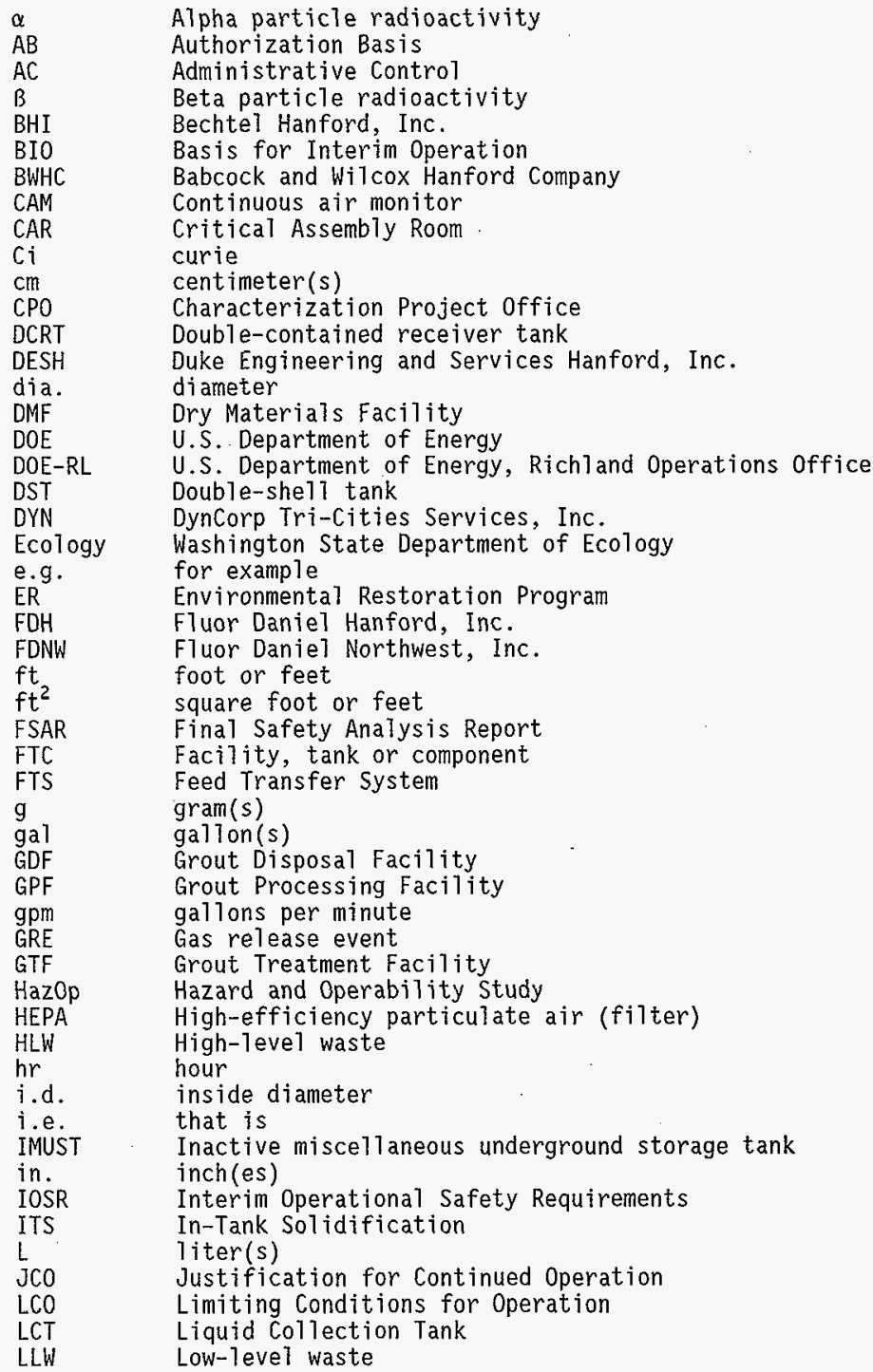


HNF-2503, Rev. 0

\section{LIST OF ABBREVIATIONS, ACRONYMS, AND INITIALISMS (Cont.)}

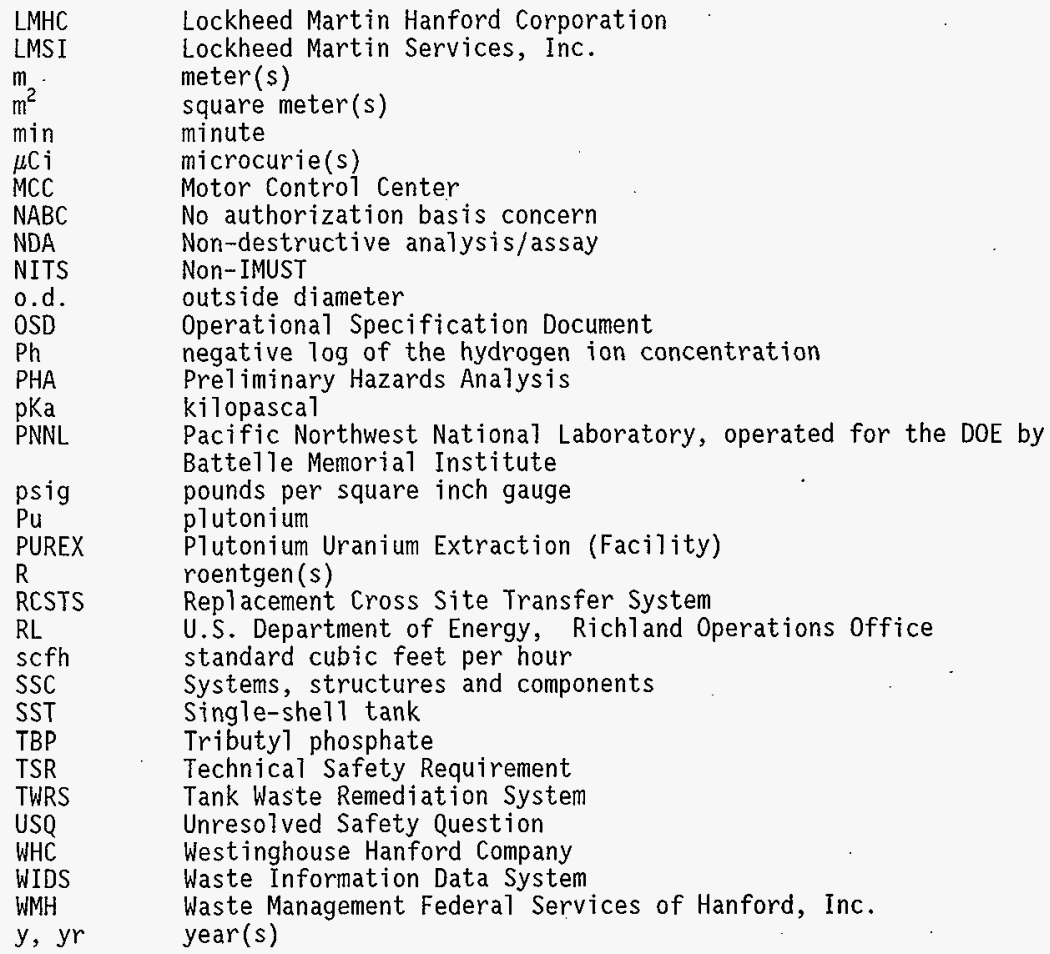


HNF-2503, Rev. 0

\subsection{INTRODUCTION AND BACKGROUND}

This report presents the results of a comprehensive activity to identify Tank Waste Remediation System (TWRS) facilities, tanks, and components (FTCS) that may require authorization basis $(A B)$ upgrades to comply with DOE order 5480.23 . The status of the $A B$ and controls implementation for each of these FTCs are examined, and prioritized plans are presented for $A B$ upgrades.

The current TWRS AB is comprised of documents identified in WHC-IP-0842, Volume IV, Section 5.4, Attachment A. The primary $A B$ documents are the TWRS Basis for Interim Operation (BIO) (HNF-SD-WM-BIO-001) and related Technical Safety Requirements (TSR) (HNF-SD-WM-TSR-006). The BIO describes and analyzes most facilities and activities associated with the TWRS waste storage mission. The BIO provides the technical basis for TSR controls that define the - operational safety envelope for operation of TWRS facilities. In addition to the $B I 0$, other specific $A B$ documentation exists for several miscellaneous tanks and facilities owned and maintained by TWRS.

It has been recognized that certain FTCS that are owned or managed by TWRS are not explicitly addressed in the current $A B$, or have not been characterized to the extent that the hazards are fully understood. Thus, upgrades to the $A B$ documentation may be needed to adequately address these FTCS. These FTCs are typically inactive and do not pose an immediate threat in their current configuration. One example of such a facility is the In-Tank Solidification (ITS) facility in the 241-BY Tank Farm, which is not described or explicitly analyzed in the BI0, nor does any other $A B$ documentation exist for this

facility. A systematic evaluation has been conducted to identify all the TWRS FTCs with potential $A B$ upgrade needs, including those that may exhibit chemical vulnerabilities and non-TWRS facilities that may contribute to the TWRS hazard profile (i.e., pose a hazard to TWRS operations, facilities, and personnel). The effort included FTC identification, process history and documentation review, controls evaluation, and development of a strategy for upgrade of the TWRS AB to address each identified FTC that was of $A B$ concern. This report presents the results of the effort and provides $p T$ ans for $A B$ upgrades. Further, a qualitative risk evaluation has been performed to prioritize the upgrade plans.

The driver for this effort is the recognition that the hazards of some TWRS FTCs have not been fully evaluated in $a n A B$ and that an evaluation of the risk posed by such facilities was needed so that strategies for updating the $A B$ could be established. This would ensure that the appropriate controls would be applied in a logical sequence and at the proper level for TWRS FTCs.

The activities described in this report are a part of the overall Hanford Site implementation of U.S. Department of Energy (DOE) Nuclear Safety Orders $5480.21,5480.22$, and 5480.23 for TWRS. This implementation is being pursued in a step wise manner, with the development and release of the TWRS BIO as a first step. The TWRS Final Safety Analys is Report (FSAR) (HNF-SD-WM-SAR-067) is being developed to comply with 5480.23 requirements. The activity described in this report is a part of the overall implementation effort, in that upgrades for the miscellaneous TWRS FTCs are required to implement 5480.23. This activity is described as a major part of the TWRS compliance activities in the Fluor Daniel Hanford, Inc. (FDH) Safety Analys is Reports and Technical Safety Requirements Implementation Plan (FDH-9852566). 
HNF-2503, Rev. 0

\subsection{SCOPE}

\subsection{OBJECTIVE}

The overall goal of the activity described in this report is to produce a prioritized $A B$ upgrade strategy to address TWRS FTCs with potential $A B$ upgrade needs. To accomplish the overall goal, the following interim objectives were established and completed:

- Identify and provide a comprehensive list of a11 200 Area inactive miscellaneous underground storage tanks (IMUSTs).

- Identify and provide a complete listing all TWRS FTCs having potentially inadequate $A B$ coverage.

- Provide a qualitative evaluation of the hazards and chemical vulnerabilities posed by these FTCs.

- Develop AB upgrade strategies for TWRS FTCs having potentially inadequate $A B$ coverage.

- Develop prioritization criteria.

- Prioritize the $A B$ upgrade strategies.

\subsection{FTCS WITHIN ACTIVITY SCOPE}

This activity encompasses TWRS facilities (defined in Section 2.6), tanks, components, or vessels that were capable of storing more than incidental quantities of hazardous materials. Considerable attention was given to TWRS IMUSTs, vaults or other structures containing waste storage tanks that may not have been previously identified in the TWRS $A B$, or have the potential to contain wastes that are not typical of single-shell tank (SST) or double shell tank (DST) wastes. These are tanks that could have been used for chemical additions or treatment missions other than routine transfers between TWRS storage tanks. IMUSTs have been the subject of several previous studies and the IMUST definition has been used in the TWRS AB to categorize a specific group of tanks (refer to Section 2.6, Definitions).

Non-TWRS facilities were considered only to the extent that they could contribute to the TWRS hazard profile. This evaluation considered the possibility of an accident in a non-TWRS facility resulting in: (1) a radiological or toxicological release from a TWRS facility, or (2) hazards to TWRS workers or disruptions to TWRS operations.

\subsection{INTERFACES}

There are other contractor work activities that are related to this FTC evaluation activity. The flammable gas program, for example, is evaluating miscellaneous TWRS facilities (including IMUSTs) for closure of the flammable gas unresolved safety Question (USQ). Each of these efforts has been examined to determine if a relationship should exist with this activity. Following is a description of key information interfaces established: 
HNF-2503, Rev. 0

Characterization Project office (CPO): The recommendations for sampling of FTCs developed in this report will be integrated into the overall tank waste characterization effort. The sampling requirements identified from the prioritization of needed $A B$ upgrades will be provided for incorporation into the overalt tank sampling priorities and the resulting sampling schedules developed for TWRS by the CPO.

Chemical Vulnerability Assessment: The TWRS activity described in this report is broader than, but in part supports, the Hanford response to process deficiencies identified from the May 14, 1997 explosion at the Plutonium Reclamation Facility. As a result of this incident, several corrective actions were undertaken. The evaluation of chemical and radiological vulnerabilities across the Hanford Site was one of the corrective actions requested by the Secretary of Energy in an August 28, 1997 memorandum. A progress report of the actions taken in response to the memorandum was published in December 1997 (DOE/RL-97-85, Rev. 0), which includes a general description of the TWRS activity described in this report.

Process Engineering: TWRS Process Engineering is responsible for establishing and maintaining tank waste behavior models, and thus has provided a significant amount of the process history information on the TWRS FTCS discussed in this report. This TWRS function is also active in the resolution of the TWRS safety issues (such as flammable gas) and is currently prioritizing IMUSTs with regard to the flammable gas hazard. This information is still being developed. An information exchange has been established with Process Engineering to ensure that a consistent set of priorities are developed.

Flammable Gas Issue Resolution: As a part of the flammable gas issue resolution activity, miscellaneous TWRS facilities, including IMUSTs, are being evaluated with respect to the flammable gas hazard. A part of this activity is the identification and field walkdown of IMUSTs. Field walkdowns were coordinated with the flammable gas program to share information and avoid duplication of effort. Information gained from the IMUST identification described in this report is being forwarded to the TWRS Safety Issue Resolution function for inclusion in the issue resolution activities.

RL Senior Management Walkthroughs: U.S. Department of Energy, Richland Operations office (RL) senior management conducts regular walkthroughs of TWRS facilities. The recent walkthroughs have focused on facilities discussed in this report. These walkthroughs have resulted in a cursory evaluation of current facility conditions and qualitative assessment of risk. Since these facilities are of primary importance to the development of this report, representatives of TWRS Nuclear Safety and Licensing, Operations and Engineering organizations have attended most of the walkthroughs. Information obtained from them has been incorporated into the facility profiles in Appendix B.

Implementation Plans for DOE Orders: The activity described in this report is part of the continuing effort to bring TWRS facilities into compliance with DOE Order 5480.23. This activity is described in the FDH Safety Analysis Reports and Technical Safety Requirements Implementation Plan (FDH-9852566). The approved actions from this plan will be incorporated into HNF-SP-1228. 
HNF-2503, Rev. 0

\subsection{FTCS NOT WITHIN ACTIVITY SCOPE}

Facilities and structures outside of the 200 Areas were not considered to be within the scope of this activity. Office facilities, change room facilities, and other structures not capable of containing radioactive, hazardous or mixed waste other than in incidental quantities were not considered. ATso excluded were: DSTs, SSTs, active catch tanks, active transfer system components, inactive transfer components (other than tanks), double-contained receiver tanks (DCRTs), diversion boxes (without tanks), cribs, septic tanks, retention basins, ponds, ditches, dumping areas, valve pits, and unplanned release sites. BIO coverage for such FTCs is considered to be adequate.

A 1997 letter (97-TWR-017) discussed the proposed transfer of waste sites between the Environmental Restoration Program (ER) and TWRS. This includes the change in ownership of seven IMUSTs between ER and TWRS (three to ER and four to TWRS). This transfer of ownership has not yet occurred, and for the purposes of this report, the tanks scheduled for transfer to ER are treated as TWRS-owned. When the transfer occurs, it may result in a change in planning for the subject tanks. For completeness, the 244-UR Vault (containing four IMUSTS), scheduled to be taken over by TWRS, is treated as a TWRS-owned facility in this report. However, any activities planned for this vault cannot be pursued unless the transfer is finalized.

\subsection{USQ STRATEGY}

The activity described in this report is an integral part of the overall Hanford implementation of DOE Nuclear Safety orders 5480.22 and 5480.23. During the process of planning for the TWRS AB upgrades to comply with these orders, it was recognized that the hazards of some TWRS FTCs have not been fully evaluated in the $A B$ and that an evaluation of the risk posed by such facilities was needed so that a prioritized plan for upgrading the $A B$ could be established. This would ensure that the appropriate controls would be applied in a logical sequence and at the proper authorization level for TWRS FTCS. This report provides a prioritized listing of the upgrade plans for certain TWRS miscellaneous FTCs. This activity is described as a major part of the TWRS compliance activities in the Fluor Daniel Hanford, Inc. (FDH) Safety Analysis Reports and Technical Safety Requirements Implementation Plan (FDH-9852566).

It is not intended that a USQ would be declared for each facility, tank, or component identified during this effort, the main purpose of which is to identify needed upgrades to the $A B$. This is consistent with the guidance provided by DOE (Memorandum, NE-70, RL commitment control \#930020.0F) which provides interpretation for use in applying DOE Order 5480.21 "Unreviewed Safety Questions." The reference states: "Actions taken in response to upgrade requirements, such as DOE 5480.22 and 5480.23 should be treated as separate upgrade activities that do not impact the current/interim $A B$ and, therefore, new information developed or discovered as a result of such upgrades is excluded from the requirements of section $10 \mathrm{~d}$ of DOE $5480.21 . "$ For facilities not covered in the BIO, shortfalis in $A B$ documentation are expected (in the same way that shortfalis in the TWRS AB documentation were expected before the BIO was developed). As an example of this, there were known inadequacies in the Interim Operational Safety Requirements (IOSR) controls during the upgrade of the TWRS AB. and issuance of the BIO and TSRs. The TSRs represent a substantial improvement over the old controls. However, 
a USQ was not declared on the IOSR controls because the TSR development activity addressed known inadequacies in the controls. Had there been a discovery of an immediate need for additional or different controls because of unacceptable risk to the facility worker, onsite workers or the public, a USQ would have been declared. As such, the new or different controls would have been implemented as soon as practicable rather than on the planned schedule for BIO implementation.

The adequacy of existing controls for the FTCS addressed in this report was evaluated during the facility walkdown and evaluation process. As a result of this, there were no cases identified where there is an immediate need to invoke new/different controls for the purposes of preventing facility worker fatality or serious injury, or unacceptable risks to onsite workers or the public. If such conditions are discovered during the subsequent evaluations proposed in this report, a Discovery USQ would be recommended to RL and appropriate interim controls would be put in place by the contractor via a vehicle such as a Standing Order. The contractor would propose that such a USQ could be closed once RL-approved controls are in place. In the case where it is concluded that a facility is addressed in the BIO, but the BIO is found to be inadequate to maintain the safety of the facility in question, a USQ screening of the Potential Inadequacy in the Authorization Basis (PIAB) could lead to the recommendation for a USQ to be declared and the imposition of interim controls. The USQ would be closed once the BIO is appropriately upgraded.

The overall strategy is to provide a systematic and rigorous means to identify and evaluate those facilities for which $A B$ upgrades are required and to develop a plan for such upgrades without having an excessive number of unnecessary USQ evaluations. This is consistent with the NE-70 guidance.

In all cases where $A B$ upgrades are required, including a systematic evaluation of hazards and subsequent development of appropriate controls, current TWRS practices associated with current facility missions were judged to sufficiently protect workers in the near term. Therefore, no additional or interim controls are proposed in the report. For instance, while the 242-T Evaporator is ranked as the highest priority concern, and it is acknowledged that there may be hazards that are not yet identified, worker activities in this facility involve only routine building surveillance and operation of the ventilation. system. No entry into contaminated areas is involved. No work involving contact with or disturbance of the radioactive or hazardous debris of the shut down facility is currently planned or authorized. No controls and practices above and beyond those currently in place could be identified based on contractor knowledge of the facility. Instead, this report reflects the conclusion that safety is best served by gaining a better understanding of hazards through structured hazards analysis and characterization. Controls associated with possible characterization activities need to be developed as a part of those activities.

Another exampie of the application of this strategy is the ITS (in-tank solidification) system in the 24l-BY Tank Farm. The facility is not explicitiy covered in the BIO. A facility walkdown and review of drawings and process history have been completed. The evidence reviewed to date suggests that there are no acute energy sources of concern in this facility. Nothing . suggests the need for a separate urgent controls development effort. Unti] there is information to suggest otherwise, the current $A B$ upgrade plan will be implemented, acknowledging that no present TWRS $A B$ document adequately 
accounts for this structure. At this point in time, declaration of a USQ would not be useful and would result in an administrative burden that does not enhance TWRS safety.

There are currently several open USQs relating to the TWRS AB. Among these, there are two that are considered major safety issues and are directly related to the activity described in this report. These are:

FLAMMABLE GAS USQ: In 1996, a flammable gas USQ (TF-96-0433) was declared, which encompassed a large number of miscellaneous TWRS tanks and facilities that had not been previously addressed in the TWRS AB. This USQ remains open, although the hazard is addressed in Appendix $E$ (Justification for Continued Operation) to the BIO and controlled through the TSRs. A strategy document for closure of the USQ has been issued (HNF-SD-WM-ER-680). This strategy document is currently being updated to address USQ closure for tanks and facilities other than DSTs and SSTs. Those of interest to this activity include IMUSTs, 204-AR Waste Unloading Facility, 244-AR Vault, 244-CR Vault, 242-T Evaporator, and 242-S Evaporator.

ORGANIC NITRATE USQ: In May 1996, an organic nitrate USQ (Letter, RL, 96-WSD-073) was declared, which encompassed a number of TWRS tanks that had considerable uncertainty regarding the potential for an organic nitrate reaction and had not been fully evaluated in the TWRS AB. The USQ applies to DSTS, SSTS, DCRTS, and IMUSTs. This USQ remains open, although the hazard is now addressed in the BIO and is controlled through the current TSRs. A strategy document for closure of the USQ has been issued (WHC-EP-0908). The applicable strategy is currently being implemented. It entails a significantly improved and refined quantification of the risk and demonstration that the risk falls within evaluation guidelines. On August 17, 1998, the contractor will submit an ECN to RL to amend the BIO and the TSRs to incorporate the new technical information. The refined quantification of risk will allow alleviation of some of the controls presentiy in place.

\subsection{DEFINITIONS}

The following are definitions applicable to this report. They are used primarily to categorize the information obtained in the identification phase of the activity, and correspond to the information categories presented in the FTC Tistings in Appendix A.

FTC:

Facility, Tank or Component designed for storage and or processing of chemicals or waste materials in greater than incidental quantities, that for the purposes of this report has potential $A B$ upgrade needs.

Facility: An identifiable unit of property that contains vessels and other components.

Major Facility: A facility designed to house multiple processes and components. A major facility would usually be housed in a building. Examples of major facilities include the 209-E Building and the 242-5 and 242-T Evaporators. Vauits and diverter stations are usually not major facilities, since 
they simply house multiple tanks to facilitate switching and interconnections but do not house multiple processes. Note that by this definition, 244-AR Vault is a major facility because of its previous housing of multiple process functions. All other vaults are not major facilities.

IMUST :

Inactive Miscellaneous Underground Storage Tank. An IMUST is (1) inactive; (2) radioactive; (3) underground; and (4) not within a major facility "miscellaneous." "Inactive" means the tank is either physically or administratively isolated. "Radioactive" means that the tank contains radioactive material. Non-radioactive chemical tanks are not IMUSTs. "Underground" means the tank is partially or wholly below grade. It has been historically accepted that "miscellaneous" means that the tank is not within a major facility (excluding tank farms in general). This category further breaks down into TWRS and non-TWRS.

As an example, the decontamination tank (TK-111) associated with 209-E is located underground and outside the facility. It is an IMUST. The dump tanks (TK-109 and TK-110), while underground, are located within the facility proper and are therefore not IMUSTs. The 242-T Evaporator decontamination tank (242-T-135) outside of the facility is an IMUST and has been categorized as an IMUST in previous IMUST lists. Tanks within or closely associated with a facility will be dispositioned with the facility whether or not those tanks are identified as IMUSTs.

Chem:

Chemical tanks are those that contain non-radioactive chemical materials. Petroleum and waste oil tanks also fall in this category. This category further breaks down into TWRS and non-TWRS.

NITs :

The Non-IMUSTs are miscellaneous tanks and other wastecontaining components that are not classified as IMUSTs or Chemical Tanks but may be of potential significance for safety issue resolution or chemical vulnerability. Examples include active tanks, storage pads, and dumping areas. Note that this category may include tanks in facilities. This category further breaks down into TWRS and non-TWRS.

NABCs:

This final category consists of facilities, tanks, and components that have No Authorization Basis Concern. Examples include water tanks or tanks that have been identified through a source document or drawing, but have never been built. 
HNF-2503, Rev. 0

\subsection{IDENTIFICATION OF FACILITIES, TANKS AND COMPONENTS}

\subsection{IDENTIFICATION PROCESS}

The first activity performed in support of this effort was to develop a comprehensive list of FTCS that have potentiaT AB upgrade needs. To do this several information sources were employed as described below:

Waste Information Data System (WIDS): The WIDS is an information database maintained by BHI Bechtel Hanford, Inc. (BHI). This database contains listings by program owner of all identified waste property units on the Hanford Site. WIDS was used as the baseline list to indicate the official facility ownership during the FTC identification process. As a result of the identification process, some discrepancies in the WIDS database were identified (e.g., incorrect tank identification numbers or definitions). These discrepancies are being corrected by submittal of the appropriate change authorizations to BHI.

Hanford Drawings: The Hanford drawings system was also used as a primary information source for tank/vessel identification. As-built drawings of the TWRS facilities and tanks were reviewed to 1) identify miscellaneous tanks and structures, and 2) determine if the drawings showed any transfer routes to previously unidentified tanks. The drawings provided information on tank and vessel dimensions, construction materials, locations, interconnections, and intended use in their respective facilities or projects.

Project Files: The records of past projects were reviewed as needed to identify and verify tank locations and determine current status. Of particular interest were the records of Project B-231, which was conducted during the late 1970 s and early 1980s. The objective of this project was to identify, stabilize, and isolate miscellaneous tanks and components that were inactive and had no future TWRS mission. These records provided information on tank contents at the time of stabilization and the physical modifications performed to isolate each of the tanks and components.

Interviews with Key Personnel: Informal interviews were conducted with current and former Tank Farms personnel. The FTC lists (Appendix A) were reviewed with these individuals, who typicaliy suggested other personnel to contact for further information. The interviews were primarily directed toward the identification of FTCS that may have been excluded from the Tistings shown in Appendix $A$; however, the individuals interviewed also provided information on FTC status, modifications, contents, and past operations. A list of key personnel contacted during the FTC identification effort is included in Table 3-1.

Documentation Sources: A number of documents have been previously produced that describe tank identification and hazard assessment activities. The bulk of this information was directed toward IMUSTs. Table 3-1 1ists several of the key documentation sources used in the development of the current listing of TWRS FTCS contained in Appendix A. The document numbers in the table refer to the references 1 isted in Chapter 8.0 of this report. 
Table 3-1. FTC Documentation and Personnel Information Sources

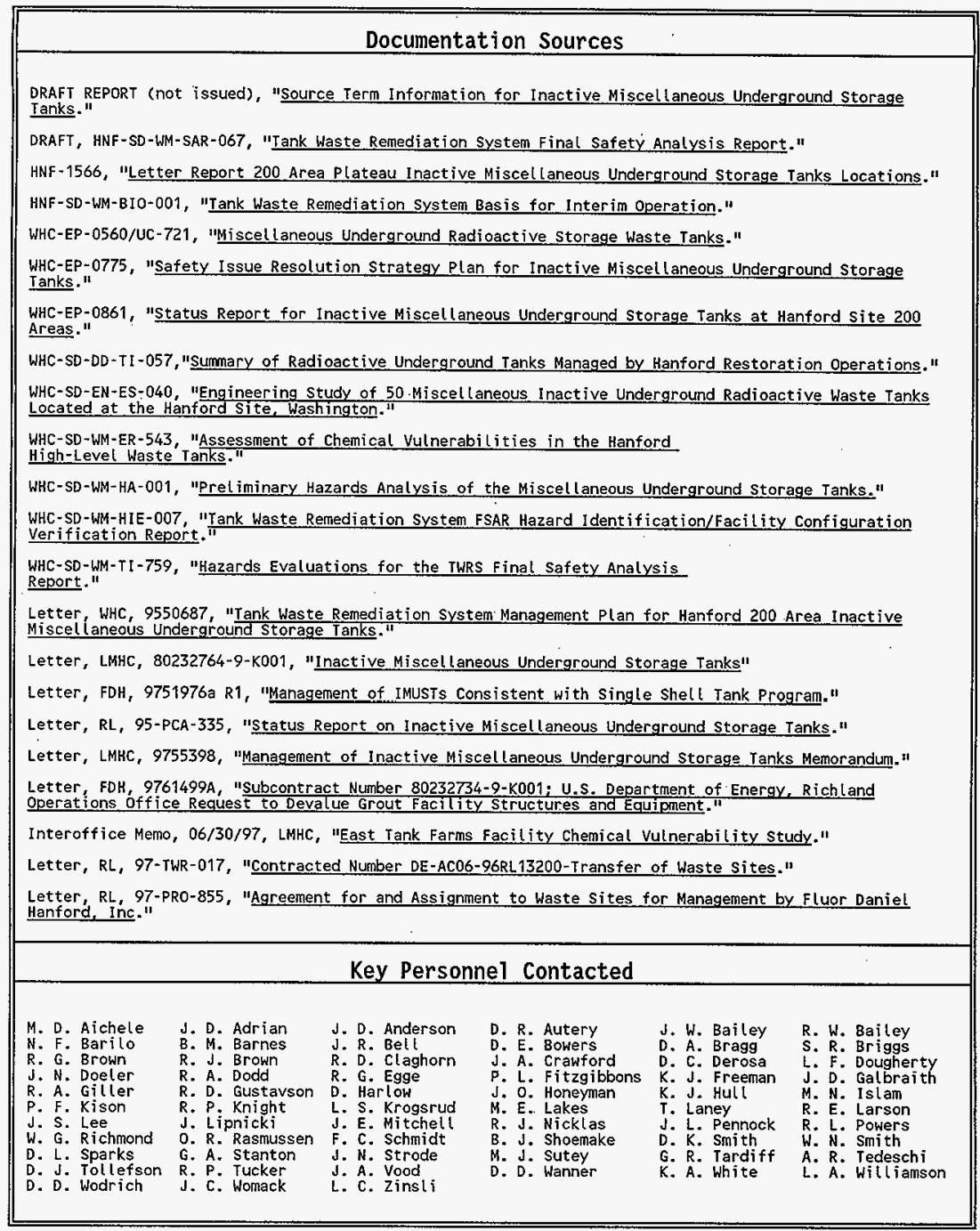


Site Maps: Maps of the areas of interest were obtained from Lockheed Martin Services, Inc. (LMSI) Printing and Reproduction Services. These are prepared and maintained by Fluor Daniel Northwest, Inc. (FDNW) Mapping Services. The maps were reviewed to identify specific TWRS facilities and structures that could potentially impact the 1ist of TWRS FTCs. The information gained was pursued through further examination of specific location aerial photographs, maps and drawings.

Aerial Photographs: A set of recent (1997) aerial photographs was obtained from Pacific Northwest National Laboratory (PNNL) Photography which provided close-up views of each complete tank farm. These photos were reviewed with the respective cognizant engineers to identify aboveground structures that could potentially be an FTC of concern. Field walkdowns were conducted as needed to verify the structures and components identified through photo evidence.

Hanford FacilitiesCORE: FacilitiesCORE is a database, maintained by DynCorp Tri-Cities Services, Inc (DYN), which contains a 7ist of previously identified facilities that have property designation numbers. This database was searched for a11 items in the 200 Areas, regardless of custodianship, that were described as tanks, vaults containers, or other vessels. This source provided a significant amount of information on chemical tanks, both TWRS and non-TWRS. The database is not completely accurate regarding tank identification and numbering, but is currently maintained.

Facility Walkdowns: Facility walkdowns were performed on an as-needed basis during the identification and verification of the TWRS FTCs with potential $A B$ upgrade needs. These walkdowns were performed to varying degrees of rigor, depending on need and were primarily conducted to verify specific detaiTs for each FTC as it was being evaluated.

Raw data files of the information gathered through the sources 7 isted above are being maintained by the TWRS Operations and Projects Safety Support organization for future reference.

\subsection{FTC INFORMATION MANAGEMENT}

The 1 ist of TWRS and non-TWRS FTCs identified by this activity are provided in Appendix A. Appendix A contains several subsections based on the sorting of information into distinct groups for further evaluation. A graphic description of information management for the Appendix A sections is provided in Figure 3-1, and the following subsections describe how that information was managed.

\subsubsection{Historical Information}

Sections A-1 and A-2 of Appendix A provide historical IMUST 1istings sorted by tank number and by tank owner, respectively. These sections were compiled from a number of sources, including the WIDS database, a 1994 engineering study (WHC-SD-EN-ES-040), a 1995 letter from WHC to RL providing a management plan for the 200 Area IMUSTS (Letter, WHC, 9550687), a 1995 status report issued by WHC (WHC-EP-0861, Rev. 0), a 1997 Tetter from RL to Fluor Danjel Hanford, Inc. (FDH) (Letter, RL, 97-PR0-855) assigning responsibility for 
HNF-2503, Rev. 0

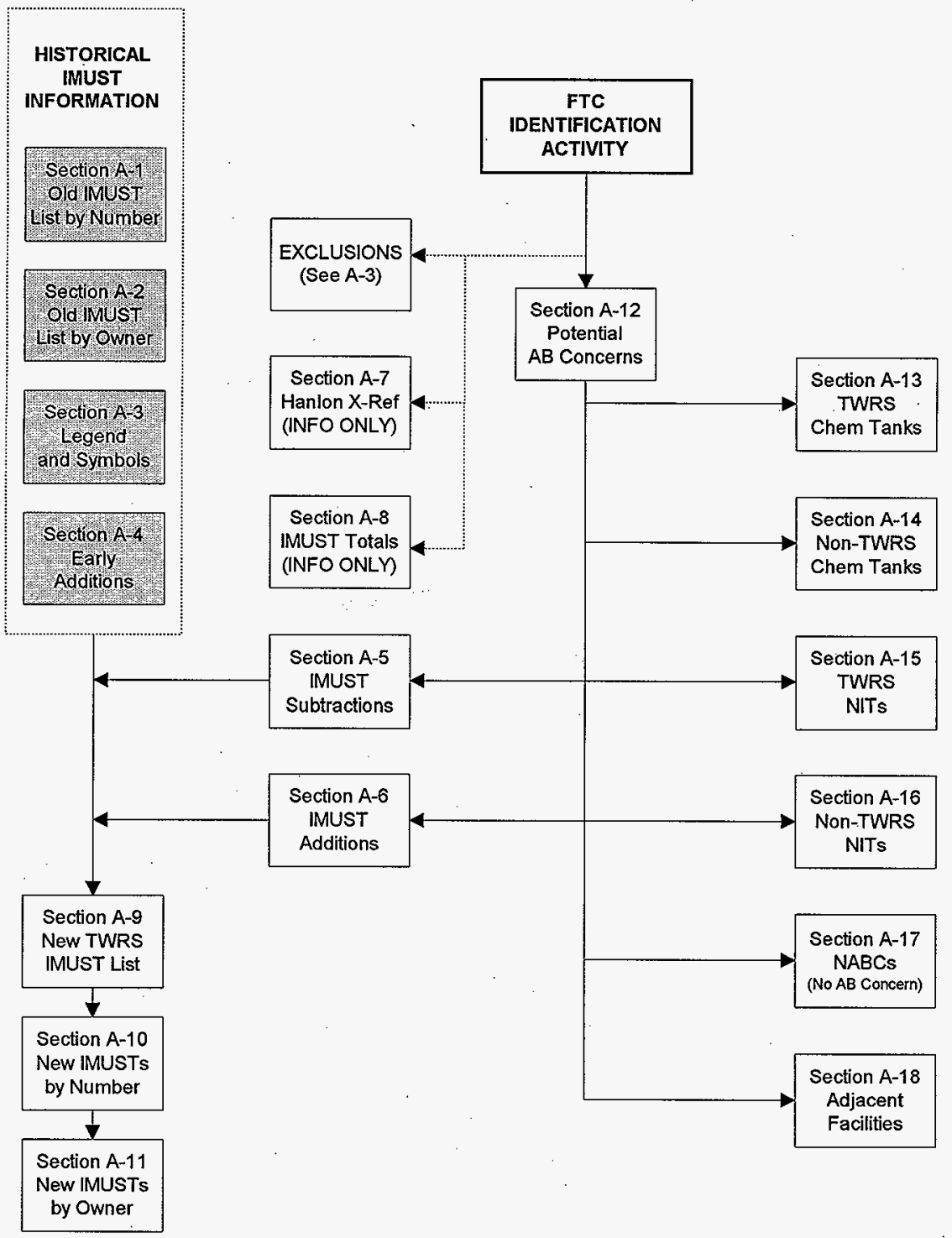

Figure 3-1. FTC Information Management 
waste site management (included the WIDS listing), and a 1997 letter from RL to $\mathrm{FDH}$ (Letter, RL, 97-TWR-017) requesting transfer of certain waste sites between BHI and Lockheed Martin Services Corporation (LMHC) (TWRS). The tables in both sections contain information columns indicating whether the sources referenced above listed the specific tank, and the ownership indicated in the reference. The tables also list whether each specific tank is listed in the TWRS BIO (HNF-SD-WM-BIO-001) or draft FSAR (HNF-SD-WM-SAR-067).

Several active catch tanks were included on the lists in Sections $A-1$ and $A-2$. This is because catch tanks were not excluded (refer to Sections 2.4 and A-3) and all items in the WIDS database that belonged to TWRS were originally listed if not on the exception list. Active catch tanks are considered to be adequately addressed in the BIO; thus, these tanks are not discussed further in this report. Note that the column headed "1997 LTR (4)" is significant insofar as it represents the IMUST 1 isting most recently approved by DOE. Changes proposed by the current activity are in reference to this column.

Section A-3 provides references, a legend of symbols used in the tables, and a listing of the items that were excluded from the data searches. Included in the legend and indicated on several of the IMUST entries in Sections A-1 and $A-2$, is the proposed transfer of waste sites between the Environmental Restoration Program (ER) and TWRS (97-TWR-017). Tanks 244-UR-1 through 4 (244-UR Vault) are scheduled to be transferred from ER to TWRS, and tanks 216-BY-201, 216-TY-201, and 270-W are scheduled to be transferred from TWRS to ER. This transfer of ownership has not yet occurred, and for the purposes of this report, the tanks scheduled for transfer to ER are treated as TWRS-owned. When the transfer occurs, a change in plans for the subject tanks may result. The 244-UR Vault which is scheduled for transfer to TWRS is included in this report as TWRS-owned; however, the strategy presented in this report assumes the transfer will occur.

Section A-4 provides the identification of IMUSTs (included in Sections A-1 and $A-2$ ) that were added to the list after the letter forwarded to The Washington State Department of Ecology (Letter, LMHC, 802327.64-9-K00I) that established the official 1 ist of IMUSTs. The tanks added were: $213-W-1$, a catch tank near the dry waste compactor facility (refer to Section 3.4.3), and 241-T-302, a catch tank in the 241-T Tank Farm, near the 241-T-151 and 241-T-152 diversion boxes (refer to Section 3.4.10). Both of these tanks are identified in the WIDS database and because of the WIDS identification, they were included in Sections $A-1$ and $A-2$, but later removed from the IMUST 1 ist (refer to Section A-5).

\subsubsection{Current FTC Identification}

As FTCS were identified through the means described in Section 3.1 above, they were compiled in Section A-12. FTCs that could obviously be exciuded from the activity (Section A-3) were eliminated and not entered into the 1 ist. However, once a specific FTC was entered into Section A-12, it was not subsequently removed from the 7 ists, even though it may have been determined to be in an excluded category. This quality control feature assured 100 percent resolution of all FTCS identified and al so assured traceability of the process. The information on a specific tank or facility was maintained in Section A-12 until enough information (e.g. description, active status, ownership) was obtained to determine its appropriate category. Once the appropriate category was established, each specific FTC entry was moved to one of the appropriate Appendix A sections. At the end of the process, Section 


$$
\text { HNF-2503, Rev. } 0
$$

A-12 was maintained as the final 1ocation of facility information only. Information on tanks and components not associated with facilities was moved to one of the sections described below.

Section A-5 identifies three IMUSTs to be removed from the IMUST 1ists. One of these is 241-AX-151CT, which was previously identified only as a catch tank. This entry was replaced by the correct diverter station identification, with all five tanks within the station 1isted (refer to Section 3.3.4). The 213-W-1 catch tank (refer to Section 3.4.3) was removed from the IMUST 1ist because it is not a radioactive tank and, thus, does not meet the IMUST definition. Tank 241-T-302 was also removed from the 1 istings because it was determined to not exist (refer to Section 3.4.10).

Section A-6 identifies nine IMUSTs that were added to the IMUST 1ists. Five of the nine additions are the tanks comprising the 241-AX-151 diverter station (refer to Section 3.3.4). 209-E-TK-111 (refer to Section 3.4.2) is an underground drain tank near 209-E that meets the definition of IMUST, but was not previously identified as such. 241-BY-ITS2-TK-1 (refer to Section 3.4.7), and 241-BY-ITS2-TK-2 (refer to Section 3.4.8) are a condenser tank and heater flush tank, respectively near Tank 241-BY-112. These two tanks were originally part of the ITS-2 system operated within the 241-BY Tank Farm. Tank 216-A-5 is a neutralization tank near the Plutonium Uranium Extraction Facility (PUREX) that was not previously identified.

Section A-7 provides information to be used in correcting the monthly waste summary report (HNF-EP-0182) produced by TWRS. The intent of the monthly report is to provide current information on the TWRS tank contents; however, the monthly report currently contains some errors with regard to miscellaneous TWRS FTCs. Information gathered through the current activity will be used as a basis to ensure that the monthly report is accurate.

Section A-8 1ists the total number of IMUSTs, by owner, contained in the current Appendix A 1 ists (Sections A-9, A-10, and A-11).

Section A-9 contains the most current list of the TWRS-owned IMUSTs, including those from both historical listings (as modified by this activity), and the newly identified IMUSTs.

Sections A-10 and A-11 contain the current total 200 Area IMUST 1ists, sorted by tank number and tank owner, respectively. One new non-TWRS IMUST has been identified as a result of this activity. Tank 216-A-5 is a neutralization tank near PUREX that was not previously identified as an IMUST. This tank has been verified to meet the IMUST definition and has been verbally confirmed with the Babcox and Wilcox Hanford Co. (BWHC) owner.

Section A-12 provides the 1ist of TWRS-owned facilities subject to the current evaluation activity and described in Section 3.3. Major components and storage vessels comprising each facility are listed with the facility in Section $\mathrm{A}-12$. It is important to note that tanks within or closely associated with a facility will be dispositioned with the facility whether or not those tanks are identified as IMUSTs.

Section A-13 lists the tanks and vessels owned by TWRS that are or were used to store non-radioactive chemicals. These are tanks that may contribute to the TWRS hazard profile if capable of causing a release of radioactive 
HNF-2503, Rev. 0

material from TWRS facilities, an independent toxicological release hazard, or a potential chemical runaway reaction.

Section A-14 lists the chemical tanks and vessels identified during this exercise that are not owned by TWRS. They are of concern only if they can contribute to the TWRS hazard profile.

Section A-15 lists TWRS non-IMUSTs and other structures/components that did not meet the IMUST definition, primarily because they are active. These are tanks that are of interest to the TWRS $A B$ because they are radioactive, and are currently covered in the BIO and draft FSAR.

Section A-16 lists non-TWRS, non-IMUSTs and other structures/components determined through one of the sources listed in Section 3.1 that did not meet the IMUST definition. The items in this list may be associated with those in Section A-18 and may be of concern if they contribute to the TWRS hazard profile.

Section A-17 contains the items determined to be of no AB concern. This includes items that normally would have been excluded (refer to Section A-3), but were listed because complete information was not available at the time they were listed. This section also includes items that were identified through one of the sources 7 isted in Section 3.1 and subsequently determined not to exist or to have been removed.

Section A-18 identifies the facilities adjacent to TWRS that may contribute to the TWRS hazard profile, disrupt TWRS operations, or pose a threat to TWRS workers. These facilities are discussed in Section 5.3.

\subsection{TWRS FACILITIES IDENTIFICATION AND DESCRIPTION}

This section describes the facilities that were identified during this activity. These are the facilities listed in Section A-12 of Appendix A. A general description of these facilities is given in the following subsections, highlighting the contents of the tanks or vessels designed for waste or chemical storage or processing. Additional information on each of these facilities is contained in the facility hazard checklists in Appendix B.

\subsubsection{4-AR Waste Unloading Facility}

The 204-AR Waste Unloading Facility is located south of the 244-AR Vault and west of the 241-AX Tank Farm. The facility was designed to receive 1 iquid waste from rail tank cars or tank trailers and pump these wastes to a designated 200-E Area tank farm. Included in the facility design is a chemical adjustment capability utilizing four chemical make-up tanks and a sluicing system to remove sludge from the tank cars. A photo and diagram of the facility is shown in Figure 3-2. The 204-AR Waste Unloading Facility was constructed in 1981 and is a reinforced concrete structure approximately 19.5 $\mathrm{m}$ (64 ft) long by $12.2 \mathrm{~m}(40 \mathrm{ft})$ wide by $7.8 \mathrm{~m}(25.5 \mathrm{ft}) \mathrm{high}$. The facility is still active except for two chemical tanks that are no longer used. 
HNF-2503, Rev. 0
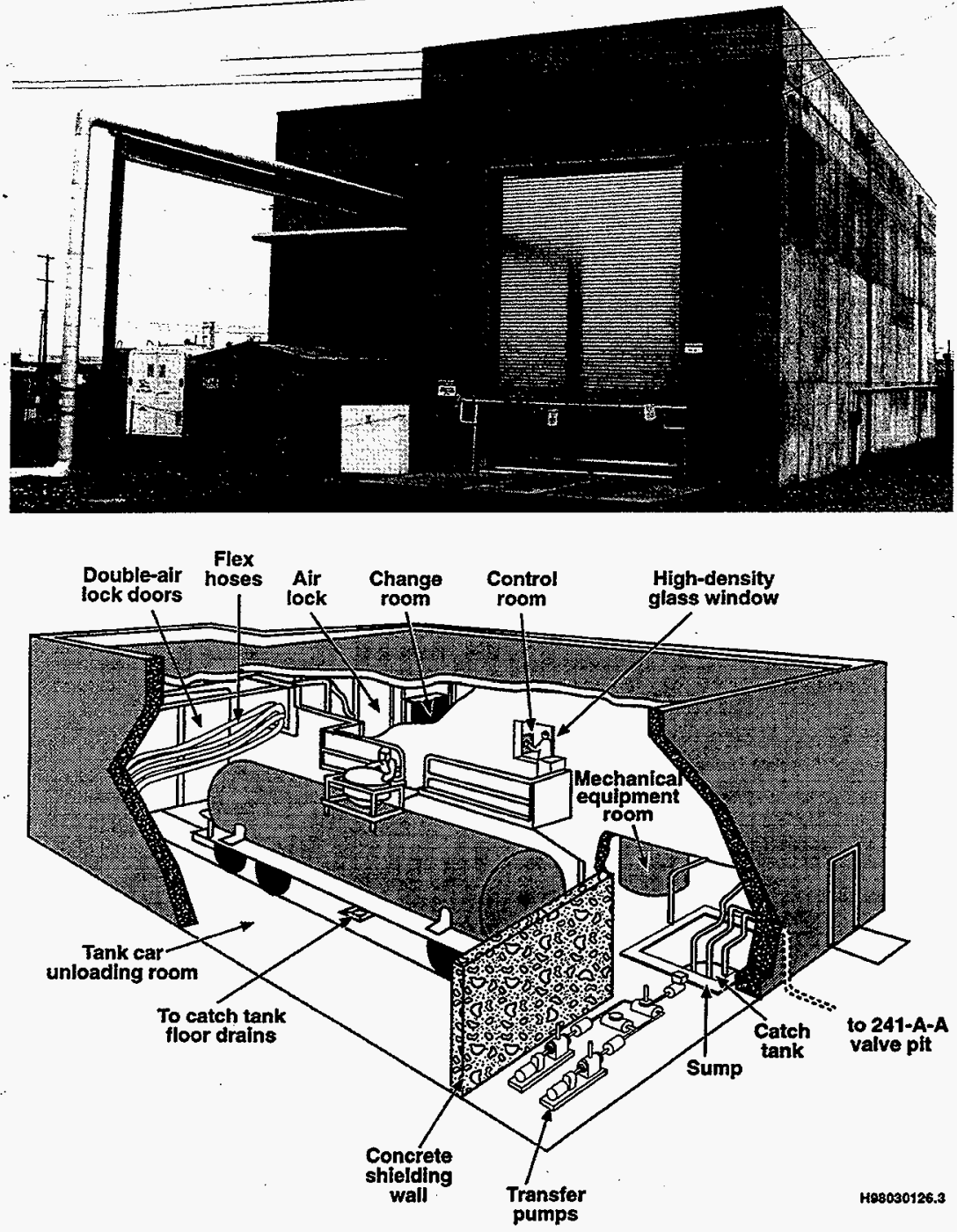

Figure 3-2. 204-AR Waste Unloading Facility 
204-AR is divided into three major areas:

- A rail tank car unloading canyon (located on the first floor) containing transfer pumps, process piping, remotely operated valves, and a catch tank (located below grade).

- A mechanical equipment room (located on the first floor) containing chemical storage and makeup tanks, motor control center, ventilation system, and fire system.

- A control room and personnel facilities (located on the second floor).

The following tanks/vessels are located within the facility:

- 204-AR-TK-1 (5,678 L [ [ , 500 gal]), a stainless steel catch tank for temporarily storing process solutions received from drains in the system. The tank is located below grade in the unloading area in a stainless steel-lined pit.

- 204-AR-TK-2 (1,893 L [500 ga]]), a carbon steel nitrite so]ution tank, located in the mechanical equipment room.

- 204-AR-TK-3 (1,893 L [500 gal]), a stain]ess steel dilute caustic solution tank, located in the mechanical equipment room.

- 204-AR-TK-4 (757 L [200 ga1]), a stainless steel high Ph buffer solution tank, located in the mechanical equipment room. This tank is out of service.

- 204-AR-TK-5 (6,814 L [1800 ga1]), a carbon stee1 50 percent caustic solution tank, located in the mechanical equipment room, that receives 50 percent sodium hydroxide solution delivered by tank truck. The fill pipe for TK-5 penetrates the 204-AR Waste Unloading Facility wall and terminates outside the building next to a platform provided for the tank truck. This tank is out of service.

Three ventilation systems within the 204-AR Waste Unloading Facility service the personnel area, the radiation zone, and the mechanical equipment room. The personnel area ventilation system operates at positive pressure. The mechanical equipment room exhaust system consists of a wal1-mounted exhaust fan operated on a demand basis and only when the radiation zone exhaust system is operable. The radiation zone exhaust system operates at a negative air pressure and draws air from the canyon area and catch tank. The fan is located in the mechanical equipment room and discharges through the roof ventilator.

Record air samplers collect particulate matter on filter paper at the exhaust stack and continuous air monitors (CAMs) monitor beta-gamma activity in the airflow at the exhaust stack. CAMS and radiation probes are also located in the facility unloading canyon. Fire protection includes heat and smoke detectors and a sprinkler system installed throughout the facility. 


\section{Material stored in the Facility}

The 204-AR Waste Unloading Facility is still active, thus waste materials are not permanently stored there. The facility receives waste from the 300 Area PNNL $1 \mathrm{abs}$ and the 222-S $1 \mathrm{ab}$. The catch tank (204-AR-TK-1) in the facility contains floor drainage from the unloading area and is maintained at a specified level (minimum 1893 L [500 gal]). Current catch tank contents are estimated to be contaminated waste water mixed with caustic (sodium hydroxide) and sodium nitrite.

Two tanks (204-AR-TK-4 and 204-AR-TK-5) in the mechanical equipment room are empty and out of service. The other two tanks in the mechanical equipment room (204-AR-TK-2 and 204-AR-TK-3) contain sodium nitrite solution and dilute caustic (sodium hydroxide) solution. Material is added to these tanks as needed for chemical adjustment of waste receipts.

\subsubsection{9-E Critical Mass Laboratory}

The 209-E Complex is located northwest of the PUREX Facility in the 200-E Area. The 209-E Building was constructed in 1960 to provide a heavily shielded room where criticality configurations were studied. In the late 1980 s, the fissile material was removed except for residual contamination and the process tanks were flushed to reduce the residual contamination. A photo and drawing of the facility is shown in Figure 3-3.

One wing of the one-story, L-shaped concrete block and reinforced concrete building houses offices, a control room, shops and a common area. The other wing includes the equipment room, the change room, the mix room and the Critical Assembly Room (CAR). The tanks in two of these rooms (CAR and Mix Room) contain residues of plutonium. Personnel are located in the office spaces of the facility. These personnel operate the less-than-90-day storage pads adjacent to the facility.

\section{CAR Description}

Criticality experiments were conducted in the CAR, which contains two reactor hoods where the critical assemblies were held. Each hood has its own high-efficiency particulate air (HEPA) filter and instrumentation that was monitored from the control room. Contaminated equipment located in the CAR includes four hood assemblies, a water tank and eleven process tanks ranging from $38 \mathrm{~L}$ (10 gal) to $400 \mathrm{~L}$ (106 gal). They are:

- TK-101 (330 L [87 gal]), TK-102 (330 L [87 gal]), TK-103 (290 L [77 gal]), TK-104 (290 L [77 gal]), TK-105 (400 L [106 gal]) and TK-106 (400 L [106 gal]), all solutjon handling tanks. These tanks are tied to the facility ventilation system and have an air purge system to remove any generated hydrogen.

- TK-108 (11,735 L [3100 ga]]), a water tank

- TK-141 (278 L [73 gal]), TK-161 (110 L [29 gal]), and TK-162 (400 L [106 gal]), all experimental vessels. These tanks have bottom drains and are tied to the facility ventilation system. 


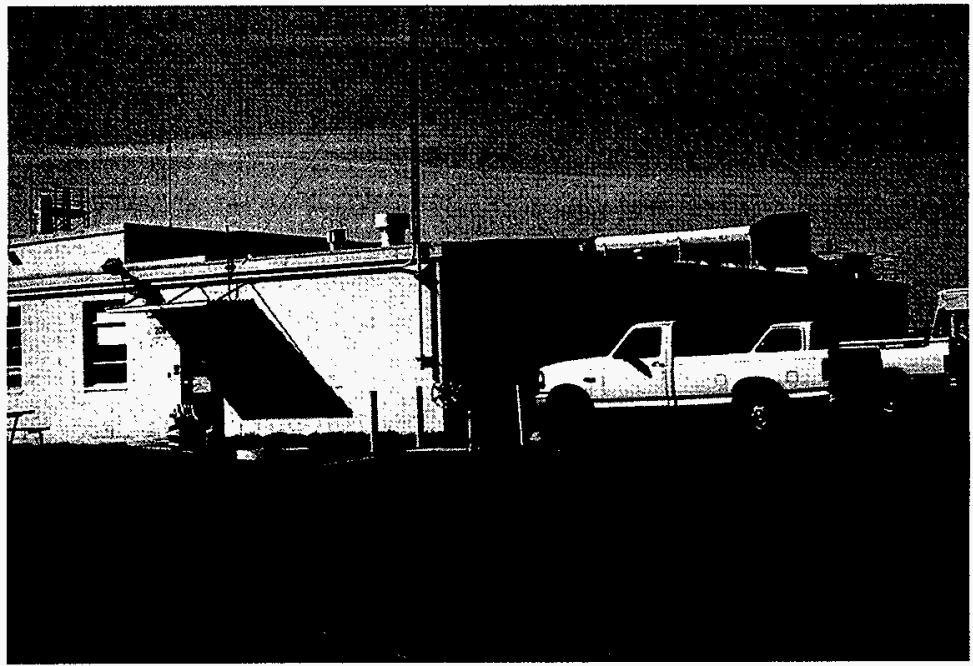

SOLUTION MIX HOOD DRY ASSEMBLY HOOD

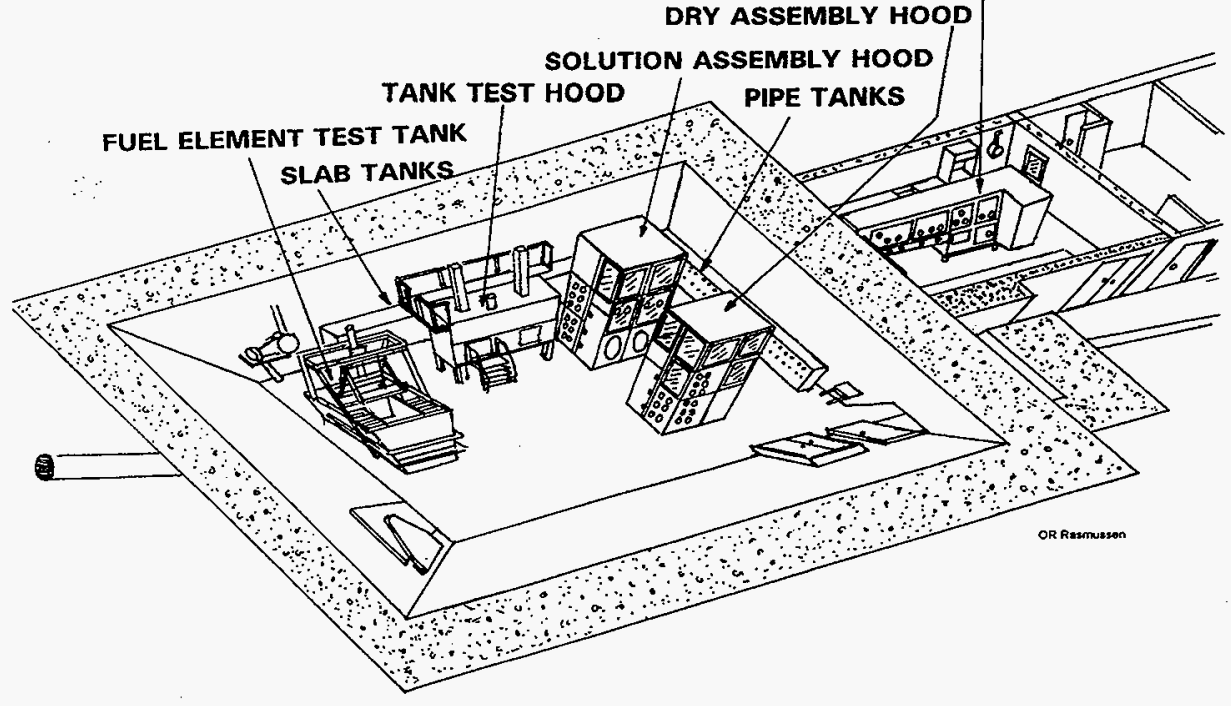

Figure 3-3, 209-E Critical Mass Laboratory 
- TK-109 (35 L [9 gai]), and TK-110 (35 L [9 gal]), both dump tanks. These tanks are encased in concrete approximately $0.6 \mathrm{~m}(2 \mathrm{ft})$ below the CAR reactor hoods.

The CAR is posted in accordance with the Hanford Site Radiological Control Manual (HSRCM-1) and is maintained locked. Access is controlled through the Facility Manager.

\section{Mix Room Description}

The Mix Room provided the necessary facilities for receiving, handling, and preparing the various types and forms of radionuclides and chemicals used in the experiments. This room is also ventilated with the exhaust ventilation system that ventilates the CAR. Like the CAR, the Mix Room contains contaminated equipment including three hood assemblies and nine tanks ranging from $10 \mathrm{~L}$ ( $3 \mathrm{gal})$ to $320 \mathrm{~L}(85 \mathrm{gal})$. They are:

- TK-213 (18 L [5 gal]), TK-231 (320 L [85 gal]), TK-232 (320 L [85 gal]), TK-233 (320 L [85 gal]), TK-234 (156 L [41 gal]) and TK-235 ( 156 L 41 gal]), all solution handling tanks. These tanks are tied to the facility ventilation system and have an air purge system to remove any generated hydrogen.

- TK-206 (10 L [3 gal]), a calibration and solution load out tank

- TK-215 (15 L [4 gal]), and TK-216 (15 L [4 gal]), both process condensate catch tanks that are vented.

The Mix Room is posted in accordance with HSRCM-1 and maintained locked. Access is controlled through the Facility Manager.

\section{Drain Tank}

Another tank, TK-111, was used as a drain tank and is located underground, adjacent to the south end of the facility. This tank is passively ventilated.

\section{Exhaust Ventilation System}

The CAR and Mix Room are ventilated with an active ventilation system. A damper in the inlet ventilation duct has been locked in the closed position, forcing ventilation to be supplied through infiltration only. The exhaust ventilation system consists of fire-resistant HEPA filters, an exhaust fan, and a stack. Power is supplied to the fan via a breaker in the Equipment Room. The damper on the exhaust fan was secured in the open position to allow a ventilation pathway in case of a ventilation failure.

\section{Air Purge System}

Air is supplied to the twelve process tanks via an air purge system. The purge air exits the tanks through tubing tied into the exhaust ventilation system. The air purge system consists of tubing, air compressors, pressure reducing valves, and flow indicating controllers (i.e., rotameters). The pressure reducing valves limit the supply pressure of the air to $5 \mathrm{Kpa}$ (35 psig). 
HNF-2503, Rev. 0

\section{Fire Suppression System}

-Fire protection for the CAR is provided by a pre-action sprinkler system, meaning the system remains dry and pressurized with air. Pressurization with air achieves freeze protection during cold weather. The Mix Room and the rest of the 209-E building have a wet pipe system.

\section{Materials Stored in the Facility}

There are twelve process tanks in the 209-E Building that were used for solution handling. These tanks include TK-101, TK-102, TK-103, TK-104, TK-105, and TK-106, located in the Criticality Assembly Room (CAR) and TK-213, TK-231, TK-232, TK-233, TK-234, and TK-235, located in the Mix Room. Per the status report, these tanks were flushed, are tied into the exhaust ventilation system, and have an air purge system to remove any generated hydrogen.

Another tank, TK-111, was used as a drain tank and is located underground, adjacent to the south end of the facility. This passively ventilated tank was sampled routinely, where it was determined that plutonium levels were below limits for discharging the contents to a crib. A recent vapor sample of the drain tank (TK-111) identified no detectable flammable gas within the tank (letter, FDH, 9760653).

One tank, TK-108, contained water and not process solution; it is open to room atmosphere, is located in the CAR, and is considered flushed since it only contained water.

The experimental vessels, TK-141, TK-161, and TK-162, have a bottom drain and are vented to the exhaust ventilation system for hydrogen removal. These tanks are all located in the CAR. As stated in the status report, TK-141 was thoroughly flushed. The status report also states that a nondestructive analysis (NDA) was performed to provide "before" plutonium quantities (i.e., baseline indications prior to decontamination efforts). This was used as a guide to perform limited decontamination on certain experimental vessels. TK-16I and TK-162, were each assayed by NDA to contain $4 \mathrm{~g}$ of plutonium and were not flushed as thoroughly as TK-141.

Tank TK-206 was used for calibration and loadout of solutions and is located in the Mix Room. The tank was flushed prior to facility turnover.

Two tanks, TK-215 and TK-216, were used as process condensate catch tanks, are vented, and are considered flushed since they only contained condensate.

These tanks are located in the Mix Room.

Lastiy, tanks TK-109 and TK-110 are designated as dump tanks and were designed to preclude criticalities at expected plutonium concentrations. The dump tanks' function was to receive the experiment solution, ending the experiment when desired or if the neutron flux became too high. The $35 \mathrm{~L}$ (10 gai) dump tanks are encased in concrete $0.6 \mathrm{~m}(2 \mathrm{ft})$ underneath the CAR reactor hoods. TK-109 is known to have received process solutions, was flushed and is vented by the ventilation system. There is no knowledge that TK-110 was ever used.

A non-destructive analysis (NDA) was performed in 1989 to quantify the fissile material remaining following the flushes at 209-E. Remaining quantities of fissile material are: $1 \mathrm{~g}$ Pu in TK-101; $8 \mathrm{~g} \mathrm{Pu}$ in TK-103; $15 \mathrm{~g} \mathrm{Pu}$ in TK-104; $38 \mathrm{~g} \mathrm{Pu}$ in TK-105; $123 \mathrm{~g} \mathrm{Pu}$ in TK-106; $36 \mathrm{~g}$ Pu in TK-14I; $4 \mathrm{~g} \mathrm{Pu}$ in TK-16I; 
$4 \mathrm{~g} \mathrm{Pu}$ in TK-162; $1 \mathrm{~g} \mathrm{Pu}$ in TK-213; $2 \mathrm{~g} \mathrm{Pu}$ in TK-206, TK-215, and TK-216; $42 \mathrm{~g}$ $\mathrm{Pu}$ in TK-23l; $31 \mathrm{~g} \mathrm{Pu}$ in TK-232; $47 \mathrm{~g} \mathrm{Pu}$ in TK-233;33 $\mathrm{g} \mathrm{Pu}$ in TK-234; $3 \mathrm{~g} \mathrm{Pu}$ in TK-235; $5 \mathrm{~g}$ Pu in pump P-203; $15 \mathrm{~g} \mathrm{Pu}$ in pump P-201; and $5 \mathrm{~g} \mathrm{Pu}$ in the valve area of the Mix Room. The remaining three tanks, TK-109, TK-110, and TK-11l could not be assayed because of their location. However, as indicated above, TK-109 was thoroughly flushed, no knowledge exists that TK-110 was ever used, and TK-111 was sampled routinely where it was determined that Pu concentration was low enough for discharge to a crib. The total Pu material at $209-\mathrm{E}$, per the status report, is $420 \mathrm{~g}+/-150 \mathrm{~g}$.

\subsubsection{3-W Dry Waste Compactor}

The 213-W Building is 1ocated in the 200-W Area, adjacent to and north of the 272-WA building and south of the Central Waste Complex. This facility was used to compact low-level solid wastes and is referred to as the Dry Waste Compactor Facility. The facility was constructed in the mid 1980 s and was used only sporadically starting in 1985 to compact low activity solid waste for disposal in the 200-W Area Low Level Waste (LLW) Burial Grounds.

compaction activities have ceased and will not be resumed. Activities such as contaminated instrument repair take advantage of the controlled environment in the 213-W Building, which is unoccupied except during such activities. Photos of the facility are shown in Figure 3-4.

The 213-W Building is a pre-engineered, self-framing metal structure having three rooms with a combined floor space of approximately $79 \mathrm{~m}^{2}\left(850 \mathrm{ft}^{2}\right)$. The rooms, arranged in series, include a personnel entry room separated by an airlock from a work room and a package inspection room with a roll-up garage door: The work room is maintained at a slight negative pressure and ventilated through two HEPA filters to an external, dedicated $8.8 \mathrm{~m}$ (29 ft) monitored exhaust stack. All rooms are protected by a dry pipe fire suppression system and have personnel doors that open to the outside. Floor drains are connected to an inactive, underground retention tank $(213-W-1)$ with a pit access. The 213-W Building is adjacent to 272-WA Building, which contains offices, change rooms, support shops, a garage, and a lunchroom.

\section{Materials Stored in the Facility}

The 213-W Dry Waste Compactor Facility is no Tonger used to compact low level solid waste. The compactor is empty and is only slightly contaminated. Radiation surveys are performed weekiy in this facility and recent results indicate no alpha contamination, less than $1,000 \mathrm{dpm} / 100 \mathrm{~cm}^{2}$ (beta) smearable contamination, and less than $5,000 \mathrm{dpm} / 100 \mathrm{~cm}^{2}$ (total beta) contamination. Dose rates throughout the facility are less than $0.5 \mathrm{mr} / \mathrm{hr}$ at $30 \mathrm{~cm}$. The Compactor Room in the facility is still occasionally used for equipment maintenance and repair activities. Waste materials or chemicals in other than household quantities are not stored there. The catch tank adjacent to the facility formerly contained floor drainage from the compactor room and the ventilation system. The contents of this catch tank have been sampled and have been determined to be below the level of radiological concern. 
HNF-2503, Rev. 0
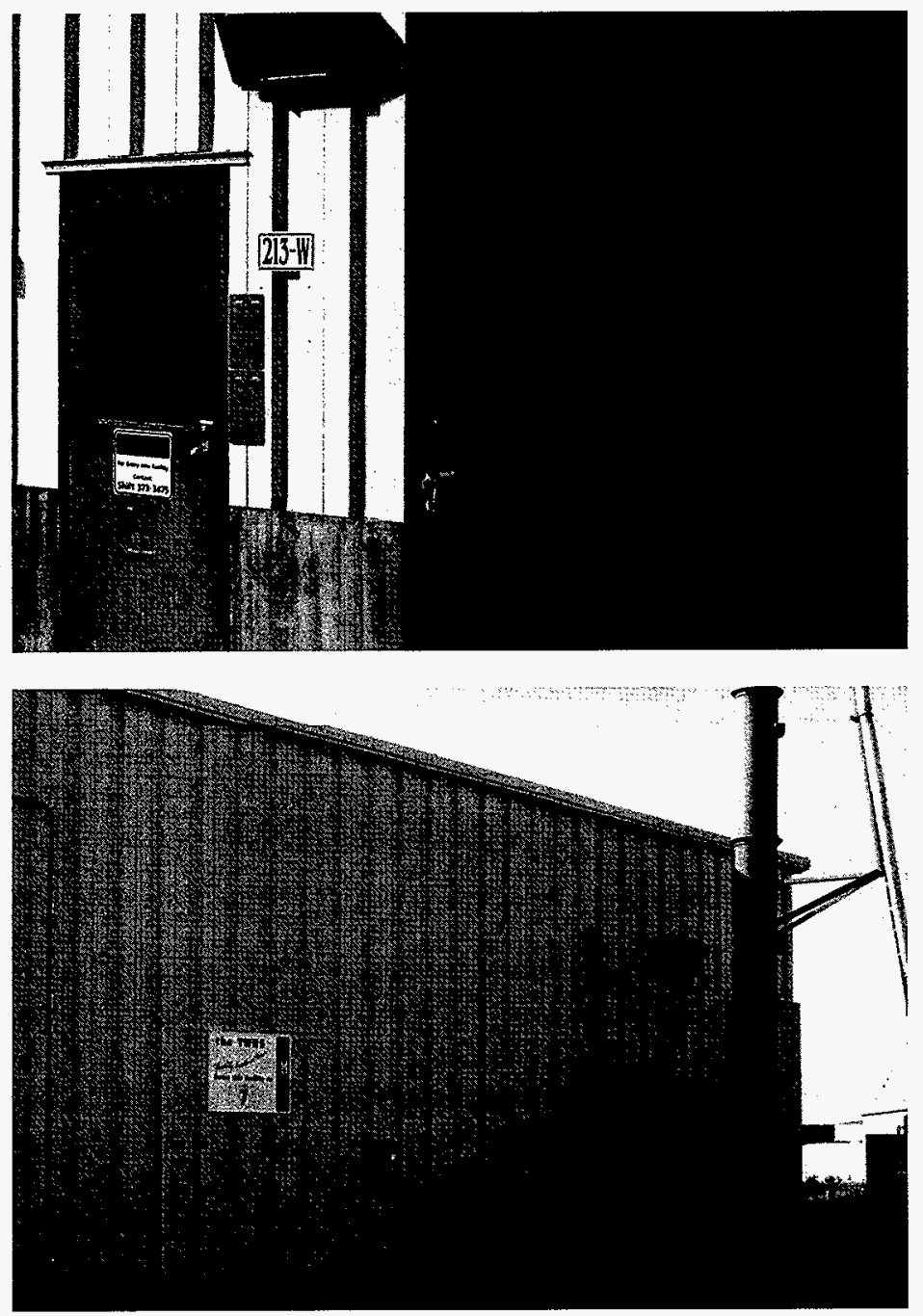

Figure 3-4. 213-W Dry Waste Compactor 


\subsubsection{1-AX-151 Diverter Station}

The 241-AX-151 diverter station is located in the 200-E Area, southwest of 241-A Tank Farm. The unit is an underground reinforced concrete structure that is $13.4 \mathrm{~m}$ (44 ft) long, $3 \mathrm{~m}(10 \mathrm{ft}$ ) wide and $7.6 \mathrm{~m}(25 \mathrm{ft}) \mathrm{high}$. The top of the diverter station extends approximately $30.5 \mathrm{~cm}$ (12 in.) above grade. There are four small. $189 \mathrm{~L}$ (50 gal) diverter tanks in individual cells and a pump pit. Each cell has a stainless steel liner on the floor that extends up the wall. The cells and pump pit drain into a catch tank below. The catch tank is equipped with a water jet so that accumulated waste solutions can be transferred to a waste storage tank. The catch tank also has a stainless steel liner. A $3.8 \mathrm{~cm}$ ( 1.5 in.) dia. liquid level port is provided for the use of portable level detection in the catch tank. Operation began in 1965, and the last documented waste transfer was in 1977 . The station was interim stabilized and isolated by the B-231 Project in the early 1985 , but there are some inconsistent transfer records indicating that transfers through the facility occurred in 1985, after it was isolated. A diagram of a typical diverter station is shown in Figure 3-5.

The diverter station is similar to a diversion box in that it houses multiple ports for routing of flow between tanks. The station differs from a diversion box (which were excluded from this activity) because it contains tanks and equipment that allow waste streams to be routed without manually changing jumpers. Several incoming waste transfer 1 ines are routed into four $189 \mathrm{~L}$ (50 gal) diverter tanks. A moveable spout on the bottom of each receiver tank directs the flow of waste to any one of several exit pipe funnels located within the diverter station. Each routing funnel represents a direct transfer line to a specific receiver tank. The diverter station operates under gravity flow only.

The following tanks are contained within the 241-AX-151 diverter station:

- 241-AX-151-CT (41,600 L [11,000 gal]) catch tank

- 241-AX-151-TK-D (189 L [50 ga1]) diverter tank

- 241-AX-151-TK-E (189 L [50 ga]]) diverter tank

- 241-AX-15]-TK-F (189 L [50 gal]) diverter tank

- 241-AX-151-TK-G (189 L [50 gal]) diverter tank.

These tanks are IMUSTs and are discussed in Sections 3.4.6 and 5.2.

\subsubsection{1-AX-IX Ion Exchange Column}

The 241-AX Tank Farm ion exchange column is located East of the 241-A Tank Farm complex, between the 241-A and 241-AX Tank Farms. The facility was designed to remove cesium from the Aging Waste Facility exhauster (702-A) condensate. Treated condensate was discharged to the 216-A-08 $\mathrm{Crib}$. The column was designed and built in about 1967-1969, and was operated routinely from 1973-1976. There are no $p$ lans for future use of the facility.

The facility consists of an ion exchange column and piping system to connect the facility to the 241-A-417 Catch Tank and transfer system, and a discharge line to the $216-\mathrm{A}-08 \mathrm{Crib}$. The facility has been isolated from the catch tank and transfer system by isolating/capping the connecting lines. The discharge line to the 216-A-08 Crib has not been modified. There is a drain line 


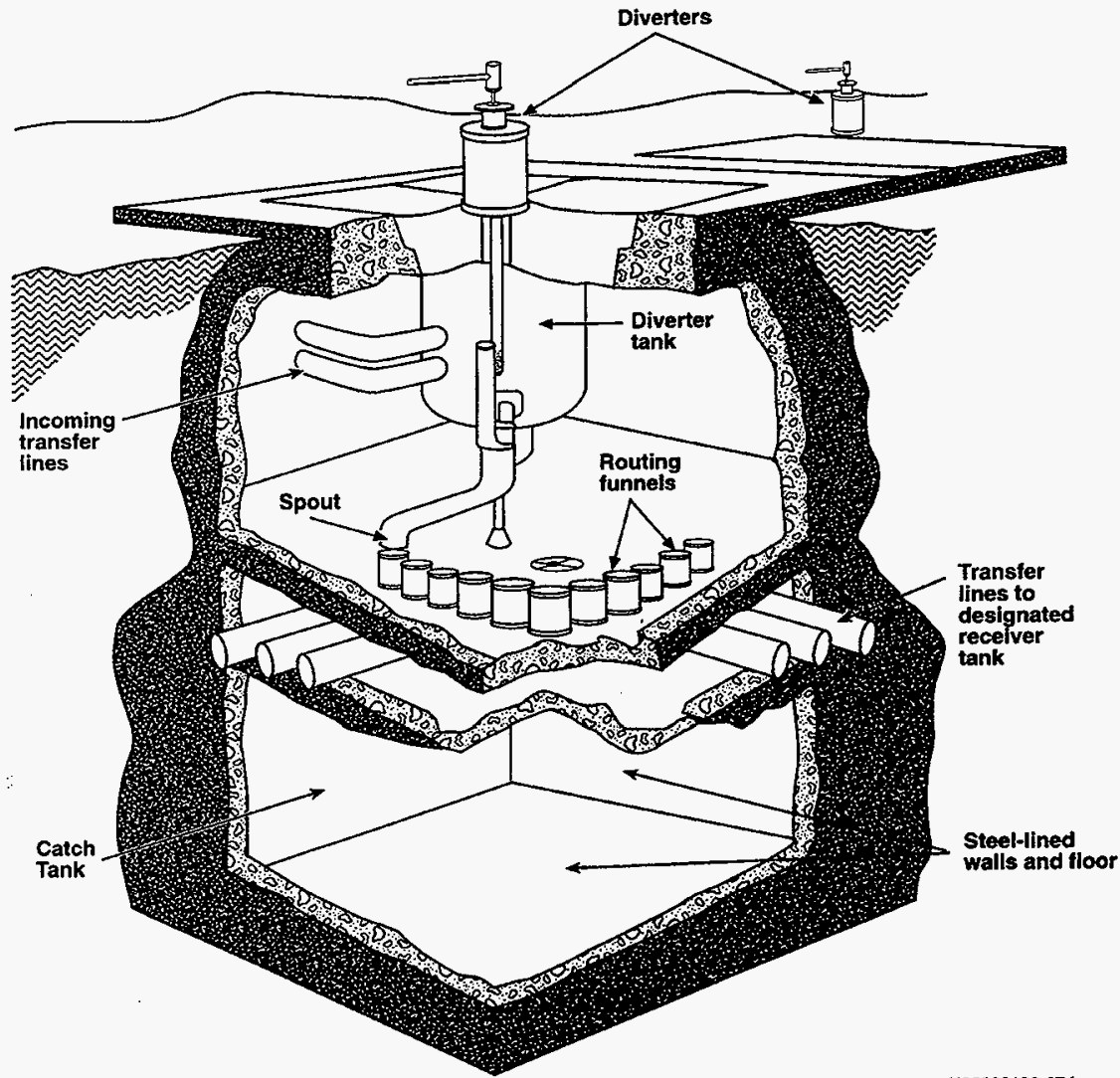

H98030126,4R1

Figure 3-5. 241-AX-151 Diverter Station 
HNF-2503, Rev, 0

running from the bottom of the column to the 241-A-417 Catch Tank. A photo and diagram of the facility are shown in Figure 3-6. Hardware includes a carbon steel ion exchange column, $0.6 \mathrm{~m}$ (24 in.) dia. by $3.5 \mathrm{~m}$ (11.5 ft) tall, on a concrete pedestal that allows access for resin removal at the bottom of the column, iron piping connecting the facility to the 241-A-417 catch tank, radiation monitoring equipment, filter assembly, flowmeter, diaphragm operated valve, and manual valves.

\section{Materials Stored in these Components}

The ion exchange column and attached filter assembly both potentially contain some residual wastes from their operation. The ion exchange column has a total capacity of $0.8 \mathrm{~m}^{3}\left(29.8 \mathrm{ft}^{3}\right)$ and is filled with a man-made zeolite ion exchange medium. It is not known if there is any liquid currently present in the column, nor is it known whether the column was eluted prior to its shutdown in 1978. The filter assembly has a capacity of approximately $0.6 \mathrm{~m}^{3}$ $\left(22.1 \mathrm{ft}^{3}\right)$ and it is not known how much waste material it contains.

The ion exchange column was used to treat condensate from the aging waste facility exhauster (702-A) stored in catch tank 241-A-417. Waste materials remaining in the column or attached filter would be derivatives of that waste stream. No process history information could be located to determine the constituents of the waste materiat remaining, if any.

An unreleased hazards evaluation conducted in 1969 (refer to the checklist in Appendix $B$ ) indicated that organic solvent material used in solvent extraction processes at PUREX and B-Plant accumulated at low leveTs in tank 241-A-417. The evaluation concluded that the accumulation of this organic material in the filter and piping was a potential hazard.

\subsubsection{2-S Evaporator}

The 242-S Evaporator faci]ity is Tocated north of the 241-S Tank Farm and West of the 241-SY Tank Farm. The 242-S Evaporator consists of a segmented building containing process, control, and personnel areas. The process section of the facility is approximately $23 \mathrm{~m}(75 \mathrm{ft}$ ) long by $15 \mathrm{~m}$ (50 ft) wide and $18 \mathrm{~m}$ (60 ft) high. The process portions of the facility contain the condenser and evaporator rooms and a separate vault for the ion exchange column. The geometry of individual vessels within the facility is described below. The control room, lunch room, change room, and cold storage room are located in a one-story service building on the west side of the process rooms. The service building is approximately $14 \mathrm{~m}(45 \mathrm{ft})$ square. A photo and diagram of the facility are shown in Figure $3-7$.

The mission of 242-S was to concentrate tank waste in the 24l-S Tank Farm. Operation of the evaporator began in 1973 and continued until 1980. The facility was shut down in 1980 and placed in a standby mode in 1981. A number of configuration changes were made to the evaporator in 1985 so that the ion exchange column and some of the process tanks could be used to reduce uranium content in the 216-U1/U2 Crib groundwater. This activity was conducted during 1985. The facility currently contains controls for the tank waste transfer system and houses the control room for the Replacement Cross Site Transfer system (RCSTS). The facility also houses instrument air compressors for 241-SY Tank Farm and alarms for the 244-S DCRT, and the 241-SY/SX Tank Farms. 


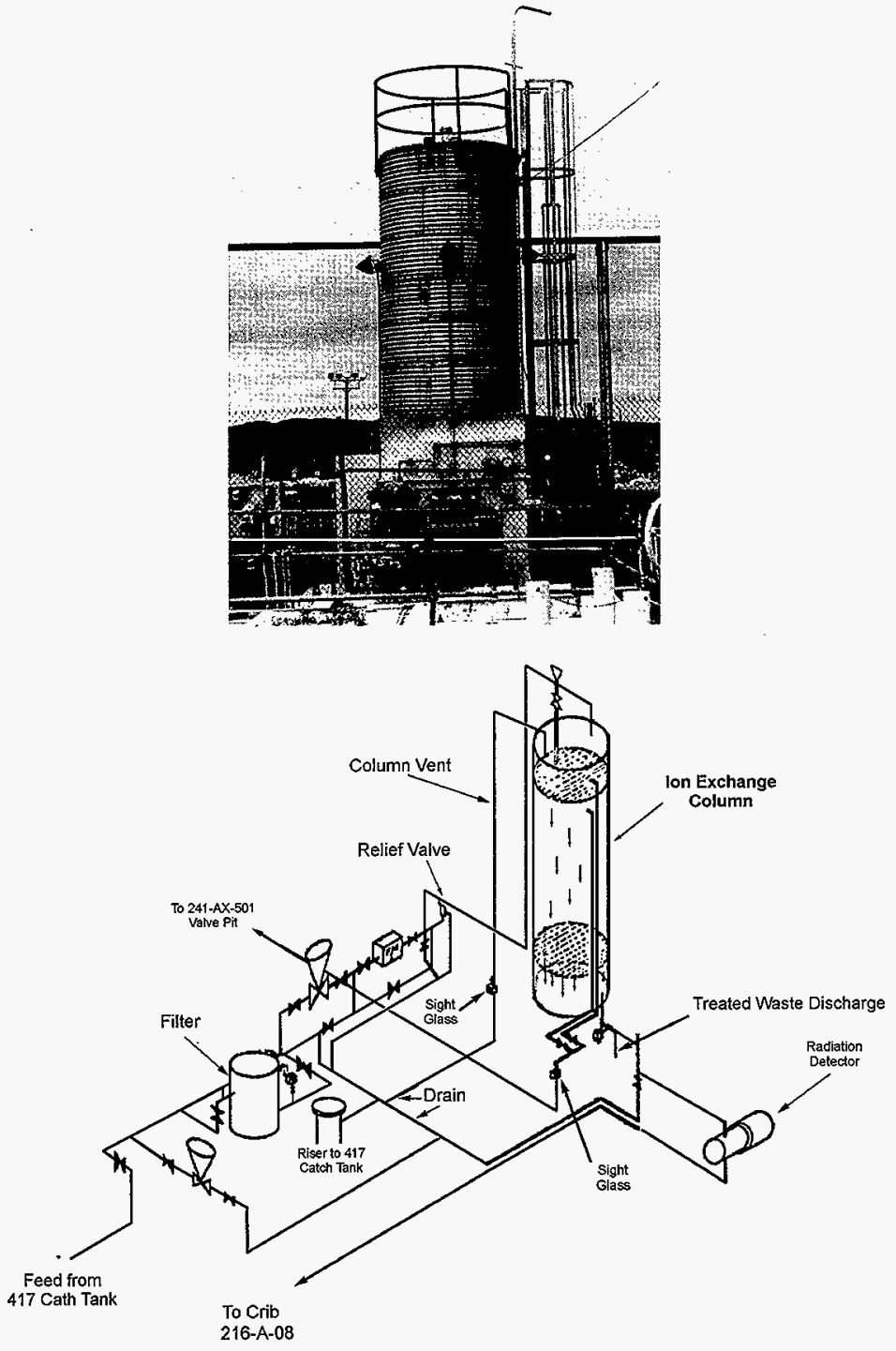

Figure 3-6. 241-AX-IX Ion Exchange Column 

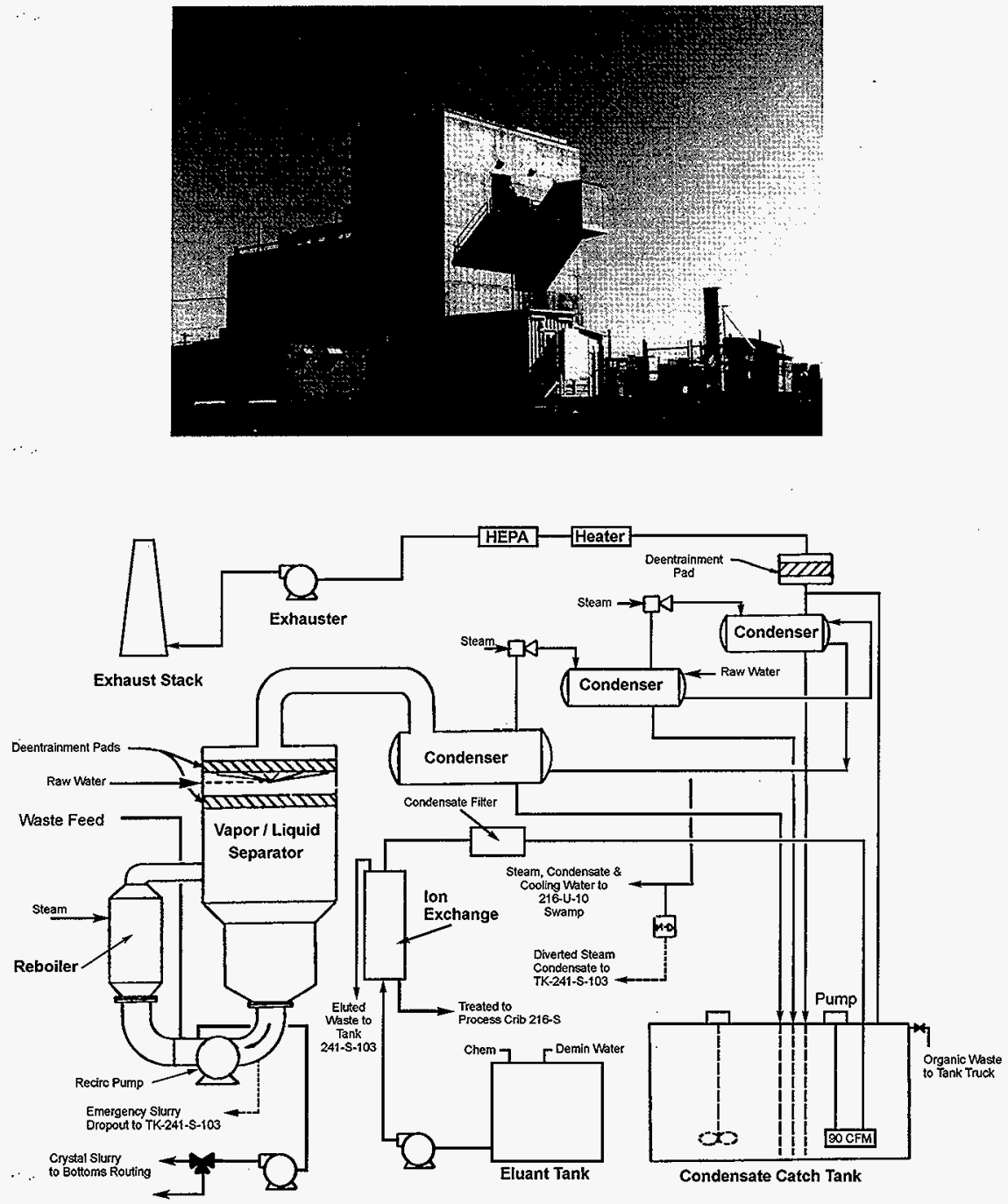

Figure 3-7. 242-S Evaporator 
HNF-2503, Rev. 0

In its original configuration, the facility was connected by piping to Tank 241-S-102 (and 1ater to Tank 241-SY-102), which was the feed and blending tank for the evaporator and Tank 24l-S-103 which was the effluent tank for concentrated waste and other byproducts of the process. Tank 241-S-103 received the concentrated waste returned from the evaporation process and other facility effluents. Treated condensate was routed to the $216-\mathrm{S}-25 \mathrm{Crib}$. The facility consists of a number of components for evaporation of the 1 iquid from the feed/staging tank (Tank 241-S-102, or 241-SY-102) and return of the concentrated waste to Tank 241-S-103. The following is a listing of the major vessels within the facility:

- 242-S-C-A-1 $(134,750 \mathrm{~L}[35,600 \mathrm{gal}])$, a vapor/ $]$ iquid separator approximately $12 \mathrm{~m}$ (40 ft) high and $4.6 \mathrm{~m}(15 \mathrm{ft}) \mathrm{dia}$.

- E-A-1, a reboiler approximately $4.6 \mathrm{~m}(15 \mathrm{ft}) \mathrm{high}$ and $1 \mathrm{~m}(3.5 \mathrm{ft}) \mathrm{dia}$.

- 242-S-E-C-1, a primary condenser approximately $5.5 \mathrm{~m}$ (18 ft) 1ong and $2 \mathrm{~m}(7 \mathrm{ft}) \mathrm{dia}$.

- 242-S-E-C-2, an inter condenser approximately $2 \mathrm{~m}$ (7 ft) long and $0.5 \mathrm{~m}$ $(1.5 \mathrm{ft}) \mathrm{dia}$.

- 242-S-E-C-3, an after condenser approximately $2.3 \mathrm{~m}(7.5 \mathrm{ft})$ 1ong $25 \mathrm{~cm}$ (10 in.) dia.

- 242-S-TK-C-100 (67,370 L [17,800 gal]), a condensate catch tank

- 242-S-IX-D-1 (4,288 L [1,133 ga] ]), an ion exchange column approximately $1.2 \mathrm{~m}(4 \mathrm{ft}) \mathrm{dia}$. and $4.9 \mathrm{~m}$ (16 ft) high

- 242-S-TK-E-101 (15,897 L [4,200 gal]), an eluent tank

- 242-S-TK-E-102 (379 L [100 gal]), an anti-foam tank

- 242-S-TK-C-103 (1,893 L [500 gal]), a flow measurement tank

- 242-S-TK-E-104 (2,347 L [620 gal]), a decontamination tank approximately $1.5 \mathrm{~m}(5 \mathrm{ft}) \mathrm{dia}$ and $1.5 \mathrm{~m} \mathrm{high}$

- 242-S-DU-C-1, a de-entrainment unit

- 242-S-TK-302-C $(177,895$ L [47,000 gal]), an acid storage tank 1ocated above ground, outside of the facility. This tank was originally an acid addition tank and was also later used as lag storage for the U1/U2 Crib groundwater before it was treated in the ion exchange column. This tank has been emptied and cleaned for use as a raw water storage and chemical addition tank for the RCSTS.

- Floor sump in the hot side of the facility, 3,785 L (1,000 gal) capacity, approximate 1 y $1.5 \mathrm{~m}(5 \mathrm{ft})$ square and $1.8 \mathrm{~m}(6 \mathrm{ft})$ deep.

The building is ventilated by two independent ventilation systems serving the "hot" and "cold" sides of the facility, respectively. The hot side of the facility (evaporator and pump rooms) is maintained at a negative pressure relative to the cold side. The facility has a raw water wet pipe fire suppression system, common to the facility and zoned for specific areas. 
Materials Stored in the Facility

The 242-S Evaporator contains residual waste materials in several of its vessels. The following process vessels were drained and flushed following the facility shutdown in 1981 and may contain small amounts of liquid from that activity: $\mathrm{E}-\mathrm{C}-1$ (Primary Condenser), $\mathrm{E}-\mathrm{C}-2$ (Inter Condenser), $\mathrm{E}-\mathrm{A}-1$ (Reboiler), E-C-3 (After Condenser), TK-C-103 (Flow Measurement Tank), DU-C-1 (De-Entrainment Unit). The following is the status of the other vessels within the facility:

C-A-1 (Vapor/Liquid Separator) - The vapor/liquid separator contains a residual liquid of about 7.6 to $10.1 \mathrm{~cm}$ ( 3 to $4 \mathrm{in.}$.) remaining in the bottom of the vessel. It is not known what this liquid is, but it is likely to be undrained liquid from the flushing operation.

TK-C-100 (Condensate Catch Tank) - The condensate catch tank was Tast used during the U1/U2 groundwater treatment campaign in 1985. It was not reused after that. The tank contains approximately 30,000 to $34,000 \mathrm{~L}(8,000$ to $9,000 \mathrm{gal}$ ) (approximately 2.5 to $3 \mathrm{~m}$ [8 to $10 \mathrm{ft}$ ] depth) of residua] waste. The amount of sludge in this waste is unknown. Since the resin in the ion exchange column was organic, the tank likely also contains some organic materials. The concentration of organic material is unknown. No sample data is available to determine the constituents of the waste material and only Timited process history information is available for 242S.

IX-D-1 (ion exchange column) - The column originally contained a zeolite ion exchange medium (ARH-MA-119). To support the U1/U2 groundwater treatment campaign in 1985, an organic ion exchange resin was added to the ion exchange column (letter, 65950-85-350-AX; SD-WM-SSP-002). After the U1/U2 treatment the resin was regenerated with sodium hydroxide and the column was filled with water to cover the resin. The column is not vented, but is opened and inspected periodicaliy. Radioactive material in the column is expected to be similar to that contained in the condensate catch tank.

TK-E-101 (Eluent Tank) - The eluent tank originally contained sodium nitrate for regeneration of the ion exchange column, and was later used in the U1/U2 treatment campaign to contain sodium hydroxide for regeneration of the ion exchange column. The tank is currently empty.

TK-E-102 (Anti-Foam Tank) - The anti-foam tank was used in the U1/U2 treatment campaign. It contains a residual amount of white powder and is labeled as "Sodium Bicarbonate." The tank was sampled in 1997 and the analysis confirmed that the tank contained sodium bicarbonate.

TK-E-104 (Decontamination Tank) - The decontamination tank was sampled in 1997. It currently contains a minimal heel of yellow-tinted water. Analysis determined a $\mathrm{Ph}$ of 10.0 and a specific gravity of 1.028 . It was concluded from the sample data that the heel was primarily water and rust residue. No hazardous materials were indicated by the sample results.

TK-302-C - This tank was originally an acid addition tank for injection of dilute nitric acid in the process stream, and was more recently used during the groundwater treatment campaign as 1 ag storage for the 
HNF-2503, Rev. 0

216-U1/U2 Crib groundwater. This tank has been emptied and cleaned for use as a raw water storage and chemical addition tank for the RCSTS.

Pump Room.Floor Sump - This sump contains an undetermined amount of floor drainage from the hot side of the facility.

\subsubsection{2-T Evaporator}

The 242-T Evaporator facility is located in the 200-W Area, northeast of and adjacent to the 241-TX Tank Farm. The facility was built as a prototype in the early 1950s to remove liquids and reclaim space in existing waste storage tanks, and later to process PFP waste. The evaporator was modified several times. It was used to process liquid into concentrated solids (crystallization), as well as to remove liquids and concentrate waste.

The evaporator was first operated as a batch unit from 1952 until its first shutdown in 1955. The plant was not used again until 1965, when the first modifications were made and the plant was run as a continuous evaporation process until 1972. In 1973 modifications were made to allow the facility to neutralize and concentrate waste from PFP. This role continued until 1980 . In April 1981, a shutdown/standby plan was written. A final waste transfer out of the facility was made in 1982. In April 1983, a revised shutdown/standby report (SD-HS-SAR-009) was issued that detajls the steps necessary to $\mathrm{place}$ the process portion of the 242-T Evaporator facility in shutdown/standby condition $V$ (no operational mission is predicted). The shutdown/standby report requires the maintenance of controlled air flow within the 242-T Evaporator facility and HEPA filtration of exhaust air.

The facility is housed in a rectangular concrete building with a divided process area (radiological area, or "hot"), a control area (non radiological, or "cold"), and a stand alone chemical storage tank building. The process area has $0.6 \mathrm{~m}$ (2 ft) of concrete shielding and is approximateily $13 \mathrm{~m}$ (43 ft)

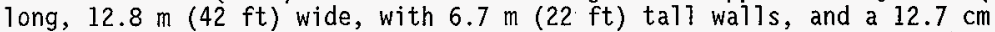
(5 in.) thick cover block (flat) roof, reinforced with external steel trusses. The process area roof cover blocks have been foamed over. The processing area consists of a feed cel1, evaporator cel1, and a condensate cell that are separated by one foot thick concrete walls. One corner of the condensate cell holds the sample gallery and the decontamination sink. A photo and diagram of the facility are shown in Figure 3-8.

The attached single story control area contained a now defunct lunch room, wash room and lavatory, a change room, a control room, instrument air dryers, and an anti-foam tank and pump.

242-T-601, a small chemical storage building, next to the evaporator has seven tanks (both inside and outside the building) that were used to store make-up chemicals for the evaporation process. 
HNF-2503, Rev. 0
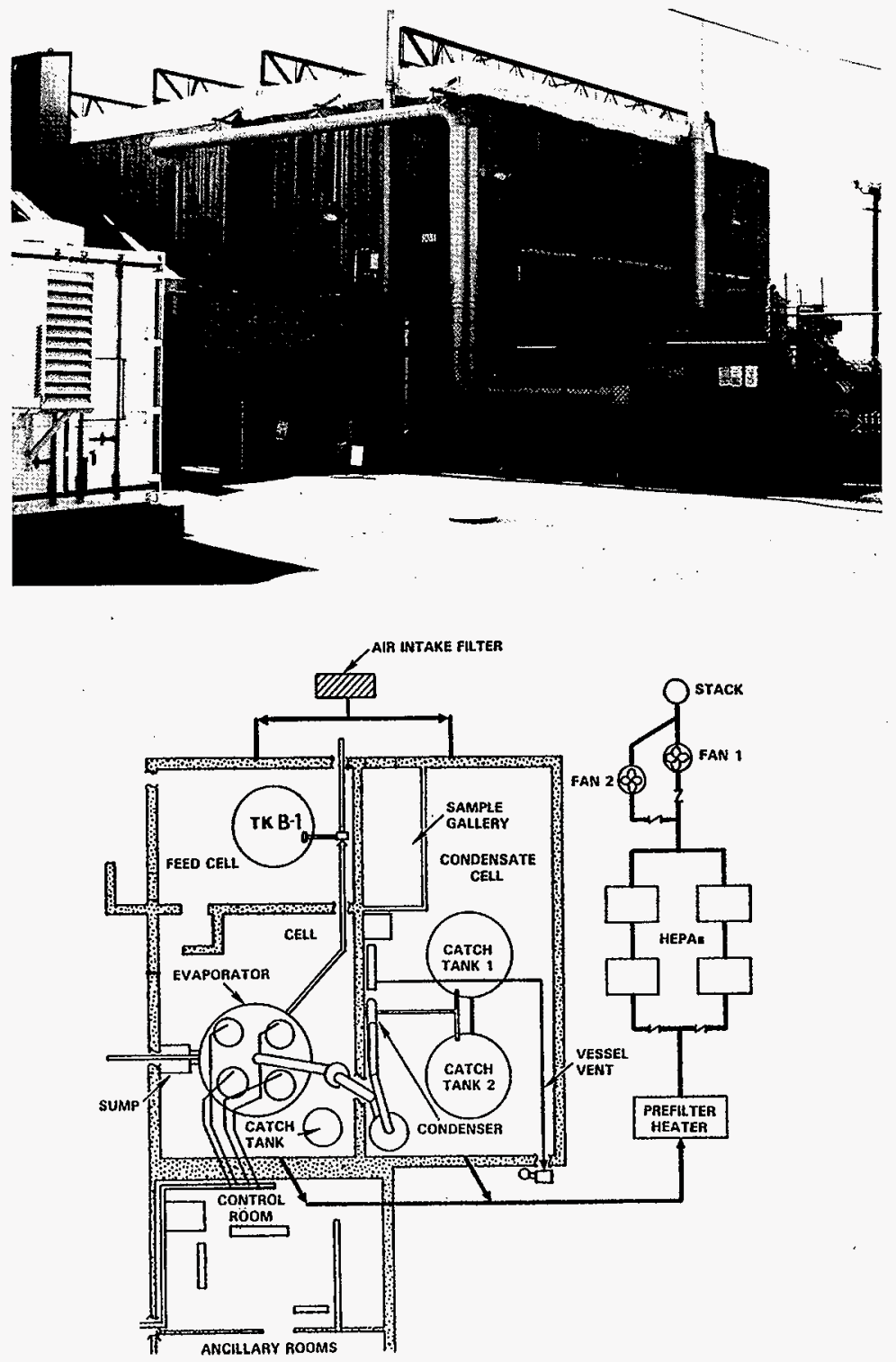

Figure 3-8. 242-T Evaporator 
The following vessels are located within the 242-T Facility:

- 242-T-101 (41,635 L [1],000 gal]), an evaporator vessel

- 242-T-102 (also known as TK-Bl) (15,987 L [4,200 gal]), a feed tank.

- 242-T-103 (178 L [47 gal]), a preheater

- 242-T-104 (178 L [47. gal ]), a preheater

- 242-T-105 (568 L [150 gal]), a cyclone separator

- 242-T-106, a packed scrubber

- 242-T-107, a condenser

- 242-T-108 $(16,276$ L [4,300 ga1]), a condenser catch tank

- 242-T-109 (16,276 L [4,300 gal]), a condenser catch tank

- 242-T-110 (360 L [95 gal]), a cyclone catch tank

- 242-T-123, a compressor receiver tank

- 242-T-112, an anti-foam tank.

The following chemical make-up tanks are located in or near the $242-T-601$ building:

- 242-T-601-TK-1 (5,000 L [1,322 gal]), a sodium ferrocyanide tank

- 242-T-601-TK-2 (24,000 L [6,345 ga1]), an acjd tank

- 242-T-601-TK-3 (1200 L [317 gal]), a nickel sulfate tank

- 242-T-601-TK-4 (208 L [55 ga] ]), a nickel sulfate tank

- 242-T-601-TK-5 $(12,810 \mathrm{~L}[3,384 \mathrm{gal}])$, a caustic tank

- 242-T-601-TK-6 (2,230 L [588 gal]), a caustic tank

- 242-T-601-TK-7 (5,000 L [1,322 gal]), a unlabeled chemical tank.

\section{Materials Stored in the Facility}

The radiological and chemical materials contained in the 242-T Evaporator are unknown. The facility suffered a breakdown in the evaporator and was abandoned. The shutdown report (SD-HS-SAR-009) tasks, if completed, were never documented. Process vessels are not maintained. The building and ventilation systems are inspected and maintained. The building and the roof are of questionable integrity. In the early 1970s, the ground under the floor of the 242-T Evaporator was washed out, and side wall and floor cracks developed. The cracks and foundation voids were back-filled with grout. Yearly structural inspections have noted no visible deterioration.

Waste material may still remain in the sump, as the shutdown plan to pump the sump back to the feed tank may not have been implemented. Other process vessels such as the evaporator, condenser, and catch tanks may contain waste material of unknown concentrations and volumes. Flammable gas is a concern for certain vessels. The radiation level from the side wall of the evaporator is $1 \mathrm{R} / \mathrm{hr}$ at $2.4 \mathrm{~m}(8 \mathrm{ft})$. The level of alpha contamination inside a vessel cannot be measured. The neutron counters in the feed tank are broken.

The seven chemical storage tanks associated with the 242-T-601 facility were inspected in 1997 (Interoffice Memo, LMHC, July 22, 1997). Six of the tanks were found to be empty and a seventh (242-T-601-TK-03) contained a small liquid heel. that was sampled and found to have a neutral $\mathrm{Ph}$. It was concluded that this liquid was water. Therefore, all of these tanks are considered to be benign. 
HNF-2503, Rev. 0

\subsubsection{4-AR Vault}

The 244-AR Vautt, located north and west of 241-A Tank Farm in the 200-E Area, was constructed in 1966. The vault was designed to remove, treat, and transfer PUREX sludges to B-Plant for fission product removal; provide interim storage for PUREX Facility acid waste feed to B-Plant; and receive and distribute the neutralized high-level waste of B-Plant. While most of the TWRS vaults are no more than an underground vault with tanks and transfer equipment, the 244-AR Vault is actually a self-contained processing facility. The major structures and components comprising this facility, described below, are the canyon building and process cells, ventilation systems, and control rooms. A photo and diagram of the facility are shown in Figure 3-9.

\section{Canyon Building and Process Cells}

The canyon building is a reinforced concrete structure with $0.5 \mathrm{~m}(1.5 \mathrm{ft})$ thick walls. The canyon building measures $29 \mathrm{~m}(94 \mathrm{ft}$ ) by $5.5 \mathrm{~m}$ (18 ft) internally and is $11 \mathrm{~m}$ (36 ft) high above the process cell concrete cover biocks on the canyon floor. The canyon building also contains two shielded personnel access doors and a large, shielded motor-driven equipment access door that slides on a rail. A metal wind-reduction structure is attached to the east end of the building for weather protection when the equipment-access doors are open.

Three process cells and a failed equipment storage cell are located below the canyon. Each of the three process cells contains a sump with an overflow connection to adjacent cells. Cell Nos. 1 and 2 have identical inside dimensions, $6.4 \mathrm{~m}$ (21 ft) square by $9.98 \mathrm{~m}(32.75 \mathrm{ft})$ deep. Cell No. 3 is $9.8 \mathrm{~m}$ (32 ft) Tong by $3.7 \mathrm{~m}(12 \mathrm{ft})$ wide by $6.4 \mathrm{~m}(21 \mathrm{ft})$ deep. The concrete cell walls are $0.6 \mathrm{~m}(2 \mathrm{ft})$ thick. The following four tanks are contained in the process cells:

- TK-244-AR-001 is located in Cell No. 1. This is a stainless steel flat-bottomed $163,333 \mathrm{~L}(43,148 \mathrm{gal})$ tank, $6.1 \mathrm{~m}(20 \mathrm{ft}) \mathrm{dia}$. and $6.02 \mathrm{~m}$ (19.75 ft) high. It was the primary storage tank for neutralized current acid waste (high-level first-cycle solvent extraction waste from the PUREX FaciTity).

- TK-244-AR-002 is located in Cell No.2. It is a stainless steel flat-bottomed $164,431 \mathrm{~L}(43,438 \mathrm{gal})$ tank, $6.1 \mathrm{~m}(20 \mathrm{ft}) \mathrm{dia}$. and $6.02 \mathrm{~m}$ (19.75 ft) high.

- TK-244-AR-003 is located in Cell No. 3. It is a stainless steel slope-bottomed $18,143 \mathrm{~L}(4,793 \mathrm{gal})$ tank, $2.9 \mathrm{~m}(9.5 \mathrm{ft}) \mathrm{dia}$. and $2.7 \mathrm{~m}$ $(9 \mathrm{ft})$ high.

- TK-244-AR-004 is located in Cell No. 3. It is a stainless steel slope-bottomed $18,143 \mathrm{~L}(4,793 \mathrm{gal})$ tank, $2.9 \mathrm{~m}(9.5 \mathrm{ft}) \mathrm{dia}$. and $2.7 \mathrm{~m}$ (9 ft) high.

The failed equipment storage area is located next to Ce11 No. 1 in the east end of the canyon building. This storage area contains three storage tubes, each constructed of $1.4 \mathrm{~m}(4.5 \mathrm{ft}) \mathrm{dia}$, 12-gauge, corrugated, galvanized pipe, that extend $11 \mathrm{~m}(35 \mathrm{ft})$ below the failed equipment storage area cover blocks. Each of the storage tubes have open drains to the Cell No. 1 floor. 

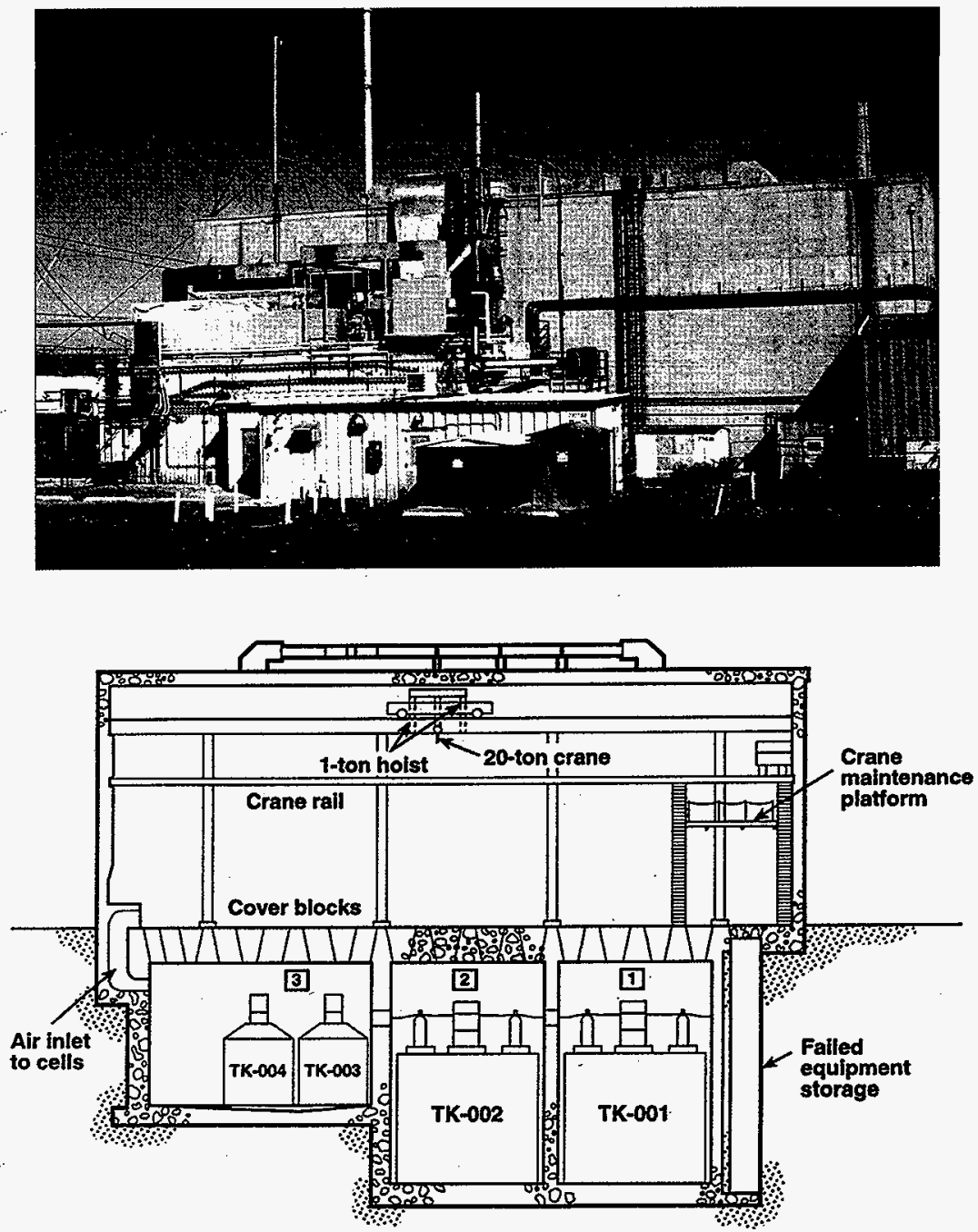

Figure 3-9. 244-AR Vault 
HNF-2503, Rev. 0

The storage tubes are vented to Cell No. 1 through $15.2 \mathrm{~cm}$ (6 in.) dia. vent pipes located $6.7 \mathrm{~m}(22 \mathrm{ft})$ above the storage tube bottom. The storage tubes are covered with a $0.6 \mathrm{~m}(2 \mathrm{ft})^{\prime}$ thick reinforced concrete block.

Four ventilation systems formerly serviced the 244-AR Vault Facility:

- Control room ventilation system, $K-1$

- Canyon intake ventilation system, $K-2$

- Canyon exhaust ventilation system, K-3

- Tank ventilation system, K-4.

These systems are not currently operable, and significant modifications or upgrades would be required to return these systems to service. The facility process area is passively ventilated to the building.

\section{Materials stored in the Facility}

The 244-AR Vault has not received wastes through the transfer system since the late 1970s. The cells and tanks within the facility currently contain wastes, as described below.

Tank TK-001 contains approximately $379 \mathrm{~L}$ (100 gal) of residual sludge from past transfers or transfer 1 ine leakage. TK-001 also contains approximately $4,540 \mathrm{~L} \cdot(1,200 \mathrm{gal})$ of liquid that is believed to be water from past transfer 1 ine flushes. No sampling information is available. The cell sump contains approximately $900 \mathrm{~L}$ (240 ga1) of liquid that may be drainage from a recent (January 1997) flooding event that was initiated by a failed sanitary water line near the facility. The level of the water in the sump is slowly decreasing, which may be attributable to leakage. There is an additional consideration that the increased sump level reading may have been partially attributable to oil leakage into the instrument air lines, which happened at the same time as the flooding event.

Tank TK-002 contains approximately 2,270 $\mathrm{L}$ (600 gal) of residual sludge from 241-AX-104. This material was transferred into the 244-CR Vault in early 1978. TK-002 al so contains about 44,100 L (11,650 gal) of water transferred from TK-004 and past transfer line flushes. Sampling information is available for the 241-AX-104 sludge. The Cel1 No. 2 sump contains about $150 \mathrm{~L}$ (40 ga 1 ) of liquid. The level of the Cell No. 2 sump also rose sharply at the time of the flooding event and has since returned to its previous level.

Tank TK-003 contains approximately $190 \mathrm{~L}$ (50 gal) of residual sludge from past transfers. TK-003 a] so contains about $7,380 \mathrm{~L}(1,950 \mathrm{gal})$ of water from the cell sump and past transfer line flushes. No sampling information is available. The Ce11 No. 3 sump contains about $11,600 \mathrm{~L}$ (3,074 gal) of water (rain and snowmelt) from roof leaks and seal pot overflow. The level of the sump in this cell also rose during the flooding event, but has remained roughly constant since then.

Tank TK-004 contains about $190 \mathrm{~L}$ (50 gal) of residual sludge from 241-AX-104 and other transfers. TK-004 also contains about $757 \mathrm{~L}$ (200 gal) of water from TK-003 and past transfer line flushes. Sampling information is available for the 241-AX-104 sludge. 
HNF-2503, Rev. 0 .

The failed equipment tubes are believed to be empty, but this cannot be verified. Removal of the cover blocks is necessary to inspect them, but the overhead crane is out of service and the cover blocks cannot be removed.

\section{3 .9 244-BXR Vault}

The 244-BXR Vault is located in the 200-E Area adjacent to and within the fencing at the southern end of 241-BX Tank Farm. 244-BXR is a four-cell, two-level, concrete underground vault. The vault dimensions are $31 \mathrm{~m}$ (102 ft) long, $8 \mathrm{~m}$ (26 ft) wide (at widest point) and $15.5 \mathrm{~m}(5 \mathrm{l} \mathrm{ft})$ deep. Two of the

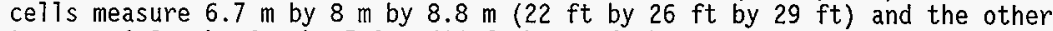
two are $4.9 \mathrm{~m}$ by $6 \mathrm{~m}$ by $5.8 \mathrm{~m}$ (16 ft by $20 \mathrm{ft}$ by $19 \mathrm{ft}$ ). The cell $1 \mathrm{~s}$ each have a pump pit located above the cells and an associated cell access pit. Each cell houses a waste storage tank. A schematic diagram of the vault is shown in Figure 3-10. The 244-BXR Vault is not a major facility; thus, its tanks are regarded as IMUSTs.

The 244-BXR Vault was operated from 1951 to 1957 and was utilized in the Uranium Recovery Program. The facility received waste material from the 241-BX and 241-BY Tank Farms, processed the waste and transferred it to U-Plant for the recovery of the uranium in the waste material. The 244-BXR Vault was isolated in 1985. Isolation was accomplished by cutting and capping the pipes connecting it to the 241-BX and 241-BY Tank Farms and the 241-ER-151 diversion station. Isolation also included cutting and capping ducts, sealing a conduit trench, and installing a weather cover over the vault at grade level. The acid tank (TK-BXR-004) used by the facility during its operation has been removed. There are no plans for future use of the facility.

Condition of the tanks is not known except for TK-BXR-011 which is reported to have a buckled wall.

244-BXR Vault contains four IMUSTs (IMUSTs are discussed in Section 5.2):

- TK-BXR-001 $(189,250 \mathrm{~L}$ [50,000 ga1]), a carbon steel slurry tank.

- TK-BXR-002 (56,775 L [15,000 gal]), a stainless steel blend tank.

- TK-BXR-003 (56,775 L [15,000 gal]), a stainless steel blend tank.

- TK-BXR-011 (189,250 L [50,000 gal]), a staintess steel pump out tank.

\subsubsection{4-CR Vault and 271-CR/CRL Laboratory}

The 244-CR Vault is located in the 200-E Area, within the fencing and at the southern end of the 241-C Tank Farm. 244-CR is a four-cell, two-level, underground concrete vault containing four tanks. The vautt dimensions are 31 $\mathrm{m}$ (102 ft) long, $8 \mathrm{~m}$ (26 ft) wide (at widest point) and $15 \mathrm{~m}$ (49 ft) deep. Two of the cells measure $6.7 \mathrm{~m}$ by $8 \mathrm{~m}$ by $8.8 \mathrm{~m}(22 \mathrm{ft}$ by $26 \mathrm{ft}$ by $29 \mathrm{ft}$ ) and the other two are $4.9 \mathrm{~m}$ by $6 \mathrm{~m}$ by $5.8 \mathrm{~m}$ ( $16 \mathrm{ft}$ by $20 \mathrm{ft}$ by $19 \mathrm{ft}$ ). The cells each have a pump pit located above the cells and an associated cell access pit. A photo and diagram of the facility is shown in Figure 3-11. The 244-CR Vault is not a major facility; thus, its tanks would be regarded as IMUSTs were it not for the fact that one of the tanks (TK-CR-003) remains active. 
HNF-2503, Rev. 0

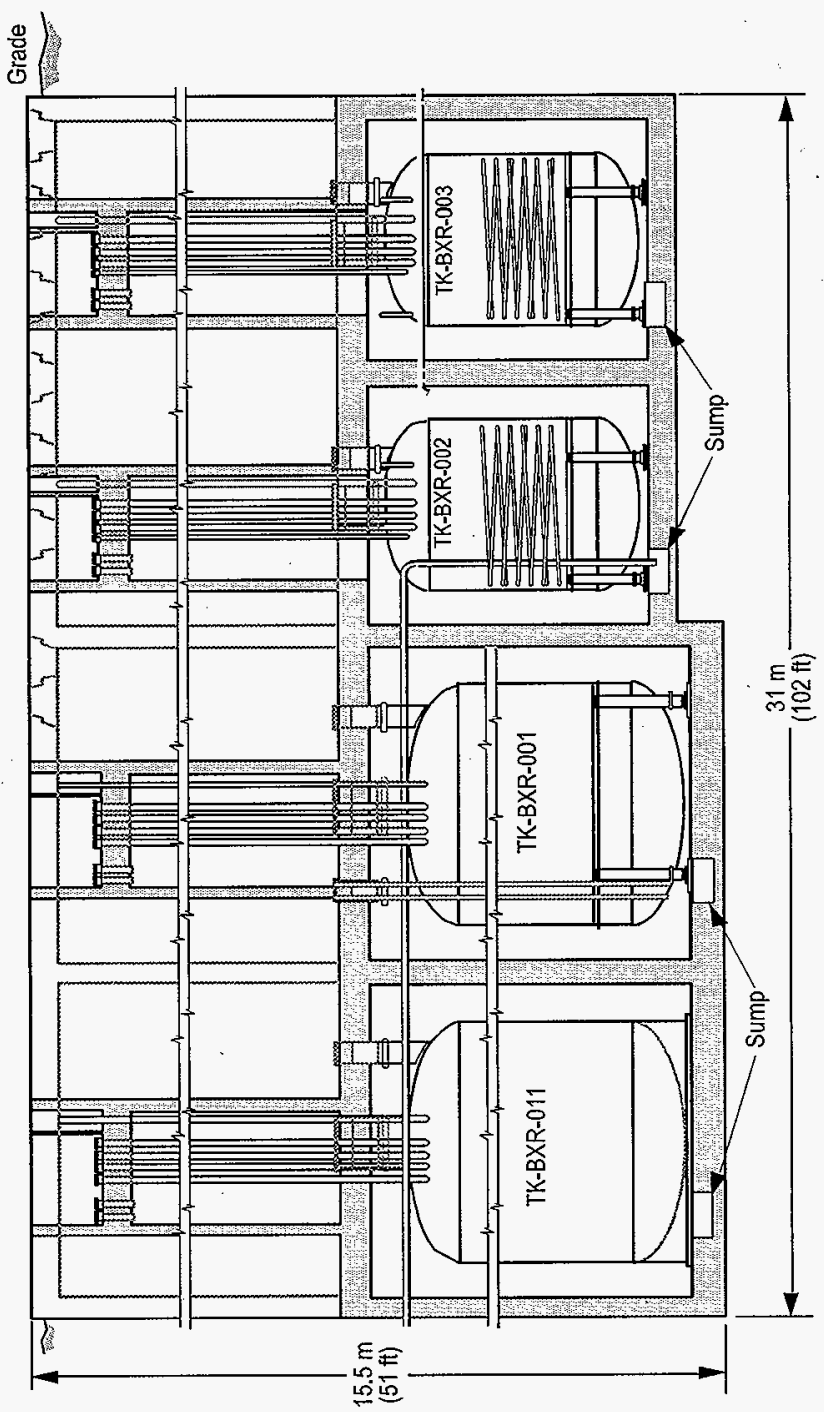

Figure 3-10. 244-BXR Vault 


$$
\text { HNF-2503, Rev. } 0
$$
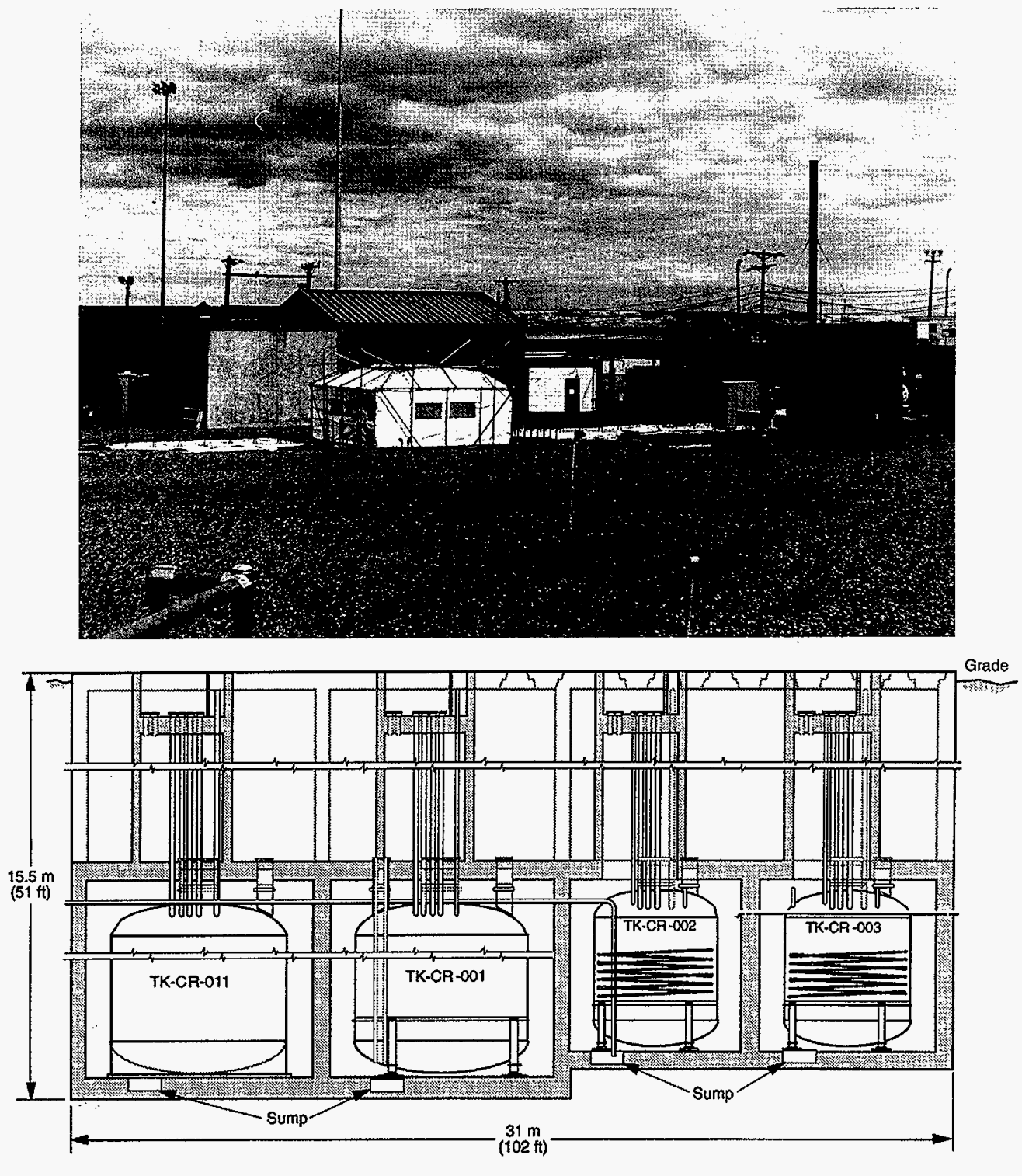

Figure 3-11. 244-CR Vault

HG98040145.2 
HNF-2503, Rev. 0

Adjacent to the vault is the 271-CR/CRL facility. 271-CR operated as the control room/shift office for the 244-CR uranium recovery and ferrocyanide programs and housed the saltwell pumping alarm panels. 271-CRL was used as a shielded laboratory facility for reactor coolant studies. 271-CR is a wood frame building $9.75 \mathrm{~m}$ (32 ft) wide at its widest and $19 \mathrm{~m}(62.5 \mathrm{ft})$ long. $271-C R L$ is a metal and concrete building $9.75 \mathrm{~m}(32 \mathrm{ft})$ wide and $15.75 \mathrm{~m}$ (51.67 ft) long. A $30,280 \mathrm{~L}(8,000 \mathrm{gal})$ tank outside the facility was previously used as the nitric acid tank for 244-CR. The tank has been removed and the facility is not currently in use.

The 244-CR Vault was also used for interim storage and transfer of waste from B-Plant, Hot Semiworks and PUREX. 244-CR Vault operation began in the early 1950 s and partial operation continued through the 1995 saltwell pumping activities. Tanks CR-001, 002 and 011 were deactivated during the 1970 to 1980 time frame and only CR-003 remained active as a saltwell receiver tank. 271-CR was built in 1953 and operated supporting various vault and 241-C Tank Farm activities through the present time. 271-CRL was constructed in 1962 and operated as a laboratory and later as a shift office through 1978.

244-CR Vautt contains four tanks:

- TK-CR-001 $(189,250 \leqq[50,000 \mathrm{gal}])$, a carbon steel slurry accumulation tank.

- TK-CR-002 (56,775 L [15,000 ga7]), a stainless steel blend tank.

- TK-CR-003 $(56,775$ L [15,000 gal]), a stainless steel blend tank.

- TK-CR-011 (189,250 L [50,000 gal]), a carbon steel pump out tank.

The 244-CR Vault is inactive except for TK-CR-003 which is an available DCRT for 241-C Tank Farm saltwell transfers. 271-CR is active as the Motor Control Center (MCC) for the 241-C Tank Farm and 271-CRL is inactive. The only identified future mission for the 244-CR Vault is the use of TK-CR-003 in conjunction with possible 241-C Tank Farm saltwell transfers (i.e., Tank 241-C-103). 271-CR will continue to provide the MCC for the 241-C Tank Farm and transfer activities. No future mission has been identified for 271-CRL.

\section{Materials stored in the Facility}

The tanks within each cel1 in the 244-CR Vault contain waste associated with their previous use as interim storage and for transfer of liquid process waste. The 244-CR Vault was used as the uranium sludge recovery and distribution vault for the 241-C Tank Farm. Sludge was recovered by siuicing, dissolved with nitric acid and pumped cross-site for uranium recovery at U-Plant. The vault was later used for interim storage and transfer of waste from B-Plant, Hot Semiworks and PUREX.

TK-CR-003 is still an active saltwell receiver tank and contains approximately $15,900 . \mathrm{L}(4,220 \mathrm{gal})$ of saltwell waste from Tanks 241-C-102, 241-C-107, and 241-C-110, with an unknown amount of solids associated with it. The TK-CR-003 tank level decreased approximately $1893 \mathrm{~L}$ (500 gal) from October 1997 to January 1998. The cause of this decrease is suspected to be evaporation, but this has not been confirmed. The contents of the other tanks are estimated based on discussions with cognizant individuals, but are not verified.

Contents are estimated to be: $7,570 \mathrm{~L}$ (2,000 gal) of Uranium Recovery Program 
solids in TK-001; $5,680 \mathrm{~L}(1,500$ gal) of waste solids from PUREX acidified sludge in TK-002; and $132,000 \mathrm{~L}(35,000 \mathrm{gal})$ of supernate and rainwater in TK-011. Each ce11 has a $170 \mathrm{~L}$ (45 gal) capacity sump with the possibility of containing standing 1 iquids that would contain contamination. Within the 271-CR/CRL complex, oniy the MCC instrumentation and piping for the fire suppression system remain as operational equipment. The buildings themselves contain radiological contamination and entry is controlled.

\subsubsection{4-TXR VauTt}

The 244-TXR Vault is located in the 200-W Area adjacent to and within the fencing at the south end of 241-TX Tank Farm. 244-TXR is a three-ce17, underground reinforced concrete vault. The vault dimensions are $22.6 \mathrm{~m}$

$(74 \mathrm{ft})$ long, $7.9 \mathrm{~m} \mathrm{(26} \mathrm{ft)} \mathrm{wide} \mathrm{at} \mathrm{widest} \mathrm{point} \mathrm{and} 15.2 \mathrm{~m}(50 \mathrm{ft})$ deep. One cell measures $6.7 \mathrm{~m}$ by $8 \mathrm{~m}$ by $8.8 \mathrm{~m}$ ( $22 \mathrm{ft}$ by $26 \mathrm{ft}$ by $29 \mathrm{ft}$ ) and the other two are $4.9 \mathrm{~m}$ by $6 \mathrm{~m}$ by $5.8 \mathrm{~m}$ (16 ft by $20 \mathrm{ft}$ by $19 \mathrm{ft}$ ). The cells each have a pump pit located above the cells and an associated cell access pit. Each cell houses a waste storage tank. A diagram of the vault is shown in Figure 3-12. The 244-TXR Vault is not a major facility; thus, its tanks are regarded as IMUSTs.

The 244-TXR Vautt contains three IMUSTs (IMUSTs are discussed in Section 5.2):

- TK-TXR-001 (189,250 L [50,000 gal]), carbon steel receiver tank.

- TK-TXR-002 (56,775 L [15,000 gal]), stainless steel blend tank.

- TK-TXR-003 (56,775 L [15,000 gal]), stainless steel blend tank.

The vault was in service from 1951 to 1956, receiving waste from tanks 241-TX-103 through 108 and 241-T-101 through 103. The waste was received in TK-TXR-001 and the waste slurry was pumped to TK-TXR-002 and/or TK-TXR-003 for acidification and blending. The processed waste was then pumped to U-Plant as feed for the uranium recovery process. The vault was taken out of regular service in 1957 and underwent isolation and interim stabilization in 1984 .

The current condition of the vault and tanks is not known. The condition of the two blend tanks is unknown.

\subsubsection{4-UR Vault}

The 244-UR Vault is located in the 200-W Area, adjacent to and within the fencing at the north end of the 241-U Tank Farm. 244-UR Vault is a four-cel1, two-level reinforced concrete underground structure $27.4 \mathrm{~m}$ (90 ft) $1 \mathrm{ong}, 8 \mathrm{~m}$ (26 ft) wide at its widest point and $15.2 \mathrm{~m}(50 \mathrm{ft})$ deep at the deepest ce 11 . Cell No. 1 has internal dimensions of $8 \mathrm{~m}$ by $6.7 \mathrm{~m}$ by $9 \mathrm{~m}$ ( $26 \mathrm{ft}$ by $22 \mathrm{ft}$ by $29.5 \mathrm{ft}$ ) with $0.6 \mathrm{~m}(2 \mathrm{ft})$ thick walls, ceiling and floor. Above the cell is a $3.8 \mathrm{~m}$ (12.5 ft) deep pump pit. Cell Nos. 2 and 3 measure $6 \mathrm{~m}$ by $4.9 \mathrm{~m}$ by $5.9 \mathrm{~m}(20 \mathrm{ft}$ by $16 \mathrm{ft}$ by $19.5 \mathrm{ft}$ ) internaliy and also have a pump pit located above them. Cel1 No. 4 measures $4.3 \mathrm{~m}$ by $4.9 \mathrm{~m}$ by $5.5 \mathrm{~m}$ (14 ft by $16 \mathrm{ft}$ by 18 1951 to 1956, receiving waste from the 241-TX Tank Farm. 
HNF-2503, Rev. 0

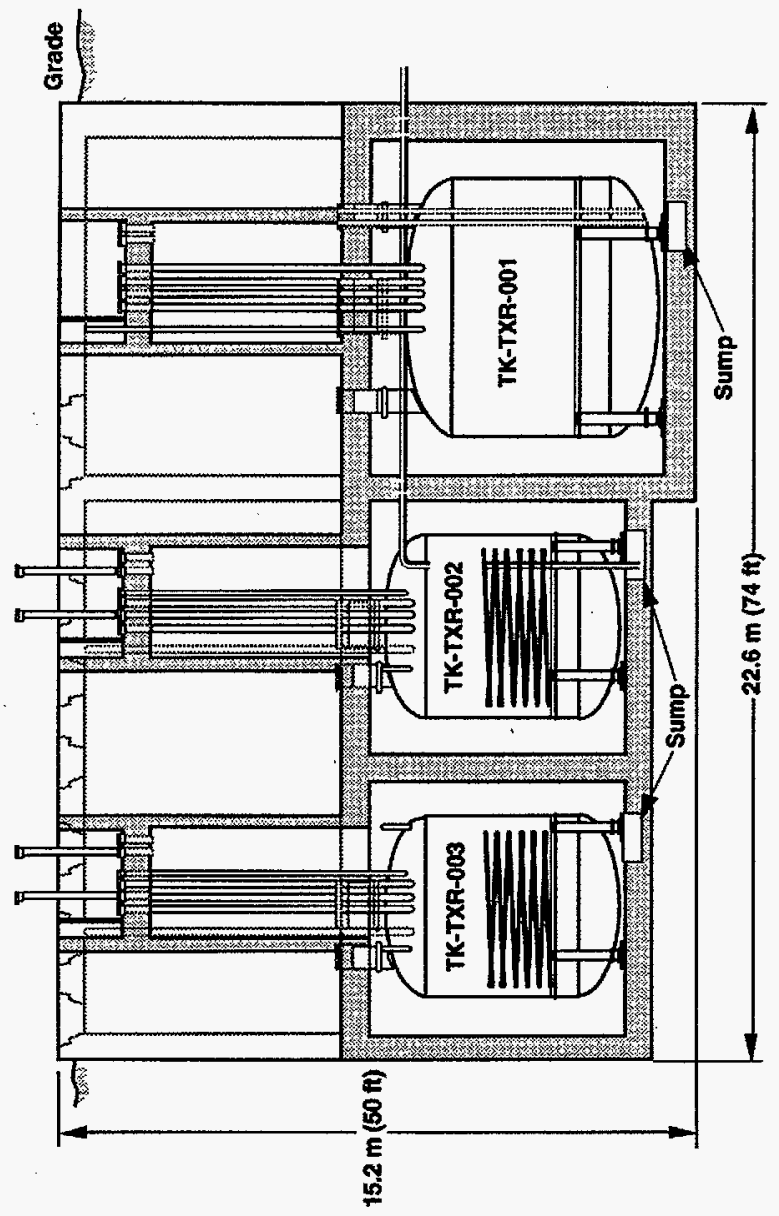

咅

Figure 3-12. 244-TXR Vault 
A diagram of the vault is shown in Figure 3-13. The 244-UR Vault is not a major facility; thus, its tanks are regarded as IMUSTs.

244-UR VauTt contains four IMUSTS (IMUSTs are discussed in Section 5.2):

- TK-UR-001 $(189,250 \mathrm{~L}[50,000 \mathrm{gal}])$, a carbon steel receiver tank.

- TK-UR-002 (56,775 L [15,000 gal]), a stainless steel blend tank.

- TK-UR-003 (56,775 L [15,000 gal]), a stainless steel blend tank.

- TK-UR-004 $(31,150 \mathrm{~L}[8,230 \mathrm{gal}])$, a stainless steel pump out tank.

The 244-UR Vault supported the uranium recovery project and was operated from 1952 to 1957. The vault was taken out of regular service in 1957 and underwent isolation and interim stabilization in 1984-1985. Current condition of the vault and tanks is not known.

\subsubsection{7-W and 2727-WA Sodium Storage Facilities}

The 2727-W Sodium Storage Facility houses five horizontally mounted sodium storage tanks in a pre-engineered, self-framing metal structure located in the south-central part of the 200-W Area approximately $11 \mathrm{~m}(35 \mathrm{ft}$ ) west of a north-south rail spur. Although according to WIDS, TWRS owns the facility, it is managed by Waste Management Federal Services Hanford, Inc. (WMH), which provides oversight, safety surveillance, and maintenance. The insulated tanks are approximate1y $4.3 \mathrm{~m}$ (14 ft) outer dia. and $7.16 \mathrm{~m}(23.5 \mathrm{ft}$ ) 1ong. A photo and drawing of the facility is shown in Figure 3-14.

The headspace of each sodium storage tank contains pressurized nitrogen gas $14 \mathrm{Kpa}$ to $69 \mathrm{Kpa}$ (2 to $10 \mathrm{psig}$ ) to preclude oxidation of the sodium.

A nitrogen gas pressure monitoring system is connected to each tank through an externally mounted, common weatherproof control panel. The common control panel includes an audible horn, indicator lights, and a strobe light. The $8.5 \mathrm{~m}$ by $26 \mathrm{~m}$ ( $28 \mathrm{ft}$ by $84 \mathrm{ft}$ ) building encloses one large room with a floor space of approximately $214 \mathrm{~m}^{2}\left(2,300 \mathrm{ft}^{2}\right)$. Features of the building include:

- Four passive roof ventilators are located on the ridge line of the roof

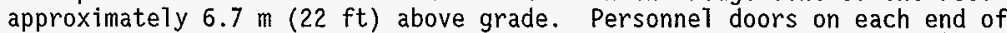
the building are louvered for ventilation.

- The metal building is electrically grounded by interconnected, $2.4 \mathrm{~m}$ ( 8 ft) grounding rods in six locations to form a grounding grid. Each internal sodium tank is grounded to the building grounding grid. The tank pressure control panel and the externally mounted master fire alarm cabinet outside the facility are also connected to the grounding grid.

- No water or steam service is provided and external signs visible from all angles clearly indicate water should not be used to fight fires. No weeds or other combustibles are allowed near the building. 
HNF-2503, Rev. 0

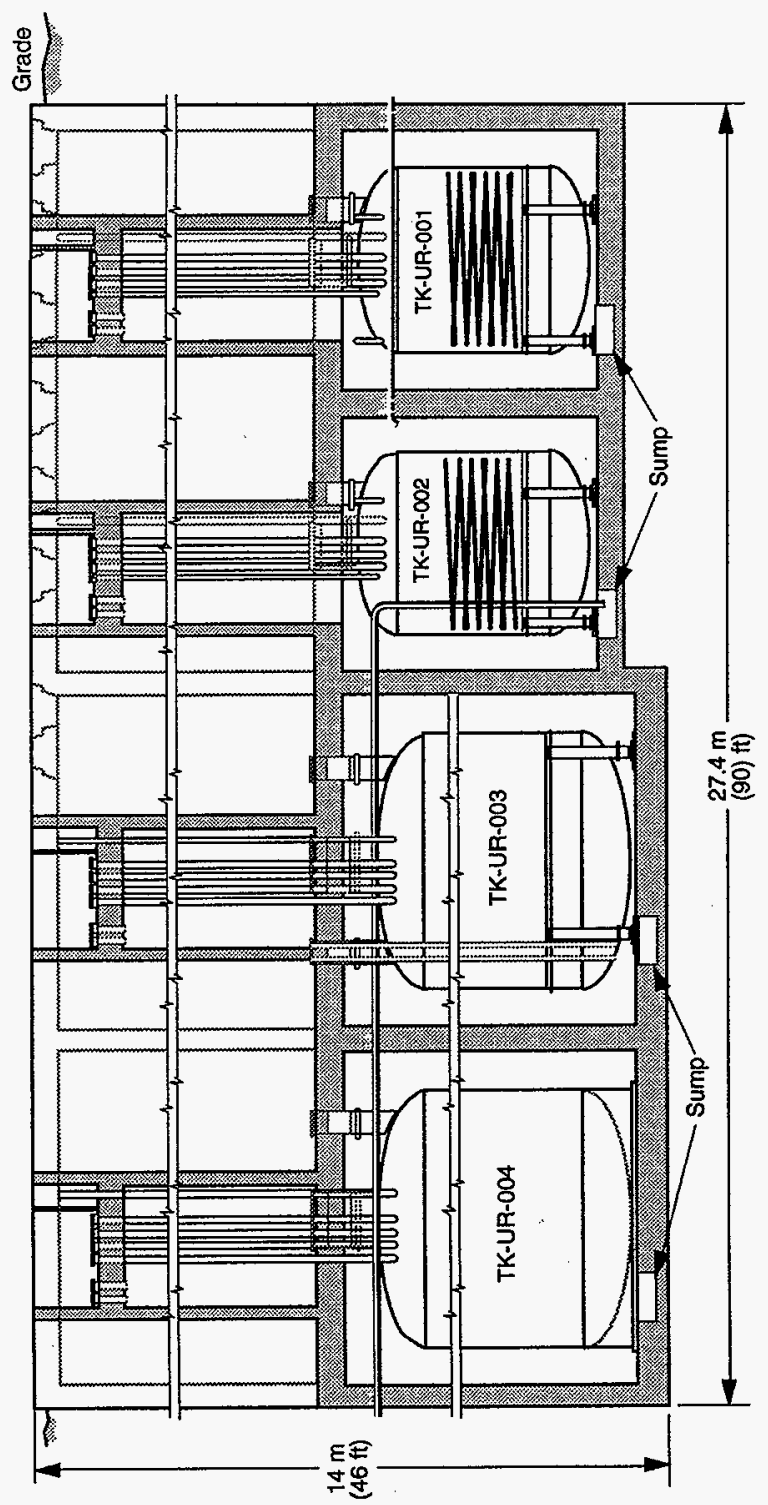

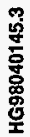

Figure 3-13. 244-UR Vault 

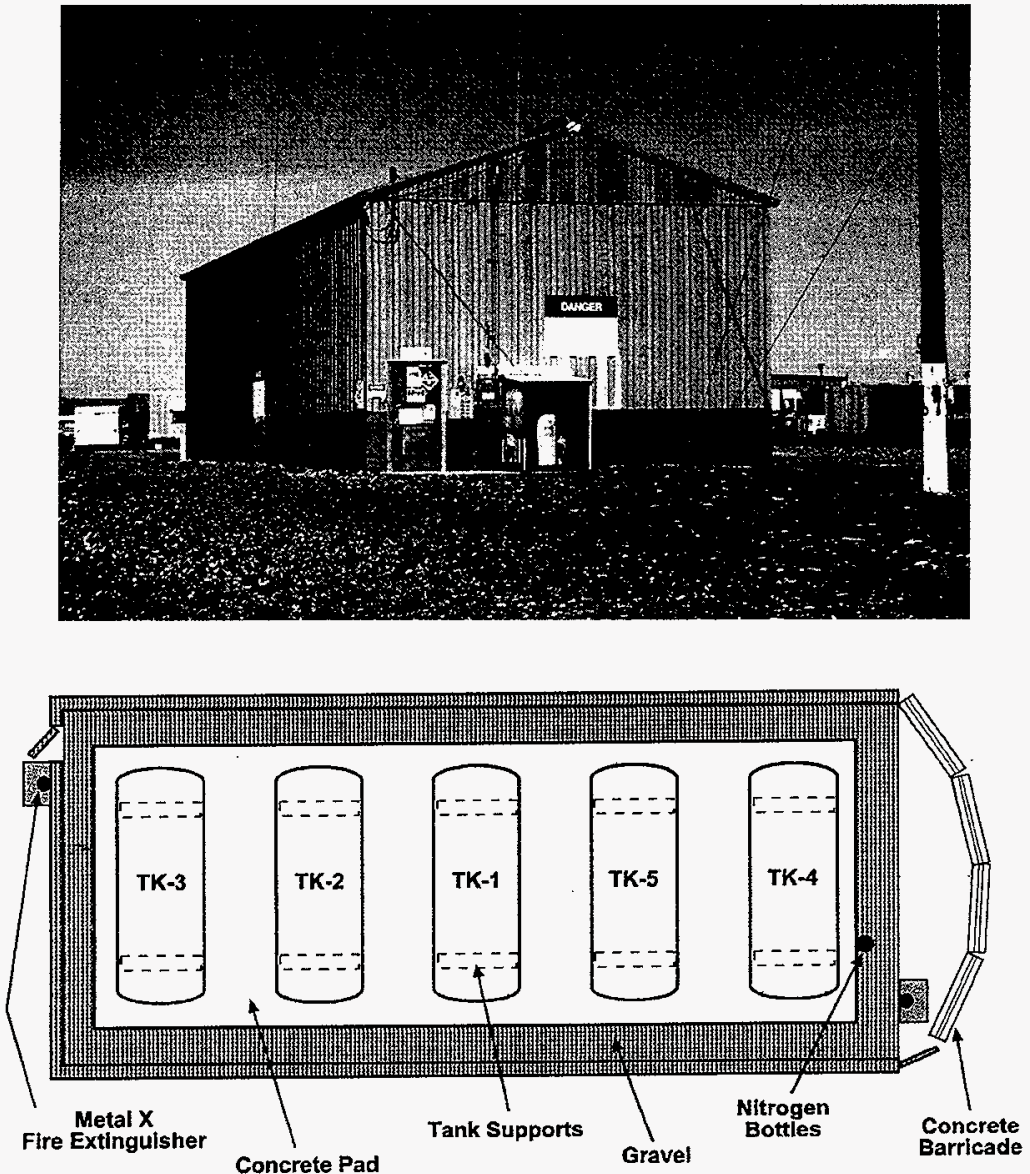

Unused Railroad Tracks

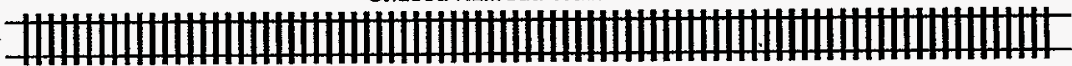

Figure 3-14. 2727-W Sodium Storage Facility 
External resistance heaters wrapped around the tanks to melt the sodium are disconnected (i.e., the sodium is solid). An insulating layer of refractory brick held in place by a wire mesh covered with an aluminum sheath surrounds the heaters and tanks. A second sodium storage facility (2727-WA) is located East of 2727-W that was used for drum storage. There are no tanks with in the facility. This facility is currently empty, and there are no plans for its future use.

\section{Materials Stored in the Facility}

The five tanks in the 2727-W Sodium Storage Facility contain a total of approximately $125,000 \mathrm{~kg} \cdot(276,000 \mathrm{lb})$ of slightly contaminated sodium metal. Contamination stems from irradiated sodium-22 that has a half-1ife of 2.58 years. Total inventory of sodium-22 is estimated to be less than $0.005 \mathrm{Ci}$ (WHC-WD-WM-TI-759).

\subsubsection{Grout Treatment Facility (GTF)}

The Grout Treatment Facility (GTF) is a low-level waste (LLW) non-reactor nuclear facility that was designed and constructed to combine cementitious materials with low-level radioactive liquid waste for permanent disposal. It consists of a nonradioactive dry component storage and mixing plant, a dry component-waste mixing facility, and below grade disposal vaults for the resultant grout. The Grout Treatment Facility was shut down in 1989 and placed in standby in 1994. The standby plan allowed for a facility restart within two years if emergency tank space is needed (WHC-SD-WM-SSP-005). Prior to placing the facility in standby mode, one below-grade disposal vault was filled with low-activity grouted waste during the August 1988 start up. This vault is actively storing radioactive waste. The above-ground portions of the GTF has recently been declared to be of no value and are planned for turnover to the ER program (Letter, RL, 97-WSD-243), and there are no plans for restart of the facility for its original purpose. The remaining vaults will be used for interim storage of immobilized LLW (Project $W-465$ ).

The GTF comprises three separate facilities, the Dry Materials Facility (DMF) located in the 200-E Area, northwest of PUREX, the Grout Processing Facility (GPF) (designated 243-G) east of and adjacent to 241-AP Tank Farm, and the Grout Disposal Facility (GDF) area near the 218-E-16 Area outside the 200-E fence. The Feed Transfer System (FTS) underground piping feeds tank waste to the GPF. Drawings and photos of the GTF are shown in Figure 3-15.

The components of the DMF are:

- 2402 Compressor Building with an 8251 L (2180 gal) Air Receiver Tank.

- 2402EA Railcar unloading pit containing an 18,925 L (5,000 ga1) dry materials transfer bin.

- 2402EB Storage Bin, $6.6 \mathrm{~m}$ (21 ft $61 / 2 \mathrm{in}$.) dia. and $19.9 \mathrm{~m}$ (65 ft $15 / 8$ in.) high.

- 2402EC Storage Bin, $8 \mathrm{~m}$ (26 ft $17 / 8 \mathrm{in}$.) dia. and $19.9 \mathrm{~m}$ (65 ft $15 / 8$ in.) high.

- 2402ED Storage Bin, $3.75 \mathrm{~m}$ (12 ft 3/4 in.) dia. and $14.9 \mathrm{~m}$ (48 ft 11 in.) high.

- 2402EF Storage Bin, $6.6 \mathrm{~m}$ (21 ft $61 / 8 \mathrm{in.}) \mathrm{dia}$, and $19.9 \mathrm{~m}$ (65 ft $1 / 8$ in.) high. 
HNF-2503, Rev. 0
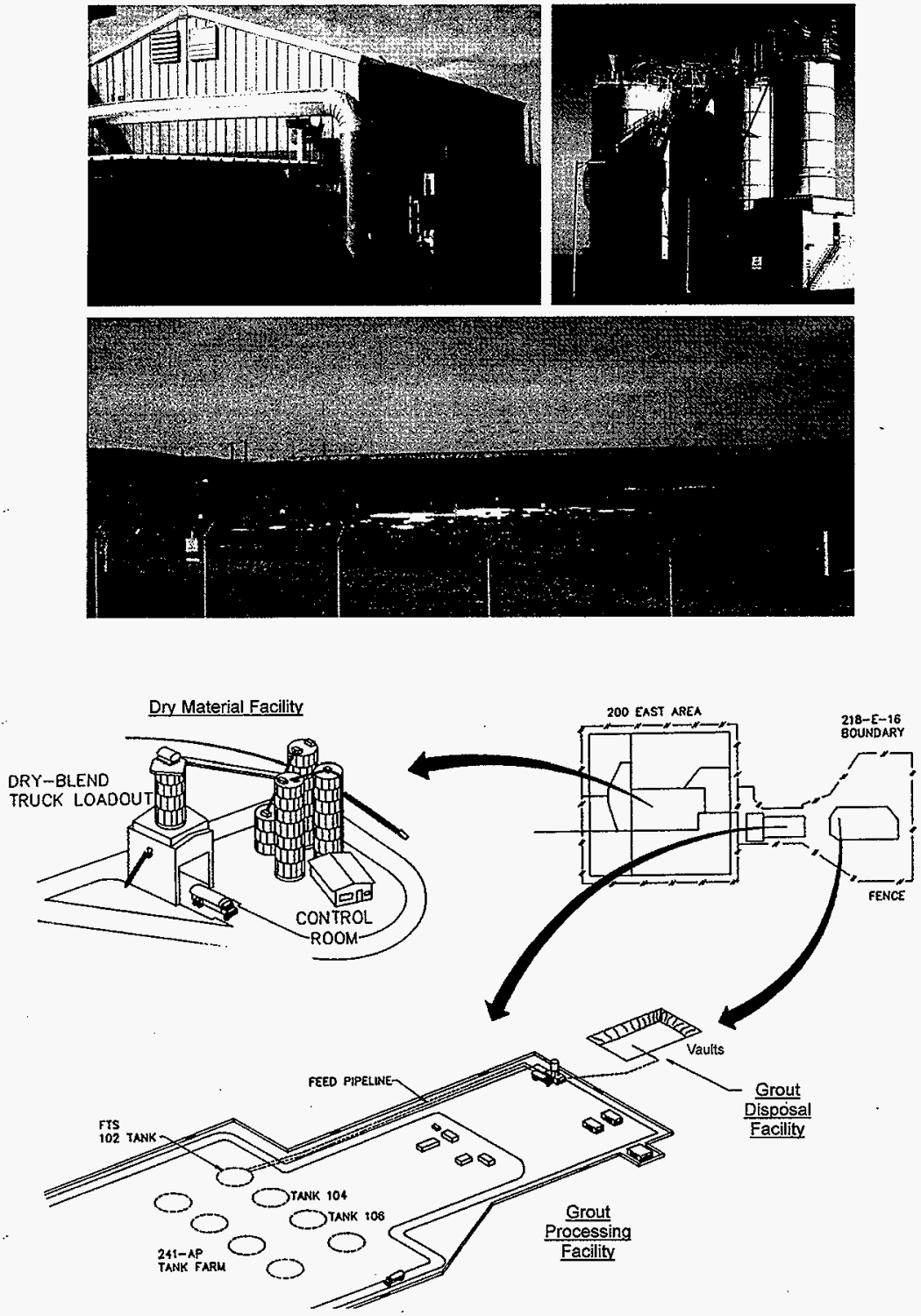

Figure 3-15. Grout Treatment Facility 
HNF-2503, Rev. 0

- 2402EG Pump Pit containing a 18,925 L (5,000 gal) transfer bin

- 2403E Blended Material Storage/Truck Loadout

- 2403EA Compressor Building

- 2451E Electrical Substation

Components of the GPF are the Control Room, Change Room/Lunch Room, Decon Additive Module, Dry Blend Module, Air Filtration module, Motor Pit, and adjacent Liquid Collection Tank (LCT.)/Mixer Module. The Decon Additive Module contains the following five tanks:

- Tank R01, a 378.5 L (100 gal) additive tank

- Tank R02, a 1,893 L (500 ga1) additive tank

- Tank R03, a 946 L (250 gal) additive tank

- Tank R04, a 757 L (200 gal) additive tank

- Tank F01, a 1,893 L (500 gal) decontamination solution storage tank.

The Dry Blend Module contains a $62.3 \mathrm{~m}^{3}\left(2,200 \mathrm{ft}^{3}\right)$ storage bin that is $3 \mathrm{~m}$ $(10 \mathrm{ft})$ dia. and $7.9 \mathrm{~m}$ (26 ft) high, and two-bag house filters. The Air Filtration module contains two separate banks of two-stage HEPA filters. The Motor Pit contains a small sampling glovebox. The LCT/Mixer Module contains a I8,925 L (5,000 gal) liquid collection tank and a 1,893 L (500 gal) hopper-fed surge tank.

The GDF consists of four empty $5,299,000 \mathrm{~L}$ (1.4 M gal) near-surface vaults, one of which is filled with low-level DST phosphate/sulfate grouted waste.

\section{Materials Stored in the GTF}

The Grout Treatment Facility (GTF) is inactive and all of the above ground facilities comprising the GTF have been declared to have no monetary value and are planned for turnover to the ER program (Letter, RL, 97-WSD-243). There is one grout disposal vault that currently contains low-level (Class C per loCFR 61) DST phosphate/sulfate grouted waste from one processing campaign through the facility. Al1 other structures, components, and vessels are empty of radioactive wastes and chemicals.

\subsubsection{ITS-1 In-Tank Solidification System}

The In-Tank Solidification (ITS) system was constructed in the 200-E Area, 241-BY Tank Farm, to concentrate wastes from tanks 241-BY-102 and 241-BY-112. Two separate systems were constructed that shared some operating components. The ITS systems were constructed in the Tate 1950 s and operated until the mid-1970s, when they were shut down.

The ITS-1 system evaporated Tank 241-BY-102 contents by circulating heated air through the waste. An offgas system removed and decontaminated condensate, and fittered the dried air exhaust. The condensate from the system was treated by use of an ion exchange column and the effluent was discharged to a crib. The ITS-2 system included in-tank heaters in tank 241-BY-112 to produce saturated offgas from the tank. Offgas from 241-BY-112 was routed by an above-ground piping system to the processing location near ITS-1. The above ground evaporation system for ITS-2 was similar to ITS-1 and some components, such as the jon exchange column, were used with both systems. 
HNF-2503, Rev. 0

Several configuration changes were made over the operating life of the ITS systems, and some processing components were used with both systems. For the most part, the ITS-2 above-ground piping and processing equipment has been removed, and the remaining above ground equipment is referred to as ITS-1.A drawing and photo of the ITS-1 system is shown in Figure 3-16.

The remaining ITS-1 equipment consists of the following components:

- 24l-BY-ITS1-IX-I ion exchange column, $0.5 \mathrm{~m}$ (18 in.) dia. by $2.7 \mathrm{~m}$ (9 ft) tal1, $0.3 \mathrm{~m}^{\frac{3}{3}}\left(10.5 \mathrm{ft}^{3}\right)$ resin capacity

- 241-BY-ITS1-IX-2 cuno fi]ter, $0.6 \mathrm{~m}(2.1 \mathrm{ft})$ dia. by $1.3 \mathrm{~m}(4.5 \mathrm{ft}) \mathrm{ta}]$

- 241-BY-ITS1-TK-2 condensate catch tank, $1.7 \mathrm{~m}(5.5 \mathrm{ft}) \mathrm{dia}$. by $1.5 \mathrm{~m}$ (5 ft) $\operatorname{tal} 1$

- 241-BY-ITS1-DM-102 de-entrainment vesse1, $3.3 \mathrm{~m}$ (11 ft) dia. by $5.8 \mathrm{~m}$ (19 ft) ta11

- 24I-BY-ITSI-EX-1 condenser, $0.7 \mathrm{~m}$ (2.25 ft) dia. by $4.3 \mathrm{~m}$ (14 ft) 1ong

- 241-BY-ITSI-DM-1 demister and cycione

- HEPA filtered exhaust system

- Concrete IX column enclosure.

There are two tanks remaining (a condenser tank and a heater flush tank) that were a part of the ITS-2 system near Tank 241-BY-112. Considering that the ITS-2 system has been removed and that these tanks are not a part of the ITS-1 system, they meet the IMUST definition. The ITS-2 IMUSTs are discussed in Sections 3.4.7 and 3.4.8.

\section{Materials Stored in the Facility}

The ITS-1 In-Tank Solidification (ITS) system has tanks and process vessels that are capable of containing waste material. The ion exchange column associated with the facility may still contain the ion exchange medium (zeolite). It is not known if there is any liquid currently present in the column, nor is it known whether the column was eluted prior to its shutdown in 1974. The other ITS-1 process vessels may also still contain residual wastes from processing. The amount of waste material contained in these vessels is also unknown. No records exist that would indicate current contents. This system treated the vapor from Tank 241-BY-102, and thus current contents could be representative of that tank, but some of the system components were shared between ITS-1 and ITS-2 so the current constituents in the remaining waste material (if any) are unknown.

\subsection{IMUST IDENTIFICATION AND DESCRIPTION}

IMUSTs encompass a variety of tanks, all of which meet the definition criteria given in Section 2.6. After considering the facilities and tanks listed above, IMUSTs by definition represent the remainder of the TWRS radiological FTCs. No above-ground radiologically contaminated tanks/vessels owned by TWRS 


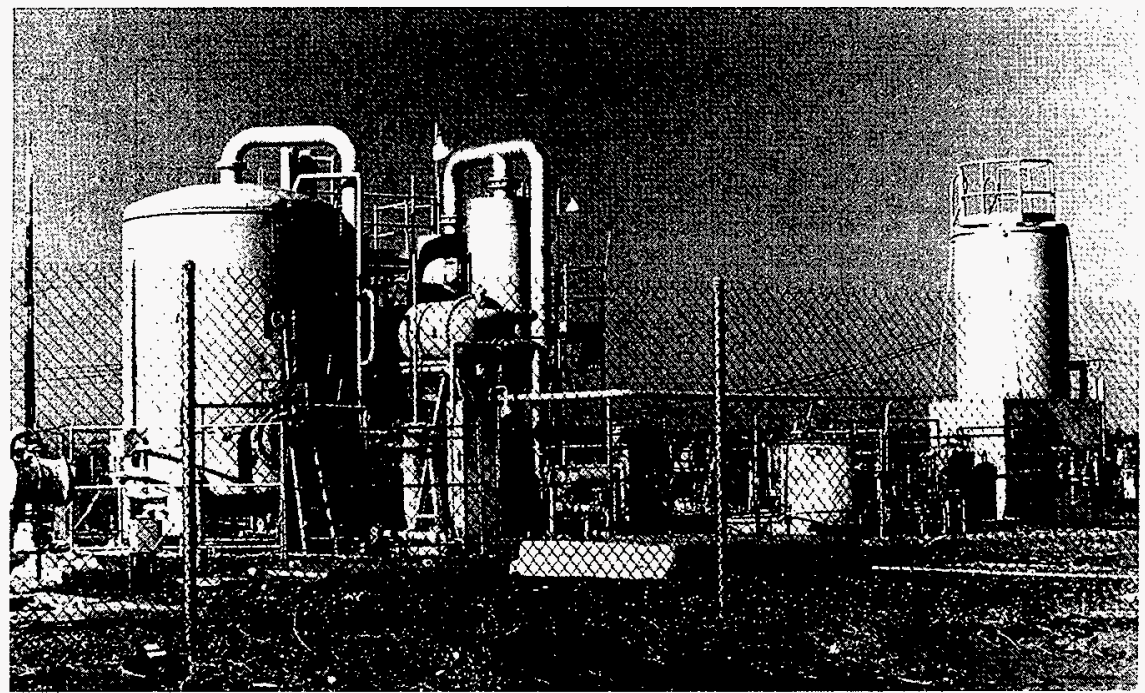

Ion Exchange Column

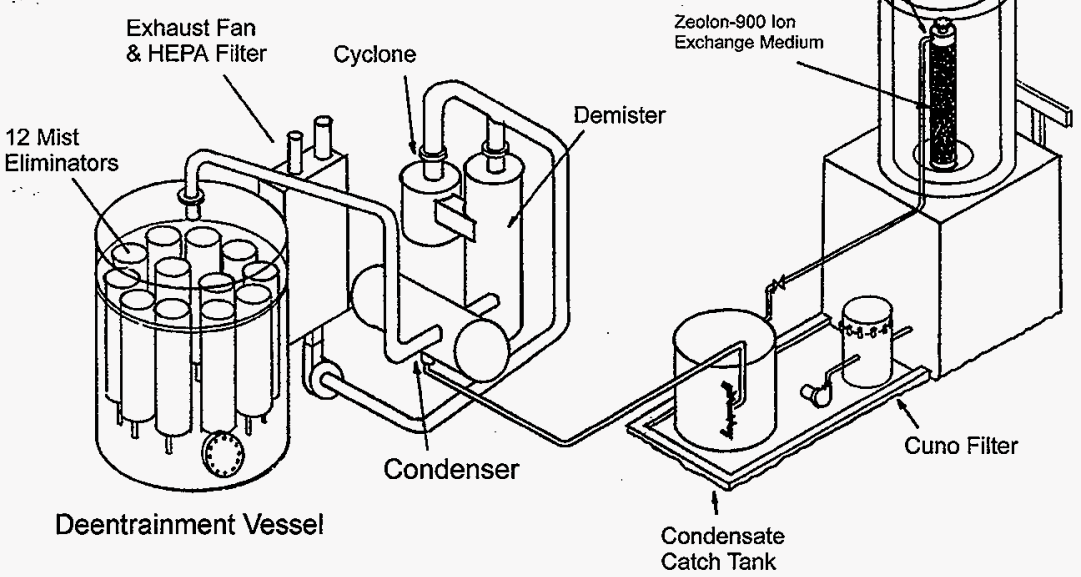

Figure 3-16. ITS-1 In-Tank Solidification System 
HNF-2503, Rev. 0

were jdentified, other than those associated with major facilities. IMUSTs are located throughout the 200-E and 200-W Areas, many of which are buried tanks, and others are contained in underground vaults. Included in the IMUST definition are catch tanks, storage and treatment tanks in vaults, decontamination tanks, experimental tanks, neutralization tanks and tanks used for other purposes such as 1 ag storage. Tanks associated with facilities have been illustrated in Figures 3-2 through 3-16. Figures 3-17 and 3-18 provide illustrations of two types of catch tanks that are fairly representative of typical IMUSTs. IMUSTs associated with a facility will be dispositioned and managed with the facility. Individual $A B$ strategies for these tanks will be a part of the strategy developed for the facility.

IMUSTs have been the subject of several previous studies and projects, notable among them was an engineering study done in 1994 (WHC-SD-EN-ES-040) that provided a reasonably rigorous process history evaluation of the IMUSTs that had been identified at that time. The engineering study provided detailed descriptions of those IMUSTs and they will not be repeated in this report. Several tanks have been added to the IMUST 7 ist since the engineering study. These are listed in the various sections of Appendix $A$ and described in the following subsections.

\section{$3.4 .1200-W-7$}

200-W-7 is a 2,082-L (550-gal) fiberglass catch tank formerly associated with M0-0326, which was a personnel decontamination facility located in the 200-W Area northwest of the 242-S. Evaporator. The decontamination trailer has been removed. The tank is located below grade with a minimum of $0.9 \mathrm{~m}$ ( $3 \mathrm{ft}$ ) of soil overburden and has three $10.2-\mathrm{cm}\left(4-i n_{.}\right)$dia. risers. This tank is also identified as 243-S-TK-1. No documentation or drawings associated with the facility have been found.

The current contents are unknown. Since it received the effluent stream from personnel decontamination, the contents are expected to be soap, water, and low levels of contamination. A walkdown revealed a cleanout riser for lines at grade and a level gauge of unknown condition. The tank is located within a chained $3 \mathrm{~m}$ by $3 \mathrm{~m}$ ( $9.8 \mathrm{ft}$ by $9.8 \mathrm{ft}$ ) area. The tank is posted as an IMUST.

\section{4 .2 209-E-TK-111}

This 189-L (50-gal) capacity tank is located underground adjacent to the CAR at the south end of the 209-E facility. TK-111 was used as a drain tank and is currently inactive. The tank is passively ventilated and was sampled routinely, where it was determined that plutonium levels were below limits for discharging the contents to a crib. A recent vapor sample of the drain tank (TK-111) identified no detectable flammable gas within the vessel.

The tank was used to hold condensate from the facility prior to its release to cribs. Based on process knowledge, this tank was routinely sampled where it was determined that plutonium levels were below limits for discharge to a crib. Therefore, the present contents of the tank are estimated to consist of residual water from the condensate collection and low levels of plutonium. 
HNF-2503, Rev. 0

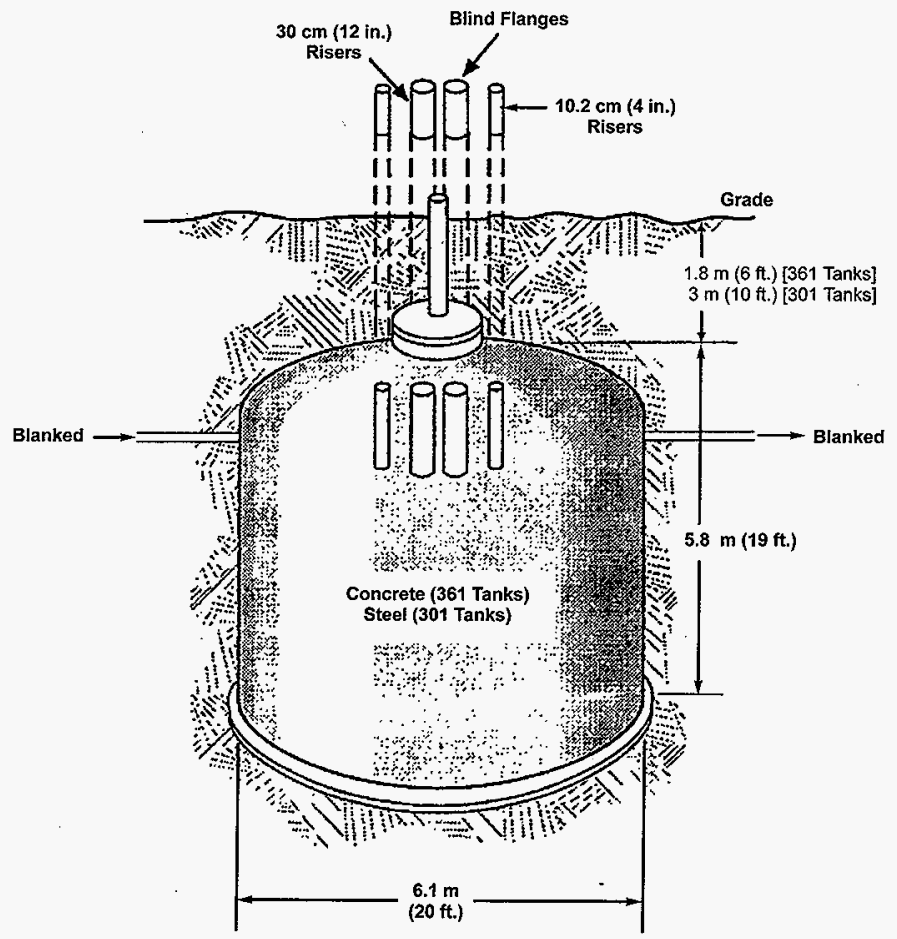

Figure 3-17. 301 Series Catch Tank 
HNF-2503, Rev. 0

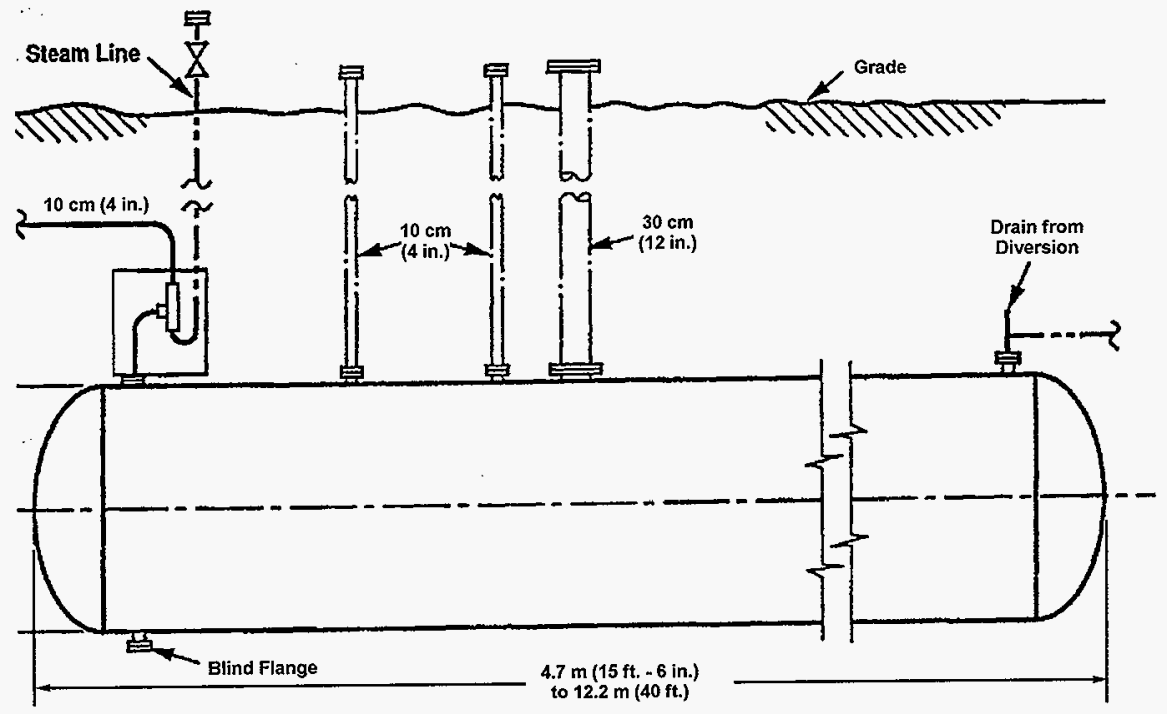

Elevation

Scale: None

Figure 3-18. 302 Series Catch Tank 
HNF-2503, Rev. 0

The tank location is covered by a steel pit cover and is posted as a radioactive material and contamination area and as a confined space entry location. This tank meets the definition of an IMUST. However, it is managed as a part of the 209-E facility.

\section{$3.4 .3 \quad 213-\mathrm{H}-1$}

This 7,097-L (1,875-gal) capacity ( $2 \mathrm{~m} \mathrm{high} \mathrm{by} 2.1 \mathrm{~m} \mathrm{dia.} \mathrm{[6.5} \mathrm{ft} \mathrm{by} 7 \mathrm{ft}]$ ) carbon steel retention tank is located east of the 213-W Compactor Facility and north of the 272-WA operations building in the 200-W Area. It is plumbed to the 213-W HVAC system, the 272-WA service garages, and the 213-W compactor room. The tank is buried with $1.2 \mathrm{~m}(4 \mathrm{ft})$ of soil overburden. It has two risers, a 7.6-cm (3-in.) HEPA vent riser and a 10.2-cm (4-in.) level gauge riser.

The tank collected drainage from floor drains in both the 213-W Compactor Room, and the 272-WA Service Garage. It also received HVAC condensate from the 213-W ventilation system. The water contained in the tank is released after analyzing for radionuclides. This tank began operation in 1985 and the tank has been inactive since 1995. It is posted as an IMUST, but there are no posted radiological signs associated with the tank.

Two samples of the contents of tank 213-W-1 were taken in March 1995, and were analyzed for $\mathrm{Ph}$ and radiological content. The results showed a $\mathrm{Ph}$ of about 7.16 with a maximum total $\alpha=\langle 1.28 \mathrm{E}-6 \mu \mathrm{Cj} / \mathrm{L}$ and maximum total $\beta=\langle 7.50 \mathrm{E}-6$ $\mu \mathrm{Ci} / \mathrm{L}$. The tank was last sampled in 1997, and contained releasable quantities of radionuclides, making it non radjoactive, and thus it does not meet the definition of an IMUST. The line from the compactor room has been reported to be sealed off, but has not been confirmed through documentation. If the compactor drain or the HVAC drains are still connected and open, the tank would be considered an active vessel.

\section{$3.4 .4 \quad 216-\mathrm{BY}-201$}

This $42,468 \mathrm{~L}(11,220 \mathrm{gaT})$ capacity (12.6 m by $1.9 \mathrm{~m}$ by $5.2 \mathrm{~m}$ [ $41.3 \mathrm{ft}$ by 6.3 $\mathrm{ft}$ by $17 \mathrm{ft}]$ ) rectangular concrete supernatant disposal flush tank is located in the northwest portion of 200-E Area, between 241-BY Tank Farm and the 216-B-43 through 216-B-50. Cribs.

The tank is underground, with at least $1.5 \mathrm{~m}$ ( $5 \mathrm{ft}$ ) of soil overburden. It has no visible risers or vents and is not discernible from the surface. A monitoring pit with a steel cover is located near the north corner of the tank. A manhole is located at each end of the tank. A siphon is located at the bottom of the tank and drains waste through a $35.6 \mathrm{~cm}$ (14 in.) line to the 216-B Cribs. An overflow pipe is also connected to this 1 ine.

Radioactive waste from the 241-BY Tank Farm system of cascading tanks overflowed to this tank en route to the 216-B Cribs. Although relatively free of solids, a small amount of saltcake may have been deposited in the tank. Based on the "Best Basis Inventory" from Appendix D of the Tank Characterization Reports (HNF-SD-WM-ER-637 and HNF-SD-WM-ER-687), the major 
HNF-2503, Rev. 0

constituents expected for the 241-BY Tanks Farm supernatant liquid would be:

- Chemical constituents of nitrate, sodium, aluminum, carbonate, and hydroxide.

- Radiological constituents of primarily strontium and cesium, with their associated decay products, yttrium and barium.

The tank also received waste from the tributyl phosphate (TBP) waste Tine. The tank was designed to scavenge the TBP waste and the supernate was sent to the 216-B Cribs. It is expected that a small amount of material, mainly water remaining from line flush, could remain in the tank. Waste containing TBP should a11 have been transferred to the cribs. 216-BY-201 is in a contamination area with a portion identified as an underground radiation area. The site is posted with an IMUST sign.

\section{$3.4 .5 \quad 216-\mathrm{TY}-201$}

This $42,468 \mathrm{~L}(11,220 \mathrm{gal})(8.2 \mathrm{~m}$ by $3 \mathrm{~m}$ by $2.9 \mathrm{~m}$ [27 ft by $10 \mathrm{ft}$ by $9.5 \mathrm{ft}]$ ) reinforced concrete rectangular supernate disposal flush tank is located in the 200-W Area, east of 241-TY Tank Farm, approx $65.5 \mathrm{~m}$ (215 ft) east of Camden Ave and $152 \mathrm{~m}$ (500 ft) north of 22nd Street. It is $30.5 \mathrm{~cm}$ (1 ft) thick with a $7.6 \mathrm{~cm}$ (3 in.) schedule 40 inlet that was blanked in 1955 halfway between the cribs (216-T-26, 216-T-27, and 216-T-28) and the 241-TY Tank Farm. There is a capped spare inlet and an $20.3 \mathrm{~cm}$ (8 in.) schedule 40 siphon (trap) under the tank leading to cribs 216-T-26, 216-T-27, and 216-T-28 through 35.6 $\mathrm{cm}$ (14 in.) schedule 40 pipe. $216-T Y-201$ has $1.5 \mathrm{~m}(5 \mathrm{ft}$ ) of soil overburden and three $20.3 \mathrm{~cm}$ ( $8 \mathrm{in.)}$ risers, two with blind flanges, and one with some electrical equipment in $\mathrm{place}$. The outlet siphon emptied the tank to a minimum of $15.2 \mathrm{~cm}(6 \mathrm{in.})$. The operating depth of the tank was $15.2 \mathrm{~cm}(0.5 \mathrm{ft})$ to $1.7 \mathrm{~m}(5.5 \mathrm{ft})$.

Supernatant 1iquid from the 241-TY Tank Farm system of cascading tanks overflowed to this tank en route to the cribs from 1953 to 1955 . This supernatant liquid originated from the 242-T Evaporator and consisted of evaporator bottoms. Although relatively clear liquid, a small amount of saltcake may have deposited in the tank. Based on the "Best Basis Inventory" from the Tank Characterization Reports (HNF-SD-WM-ER-699) the major constituents expected for the 241-TY Tank Farm supernatant Tiquid would be:

- Chemical constituents of sodium, nitrate, phosphate and hydroxide.

- Radiological constituents of primarily strontium and cesium, with their associated decay products, yttrium and barium.

There should be no organic or explosive materials (LA-UR-97-311 and HNF-SD-ER-699) in this IMUST. The tank is posted as an underground radioactive area and as an IMUST location.

\section{$3.4 .6 \quad 241-A X-151$}

The 241-AX-151 diverter station location is described in Section 3.3.4. Previous IMUST lists contained only a single entry for the catch tank (241-AX-151CT) in this diverter station. The station is an underground 
(241-AX-151CT) in this diverter station. The station is an underground reinforced concrete structure located in a large dirt mound. The top of the diverter station extends approximately $30.5 \mathrm{~cm}$ (12 in.) above grade. Within the diverter station there are four small $76-\mathrm{cm}$ (30-in.) dia. by $1.3-\mathrm{m}$ (52-in.) high stainless steel diverter tanks with a maximum capacity of $602 \mathrm{~L}$ (159 gal) and an operating capacity of $189 \mathrm{~L}$ (50 gal). The tanks are designated 241-AX-151TK D, E, F and $G$ and are located in individual cells. Located with these cells on the upper level of the diverter station is a pump pit containing a $378.5 \mathrm{~L} / \mathrm{min}(100 \mathrm{gpm})$ pump. Each cell has a stainless steel liner on the floor that extends up the wal1. A $41,635 \mathrm{~L}$ (11,000 gal) stainless steel-lined catch tank is located below the diverter tanks. A 3.8 $\mathrm{cm}$ (1-1/2 in.) dia. Tiquid level port is provided for the use of portable level detection in the catch tank. Each cell having a tank is furnished with a diverter operator mechanism. The diverter operators were used to route the waste out of the tanks to any desired transfer line. Drainage into the catch tank was pumped or jetted to diverter tank $E$ or $F$. Each diverter tank was equipped with a 5-cm (2-in.) dia. clean out pipe.

The diverter station was in operation from 1962 to 1985. The station was isolated by the B-231 Project in 1985 and was covered with foam weather covering. The four diverter operator mechanisms, leak detector 1 ines, electrical conduits, flush lines, raw water line and other piping systems were isolated as part of the B-23I project.

This diverter station originally provided multiple diversion capabilities from which four PUREX 1 ines could be routed to lines connecting tanks in the 24I-A, -AX, and -AY Tank Farms and the 244-AR Vault. Since the diversion station tanks were used in the routing of liquids for the 241-AX Tank Farm, any contents remaining should reflect the waste types similar to the 241-AX tanks. An accumulation of solids is unlikely. It is be possible that any remaining solids (and certainly liquids) are of the type represented by the last transfer through the diversion station tanks. The last transfers from the 241-AX Tank Farm were saltwel1 1iquor. Tank 241-AX-102 historical sample data for supernate (similar to saltwell liquor) is avajlable for 1981 and 1988 .

The catch tank contents are questionable since one cannot determine which transfers had spills to the catch tank. It is expected that the contents are bounded by the overall composition of the wastes in the 241-AX tanks.

Significant accumulations are unlikely since this tank was not used for long term storage.

Based on "Best Basis Inventory" (HNF-SD-WM-ER-472) for the AX tanks, the possible contents for these vessels are 1ikely to be: (in order of content)

- Chemical constituents of sodium, nitrate/nitrite, hydroxide, and some iron and potassium.

- Radiological constituents of strontium, cesium, with their associated decay products, yttrium and barium, with small amounts of plutonium and americium.

Although Tanks 241-AX-101 and 241-AX-103 are on the hydrogen/flammable gas watchlist and $241-A X-102$ contains some organic salts, it is unlikely that more than a trace of organic materials is present in these vessels. The diverter station is posted as an underground radioactive area and as an IMUST location. 
HNF-2503, Rev. 0

\subsubsection{1-BY-ITS2-TK-1}

Tank 241-BY-ITS2-TK-1 is located in the 241-BY Tank Farm in the 200-E Area. It is a small vapor condenser, $76.2 \mathrm{~cm}$ (30 in.) dia. by $2.9 \mathrm{~m}(9.5 \mathrm{ft}$ ) jong with approximately $1,320 \mathrm{~L}$ (349 ga1) capacity. The tank is contained within the sluice pit of Tank 241-BY-112. This condenser was a component of the ITS-2 In-Tank Solidification (ITS) system (refer to Section 3.3.15). The above ground components of the ITS-2 system have been removed and this tank was abandoned in place. The current contents of the condenser tank are unknown. However, the tank would have received condensate from the heated inground waste tank for return to Tank 241-BY-112. Any residual material would have the composition of the tank waste vapors and carry over particles.

\subsubsection{1-BY-ITS2-TK-2}

Tank 241-BY-ITS2-TK-2 is a heater flush tank 1ocated in the 200-E Area, 241-BY Tank Farm, between Tanks 241-BY-111 and 241-BY-112. This tank was used in support of the ITS-2 system (refer to section 3.3.15). The above ground components of the ITS- 2 system have been removed and this tank was abandoned in place.

The tank served as a decontamination solution receiver tank for decontamination of the in-tank heater assemblies used in the ITS-2 system. It is vertically oriented, constructed of carbon steel and is $1 \mathrm{~m}$ (40 in.) i.d. by $12.8 \mathrm{~m}$ (42 ft) long. The tank is encased in a stepped two-piece caisson. The upper section of the caisson is $122 \mathrm{~cm}$ (48 in.) dia., extending to a. depth of $5.18 \mathrm{~m}$ ( $17 \mathrm{ft}$ ) below grade, and the lower section is $118 \mathrm{~cm}$ (46.5 in.) dia., extending to the bottom of the flush tank.

The radiological and chemical contents in the approximately $10,400 \mathrm{~L}$ $(2,700$ gal) flush tank are unknown. However, the radiological composition of any residual material would be expected to consist of the same material as in the heated waste tank. The tank was abandoned when the ITS-2 above ground components were removed. The tank has been inactive since 1977 .

\subsubsection{1-ER-311A}

This $104,485-\mathrm{L}(27,700-\mathrm{gal}), 11-\mathrm{m}(36-\mathrm{ft})$ long by $2.7-\mathrm{m}(9-\mathrm{ft}) \mathrm{dia}$. carbon steel catch tank is located in the $200-\mathrm{E}$ Area approximately $220 \mathrm{~m}$ (720 ft) southwest of B-Plant. The top of the tank is $5.2 \mathrm{~m}(17 \mathrm{ft})$ below grade. A $1.9-\mathrm{cm}(3 / 4-i n$.$) dia. riser with an elbow extends 15 \mathrm{~cm}$ (6 in.) above grade. There are two $5-\mathrm{cm}(2-i n$.$) dia. pipes with elbows and pipe caps extending 0.6$ $\mathrm{m}(2 \mathrm{ft})$ above grade at the north end of the tank area.

The tank received waste from the 241-ER-15.1 Diversion Box due to leaks and decontamination activities. It appears that this system interfaced with B-Plant but information is not conclusive. Since it was a catch tank that would receive occasional leaks and surface runoff, the composition of any residuals is unknown. This tank was taken out of service (abandoned in place) in 1954 and replaced by 24l-ER-311. It is unlikely that any significant accumulations remain in this tank. There are no records of contents or pump out when the tank was replaced. 
HNF-2503, Rev. 0

The tank is located within a chain link fenced area. The area within the

fence is posted as a surface contamination area and 1 abeled with IMUST signs.

\section{$3.4 .10 \quad 241-T-302$}

Tank 241-T-302 was referenced in two of the source documents reviewed as a part of this activity (DOE/RL-91-61, and HNF-1566). It is also identified in the WIDS database and was thus initially listed in the Appendix A tables (Sections $A-1$ and $A-2$ ).

The "T-Plant Source Aggregate Area Management Study Report" (DOE/RL-91-61) states "additional research will be required to verify the existence of this catch tank" and indicates that the tank is posted with a placard and is surrounded by a metal fence. Location drawings in this report show that the tank is located west of the 241-T-152 diversion box, in the southeast corner of the 241-T Tank Farm, 200-W Area. This report (DOE/RL-91-61) references the WIDS database as the identification source for 241-T-302.

A recent report on IMUST locations (HNF-1566) indicates the location of the tank in the northeast corner of the 241-T Tank Farm, as opposed to the southeast location reported in the earlier document. HNF-1566 does not contain a narrative description of the IMUSTs or the methods used to verify the locations presented.

Several field walkdowns were conducted to locate this tank by both cognizant Operations and Engineering staff, none of which provided any physical evidence of the existence of the tank. There were no visible risers in either indicated location, no postings, nor any fenced off areas that would indicate the presence of this tank. The walkdowns were supplemented by discussions with the cognizant Engineering and Operations personnel, as well as former Tank Farms employees. None of the personnel consulted had any knowledge of the existence of the tank.

In addition to field walkdowns and interviews, an extensive review of the Hanford drawings was conducted. The drawings associated with the 241-T Tank Farm (other than SST detai1s) and the B-231 project were reviewed. None of the drawings indicated the existence of the tank, nor did any of them show a pipeline routing to an unidentified location. Typically, the 302 series catch tanks received drainage from the diversion boxes. However, al1 the diversion boxes in the 241-T Tank Farm drain to the 241-T-301B catch tank.

The final effort conducted to verify the existence of the 241-T-302 catch tank consisted of a geophysical survey of the 241-T Tank Farm locations where the tank was indicated by the source documents. This survey was conducted using ground electrical magnetic conductivity scanning, with a GEONICS EM-31 system. The results of the survey verified the locations of several underground structures indicated in the tank farm drawings, but there was no evidence of a catch tank in either of the reported locations.

Based on the activities described above, the tank is being removed from the list of IMUSTS; is considered to be nonexistent and will not be further evaluated in this report. Considering the thoroughness of the investigation to verify this tank's existence, follow-on investigations to locate the tank are not deemed necessary. 
HNF-2503, Rev. 0

\section{$3.4 .11 \quad 242-\mathrm{T}-135$}

This $3,142-\mathrm{L}(830-\mathrm{gal}), 1.4-\mathrm{m}(4.5-\mathrm{ft})$ dia. by $2.1-\mathrm{m}(7-\mathrm{ft})$ high stainless steel decontamination liquid storage tank is located in the 200-W Area, outside 241-TX Tank Farm. It is partially below grade with a hopper installed on top. It has two $7.6-\mathrm{cm}(3-i n$.$) risers and one 5-cm (2-in.) riser$ that may contain equipment.

The purpose of this tank when installed at the 242-T Evaporator was to provide decontamination solutions (probably caustic and acid solutions) to the feed tank, evaporator, cyclone separator, and scrubber. Decontamination solutions were charged through a hopper in the tank top and solutions were removed through the top using a jet. The tank is equipped with an agitator but has no instrumentation.

The contents of the tank are unknown but it is assumed that any remaining materials would consist of the decontamination solutions previously stored in the vessel. The hopper cover above the tank is offset and is not covering the opening completely, exposing the inside of the tank to the atmosphere.

The area around the tank is congested and considered a contamination area. A radiation shield wall consisting of a steel structural frame filled with approximately $15 \mathrm{~cm}$ ( $6 \mathrm{in.}$ ) of concrete is placed on the northeast side of the tank for radiation shielding.

The area around the tank is posted as a contamination area and is also posted as an IMUST location.

\subsubsection{2-TA-R1}

This 15,897-L $(4,200-\mathrm{gal}), 2.7-\mathrm{m}(9-\mathrm{ft})$ dia. by $3-\mathrm{m}(9.7-\mathrm{ft})$ high stainless steel tank is located in the 200-W Area, within the 241-TX Tank Farm, southwest of the 242-T Evaporator. The tank is located in the bottom of the 242-TA concrete receiver vault $(4.9 \mathrm{~m}$ [16 ft] dia. by $6 \mathrm{~m}$ [20 ft] high). The tank has seventeen nozzles including six spare nozzles. The tank overflows to a sump at the receiver vault bottom. The tank is equipped with a pump and agitator. The sump is also equipped with a pump. The receiver tank and the blending tank were used for neutralization of PFP acid waste. Use of the 242-T Evaporator facility to neutralize PFP waste was concluded with the anticipated start up of $244-\mathrm{TX}$, a double shell receiver tank (RHO-CD-1410). The transfer 1 ine was re-routed to a different receiver tank (244-TX Vault) in 1980. It is estimated that the receiver tank was in operation from 1972 to 1980.

In April 1981, a shutdown/standby plan (RHO-CD-1410) was developed for the 242-T Evaporator. The plan detailed the activities that would place the entire 242-T Evaporator facility, including 242-TA-R1 tank in a condition wherein a]l process lines would be blanked, equipment would be disabled, and instruments disconnected, to effectively isolate the $242-T$ process area. The 242-T Evaporator facility shutdown/standby plan was never fully implemented. This is documented in an RL audit conducted in 1987 (letter, RL, FDH\# 8956942) that recommends that the shutdown/standby plan be deleted. Examination of existing documentation provides no proof that many parts of the plan were ever actually completed, although some tasks identified in the plan have been verified as complete. 
The contents, amount, and residual heel remaining are unknown. However, since this tank was used to receive plutonium-bearing wastes, the bottom layers of residual material can be expected to contain this constituent. The waste stream composition is based on design criteria established for the process. The mixed aqueous waste stream No. 3 was used for processing High Salt waste from $236-Z$ and $242-Z$ after it was treated in Tank D-5 located in the 241-Z building. This waste stream was routed from Tank D-5 to 242-TA-R1, then to Blending Tank TK-B1 (242-T-102) and then on to the evaporator (242-T-101). Waste stream No. 3 composition was as follows:

$0.005 \mathrm{~g} / \mathrm{gal}$ of plutonium (Pu), 3.457 molar concentration of nitrate ion, 0.124 molar concentration of sodjum ion, 0.564 molar concentration of trivalent aluminum, 0.620 molar concentration of free hydrogen ions, 0.331 molar concentration of divalent aluminum fluoride, 0.091 molar concentration of bivalent magnesium, 0.012 molar concentration of trivalent iron, 0.040 molar concentration of potassium ion, 0.009 molar concentration of sulphate ion, and 0.0004 molar concentration of divalent uranium oxide.

The tank is located in a contamination area. Alpha contamination exists in the area. The area around the tank is posted as an IMUST area.

\subsection{TWRS CHEMICAL TANKS AND FACILITIES}

There are several chemical, nonradioactive tanks and facilities owned by TWRS in the 200 Areas. These are listed in Appendix A, Section A-13. They are primarily tanks associated with facilities, and their contents (if any) are discussed in the respective facility descriptions in Section 3.3. Tanks in the 204-AR Unloading Facility contain chemicals for treatment of received waste (refer to Section 3.3.1) and the tanks in 242-T-601 are associated with the 242-T Evaporator and are discussed in Section 3.3.7. The two other chemical tanks listed in Appendix A-13 are on a concrete storage pad outside of the 241-BY Tank Farm. Both of these tanks have been flushed and are currently empty (Interoffice Memorandum, Jụly 22, 1997).

\subsection{NON-TWRS FACILITIES, TANKS AND COMPONENTS}

There are a 1 arge number of chemical tanks and facilities in the 200 Areas that are not owned by TWRS that are 1isted in Appendix A, Sections A-14 and A-18. These tanks and facilities could potentially contribute to the TWRS hazard profile by presenting accident initiators for TWRS, resulting in consequences to TWRS workers or disruption to TWRS operations. The tanks and facilities in Sections A-14 and A-15 encompass items ranging from individual chemical tanks, shops, chemical tank farms and major facilities. A qualitative evaluation of whether or not these tanks and facilities will have an effect on the TWRS hazard profile is given in Section 5.3. 


\subsection{PRIORITIZATION}

\subsection{EVALUATION CRITERIA}

One objective of this effort is to prioritize the $A B$ upgrade actions listed in Section 5 . The results of that prioritization are presented in this section of the report. To develop criteria for ranking the proposed actions, qualitative factors that could be observed during FTC reviews and walkdowns were considered. The resulting criteria needed to reflect a relative, perceived risk presented by the FTC being evaluated. This provides only a comparative basis among the FTCs and not a qualitative determination of risk or consequences, which would be a part of upgrade activities if warranted. The criteria developed and used for the prioritization of the FTCs having potential $A B$ upgrade needs are listed in Table 4-1.

It should be noted that detailed Hazard and Operability Studies (HazOp) or Preliminary Hazards Analyses (PHA) have not been done specifically as a part of this exercise for the FTCs covered by this report. However, some of the facilities covered in this report were subject to hazard evaluations as a part of the BI0/FSAR development effort (WHC-SD-WM-TI-759) or have had a hazard evaluation done in the past when the facilities were active. The information contained in such evaluations was considered in determining $A B$ needs.

The factors used in ranking the upgrade recommendations included tank/vesse] contents, controls, $A B$ status, configuration, containment, and personnel access. These are all factors that can usually be readily determined. If certain factors in the list are unknown, a high risk is assigned. For example, a tank may be thought to contain relatively benign materials, but if there is no characterization data or process history information available, a high risk is assigned because there is no knowledge of tank contents. On the other hand, if there is confirmed characterization data or a well-documented process history available, risk level is assigned based on knowledge of the tank contents.

Risk ranking factors were applied to the categories below based on perceived dominance of the specific category to drive subsequent action. The numbers given are arbitrary and serve only to differentiate the results generated for respective FTCs.

\section{Risk Ranking Factors (RRF):}

Tank/Vesse 1 Contents $\quad 10$

Controls . 8

AB Coverage 7

Configuration 5

Containment 5

Personnel Access 5

Tank/Vesse 1 Contents: The material at risk (tank/vessel contents) was given the highest risk ranking factor. This assures that an FTC that does not contain hazardous materials is not given a high priority simpiy because it has no controls and is not described in the AB. Factors of concern are whether there is sufficient knowledge of the tank/vessel contents, whether those contents differ from typical DST or SST waste, and whether the tanks contain reactive materials. 
HNF-2503, Rev. 0

Table 4-1. Risk Ranking Criteria

\begin{tabular}{|c|c|c|c|}
\hline \multirow{5}{*}{$\begin{array}{l}\text { TANK/VESSEL } \\
\text { CONTENTS } \\
\text { RRF }=10\end{array}$} & \multicolumn{3}{|c|}{$H_{a}-$ Unknown } \\
\hline & \multicolumn{3}{|l|}{$\mathbf{L}_{\mathbf{a}}-$ Empty } \\
\hline & \multirow[t]{3}{*}{$\begin{array}{l}\text { Material } \\
\text { Present }\end{array}$} & Characterized & $\begin{array}{l}L_{b} \text { - Rad content below concern } \\
L_{c} \text { - Contains typical tank waste } \\
M_{a} \text { - Not typical tank waste } \\
M_{b} \text { - Organic materials present } \\
H_{b} \text { - Organics and acids both present }\end{array}$ \\
\hline & & $\begin{array}{l}\text { Process History } \\
\text { Known/Documented }\end{array}$ & $\begin{array}{l}L_{d}-\text { Typical tank waste } \\
M_{c}-\text { Not typical tank waste } \\
M_{d}-\text { Organics used in process } \\
H_{c} \text { - Organics and acids both used in process }\end{array}$ \\
\hline & & $\begin{array}{l}\text { Process History } \\
\text { Not Well } \\
\text { Documented }\end{array}$ & $\begin{array}{l}\mathrm{M}_{e} \text { - Unconfirmed benign information } \\
H_{d} \text { - Process unknown } \\
H_{e} \text { - Unconfirmed adverse information }\end{array}$ \\
\hline \multirow[t]{4}{*}{$\begin{array}{l}\text { CONTROLS } \\
\text { RRF }=8\end{array}$} & \multirow[t]{2}{*}{$\begin{array}{l}\text { No Controls } \\
\text { Applied }\end{array}$} & Controls Needed & $\begin{array}{l}L_{a} \text { - Programmatic controls adequate } \\
M_{a} \text { - Procedural controls needed } \\
H_{a}-T S R / A B \text { level controls needed }\end{array}$ \\
\hline & & \multicolumn{2}{|c|}{$L_{b}$ - Controls Not Needed } \\
\hline & \multirow[t]{2}{*}{$\begin{array}{l}\text { Controls In } \\
\text { Place }\end{array}$} & Adequate & $\begin{array}{l}L_{c}-\text { Correct level } \\
M_{b} \text { - Incorrect level }\end{array}$ \\
\hline & & Inadequate & $\begin{array}{l}\mathrm{M}_{c}-\text { Procedural level controls needed } \\
\mathrm{H}_{b}-A B / T S R \text { level controls needed }\end{array}$ \\
\hline Note: & $\begin{array}{l}\text { Low risk (w } \\
\text { Medium risk } \\
\text { High risk }\end{array}$ & $\begin{array}{l}\text { factor }=12 \\
\text { ing factor }=32 \\
\text { g factor }=5 \text { ) }\end{array}$ & \\
\hline
\end{tabular}


HNF-2503, Rev. 0

Table 4-1. (cont) Risk Ranking Criteria

\begin{tabular}{|c|c|c|c|}
\hline \multirow{5}{*}{$\begin{array}{l}\text { AUTHORIZATION } \\
\text { BASIS STATUS } \\
\text { RRF }=7\end{array}$} & \multirow[t]{2}{*}{$\begin{array}{l}\text { Described/ } \\
\text { Analyzed in } \\
\text { BIO/FSAR }\end{array}$} & $\begin{array}{l}\text { No Upgrade } \\
\text { Requi red }\end{array}$ & Not of further $A B$ concern \\
\hline & & Upgrade Needed & $\begin{array}{l}L_{a} \text { - Descriptive information only } \\
\mathrm{M}_{a} \text { - Evaluation required } \\
\mathrm{H}_{\mathrm{a}} \text { - Analysis needed }\end{array}$ \\
\hline & \multirow[t]{3}{*}{ Not in BLO/FSAR } & $\begin{array}{l}\text { Other } A B \\
\text { Documentation } \\
\text { Exists }\end{array}$ & $\begin{array}{l}\text { Adequate as-is - Not of further AB concern } \\
\mathrm{M}_{b} \text { - Integrate into BJO/FSAR } \\
\mathrm{H}_{\mathrm{b}} \text { - Analysis Needed }\end{array}$ \\
\hline & & $\begin{array}{l}\text { Outdated Safety } \\
\text { Documentation } \\
\text { Exists (not } A B \text { ) }\end{array}$ & $\begin{array}{l}H_{c} \text { - Can upgrade and integrate into BIO/FSAR } \\
H_{d} \text { - Additional analysis needed } \\
H_{c} \text { - Not applicable/new anatysis needed }\end{array}$ \\
\hline & & $\begin{array}{l}\text { No Safety } \\
\text { Documentation } \\
\text { Exists }\end{array}$ & $\begin{array}{l}M_{e} \text { - Descriptive information needed } \\
H_{d}-\text { New analysis needed }\end{array}$ \\
\hline \multirow[t]{4}{*}{$\begin{array}{l}\text { CONFI GURATION } \\
\text { RRF }=5\end{array}$} & $\begin{array}{l}\text { Open Connection } \\
\text { to Active TWRS } \\
\text { Systems }\end{array}$ & \multicolumn{2}{|c|}{$\begin{array}{l}L_{a} \text { - No interaction likely } \\
M_{a} \text { - Limited interaction } \\
H_{a} \text { - Near ongoing operations/interactions possible }\end{array}$} \\
\hline & Isolated & \multicolumn{2}{|c|}{$\begin{array}{l}L_{b} \text { - No interaction with other TWRS facilities } \\
M_{b} \text { - Near other TWRS/interaction possible }\end{array}$} \\
\hline & $\begin{array}{l}\text { Stabilized/ } \\
\text { Solidified }\end{array}$ & \multicolumn{2}{|c|}{$\begin{array}{l}L_{c}-\text { Known/documented stabilization } \\
M_{c} \text { - No documentation/not stabilized }\end{array}$} \\
\hline & $\begin{array}{l}\text { Ventilation of } \\
\text { Waste } \\
\text { Containing } \\
\text { Vessels }\end{array}$ & \multicolumn{2}{|c|}{$\begin{array}{l}L_{d}-\text { Ventilation not needed } \\
L_{e}-\text { Ventilation present/operating } \\
\mathrm{M}_{d}-\text { Ventilation present/vent path not confirmed } \\
\mathrm{H}_{b}-\text { Ventilation not present }\end{array}$} \\
\hline
\end{tabular}

Notes: $\quad \mathrm{L}=$ Low risk (weighting factor $=1$ )

$M=$ Medium risk (weighting factor $=3$ )

$H=H i g h$ risk (weighting factor $=5$ )

Subscripts are used in Table 4-2 to indicate the source of the risk ranking result. 
HNF-2503, Rev. 0

\section{Table 4-1. (cont) Risk Ranking Criteria}

\begin{tabular}{|c|c|}
\hline \multirow{2}{*}{$\begin{array}{l}\text { CONTAINMENT } \\
\text { RRF }=5\end{array}$} & $L_{a}$ - Material Containment Assured \\
\hline & $\begin{array}{l}\mathrm{H}_{\mathrm{a}} \text { - Not confirmed/leakage possible } \\
\mathrm{H}_{a} \text { - Leakage șuspected } \\
\mathrm{H}_{\mathrm{b}} \text { - Confirmed leak potential } \\
\mathrm{H}_{c} \text { - Material containnent capabil ity unknown }\end{array}$ \\
\hline $\begin{array}{l}\text { PERSONMEL } \\
\text { ACCESS } \\
\text { RRF }=5\end{array}$ & $\begin{array}{l}L_{a} \text { - No or very little personnel access needed } \\
M_{a} \text { - Personnel routinely work in or near facility } \\
M_{b} \text { - Personnel permanently housed in or near facility } \\
H_{a} \text { - Personnel routinely access waste areas }\end{array}$ \\
\hline
\end{tabular}

Notes: $\quad L=$ Low risk (weighting factor $=1$ )

$M=$ Medium risk (weighting factor $=3$ )

$H=$ High risk (weighting factor $=5$ )

Subscripts are used in Table 4-2 to indicate the source of the risk ranking result. 
HNF-2503, Rev. 0

Controls: The next highest risk ranking factor was given to controls, since controlling whatever risks are present is the objective of the AB. The evaluation considers whether or not appropriate controls are applied to manage the known or perceived risks, and whether those controls are applied at the correct level (e.g., TSR level, safety programs, operating procedures, standard field practice). This requires a subjective evaluation considering the lack of consequence analyses for the FTCs discussed in this report. In ranking the adequacy of controls, TWRS or site-wide programmatic safety was considered (see Section 5.1). This includes, for example, the Radiation Control Program, the Emergency Preparedness Program, the Fire Protection Program, and standard industrial safety practices such as scheduled roof inspections. Implementation and effectiveness of these programs and practices were assumed for the controls evaluation unless there was indication during the review of a given FTC that it should be assumed otherwise.

$A B$ Status: The status or condition of the $A B$ documentation followed controls on the risk ranking list. The evaluation of $A B$ status considers whether any $A B$ documentation exists, whether this documentation is adequate, and estimated level of coverage required. In the unique case where the $A B$ is considered completely adequate (including controls), the ranking process was suspended and the FTC was considered not to be of further $A B$ concern. This precludes a high relative risk ranking based solely on the presence of a high risk in the tank/vesseT contents RRF.

Configuration: Configuration refers to the current mission and status of the FTC. Specific consideration is given to relationship to active TWRS systems and structures, configuration of the waste container and hazardous materials. Also considered was the status and need for ventilation systems.

Containment: Containment refers to the condition of the FTC and its ability to safely store contained hazardous materials. Evidence of past leakage is evaluated under this RRF.

Personnel Access: Personnel access considers whether TWRS workers are routinely working in or near the FTC, or routinely need to gain access to the hazardous materials.

Collectively, these RRFs address relative safety risk and TWRS mission needs for the purpose of ranking the importance of individual FTC AB upgrades. The Tank/Vessel Contents, Containment, Personnel Access, and Controls RRFs address the potential for releases, immediate threats to workers, and thus, relative safety risk. Additionally, significant uncertainty about FTC Configuration may also contribute to the relative safety risk. The FTC Configuration, including operational status, and the Personnel Access RRFs address the TWRS mission objectives for the FTC. For instance, a permanently shut down facility with no possible mission function (other than its own deactivation and decommissioning) and little or no personnel access does not have an immediate mission driver for an $A B$ upgrade.

\subsection{RISK RANKING RESULTS}

Table 4-2 presents a tabulation of the relative risk ranking results for TWRS facilities and IMUSTs. The TWRS facilities are listed in order of priority, as are the IMUSTs. The table does not provide the individual numerical scores assigned to a facility or tank by the prioritization exercise. But, for 
HNF-2503, Rev. 0

Table 4-2. Relative Risk Ranking Results

\begin{tabular}{|c|c|c|c|c|c|c|}
\hline Relative Ranking & Contents & Controls & $\begin{array}{c}\text { AB } \\
\text { Status } \\
\end{array}$ & $\begin{array}{l}\text { Config- } \\
\text { uration }\end{array}$ & $\begin{array}{l}\text { Contain- } \\
\text { ment }\end{array}$ & Access \\
\hline \multicolumn{7}{|c|}{ Facilities (in order of priority): } \\
\hline 1. $242-\mathrm{T}$ & $\mathrm{H}_{\mathrm{a}}$ & $H_{b}$ & $\mathrm{H}_{\mathrm{b}}$ & $M_{b}$ & $\mathrm{H}_{\mathrm{a}}$ & $L_{\mathrm{a}}$ \\
\hline 2. $244-C R$ & $H_{e}$. & $M_{c}$ & $M_{2}$ & $M_{a}$ & $M_{a}$ & $M_{a}$ \\
\hline 3. $244-A R$ & $M_{c}$ & $M_{c}$ & $\mathrm{H}_{\mathrm{a}}$ & $M_{b}$ & $\mathrm{Ha}_{\mathrm{a}}$ & $M_{a}$ \\
\hline 4. $242-S$ & $M_{d}$ & $\mathrm{H}_{\mathrm{b}}$ & $\mathrm{H}_{\mathrm{b}}$ & $L_{\mathrm{L}}$ & $M_{a}$ & $\mathrm{M}_{\mathrm{a}}$ \\
\hline 5. ITS-1 & $\mathrm{H}_{3}$ & $\mathrm{M}_{a}$ & $M_{e}$ & $M_{b}$ & $M_{2}$ & $M_{a}$ \\
\hline 6. 241-AX-IX & $\mathrm{H}_{\mathrm{a}}$ & $M_{a}$ & $M_{e}$ & $M_{b}$ & $\mathrm{Ma}_{\mathrm{a}}$ & $M_{a}$ \\
\hline 7. 204-AR & $M_{c}$ & $H_{b}$ & $M_{2}$ & $\mathrm{H}_{\mathrm{a}}$ & $L_{a}$ & $M_{2}$ \\
\hline 8. $2727-W$ & $L_{b}$ & $M_{c}$ & $L_{a}$ & $M_{b}$ & $L_{a}$ & $\mathrm{~L}_{\mathrm{a}}$ \\
\hline 9. GTF & $L_{c}$ & $L_{b}$ & $M_{b}$ & $\mathrm{~L}_{b}$ & $\mathrm{~L}_{\mathrm{a}}$ & $\mathrm{L}_{\mathrm{a}}$ \\
\hline 10. $213-W$ & $L_{b}$ & $L_{c}$ & $L_{a}$ & $L_{b}$ & $L_{a}$ & $M_{3}$ \\
\hline 11. $209-E$ & $N / A$ & $\mathrm{~N} / \mathrm{A}$ & $N / A$ & $\mathrm{~N} / \mathrm{A}$ & N/A & $\mathrm{N} / \mathrm{A}$ \\
\hline \multicolumn{7}{|c|}{ IMUSTs (in order of priority): } \\
\hline 1. $240-5-302$ & $\mathrm{H}_{\mathrm{e}}$ & $H_{b}$ & $M_{a}$ & $L_{b}$ & $H_{b}$ & $L_{a}$ \\
\hline 2. $241-A X-151-T K-D$ & $H_{e}$ & $\mathrm{H}_{\mathrm{a}}$ & $H_{d}$ & $\mathrm{~L}_{b}$ & $L_{a}$ & $L_{a}$ \\
\hline 3. 241-AX-151-TK-E & $\mathrm{He}_{\mathrm{e}}$ & $\mathrm{H}_{2}$ & $H_{d}$ & $L_{b}$ & $\mathrm{~L}_{\mathrm{a}}$ & $L_{2}$ \\
\hline 4. 241-AX-151-TK-F & $\mathrm{H}_{e}$ & $\mathrm{H}_{\mathrm{a}}$ & $H_{\alpha}$ & $L_{b}$ & $L_{a}$ & $L_{0}$ \\
\hline 5. 241-AX-151-TK-G & $\mathrm{He}_{\mathrm{e}}$ & $\mathrm{H}_{a}$ & $\mathrm{H}_{\alpha}$ & $L_{b}$ & $L_{a}$ & $\underline{L_{a}}$ \\
\hline 6. $244-U R-002$ & $H_{b}$ & $\mathrm{H}_{3}$ & $H_{d}$ & $L_{b}$ & $\mathrm{~L}_{2}$ & $L_{a}$ \\
\hline 7. $244-U R-003$ & $\mathrm{H}_{c}$ & $\mathrm{H}_{b}$ & $H_{d}$ & $L_{b}$ & $\mathrm{~L}_{\mathrm{a}}$ & $L_{a}$ \\
\hline 8. $241-A-302 B$ & $\mathrm{H}_{\mathrm{e}}$ & $\mathrm{H}_{6}$ & $M_{a}$ & $L_{b}$ & $M_{3}$ & $L_{a}$ \\
\hline 9. $241-\mathrm{AX}-151 \mathrm{CT}$ & $\mathrm{H}_{\mathrm{e}}$ & $H_{b}$ & $M_{a}$ & $L_{b}$ & $M_{a}$ & $L_{a}$ \\
\hline 10. $241-C-301$ & $\mathrm{H}_{e}$ & $H_{b}$ & $M_{0}$ & $L_{b}$ & $\mathrm{M}_{0}$ & $L_{a}$ \\
\hline 11. $270-W$ & $\mathrm{H}_{c}$ & $\mathrm{H}_{b}$ & $M_{a}$ & $L_{b}$ & $M_{a}$ & $\mathrm{~L}_{2}$ \\
\hline 12. $241-B-301$ & $H_{e}$ & $H_{b}$ & $M_{a}$ & $L_{b}$ & $M_{a}$ & $\mathrm{~L}_{\mathrm{a}}$ \\
\hline 13. $241-B-302 B$ & $\mathrm{H}_{e}$ & $\mathrm{H}_{\mathrm{b}}$ & $M_{a}$ & $L_{b}$ & $M_{2}$ & $L_{a}$ \\
\hline 14. $241-B X-302 B$ & $\mathrm{H}_{e}$ & $H_{b}$ & $M_{a}$ & $L_{b}$ & $M_{z}$ & $\mathrm{~L}_{\mathrm{a}}$ \\
\hline
\end{tabular}


HNF-2503, Rev. 0

Table 4-2. (cont) Relative Risk Ranking Results

\begin{tabular}{|c|c|c|c|c|c|c|}
\hline IMUSTS: (Cont) & Contents & Controls & $\begin{array}{c}\text { AB } \\
\text { status }\end{array}$ & $\begin{array}{l}\text { Config- } \\
\text { uration }\end{array}$ & $\begin{array}{c}\text { Contain- } \\
\text { ment }\end{array}$ & Access \\
\hline 15. $241-\mathrm{BX}-302 \mathrm{C}$ & $\mathrm{H}_{e}$ & $\mathrm{H}_{0}$ & $M_{a}$ & $\mathrm{~L}_{b}$ & $M_{a}$ & $L_{a}$ \\
\hline 16. $241-S X-302$ & $\mathrm{H}_{e}$ & $\mathrm{H}_{b}$ & $M_{a}$ & $L_{b}$ & $M_{a}$ & $\mathrm{~L}_{\mathrm{a}}$ \\
\hline 17. $241-T X-302 B(R)$ & $\mathrm{H}_{\mathrm{e}}$ & $H_{b}$ & $M_{3}$ & $\mathrm{~L}_{b}$ & $M_{a}$ & $L_{2}$ \\
\hline 18. $241-T X-302 X B$ & $\mathrm{H}_{\mathrm{e}}$ & $\mathrm{H}_{6}$ & $M_{2}$ & $\mathrm{~L}_{6}$ & $M_{0}$ & $L_{a}$ \\
\hline 19. $241-T Y-302 \mathrm{~A}$ & $\mathrm{H}_{e}$ & $\mathrm{H}_{b}$ & $\mathrm{M}_{0}$ & $L_{b}$ & $M_{3}$ & $L_{a}$ \\
\hline 20. $241-Z-8$ & $\mathrm{H}_{\mathrm{e}}$ & $\mathrm{H}_{6}$ & $M_{a}$ & $\mathrm{~L}_{b}$ & $M_{a}$ & $\mathrm{~L}_{\mathrm{a}}$ \\
\hline 21. $241-T X-302 B \quad C T$ & $M_{\alpha}$ & $H_{b}$ & $H_{b}$ & $L_{b}$ & $M_{a}$ & $L_{2}$ \\
\hline 22. $244-B X R-002$ & $\mathrm{H}_{c}$ & $H_{b}$ & $M_{0}$ & $L_{b}$ & $L_{a}$ & $\mathrm{~L}_{\mathrm{a}}$ \\
\hline 23. $244-B X R-003$ & $\mathrm{H}_{c}$ & $H_{b}$ & $M_{3}$ & $L_{h}$ & $L_{0}$ & $L_{0}$ \\
\hline 24. $241-T X-302 A$ & $M_{d}$ & $M_{c}$ & $M_{a}$ & $L_{b}$ & $H_{b}$ & $\mathrm{~L}_{\mathrm{a}}$ \\
\hline 25. $244-U R-0.01$ & $M_{d}$ & $M_{2}$ & $H_{d}$ & $L_{b}$ & $L_{a}$ & $\mathrm{~L}_{\mathrm{a}}$ \\
\hline 26. $216-B Y-201$ & $M_{d}$ & $M_{c}$ & $M_{a}$ & $\mathrm{~L}_{b}$ & $M_{a}$ & $L_{a}$ \\
\hline 27. $216-T Y-201$ & $M_{d}$ & $M_{c}$ & $M_{a}$ & $L_{b}$ & $M_{a}$ & $\underline{L}_{\mathrm{a}}$ \\
\hline 28. 241-BY-ITS2-TK-1 & $M_{e}$ & $M_{a}$ & $M_{e}$ & $L_{b}$ & $M_{a}$ & $\mathrm{~L}_{\mathrm{a}}$ \\
\hline 29. 241-BY-ITS2-TK-2 & $M_{e}$ & $M_{a}$ & $M_{e}$ & $L_{b}$ & $M_{a}$ & $L_{a}$ \\
\hline 30. $241-T-301 B$ & $M_{d}$ & $M_{c}$ & $M_{a}$ & $L_{b}$ & $M_{2}$ & $\mathrm{~L}_{a}$ \\
\hline 31. $242-T-135$ & $M_{e}$ & $M_{c}$ & $M_{a}$ & $L_{b}$ & $M_{a}$ & $L_{a}$ \\
\hline 32. $241-S-302 A$ & $M_{e}$ & $M_{b}$ & $\mathrm{~L}_{\mathrm{a}}$ & $L_{b}$ & $H_{b}$ & $\mathrm{~L}_{\mathrm{a}}$ \\
\hline 33. $244-T X R-002$ & $M_{a}$ & $M_{c}$ & $M_{0}$ & $L_{b}$ & $\mathrm{~L}_{\mathrm{a}}$ & $L_{a}$ \\
\hline 34. $244-T X R-003$ & $M_{c}$ & $M_{c}$ & $M_{a}$ & $L_{b}$ & $L_{a}$ & $L_{a}$ \\
\hline 35. 242-TA-R1 & $M_{e}$ & $M_{c}$ & $M_{a}$ & $L_{b}$ & $\mathrm{~L}_{a}$ & $L_{0}$ \\
\hline 36. $244-B X R-001$ & $M_{e}$ & $M_{c}$ & $M_{a}$ & $L_{b}$ & $L_{a}$ & $\mathrm{~L}_{\mathrm{a}}$ \\
\hline 37. $244-U R-004$ & $L_{0}$ & $H_{a}$ & $M_{e}$ & $L_{t}$ & $L_{a}$ & $\mathrm{~L}_{2}$ \\
\hline 38. 209-E-TK-1:11 & $M_{c}$ & $\mathrm{~L}_{\mathrm{a}}$ & $M_{e}$ & $L_{b}$ & $\mathrm{M}_{\mathrm{a}}$ & $L_{a}$ \\
\hline 39. $241-E R-311 A$ & $M_{e}$ & $\mathrm{~L}_{c}$ & $L_{3}$ & $L_{b}$ & $\mathrm{H}_{\mathrm{a}}$ & $\mathrm{L}_{\mathrm{a}}$ \\
\hline 40. $200-W-7$ & $M_{c}$ & $L_{c}$ & $L_{a}$ & $L_{b}$ & $M_{a}$ & $\mathrm{~L}_{\mathrm{a}}$ \\
\hline
\end{tabular}


HNF-2503, Rev. 0

Tabie 4-2. (cont) Relative Risk Ranking Results

\begin{tabular}{||c|c|c|c|c|c|c||}
\hline IMUSTS: (Cont) & contents & Controls & $\begin{array}{c}\text { AB } \\
\text { Status }\end{array}$ & $\begin{array}{c}\text { Config- } \\
\text { uration }\end{array}$ & $\begin{array}{c}\text { Contain- } \\
\text { ment }\end{array}$ & Access \\
\hline $41.231-W-15 I-001$ & $M_{a}$ & $\mathrm{~L}_{b}$ & $\mathrm{~L}_{a}$ & $\mathrm{~L}_{b}$ & $\mathrm{~L}_{a}$ & $\mathrm{~L}_{a}$ \\
\hline $42.231-W-151-002$ & $\mathrm{M}_{a}$ & $\mathrm{~L}_{b}$ & $\mathrm{~L}_{a}$ & $\mathrm{~L}_{b}$ & $\mathrm{~L}_{a}$ & $\mathrm{~L}_{a}$ \\
\hline $43.241-\mathrm{BX}-302 \mathrm{~A}$ & $\mathrm{~L}_{c}$ & $\mathrm{~L}_{c}$ & $\mathrm{~L}_{a}$ & $\mathrm{~L}_{b}$ & $\mathrm{M}_{a}$ & $\mathrm{~L}_{a}$ \\
\hline $44.241-\mathrm{S}-302 \mathrm{~B}$ & $\mathrm{~L}_{a}$ & $\mathrm{~L}_{c}$ & $\mathrm{~L}_{a}$ & $\mathrm{~L}_{b}$ & $\mathrm{M}_{a}$ & $\mathrm{~L}_{a}$ \\
\hline $45.244-\mathrm{BXR}-011$ & $\mathrm{~L}_{c}$ & $\mathrm{~L}_{c}$ & $\mathrm{~L}_{a}$ & $\mathrm{~L}_{b}$ & $\mathrm{~L}_{a}$ & $\mathrm{~L}_{a}$ \\
\hline $46.241-T Y-302 B$ & $\mathrm{~L}_{a}$ & $\mathrm{~L}_{c}$ & $\mathrm{~L}_{a}$ & $\mathrm{~L}_{b}$ & $\mathrm{~L}_{a}$ & $\mathrm{~L}_{a}$ \\
\hline $47.244-\mathrm{TXR}-001$ & $\mathrm{~L}_{d}$ & $\mathrm{~L}_{c}$ & $\mathrm{~L}_{a}$ & $\mathrm{~L}_{b}$ & $\mathrm{~L}_{a}$ & $\mathrm{~L}_{a}$ \\
\hline
\end{tabular}

Note: Subscripts refer to Table 4-1 
purposes of determining the ranking of the FTCS, a distinct numerical value was tabulated for each FTC by assigning the low (L), medium (M), and high (H) designation values of 1,3 , and 5 , respectively. These scores are not significant for any purpose other than to create the prioritized list (i.e., the number does not indicate a quantification of risk posed by any of the FTCS). An indication of the risk level ranking for each of the Table 4-1 categories is included in Table 4-2 to provide an indication of the areas of concern. Refer to the discussions of each facility or IMUST in Sections 5.1 and 5.2 , respectively, for further information.

IMUST priorities are given individualiy for each tank, with required actions being the summation of all those 1 isted within the respective IMUST groupings in Section 5.2. Of the facilities evaluated, the 242-T Evaporator was ranked as the first priority. This is primarily due to the facts that the material inventory and constituents in the facility tanks/vessels are unknown and the current $A B$ describes a facility configuration that is known to be inaccurate. The highest priority for IMUSTs are those tanks that have unknown contents or are known to contain both acid and organic waste materials. These are the tanks that need to be evaluated for organic nitrate reaction potential.

A final consideration for prioritization is addressed in Chapter 6.0. This is the relative safety and $A B$ documentation benefit derived from the cost of the upgrade effort. Chapter 6.0 provides cost estimates for $A B$ documentation work and commentary on the additional costs associated with improvement of technical bases (e.g., waste sampling and characterization). This input is used as a final check to validate or adjust the prioritization. 


\subsection{AUTHORIZATION BASIS STRATEGY}

The following sections present the strategy to upgrade the $A B$ for the identified TWRS Facilities and IMUSTs. Controls specific to each of the identified facilities and IMUSTs are listed in the following sections. The controls listed are those specifically called out in the applicable AB document. In addition to the specific controls identified in the following sections, site-wide and TWRS administrative and safety programs are implemented that further provide the overall control necessary for ensuring safety of TWRS FTCs:

Criticality Safety: The provisions of the Hanford Site Nuclear Criticality Safety program as detailed in the HNF Procedures and Criticality Safety Evaluation Reports and specification documents for specific TWRS facilities apply to the TWRS FTCs identified in this report. This program places requirements and controls on the handling, storage, transfer, and posting of fissionable material.

Radiation Protection: The provisions of the Hanford Site Radiological Contro] Manual (HSRCM-1) app7y to the TWRS FTCS identified in this report. This manual defines the requirements and controls necessary to assure radiological safety and protection for TWRS workers and other onsite personnel.

Occupational Safety and Industrial Hygiene: The Hanford Site Safety and Industrial Hygiene programs as defined by the HNF procedures relating to occupational health and safety apply to the TWRS FTCs identified in this report. These program procedures define the requirements and controls to be applied throughout the Hanford Site to assure safe working conditions.

Fire Protection: The fire protection requirements and controls identified in the Hanford Fire Protection program apply to the TWRS FTCs identified in this report. The requirements and controls identified in the program are contained in FDH procedures dealing with methods and requirements for providing adequate fire protection and prevention throughout the Hanford Site. Specific Fire Hazards Analysis (FHA) documentation relating to TWRS activities and facilities incTude WHC-SD-WM-FHA-020, WHC-SD-WM-FHA-022 and WHC-SD-WM-FHA-023.

Quality Assurance: The Quality Assurance program defined for the Hanford Site applies to the. TWRS FTCS identified in this report. Quality assurance requirements and controls are detailed in HNF-MP-599 and in specific activity plans or the TWRS Quality Assurance Program Plan (HNF-IP-0842).

Environmental Compliance: The Hanford Site Environmental Compliance program and the specific requirements of permits for TWRS facilities apply to the TWRS FTCs identified in this report. 
HNF-2503, Rev. 0

Emergency Preparedness: The Hanford Site Emergency Preparedness program and TWRS facility-specific emergency plans apply to the TWRS FTCs

identified in this report. The site-wide and TWRS emergency preparedness

requirements are documented in the Hanford Emergency Response Plan

(D0E/RL-94-02) and the TWRS Emergency Preparedness Program Plan

(WHC-IP-0971), respectively.

Except where specifically noted in the balance of this chapter, these programs were observed to be implemented and effective.

\subsection{TWRS FACILITIES}

\subsubsection{4-AR Waste Unloading Facility}

\subsubsection{Authorization Basis Status}

The BIO and draft FSAR both currently address the 204-AR facility. The facility was included in the hazards identification walkdowns conducted as a part of the BI0/FSAR preparation (WHC-SD-WM-HIE-007). These walkdowns resulted in identification of hazards in the following categories: corrosives, criticality, flammable materials, friction, electrical, radiation, kinetic energy, mass, gravity-height, pressure-volume, and thermal. A recent walkdown of the facility did not reveal any hazards additional to those previously identified, other than normally encountered industrial hazards. Natural event phenomena such as 1 ightning and seismic events were also identified during the walkdown. These accident initiators are addressed in the BIO. There were no bounding scenarios that were found to involve 204-AR related to natural phenomena.

A specific HazOp analysis was conducted to identify accident scenarios for the 204-AR facility and is documented in WHC-SD-WM-TI-759. Representative and bounding accidents identified by the HazOp were carried forward into the BI0/FSAR accident analyses. The HazOp, in general, reflects the current facility configuration with the exception that a waste transporter (LR-56) will replace the current rail cars used to transport waste from the 340 facjlity to 204-AR. The volume of the transporter $(5,678 \mathrm{~L}[1,500$ gal]) is considerably smaller than that of the rail cars $(75,700 \mathrm{~L}[20,000$ gal]). The impact of the change in transporters needs to be evaluated to determine if there is any effect on the accidents evaluated in the BIO.

\subsubsection{Controls Evaluation}

The controls currently applied to the Waste Unloading Facility are listed in Table 5-1.

There is one instance where the TSR written for general usage in the tank farms may not be suitable for the 204-AR facility, related to the transfer pump administrative lock program (Administrative Control [AC] 5.20). Limiting Condition for Operation (LCO) 3.1 .2 (temporarily exempted) 
HNF-2503, Rev. 0

TabTe 5-1. 204-AR Controls

\begin{tabular}{|c|c|c|}
\hline CONTROL & LEVEL & SOURCE \\
\hline $\begin{array}{l}\text { Service water pressure } \\
\text { detection system operability }\end{array}$ & $\begin{array}{l}\text { TSR (temporary exemption } \\
\text { through } 9 / 30 / 98 \text { ) }\end{array}$ & LCO 3.1 .2 (see note) \\
\hline $\begin{array}{l}\text { Ventilation stack CAM interlock } \\
\text { system operability }\end{array}$ & $\begin{array}{l}\text { TSR (temporary exemption } \\
\text { through } 9 / 30 / 98 \text { ) }\end{array}$ & LCO 3.1 .4 (see note) \\
\hline \multirow{3}{*}{$\begin{array}{l}\text { Exhaust stack high radiation } \\
\text { alarm operability }\end{array}$} & TSR & $\mathrm{LCO} 3.1 .4 \mathrm{~A}$ \\
\hline & OSD & OSD-T-151-00008 \\
\hline & Procedure & T0-040-710 \\
\hline $\begin{array}{l}\text { Leak detection system } \\
\text { operability }\end{array}$ & TSR & LCO 3.1 .3 \\
\hline \multirow[t]{2}{*}{ Criticality } & TSR & AC 5.7 \\
\hline & Specification & CPS-T-149-00010 \\
\hline Transfer controls & TSR & AC 5.12 \\
\hline \multirow[t]{4}{*}{ HEPA filter controls } & TSR & AC 5.18 \\
\hline & OSD & OSD-T-151-00008 \\
\hline & \multirow[t]{2}{*}{ Procedure } & T0-040-710 \\
\hline & & TF-OR-EF-204AR \\
\hline \multirow[t]{3}{*}{ Catch tank vent temperature } & OSD & 0SD-T-151-00008 \\
\hline & \multirow[t]{2}{*}{ Procedure } & T0-040-710 \\
\hline & & TF-0R-EF-204AR \\
\hline \multirow[t]{3}{*}{ Catch tank level } & OSD & OSD-T-151-00008 \\
\hline & \multirow[t]{2}{*}{ Procedure } & TO- $040-710$ \\
\hline & & TF-0R-EF-204AR \\
\hline Flammability controls & TSR (204-AR-TK-1 only) & $\begin{array}{l}\text { AC } 5.9(204-A R-T K-1 \\
\text { only) }\end{array}$ \\
\hline \multirow{6}{*}{$\begin{array}{l}\text { Waste composition/ } \\
\text { Source inventory control }\end{array}$} & \multirow[t]{2}{*}{ TSR } & AC 5.8 (see note) \\
\hline & & AC 5.12 (see note) \\
\hline & OSD & OSD-T-151-00008 \\
\hline & \multirow[t]{3}{*}{ Procedure } & T0-290-052 \\
\hline & & T0-290-120 \\
\hline & & TO-290-130 \\
\hline
\end{tabular}


HNF-2503, Rev. 0

\section{Table 5-1. (cont) 204-AR Controls}

\begin{tabular}{|l|l|l||}
\hline \multirow{2}{*}{$\begin{array}{l}\text { Transfer pump lock } \\
\text { administrative controls }\end{array}$} & TSR & AC 5.20 \\
\cline { 2 - 3 } & Procedure & T0-290-052 \\
\cline { 2 - 2 } & & T0-290-120 \\
\cline { 2 - 3 } & & T0-290-130 \\
\hline
\end{tabular}

Notes: $\quad L C O 3.1 .2, L C O 3.1 .4, A C 5.8$, and $A C 5.12$ contain requirements specific to 204-AR.

TSR controls are contained in HNF-SD-WM-TSR-006. 
HNF-2503, Rev. 0

requires the service water pressure detection system to be operable if the detection system is connected to a transfer pump that is not administratively locked out. An alarming pressure detector requires physically connected transfer pumps to be shut down. This effectively prevents 1 ine flushing at 204-AR since the transfer pumps are needed for line flushing. Compensatory actions are in progress to resolve this issue.

Since this facility is a point of receipt for introduction of hazardous mixed wastes into the tank farms, the controls on receipt of material into the facility ( $A C 5.8$ and 5.12) are important. The appropriate controls are in place, in that waste verification is required before receipt into the facility and transfer to the tank farms.

\subsubsection{Authorization Basis Strategy}

The following actions are required for this facility:

- Evaluate the need to update the BIO or FSAR to reflect the changes related to the waste transporter (LR-56 transporter).

- Resolve the pressure switch issue under the compensatory measures actions, and prepare a TSR modification, if necessary.

- Complete facility modifications to comply with LCO 3.1.2 and 3.1.4, currently exempted under compensatory measures.

- If the evaluations above indicate that analysis changes are required, prepare modifications to the BIO or FSAR and submit for RL approval as appropriate.

- Close the flammable gas USQ for Tank 204-AR-TK-0I according to the USQ closure strategy document (HNF-SD-WM-ER-680).

\subsubsection{9-E Critical Mass Laboratory}

\subsubsection{Authorization Basis Status}

A small description of the 209-E Complex is in the BIO, but is mainly applicable to the less-than-90-day waste storage pad to the west of the 209-E Building. The 209-E Complex BI0 description includes a few sentences about the layout of the 209-E Building, but no hazards or controls are identified. Additionally, the 209-E Complex was included in the hazards identification walkdowns conducted as a part of the BIO/FSAR preparation (WHC-SD-WM-HIE-007); however, information is only recorded for the 1ess-than-90-day storage pad. No unique accident phenomena were identified pertaining to the 209-E Building at that time. The 209-E lessthan-90-day storage pad is assigned a Hazard Category 3 in the BIO and draft FSAR. 
A Preliminary Hazards Analysis (WHC-SD-WM-TI-789) was developed for the 209-E Building. During the development, hazards were identified and frequency and consequences were qualitatively assessed. One hazard, fire in the CAR, was assigned a frequency of "Anticipated" with potential consequences to the onsite worker.

In 0ctober of 1996, an Unreviewed Safety Question (USQ) screening/ determination (USQ TF-96-1000) was performed that led to the conclusion that the 209-E Building did not have an $A B$. Subsequent review of documentation identified that the facility contains 562 grams of plutonium (conservative total based on both $\mathrm{Pu}^{239}$ and $\mathrm{Pu}^{240}$ from a plutonium inventory performed in 1990). Additionally, a Criticality Safety Evaluation Report (CSER 90-008) concluded that a criticality is not credible. Since a criticality is not credible and the facility contains more than $450 \mathrm{~g}$ of plutonium (conservative value based on estimated margin of error, $420 \mathrm{~g}+$ $150 \mathrm{~g}=570 \mathrm{~g} \mathrm{Pu}$, the facility is considered a Hazard Category 3 nuclear facility per DOE-STD-1027-94. This categorization requires that the facility have an AB per DOE Order 5480.23.

Shortly after the USQ determination was completed, interim controls were imposed as a precautionary measure for personnel safety. These interim controls were not $A B$ level controls and were intended to remain in place only until the hazards were addressed and the $A B$ issue was resolved. An $A B$ (WSD-97-160) for the 209-E Building was issued by the U.S. Department of Energy, Richland Office (RL) on August 8, 1997 and included many of the initial contractor imposed interim controls. The $A B$ was implemented at a time when there were still unknowns associated with the facility (e.g., extent of contamination in the CAR and Mix Room, configuration and operability of SSCS). Information was subsequent7y obtained during entries into the CAR and Mix Room for purposes of assessing hazards and implementation of the interim controls of WSD-97-160. Additional information was obtained through vapor sampling activities on the drain tank (TK-11I). The PHA and the subsequently obtained physical data and observations provided a basis to depart from many of the interim controls that were imposed as precautionary measures. The basis for departure from the controls is documented in the $A B$ that will close the USQ for the 209-E Building (LMHC-9851283). Once approved, the document provided in letter LMHC-981283 will become the $A B$ for pre-deactivation activities at the 209-E Building.

The pre-deactivation $A B$ was written to fully replace RL letter WSD-97-160 as the 209-E Building $A B$. The pre-deactivation $A B$ identifies activities allowed during the pre-deactivation phase and provides the controls and safety programs necessary to maintain the facility in a safe configuration. The controls and safety programs are based on the hazards identified in the PHA in addition to supplemental information obtained through facility evolutions (e.g., entries into the CAR and Mix Room, vapor sampling of TK-111, management walkdowris). The pre-deactivation $A B$ and its associated controls and safety programs will remain in place until safety documentation addressing deactivation of the 209-E Building is developed by the contractor and approved by RL. 


\subsubsection{Controls Evaluation}

The $A B$ controls applicable to the 209-E Building are provided in the predeactivation $A B$ for the 209-E Building. Bases and applicable safety analysis are provided for each control. A very brief summary of the controls is as follows. The pre-deactivation $A B$ for the 209-E Building must be consulted for control details.

- LCO: The exhaust ventilation system shali be operable.

- LCO: The air purge on the twelve solution handling tanks (TK-101, TK-102, TK-103, TK-104, TK-105, TK-106, TK-213, TK-231, TK-232, TK-233, TK-234, TK-235) shall be operable.

- AC: HEPA filter nominal particulate removal efficiency shall be verified to be $\geq 99.95$ percent.

These controls are sufficient to maintain the 209-E Building in a safe configuration.

\subsubsection{Authorization Basis Strategy}

Upon approval, the pre-deactivation $A B$ will become the $A B$ for the 209-E Building and will serve as the $A B$ until the start of deactivation. The deactivation activities will require a deactivation $A B$ to be developed and approved by $R L$. Once approved by $R L$, the deactivation $A B$ will replace the pre-deactivation $A B$ as the 209-E Building $A B$. Thus, no further $A B$ actions are required for the 209-E Building.

\subsubsection{3-W Dry Waste Compactor Facility}

\subsubsection{Authorization Basis Status}

The BIO currently contains a description of the 213- $W$ facility and adjacent catch tank. The facility was inciuded in the hazards identification walkdowns conducted as a part of the BIO/FSAR preparation (WHC-SD-WM-HIE-007). The BIO Appendix D (draft FSAR Appendix A) "Material at Risk" table identifies that residue of radioactive materials are present in the facility HEPA filtration system and that there are some household quantities of cleaning materials.

A PHA was conducted specificaliy for this facility (WHC-SD-WM-TI-759). Identified accident scenarios were carried forward in the BIO/FSAR analyses, but did not result in significant consequences. This facility was assigned Hazard Category 3 in the BIO and draft FSAR.

\subsubsection{Controls Evaluation}

The following control is currently applied to the compactor facility: 
HNF-2503, Rev. 0

- AC 5.18: HEPA Filter Controls

There are no implementing procedures specific to this facility and none are warranted considering the low inventories of materials present. Normal programmatic controls are adequate to maintain this facility in a safe condition.

\subsubsection{Authorization Basis Strategy}

The following actions are required for this facility:

- Review of the radiation survey data available for the facility to estimate the volume of radioactive materials remaining.

- Estimate radioactive material inventory to re-evaluate the facility hazard classification for a possible reduction to "Radiological Facility."

- Prepare an update to the BIO or FSAR to reflect the revised hazard classification, if the facility is re-classified.

\subsubsection{1-AX-151 Diverter Station}

The 241-AX-151 Diverter Station is inactive and has been isolated. The individuaT tanks within the diverter station are IMUSTs. The AB strategy for IMUSTS is discussed in Section 5.2.

\subsubsection{1-AX-IX Ion Exchange Column}

\subsubsection{Authorization Basis Status}

Neither the BIO nor draft FSAR currently contains a hazard or accident analysis that addresses the 241-AX ion exchange column. However, the facility is listed in the "Material at Risk" tables contained in BIO Appendix D (FSAR Appendix A), which indicate only low level waste residue being present. The facility was included in the hazards identification walkdowns conducted as a part of the BIO/FSAR preparation (WHC-SD-WM-HIE-007), but no hazards or unique accident phenomena were identified.

\subsubsection{Hazards Controls Assessment}

Normal programmatic and access controls are currently applied to the ion exchange column. There are no procedural inspection or maintenance requirements. Based on the fact that the waste content in the exchange column and filter are unknown, access control and monitoring for flammable gases/organic vapors before conducting work within these vessels is needed. There is no immediate concern with the facility in its current shutdown state; however, if the subsequent actions specified below 
HNF-2503, Rev. 0

indicate the presence of flammable gases or organic materials, interim controls would need to be established.

\subsubsection{Authorization Basis Strategy}

The following actions are required for this facility:

- Perform vapor space sampling of both the ion exchange column and filter assembly to determine if flammable gases/organic vapors are present.

- Perform an inspection of vessel contents and perform sampling, if any significant quantity of material is indicated to be present by the vapor sampling results:

- Perform a limited hazards analysis to determine if the facility presents any unique hazards that need to be analyzed for inclusion in the BIO or FSAR.

- Impose interim controls through a Standing order if the need is indicated by hazards analysis and/or sampling results.

- Prepare an update to the BIO or FSAR to include a description of this facility, or if hazards analysis warrants, update the appropriate analysis sections, modify the TSRs, and submit for RL approval as appropriate.

\subsubsection{2-S Evaporator}

\subsubsection{Authorization Basis Status}

Neither the BIO nor the draft FSAR currently provides analysis of the 242-S Evaporator facility. The facility was not included in the hazards identification walkdowns conducted as a part of the BIO/FSAR preparation (WHC-SD-WM-HIE-007).

A specific Haz0p analysis was conducted for the 242-S facility as a part of the BIO/FSAR preparation, and is documented in WHC-SD-WM-TI-759. However, the scope of this HazOp was Timited to the consideration of 242-S as an interfacing facility to TWRS, and accident scenarios for the facility were not developed as a part of this effort.

The 242-S Facility Shutdown and Standby P1an (SD-WM-SSP-002), issued in 1988 , is the current $A B$ documentation for the 242-S Evaporator. This report was written to describe the physical modifications made to the facility to place it into standby condition III (whereby re-start of the facility is possible, but would require more than six months to accomplish). The document also provides a number of maintenance and monitoring requirements to maintain the facility's standby status. It does not identify or evaluate the consequences of accident scenarios for the facility. The shutdown/standby $p l a n$ has not been kept current, and 
HNF-2503, Rev. 0

does not reflect the facility configuration, since not all the actions specified in the plan were completed.

\subsubsection{Controls Evaluation}

The types of controls current7y applied to the 242-5 Evaporator are shown in Table 5-2. There are no TSR controls applied to the facility and the scope statement in the TSR document (HNF-SD-WM-TSR-006) specifically excludes 242-S. Although the $A B$ document contains several controls/monitoring requirements (not derived from accident analyses), many of them are not currentiy implemented because they describe equipment that is no longer in service. The facility is periodically inspected and liquid Tevels in the catch tank (TK-C-100) are regularly checked and maintained under the maintenance procedure (T0-780-020). The 1iquid cover over the ion exchange column resin is actively monitored and maintained under the general maintenance procedure and round sheet.

Based on current knowledge of 242-S, the inspection activity and the maintenance of liquid cover over the ion exchange resin are currently maintaining the facility in a safe condition. Key safety systems such as ventilation and fire protection are being maintained. However, if the subsequent actions specified below indicate any hazards not presently controlled, interim controls would need to be established.

\subsubsection{Authorization Basis Strategy}

The following actions are required for this facility:

- Perform sampling and analysis of the contents of Tank TK-C-100.

- Perform a hazards evaluation to determine credible accident scenarios that need to be addressed in the $A B$.

- Impose interim controls through a Standing Order if the need is indicated by the hazard evaluation and/or sampling results.

- Perform consequence analyses for credibie accident scenarios, as needed.

- Prepare an update to the BIO or FSAR to inciude a description of this facility, or if hazards and consequence analyses warrant, update the appropriate anaiysis sections, modify the TSRs, and submit for RL approval as appropriate.

- Remove the shutdown/standby plan from the $A B$ and use only as a historical document upon issuance of the BIO or FSAR revisions. 
HNF-2503, Rev. 0

Table 5-2. 242-S Controls

\begin{tabular}{|c|c|c|}
\hline CONTROL & LEVEL & SOURCE \\
\hline \multirow{3}{*}{$\begin{array}{l}\text { Contamination control } \\
\text { and housekeeping }\end{array}$} & $A B$ & SD-WM-SSP-002 \\
\hline & $\begin{array}{l}\text { Radiation Control } \\
\text { Manual }\end{array}$ & HSRCM-1 \\
\hline & Procedure & TO-780-020 \\
\hline \multirow{3}{*}{$\begin{array}{l}\text { Building ventilation } \\
\text { control and monitoring }\end{array}$} & $A B$ & SD-WM-SSP-002 \\
\hline & OSD & OSD-T-151-00015 \\
\hline & Procedures & $\begin{array}{l}\text { TO-780-020 } \\
\text { TO-720-020 } \\
\text { TO-720-140 } \\
\end{array}$ \\
\hline \multirow[t]{2}{*}{ Emergency procedures } & $A B$ & SD-WM-SSP-002 \\
\hline & Procedures & $\begin{array}{l}\text { ARP-T-701-0001 through } \\
\text { ARP-T-701-0007 }\end{array}$ \\
\hline \multirow{2}{*}{$\begin{array}{l}\text { Intrusion detection and } \\
\text { removal (rain water, } \\
\text { flooding) }\end{array}$} & $A B$ & SD-WM-SSP-002 \\
\hline & Procedure & T0-780-020 \\
\hline $\begin{array}{l}\text { Shutdown/standby } \\
\text { logbook }\end{array}$ & $A B$ & SD-WM-SSP-002 \\
\hline Property control & $A B$ & SD-WM-SSP-002 \\
\hline $\begin{array}{l}\text { Effluent discharge } \\
\text { sources }\end{array}$ & $A B$ & SD-WM-SSP-002 \\
\hline Safety showers & $A B$ & SD-WM-SSP-002 \\
\hline \multirow{2}{*}{$\begin{array}{l}\text { Equipment and } \\
\text { facilities left in } \\
\text { service }\end{array}$} & $A B$ & SD-WM-SSP-002 \\
\hline & Procedure * & TO-780-020 \\
\hline \multirow{2}{*}{$\begin{array}{l}\text { Miscellaneous } \\
\text { maintenance }\end{array}$} & $A B$ & SD-WM-SSP-002 \\
\hline & Procedure * & $\mathrm{T} 0-780-020$ \\
\hline
\end{tabular}

* The procedure only partially implements the maintenance activities specified in the shutdown/standby plan. Monitoring of the catch tank and facility inspection are required by procedure T0-780-020. 
- Close the flammable gas USQ for this facility according to the USQ closure strategy document (HNF-SD-WM-ER-680).

The above actions are limited to the maintenance of the facility in its current shutdown/standby condition. Further actions would be necessary to address facility deactivation.

\subsubsection{2-T Evaporator}

\subsubsection{Authorization Basis Status}

Neither the BIO nor the draft FSAR currently provides analysis of the 242-T Evaporator facility. The facility was not included in the hazards identification walkdowns conducted as a part of the BIO/FSAR preparation (WHC-SD-WM-HIE-007).

A specific Haz0p analysis was conducted for the 242-T facility as a part of the BIO/FSAR preparation, and is documented in WHC-SD-WM-TI-759.

However, the scope of this Haz0p was Timited to the consideration of 242-T as an interfacing facility to TWRS, and accident scenarios for the facility were not developed as a part of this effort.

The 242-T Facility Shutdown/Standby to Condition V Safety Analysis Report (SD-HS-SAR-009), is the current AB documentation for the 242-T Evaporator. This report was written to describe the physical modifications made to the facility to $p$ lace it into Standby Condition $V$ (no operational mission is predicted). The physical modifications to 242-T described in the shutdown/standby report were started but were never completed.

\subsubsection{Controls Evaluation}

The controls currently applied to the 242-T Evaporator are 1isted in Table 5-3. Although the shutdown/standby plan (SD-HS-SAR-009) has controls listed, there is no implementing document other than a procedure for ventilation control. The controls in the shutdown/standby $\mathrm{plan}$ do not address accident consequences and the $\mathrm{pl}$ an does not provide any accident analyses. Radioactive material controls are programmatic in nature and are implemented through the site radiological control program (HSRCM-1). There are no TSR controls applied to the facility and the scope statement in the TSR document (HNF-SD-WM-TSR-006) specifically excludes 242-T.

Current controls require an annual building structural inspection to verify integrity. Because of structural concerns, roof trusses were added to the facility in 1989. There is no current safety analysis of this configuration. Specific inspection and analysis of the ability of the decaying building walls to support the (increased) roof load (static and dynamic) need to be conducted as a part of the $A B$ upgrade strategy. Based on the current knowledge of the facility, there is no reason to believe that an imminent hazard exists that would require the immediate imposition 
HNF-2503, Rev. 0

Table 5-3. 242-T Controls

\begin{tabular}{|c|c|c|}
\hline CONTROL. & LEVEL & SOURCE \\
\hline \multirow{2}{*}{$\begin{array}{l}\text { Control of radioactive } \\
\text { contamination and } \\
\text { exposure to radiation - } \\
\text { minimize exposure }\end{array}$} & $A B$ & $\begin{array}{l}\text { SD-HS-SAR-009, Section } \\
11.1 .1 \text { Safety Limit and } \\
\text { LCO }\end{array}$ \\
\hline & $\begin{array}{l}\text { Radiological Control } \\
\text { Manual }\end{array}$ & HSRCM-1 \\
\hline \multirow{2}{*}{$\begin{array}{l}\text { Survey instruments and } \\
\text { protective clothing - } \\
\text { minimize exposure }\end{array}$} & $A B$ & $\begin{array}{l}\text { SD-HS-SAR-009, Section } \\
11.2 .1 \mathrm{LCO}\end{array}$ \\
\hline & $\begin{array}{l}\text { Radiological Control } \\
\text { Manual }\end{array}$ & HSRCM-1 \\
\hline \multirow{3}{*}{$\begin{array}{l}\text { Building ventilation } \\
\text { control and monitoring } \\
\text { - minimize spread of } \\
\text { contamination }\end{array}$} & $A B$ & $\begin{array}{l}\text { SD-HS-SAR-009, Section } \\
11.2 .2 \text { LCO }\end{array}$ \\
\hline & OSD & OSD-T-151-00015 \\
\hline & Procedure & T0-820-040 \\
\hline $\begin{array}{l}\text { Structural containment } \\
\text { - assure structural } \\
\text { integrity }\end{array}$ & $A B$ & $\begin{array}{l}\text { SD-HS-SAR-009, Section } \\
11.2 .3 \text { LCO }\end{array}$ \\
\hline $\begin{array}{l}\text { Nuclear criticality } \\
\text { accident prevention - } \\
\text { prevent criticality }\end{array}$ & $A B$ & $\begin{array}{l}\text { SD-HS-SAR-009, Section } \\
11.2 .4 \text { LCO }\end{array}$ \\
\hline
\end{tabular}

Note: $\quad$ BIO Appendix $E$ imposes flammable gas ignition and monitoring controls on the blend tank (242-T-TK-B1) and evaporator vessel (242-T-101). These controls are not included in the TSR because the TSR specifically excludes 242-T. 
HNF-2503, Rev. 0

of interim controls. However, because the contents of many of the vessels in the facility are unknown and the building structure is of questionable integrity, the actions specified below should be pursued as a high priority.

\subsubsection{Authorization Basis Strategy}

The following actions are required for this facility:

- Perform sampling and analysis of the contents of tanks and storage vessels, pending determination of accessibility, worker safety considerations, and cost-benefit evaluation.

- Perform a hazards evaluation to determine credible accident scenarios that need to be addressed in the $A B$.

- Perform static and dynamic analyses of the roof loading configuration.

- Impose interim controls through a Standing order if the need is indicated by the hazard evaluation and/or sampling results.

- Perform consequence analyses for credible accident scenarios, as needed.

- Prepare an update to the BIO or FSAR to include a description of this facility, or if hazards and consequence analyses warrant, update the appropriate analysis sections, modify the TSRs, and submit for RL approval as appropriate.

- Remove the shutdown/standby report from the $A B$ and use only as a historical document upon issuance of the BIO or FSAR revisions.

- Close the flammable gas USQ for this facility according to the USQ closure strategy document (HNF-SD-WM-ER-680).

The above actions are limited to the maintenance of the facility in its current shutdown/standby condition. Further actions would be necessary to address facility deactivation.

\section{1 .8 244-AR Vault}

\subsubsection{Authorization Basis Status}

The BIO and draft FSAR currently address the 244-AR Vauit. The vault was. included in the hazards identification walkdowns conducted as a part of the BIO/FSAR preparation (WHC-SD-WM-HIE-007). A PHA was conducted specifically for this facility (WHC-SD-WM-TI-759). Identified accident scenarios were carried forward in the BIO/FSAR analyses. The description in the BIO does not currently reflect the modifications made in an unsuccessful attempt to jet pump the sump contents. If the sump levels increase significantly above current levels, damage to the tanks could 
HNF-2503, Rev. 0

occur, releasing radioactive material, which would be of $A B$ and safety concern.

\subsubsection{Controls Evaluation}

The controls currently applied to the 244-AR Vault are listed in Table 5-4. The controls applied to 244-AR are primarily applied to a single tank (244-AR-TK-002). This is appropriate since TK-002 is reported to contain the bulk of the facility ${ }^{\ddagger}$ s radioactive waste. Vapor samples of the tanks in the facility did not indicate the presence of flammable gas in tanks other than TK-002.

The controls currently in place in the facility are adequate to maintain it in a safe configuration, based on currently known information. However, controls may be required for mitigation of the current sump levels, if indicated by the actions specified below. The facility is suspected of leakage and has had water intrusion problems in the past. Deactivation of the facility and removal of sump contents should be a priority, even if there are no immediate $A B$ concerns.

\subsubsection{Authorization Basis Strategy}

The following actions are required for this facility:

- Perform a re-evaluation of sump level data and instrument performance to determine if the potential for tank damage or leakage exists.

- Characterize vault contents and develop a plan for waste removal.

- Perform a limited hazards analysis to determine if there are any unique accident phenomena or scenarios associated with the facility and current water intrusion problems.

- Perform consequence anajyses for credible accident scenarios, as needed.

- Impose interim controls through a Standing order if the need is indicated by the hazard evaluation results.

- Update the BIO or FSAR, and the TSRs if required by the above activities, and submit for RL approval as appropriate.

- Close the flammable gas USQ for this facility according to the USQ closure strategy document (HNF-SD-WM-ER-680).

\section{1 .9 244-BXR Vault}

The 244-BXR Vault is inactive and has been isolated. The individual tanks within the vault are IMUSTs. The $A B$ strategy for IMUSTs, including those in the 244-BXR Vault, is discussed in Section 5.2. 
HNF-2503, Rev. 0

Table 5-4. 244-AR Controls

\begin{tabular}{|c|c|c|}
\hline CONTROL & LEVEL & SOURCE \\
\hline \multirow{4}{*}{$\begin{array}{l}\geq 3 \text { scfh purge air flow } \\
\text { to TK-002 }\end{array}$} & TSR & $\operatorname{LCO} 3.2 .5$ \\
\hline & OSD & OSD-T-151-00014 \\
\hline & \multirow[t]{2}{*}{ Procedure } & TO-040-700 \\
\hline & & TF-0R-ER-244AR \\
\hline $\begin{array}{l}\text { Leak detection system } \\
\text { operability }\end{array}$ & TSR & $\operatorname{LCO} 3.1 .1$ \\
\hline \multirow[t]{2}{*}{ Criticality } & TSR & $\mathrm{AC} 5.7$ \\
\hline & $\begin{array}{l}\text { Criticality } \\
\text { Specification }\end{array}$ & CPS-T-149-00010 \\
\hline $\begin{array}{l}\text { Source inventory } \\
\text { controls }\end{array}$ & TSR & $A C 5.8$ \\
\hline \multirow[t]{2}{*}{ Flammability controls } & TSR & AC 5.9 \\
\hline & OSD & 0SD-T-151-00014 \\
\hline \multirow[t]{2}{*}{ Ignition controls } & TSR & AC 5.10 \\
\hline & OSD & OSD-T-151-00014 \\
\hline \multirow{2}{*}{$\begin{array}{l}\text { Flammable gas } \\
\text { monitoring controls }\end{array}$} & TSR & AC 5.11 \\
\hline & OSD & OSD-T-151-00014 \\
\hline Transfer controls & TSR & AC 5.12 \\
\hline HEPA filter controls & TSR & AC 5.18 \\
\hline \multirow[t]{2}{*}{ Tank levels } & OSD & OSD-T-151-00014 \\
\hline & Procedure & TF-OR-EF-244AR \\
\hline Sump levels & Procedure & TF-OR-EF-244AR \\
\hline
\end{tabular}

Note: TSR controls are contained in HNF-SD-WM-TSR-006. 


\subsubsection{4-CR Vault}

\subsubsection{Authorization Basis Status}

The BIO and draft FSAR currently address the 244-CR facility. A brief description of the facility in general and Tank TK-003 in particular are included in the facility description sections. The facility was included in the hazards identification walkdowns conducted as a part of the BIO/FSAR preparation (WHC-SD-WM-HIE-007). This included the identification of only the material in the active tank (TK-003); The contents of the other tanks in the vault are listed as unknown. No unique accident phenomena or scenarios were identified for 244-CR during the walkdown.

Neither a PHA nor HazOp was conducted specifically for this facility in preparation for the BIO and draft FSAR. The vault is specifically called out in the following BIO accident scenarios: HEPA filter failure, flammable gas deflagration, organic solvent fire, and spray leaks from structures. With the exception of the flammable gas deflagration scenario, this coverage is 1 imited to TK-003, as an active saltwel1 pumping receiver tank.

\subsubsection{Controls Evaluation}

The controls currently applied to the 244-CR Vault are listed in Table 5-5. Based on the current lack of knowledge of the contents of the tanks within 244-CR, the controls need to be re-evaluated through hazards and accident analyses to determine applicability of existing controls and need for additional controls. Flammable gas monitoring and ignition controls apply to a11 the tanks in the facility and the ventilation control applies to TK-003. There is no evidence that an unsafe condition of immediate concern currently exists and the controls applied to the facility are adequate to maintain facility safety, since monitoring is required before work is performed in the tanks.

\subsubsection{Authorization Basis Strategy}

The following actions are required for this facility:

- Perform sampling and analysis of the contents of tanks and cell sumps, to the extent accessible.

- Perform a hazards evaluation to determine credible accident scenarios that need to be addressed in the $A B$.

- Continue tank and sump level monitoring for leakage and intrusion.

- Perform consequence analyses for credible accident scenarios, as needed. 
HNF-2503, Rev. 0

Table 5-5. 244-CR Controls

\begin{tabular}{|l|l|l||}
\hline \hline CONTROL & LEVEL & SOURCE \\
\hline \hline $\begin{array}{l}\text { Ventilation: Active } \\
\text { system, vent stack CAM } \\
\text { interlock, and HEPA low } \\
\text { differential pressure } \\
\text { interlock or stack hi } \\
\text { rad operable for } \\
\text { TK-CR-003 }\end{array}$ & TSR & LCO 3.1.4/3.1.4A \\
\cline { 2 - 3 } & OSD & LCO 3.2.4 \\
\cline { 2 - 3 } & Procedures & OSD-T-151-00015 \\
\cline { 2 - 3 } $\begin{array}{l}\text { Leak detection system } \\
\text { operability }\end{array}$ & TSR & TO-060-205 \\
\hline \begin{tabular}{l} 
Flammability \\
\hline Ignition control
\end{tabular} & TSR & TF-FT-359-007 \\
\hline $\begin{array}{l}\text { Flammable gas } \\
\text { monitoring }\end{array}$ & TSR & AC 5.9 \\
\hline Transfer controls & TSR & AC 5.10 \\
\hline \hline
\end{tabular}

Note: TSR controls are contained in HNF-SD-WM-TSR-006. 
- Impose interim controls through a Standing Order if the need is indicated by the hazard evaluation results.

- Update the BIO or FSAR, and the TSRs if required by the above activities, and submit for RL approval as appropriate.

- Close the flammable gas USQ for this facility according to the USQ closure strategy document (HNF-SD-WM-ER-680).

The above actions should be limited to the maintenance of the facility in its current configuration. Further actions would be necessary to address facility deactivation.

\subsubsection{4-TXR Vault}

The 244-TXR Vault is inactive and has been isolated. The individual tanks within the vault are IMUSTs. The AB strategy for IMUSTs, including those in the 244-TXR Vault, is discussed in Section 5.2.

\subsubsection{4-UR Vault}

The 244-UR Vault is inactive and has been isolated. The individual tanks within the vault are IMUSTs. The AB strategy for IMUSTs, including those in 244-UR, is discussed in Section 5.2. AB actions relative to the tanks in the 244-UR Vault are subject to the transfer of ownership of the facility from ER to TWRS (97-TWR-017).

\section{1 .13 2727-W Sodium Storage Facility}

\subsubsection{Authorization Basis Status}

The BIO and draft FSAR currently address the 2727-W facility. The facility was included in the hazards identification walkdowns conducted as a part of the BIO/FSAR preparation (WHC-SD-WM-HIE-007), and a PHA specific to the facility was performed (WHC-SD-WM-TI-759). One accident scenario (sodjum fire) is included as one of the representative and bounding accidents in both the BIO and FSAR.

The material in the facility is owned and managed by WMH, although the facility "landlord" is TWRS and the facility is covered by the TWRS AB. There is no $A B$ documentation maintained by WMH for $2727-W$. The facility is carried in the TWRS $A B$ as a "Radiological Facility" per the definition in HNF-PRO-704. 
HNF-2503, Rev. 0

\subsubsection{Controls Evaluation}

The controls currently applied to the 2727-W Sodium Storage Facility are listed in Table 5-6.

There is an issue with ownership of the facility as it relates to controls implementation. Although the defense-in-depth controls identified in the BIO are currentiy implemented, an interface with WMH for implementation of TWRS controls has not been established. The procedures being followed by WMH comply with those specified in the BIO, so the facility is being maintained in a safe condition, but there is no formal interface or mechanism to ensure that this continues to be the case.

\subsubsection{Authorization Basis Strategy}

The following actions are required for this facility:

- Establish/confirm ownership of facility.

- If TWRS-owned, develop Memorandum of Understanding with WMH regarding implementation of TWRS controls.

- If WMH-owned, remove the facility from the TWRS $A B$.

\subsubsection{Grout Treatment Facility (GTF)}

\subsubsection{Authorization Basis Status}

Neither the BIO nor the draft FSAR currently addresses the Grout Treatment Facility. The GTF is currently considered a Hazard Category 2 facility. The facility is addressed in a separate $A B$ document (WHC-SD-WM-SSP-005, Grout Facilities Standby $\mathrm{Plan}$ ). The purpose of this report was to describe the actions and physical modifications necessary to place the GTF in a standby condition, with ability to restart with two years notice. This does not reflect the current status of the facility since there are no plans for restart. At present, the empty vaults are planned for modification by TWRS Project $W-465$. The modified vaults will contain immobilized low level waste from Phase I of the TWRS tank waste treatment mission.

\subsubsection{Controls Evaluation}

There are no controls currently applied to the GTF. No controls are required, based on information in the shutdown/standby plan (i.e., there are no hazards requiring controls). 
HNF-2503, Rev. 0

Table 5-6. 2727-W Controls

\begin{tabular}{||l|l|l||}
\hline CONTROL & LEVEL & SOURCE \\
\hline Facility structure & Design feature & HNF-SD-WM-BI0-001 \\
\hline $\begin{array}{l}\text { Nitrogen cover gas - } \\
\text { preclude oxidation (2 } \\
\text { to 10 psig) }\end{array}$ & Defense-in-depth & HNF-SD-WM-BI0-001 \\
\cline { 2 - 3 } & Procedure & SW-040-043 \\
\hline $\begin{array}{l}\text { Building and tank } \\
\text { grounding - to prevent } \\
\text { 1ightning damage }\end{array}$ & Defense-in-depth & HNF-SD-WM-BI0-001 \\
\hline $\begin{array}{l}\text { No water service to } \\
\text { building }\end{array}$ & Defense-in-depth & HNF-SD-WM-BI0-001 \\
\hline $\begin{array}{l}\text { Fire detectors - warn } \\
\text { of early threat to } \\
\text { tanks }\end{array}$ & Defense-in-depth & HNF-SD-WM-BI0-001 \\
\hline $\begin{array}{l}\text { Metal-X fire } \\
\text { extinguishers and } \\
\text { external postings - no } \\
\text { water to be used to } \\
\text { fight fires. }\end{array}$ & Defense-in-depth & HNF-SD-WM-BI0-001 \\
\hline
\end{tabular}


HNF-2503, Rev. 0

\subsubsection{Authorization Basis Strategy}

The following actions are required for this facility:

- Re-evaluation of the hazard categorization assignment for possible reduction.

- Removat of WHC-SD-WM-SSP-005 from the AB.

- Update of the BIO or FSAR to include a description of the disposal vault containing waste material.

- The remaining vaults are being addressed as part of TWRS Project $W-465$.

\subsubsection{ITS-1 In-Tank Solidification System}

\subsubsection{Authorization Basis Status}

Neither the BIO nor draft FSAR currently addresses the ITS-1 system. The facility was included in the hazards identification walkdowns conducted as a part of the BIO/FSAR preparation (WHC-SD-WM-HIE-007). However, the components were assumed to be empty and no further evaluation of the system was performed. There is no other $A B$ documentation covering this facility.

\subsubsection{Controls Evaluation}

Normal programmatic safety and access controls are currently applied to the ITS-1 system. There are no procedural inspection or maintenance requirements. Based on the fact that the waste contents in the system components are unknown, access control and monitoring for flammable gases before conducting work within these vessels is needed. There is no immediate concern with the facility in its current shutdown state; however, if the subsequent actions specified below indicate the presence of flammable gases or organic materials, interim controls would need to be estabi ished.

\subsubsection{Authorization Basis Strategy}

The following actions are required for this facility:

- Perform vapor space sampling of ITS-1 components to determine if flammable gases/organic vapors are present.

- Perform an inspection of vessel contents and perform sampling, if any significant quantity of material is indicated to be present by the vapor sampling results.

- Inspection of vessel contents and sampling if any significant material is present. 
HNF-2503, Rev. 0

- Perform a limited hazards analysis to determine if the facility presents any unique hazards that need to be analyzed for inclusion in the BIO or FSAR.

- Impose interim controls through a Standing Order if the need is indicated by hazards analysis and/or sampling results.

- Prepare an update to the BIO or FSAR to include a description of this facility, or if hazards analysis warrants, update the appropriate analysis sections, modify the TSRs, and submit for RL approval as appropriate.

\subsection{IMUST CATEGORIZATION}

The TWRS IMUSTs have been categorized using the information gathered during the process history reviews. A matrix on the information used to group the tanks is contained in Table 5-7. Tanks are placed into groups that have common $A B$ actions required. It should be noted that tanks can be placed into more than one group, depending on their characteristics. Tanks within major facilities are not IMUSTs and will be dispositioned with the facility, i.e. all of the tanks will be managed as a common unit of property. Note that not all of the TWRS IMUSTs are listed in the following groups. Tanks that do not fall in the groups below are considered to be adequately managed in the current configuration and there is no further action required for them. The one exception to this is that closure of the flammable gas USQ for all IMUSTs is required, according to the USQ closure strategy document

(HNF-SD-WM-ER-680).

\subsubsection{IMUST Group 1: IMUSTS Not Listed, or Incorrectly Listed in the AB}

Several of the IMUSTs are not currently contained in the TWRS AB. This is primarily due to the fact that some of them were not identified as IMUSTs prior to the activity described in this report. The tanks in the 244-UR Vault were previously identified as IMUSTs, but are not in the $A B$ because ownership of the vault has not yet transferred to TWRS. The following IMUSTS are not current7y addressed in the TWRS AB: 209-E-TK-111, 241-AX-151-TKD, 241-AX-151-TKE, 241-AX-151-TKF, 241-AX-151-TKG, 241-BY-ITS2-TK1, 241-BY-ITS2-TK-2, 244-UR-001, 244-UR-002, 244-UR-003, and 244-UR-004.

Based on the reviews conducted, some of the IMUSTs 7 isted in the BIO and TSRs (HNF-SD-WM-TSR-006) may be listed incorrectly in the facility groups under AC 5.9, "Flammability Controls." Tank 241-S-302A has been grouted and documentation indicates that it contains no liquids, yet it is 1 isted in facility group 2 (capable of large induced gas release events). Tank 241-ER-311A is also 1isted in facility group 2, but documentation indicates this tank is empty. Tank 241-TX-302B is 1isted as a facility group 2 tank, but is not listed in the BI0, Table B2-16. Tanks 241-BX-302A, 241-TY-302A, 241-Z-8, 244-BXR-001, 244-TXR-002, and 244-TXR-003 do not contain liquids and 
HNF-2503, Rev. 0

are 7 isted in facility group 3 (small induced gas release events may be possible). These listings are not of immediate concern because all of the foregoing tanks appear to be listed in a more conservative facility group than they should be. 
Table 5-7. IMUST Categorization

\begin{tabular}{||l|c|c|c|c|c|c||}
\hline \multicolumn{1}{|c|}{ IMUST TANK } & $\begin{array}{c}\text { ANALYSIS } \\
\text { DATA }\end{array}$ & $\begin{array}{c}\text { PROCESS } \\
\text { KNOWLEDGE }\end{array}$ & ORGANICS & $\begin{array}{l}\text { ACID } \\
\text { TREAT/ } \\
\text { RECPT }\end{array}$ & $\begin{array}{c}\text { WASTE TYPE } \\
\text { F.G. } \\
\text { FACP }\end{array}$ \\
\hline \hline $200-W-7$ & NONE & LIMITED & NOT INDICATED & NO & $\begin{array}{l}\text { DECON SOLUTION - FORM } \\
\text { UNKNOWN }\end{array}$ & 2 \\
\hline $209-E-T K-111$ & LIMITED & GOOD & NOT INDICATED & NO & DECON SOLUTION LIQUID & N/A \\
\hline $216-$ BY-201 & NONE & LIMITED & INDICATED & NO & $\begin{array}{l}\text { SST TYPE WASTE - FORM } \\
\text { UNKNOWN }\end{array}$ & 2 \\
\hline $216-T Y-201$ & NONE & LIMITED & INDICATED & NO & $\begin{array}{l}\text { SST TYPE WASTE - FORM } \\
\text { UNKNOWN }\end{array}$ & 2 \\
\hline $231-W-151-001$ & LIMITED & GOOD & NOT INDICATED & NO & UNKNOWN TYPE SUPERNATANT & NGRE \\
\hline $231-W-151-002$ & LIMITED & GOOD & NOT INDICATED & NO & $\begin{array}{l}\text { UNKNOWN TYPE SUPERNATANT } \\
\text { AND SLUDGE }\end{array}$ & NGRE \\
\hline $240-S-302$ & NONE & POOR & INDICATED & NO & $\begin{array}{l}\text { WASTE TYPE AND FORM } \\
\text { UNKNOWN }\end{array}$ & 2 \\
\hline $241-A-302 B$ & NONE & POOR & INDICATED & YES & $\begin{array}{l}\text { PUREX PROCESS SUPERNATANT } \\
\text { AND SLUDGE }\end{array}$ & 2 \\
\hline $241-A X-151-T K-D$ & NONE & POOR & INDICATED & YES & $\begin{array}{l}\text { PUREX WASTE TYPE - FORM } \\
\text { UNKNOWN }\end{array}$ & 2 \\
\hline $241-A X-151-T K-E$ & NONE & POOR & INDICATED & YES & $\begin{array}{l}\text { PUREX WASTE TYPE - FORM } \\
\text { UNKNOWN }\end{array}$ & 2 \\
\hline $241-A X-151-T K-F$ & NONE & POOR & INDICATED & YES & $\begin{array}{l}\text { PUREX WASTE TYPE - FORM } \\
\text { UNKNOWN }\end{array}$ & 2 \\
\hline $241-A X-151-T K-G$ & NONE & POOR & INDICATED & YES & $\begin{array}{l}\text { PUREX WASTE TYPE - FORM } \\
\text { UNKNOWN }\end{array}$ & $\begin{array}{l}\text { PUREX WASTE TYPE - FORM } \\
\text { UNKNOWN }\end{array}$ \\
\hline $241-A X-151 C T$ & NONE & POOR & INDICATED & YES & 2 \\
\hline
\end{tabular}


Table 5-7. (cont) IMUST Categorization

\begin{tabular}{|c|c|c|c|c|c|c|}
\hline IMUST TANK & $\begin{array}{l}\text { ANALYSIS } \\
\text { DATA }\end{array}$ & $\begin{array}{l}\text { PROCESS } \\
\text { KNOWLEDGE }\end{array}$ & ORGANICS & $\begin{array}{l}\text { ACID } \\
\text { TREAT/ } \\
\text { RECPT }\end{array}$ & HASTE TYPE & $\begin{array}{l}\text { AC5.9 } \\
\text { F.G. } \\
\text { FAC GRP }\end{array}$ \\
\hline $241-B-301$ & LIMITED & LIMITED & INDICATED & No & $\begin{array}{l}\text { B PLANT UNKNOWN TYPE } \\
\text { SUPERNATANT AND SLUDGE }\end{array}$ & 2 \\
\hline $241-B-302 B$ & NONE & LIMITED & INDICATED & NO & $\begin{array}{l}\text { B PLANT UNKNOWN TYPE } \\
\text { SUPERNATANT AND SLUDGE }\end{array}$ & 2 \\
\hline $241-B X-302 A$ & GOOD & GO0D & $<3 \%$ TOC & No & B PLANT PROCESS SLUDGE & 3 \\
\hline $241-B X-302 B$ & NONE & LIMITED & INDICATED & NO & $\begin{array}{l}\text { B PLANT PROCESS } \\
\text { SUPERNATANT AND SLUDGE }\end{array}$ & 3 \\
\hline $241-B X-302 C$ & NONE & LIMITED & INDICATED & NO & $\begin{array}{l}\text { B PLANT PROCESS } \\
\text { SUPERNATANT AND SLUDGE }\end{array}$ & 2 \\
\hline 241-BY-ITS2-TK-1 & NONE & LIMITEED & NOT INDICATED & NO & $\begin{array}{l}\text { B PLANT PROCESS WASTE - } \\
\text { FORM UNKNOWN }\end{array}$ & $N / A$ \\
\hline 241-BY-ITS2-TK-2 & NONE & LIMITED & NOT INDICATED & NO & $\begin{array}{l}\text { B PLANT PROCESS WASTE - } \\
\text { FORM UNKNOWN }\end{array}$ & $N / A$ \\
\hline $241-C-301$ & LIMITED & LIMITED & INDICATED & YES & $\begin{array}{l}\text { REDOX/PUREX UNKNOWN TYPE } \\
\text { SUPERNATANT AND SLUDGE }\end{array}$ & 2 \\
\hline 241-ER-311A & NONE & LIMITED & NOT INDICATED & NO & $\begin{array}{l}\text { WASTE UNKNOWN - POSSIBLY } \\
\text { EMPTY }\end{array}$ & 2 \\
\hline $241-S-302 A$ & NONE & LIMITED & INDICATED & NO & UNKNOWN WASTE AND GROUT & 2 \\
\hline $241-S-302 B$ & NONE & LIMITED & NOT INDICATED & NO & EMPTY & NGRE \\
\hline $241-5 X-302$ & NONE & LIMITED & INDICATED & NO & $\begin{array}{l}\text { SX FARM SUPERNATANT AND } \\
\text { SLUDGE }\end{array}$ & 2 \\
\hline $241-T-301 B$ & LIMITED & GOOD & INDICATED & NO & $\begin{array}{l}\text { TX FARM SUPERNATANT AND } \\
\text { SLUDGE }\end{array}$ & 2 \\
\hline
\end{tabular}


Table 5-7. (cont) IMUST Categorization

\begin{tabular}{|c|c|c|c|c|c|c|}
\hline IMUST TANK & $\begin{array}{l}\text { ANALYSIS } \\
\text { DATA }\end{array}$ & $\begin{array}{l}\text { PROCESS } \\
\text { KNOWLEDGE }\end{array}$ & ORGANICS & $\begin{array}{l}\text { ACID } \\
\text { TREAT/ } \\
\text { RECPT }\end{array}$ & WASTE TYPE & $\begin{array}{l}\text { AC5.9 } \\
\text { F.G. } \\
\text { FAC GRP }\end{array}$ \\
\hline $241-T \dot{X}-302 A$ & LIMITED & LIMITED & INDICATED & NO & $\begin{array}{l}\text { MIXED WASTE SUPERNATANT } \\
\text { AND SLUDGE }\end{array}$ & 3 \\
\hline 241-TX-302B CT & LIMITED & GOOD & INDICATED & NO & $\begin{array}{l}\text { TX FARM WASTE - FORM } \\
\text { UNKNOWN }\end{array}$ & $2^{*}$ \\
\hline $241-T X-302 B(R)$ & NONE & LIMITED & INDICATED & NO & $\begin{array}{l}\text { TX FARM WASTE - FORM } \\
\text { UNKNOWN }\end{array}$ & 2 \\
\hline $241-T X-302 X B$ & NONE & LIMITED & INDICATED & NO & $\begin{array}{l}\text { TX FARM SUPERNATANT AND } \\
\text { SLUDGE }\end{array}$ & 2 \\
\hline $241-T Y-302 A$ & NONE & POOR & INDICATED & NO & TY FARM SLUDGE & 3 \\
\hline $241-T Y-302 B$ & NONE & LIMITED & NOT INDICATED & NO & EMPTY & NGRE \\
\hline $241-Z-8$ & LIMITED & LIMITED & INDICATED & NO & RECUPLEX SLUDGE & 3 \\
\hline $242-T-135$ & NONE & POOR & NOT INDICATED & NO & $\begin{array}{l}242-T \text { DECON WASTE - FORM } \\
\text { UNKNOWN }\end{array}$ & 2 \\
\hline 242-TA-RI & LIMITED & LIMITED & NOT INDICATED & NO & $\begin{array}{l}\text { EVAPORATOR FEED WASTE - } \\
\text { FORM UNKNOWN }\end{array}$ & 2 \\
\hline 244-BXR-001 & LIMITED & GOOD & INDICATED & NO & BX AND BY FARM SLUDGE & 3 \\
\hline 244-BXR-002 & LIMITED & GOOD & INDICATED & YES & $\begin{array}{l}\text { BX AND BY PROCESSED WASTE } \\
\text { SUPERNATANT AND SLUDGE }\end{array}$ & 2 \\
\hline 244-BXR-003 & LIMITED & GOOD & INDICATED & YES & $\begin{array}{l}\text { BX AND BY PROCESSED WASTE } \\
\text { SUPERNATANT AND SLUDGE }\end{array}$ & 2 \\
\hline 244-BXR-011 & GOOD & GOOD & $<3 \%$ TOC & YES & $\begin{array}{l}\text { BX AND BY PROCESSED WASTE } \\
\text { SUPERNATANT AND SLUDGE }\end{array}$ & 3 \\
\hline
\end{tabular}


Table 5-7. (cont) IMUST Categorization

\begin{tabular}{|c|c|c|c|c|c|c|}
\hline IMUST TANK & $\begin{array}{l}\text { ANALYSIS } \\
\text { DATA }\end{array}$ & $\begin{array}{l}\text { PROCESS } \\
\text { KNOWLEDGE }\end{array}$ & ORGANICS & $\begin{array}{l}\text { ACID } \\
\text { TREAT/ } \\
\text { RECPT }\end{array}$ & WASTE TYPE & $\begin{array}{l}\text { AC5.9 } \\
\text { F.G. } \\
\text { FAC GRP }\end{array}$ \\
\hline 244-TXR-001 & LIMITED & GOOD & NOT INDICATED & NO & $\begin{array}{l}\text { T AND TX FARM SUPERNATANT } \\
\text { AND SLUDGE }\end{array}$ & 3 \\
\hline 244-TXR-002 & $\mathrm{G} 000$ & GOOD & NOT INDICATED & YES & T AND TX PROCESSED SLUDGE & 3 \\
\hline 244-TXR-003 & NONE & GOOD & NOT INDICATED & YES & T AND TX PROCESSED SLUDGE & 3 \\
\hline 244-UR-001 & LIMITED & GOOD & INDICATED & NO & $\begin{array}{l}\text { U FARM SUPERNATANT AND } \\
\text { SLUDGE }\end{array}$ & $N / A$ \\
\hline 244-UR-002 & GOOD & GOOD & INDICATED & YES & $\begin{array}{l}\text { U FARM PROCESSED } \\
\text { SUPERNATANT AND SLUDGE }\end{array}$ & $N / A$ \\
\hline 244-UR-003 & LIMITED & GOOD & INDICATED & YES & U FARM PROCESSED SLUDGE & $N / A$ \\
\hline 244-UR-004 & NONE & GOOD & NOT INDICATED & YES & EMPTY & $N / A$ \\
\hline $270-W$ & NONE & GOOD & INDICATED & YES & $\begin{array}{l}\text { U PLANT WASTE - FORM } \\
\text { UNKNOWN }\end{array}$ & 2 \\
\hline
\end{tabular}

* Flammable Gas Facility Group designation is included in AC 5.9, but the tank is not 7 isted in BI0 Table B2-16. BIO Table B2-16 needs to be updated to include this IMUST. 
HNF-2503, Rev. 0

The required actions for IMUST group I tanks are:

- Determine the correct flammability control facility group for each tank.

- Modify the BIO or FSAR, and TSRs to include the tanks not previousiy listed as IMUSTs and to place the incorrectiy listed tanks in the correct facility group.

- Close the flammable gas USQ for this group of tanks according to the USQ closure strategy document (HNF-SD-WM-ER-680).

Required actions for the 244-UR Vault tanks are dependent on transfer of ownership to TWRS.

\subsubsection{IMUST Group 2: Tanks With Unknown Contents}

The contents of several tanks could not be determined through process history review, nor was any characterization data available for them. Even though the total volume of waste contained in some of them was known, the process knowledge was considered poor. The following tanks have unknown contents: 240-S-302, 241-A-302B, 241-AX-151CT, 241-AX-151-TKD, 241-AX-151-TKE, 24I-AX-151-TKF, 241-AX-151-TKG, 241-TX-302B(R), 241-TY-302A, 241-C-301, $241-\mathrm{B}-301,241-302 \mathrm{~B}, 241-\mathrm{BX}-302 \mathrm{~B}, 241-\mathrm{BX}-302 \mathrm{C}, 241-\mathrm{SX}-302,241-\mathrm{TX}-302 \mathrm{XB}$, and 241-Z-8.

The required actions for this group of tanks are:

- Perform sampling and analysis of tank contents, if accessible.

- Continue current access. restrictions pending further characterization.

- Continue process history evaluation.

- Perform further $A B$ actions as dictated by the results of the above activities.

- Close the flammable gas USQ for this group of tanks according to the USQ closure strategy document (HNF-SD-WM-ER-680).

The tanks are currently maintained in a safe condition by access restriction and the monitoring required before work within the tanks is conducted.

\subsubsection{IMUST Group 3: Tanks Containing organics}

Based on the review of process history data and available analytical data, the following tanks may contain more than incidental quantities of organic materials: 216-BY-201, 216-TY-201, 241-T-301B, 241-TX-302A, 241-TX-302B CT, 
244-BXR-002, 244-BXR-003, 244-UR-001, 244-UR-002, 244-UR-003, and 270-W. This group of tanks is of concern for the organic salt-nitrate reaction described in the BIO (Section 5.3.2.17). The analysis referenced in the BIO indicates that a risk of this reaction is possible if the concentration of certain organic complexants in the waste is greater than 3 percent total organic content (TOC) by weight. The concentration of organic material in the waste is not known for most of the tanks. They are identified on this list because the process history indicated the likelihood of organics being present in more than incidental quantities (refer to Table 5-7). None of the tanks that had quantified analytical sample data available on TOC content were shown to have greater than 3 percent TOC.

If tank contents can be demonstrated to be typical of DST or SST waste, it can likely be concluded (from the evaluations already done under the organic safety program) that no chemical runaway is possible: However, if tank contents are not similar to SST and DST waste, the possibility of an uncontrolled chemical reaction must be considered.

The required actions for this group of tanks are:

- Perform sampling and analysis of contents, if quantity of organics is unknown, cannot be reasonably estimated, or concentration through evaporation is suspected.

- Continue current access restrictions pending further evaluation.

- Perform a limited hazard evaluation to determine if these tanks represent an unanalyzed risk in their current configuration.

- Perform further $A B$ actions as dictated by the results of the above activities.

- Close the flammable gas USQ for this group of tanks according to the USQ closure strategy document (HNF-SD-WM-ER-680).

The tanks are currently maintained in a safe condition by access restriction and the monitoring required before work within the tanks is conducted.

\subsubsection{IMUST Group 4: Acid Treatment or Receipt Tanks with Organics}

Based on the review of process history data and avajlable analytical data, the following tanks are known to have received acidic waste or were used for acid treatment of waste materials and are known or suspected to contain organics: 244-BXR-002, 244-BXR-003, 244-UR-002, 244-UR-003, and 270-W. This is of concern because the acids used in the Hanford processes can contribute oxidizers for an organic salt-nitrate reaction as discussed in Section 5.3.2.17 of the BIO (HNF-SD-WM-BIO-001).

The required actions for this group of tanks are: 
HNF-2503, Rev. 0

- Sampling and analysis of contents if accessible and if organics are known to be present.

- Continue access restrictions pending further evaluation.

- Perform a limited hazard evaluation to determine if these tanks represent an unanalyzed risk in their current configuration.

- Perform further $A B$ actions as dictated by the results of the above activities.

- Close the flammable gas USQ for this group of tanks according to the USQ closure strategy document (HNF-SD-WM-ER-680).

The tanks are currently maintained in a safe condition by access restriction and the monitoring required before work within the tanks is conducted.

\subsection{FACILITIES ADJACENT TO TWRS}

Non-TWRS facilities in the 200 Area of the Hanford Site were evaluated for potential impacts to TWRS facilities and personne].

\subsubsection{Methodology}

A11 non-TWRS facilities in the 200 Area were grouped into two main categories:

- Facilities with no significant amounts of hazardous materials present and no authorization basis concern (Section 5.3.2).

- Facilities with significant amounts or unknown quantities of hazardous materials.

The facilities with significant amounts or unknown quantities of hazardous materials were further categorized:

- Facilities with SARs (Section 5.3.3).

- Facilities without SARs (Section 5.3.4).

Facilities with SARs were reviewed for accidents with the potential to impact

TWRS facilities. No mitigated accidents exceed the onsite risk guidelines used in these SARs for control selection. Further, no new safety interfaces were identified to be required between these non-TWRS facilities and TWRS.

Facilities without SARs and significant amounts of hazardous materials need to be screened for potential impact to TWRS facilities and personnel. Facilities without SARs and with unknown amounts of hazardous materials require further investigation. Facilities posing a potential impact to TWRS facilities need to be screened for a TWRS Authorization Basis update. 
HNF-2503, Rev. 0

\subsubsection{Facilities with no Significant Amounts of Hazardous Materials}

The following facilities have no significant amounts of hazardous materials, or are in a long-term disposal condition (e.g., LLW Burial Grounds):

- 242-B, PNNL particle research lab

- 2721-EA, Hanford Fire Department maintenance shop

- 276-C, Hot Semiworks solvent storage building

- 283-E, 200-E Area water treatment plant

- 284-E, 200-E Area powerhouse

- 200 Area Liquid Effluents Treatment Facility (includes 200 Area Effluent Treatment Facility, 200 Area Liquid Effluent Retention Facility, 200 Area Treated Effluent Disposal Facility, and State-Approved Land Disposal System)

- 200-W-13, 2713WB shop

- 283-W, West Area water treatment plant

- 284-W, West Area powerhouse

- Environmental Restoration Disposal Facility (ERDF)

- 616 Nonradioactive Dangerous Waste Storage Facility

- Waste Retrieval and Packaging (WRAP) facility (unfinished, evaluate when operational)

- LLW Burial Grounds, 200-E and 200-W Areas

- US Ecology commercial LLW disposal facility

- 600 Area Purgewater Storage and Treatment Facility

- REDOX (202-S)

- U-Plant

\subsubsection{Facilities with SARs}

The facilities not eliminated from consideration in Section 5.3.2 that have active SARs are shown in Table 5-8. All accidents postulated in the facility SARs were evaluated for the potential to initiate a release at TWRS facilities, a disruption of TWRS operations, or a potential dose to TWRS personnel above risk guidelines. Whether an accident in an adjacent facility could result in a TWRS release or disrupt TWRS operations was a qualitative judgement, since this information is not contained in the referenced SARs. No mitigated accidents in these SARs resulted in an unacceptable dose above risk guidelines to onsite workers.

These SARs do not specifically provide an interface with TWRS for response to the accidents analyzed. However, the Hanford Site Emergency Preparedness Program (EPP) (DOE/RL-94-02) controls interfaces between the TWRS EPP (HNF-IP-0971) and other site contractor EPPs. These programs and their implementing procedures are relied upon to assure worker protection. 
HNF-2503, Rev. 0

Table 5-8. Facilities with SARs (3 Sheets)

\begin{tabular}{|c|c|c|c|c|}
\hline FACILITY \& SAR & ACCIDENTS & $\begin{array}{l}\text { CAN INITIATE } \\
\text { TURS RELEASE? }\end{array}$ & $\begin{array}{l}\text { POTENTIAL DOSE TO } \\
\text { TWRS PERSONNEL ABOVE } \\
\text { RISK GUIDELINES? } \\
\end{array}$ & $\begin{array}{l}\text { CAN DISRUPT } \\
\text { TWRS } \\
\text { OPERATIONS? }\end{array}$ \\
\hline \multirow{11}{*}{$\begin{array}{l}\text { B-Pl ant, } \\
\text { HNF-SD-WM-BI0-003 } \\
\text { Rev. } 0\end{array}$} & Seismic & No & No & NO \\
\hline & High winds & NO & No & No \\
\hline & Flood & No & No & No \\
\hline & Ashfall/snow Toad & No & No & NO \\
\hline & Leaks and spills & No & No & No \\
\hline & HEPA filter fire & No & No & YES \\
\hline & $\begin{array}{l}\text { Organic solvent } \\
\text { fire in canyon } \\
\end{array}$ & No & No & NO \\
\hline & Hydrogen generation & NO & No & NO \\
\hline & Red oil explosion & NO & NO & NO \\
\hline & $\begin{array}{l}\text { Misc. mechanical } \\
\text { failures }\end{array}$ & No & NO & NO \\
\hline & $\begin{array}{l}\text { Air cleaning train } \\
\text { (ACT) filter } \\
\text { failure }\end{array}$ & NO & NO & YES \\
\hline \multirow{8}{*}{$\begin{array}{l}\text { T-Plant, } \\
\text { HNF-SD-WM-ISB-006 } \\
\text { Rev. } 0\end{array}$} & Spray release & No & NO & NO \\
\hline & Spill release & No & NO & NO \\
\hline & Spent fuel release & NO & NO & No \\
\hline & 2706-T filter fire & NO & NO & NO \\
\hline & LLW drum fire & NO & NO & NO \\
\hline & 291-T filter fire & NO & NO & YES \\
\hline & $\begin{array}{l}\text { Organic/acid } \\
\text { explosion }\end{array}$ & NO & NO & NO \\
\hline & Sodium metal fire & No & NO & NO \\
\hline \multirow{4}{*}{$\begin{array}{l}\text { 222-S Laboratory, } \\
\text { HNF-SD-CP-ISB-002 } \\
\text { Rev. } 2\end{array}$} & Earthquake & No & No & NO \\
\hline & Laboratory spills & No & NO & No \\
\hline & Fire & No. & NO & YES \\
\hline & Dropped cover block & NO & NO & NO \\
\hline
\end{tabular}


HNF-2503, Rev. 0

Table 5-8. Facilities with SARs (3 Sheets)

\begin{tabular}{|c|c|c|c|c|}
\hline FACILITY \& SAR & ACCIDENTS & \begin{tabular}{|l} 
CAN INITIATE \\
TWRS RELEASE? \\
\end{tabular} & $\begin{array}{l}\text { POTENIIAL DOSE TO } \\
\text { TWRS PERSONNEL ABOVE } \\
\text { RISK GUIDELINES? }\end{array}$ & $\begin{array}{l}\text { CAN DISRUPT } \\
\text { TWRS } \\
\text { OPERATIONS? }\end{array}$ \\
\hline \multirow{9}{*}{$\begin{array}{l}\text { WESF }(225-B), \\
\text { WHC-SD-WM-SAR-005 } \\
\text { Rev. } 12\end{array}$} & $\begin{array}{l}\text { Hydrogen explosion } \\
\text { in cells }\end{array}$ & No & No & NO \\
\hline & $\begin{array}{l}\text { Release of } \\
\text { contamination to } \\
\text { the } \mathrm{K}-3 \text { filter }\end{array}$ & NO & NO & NO \\
\hline & $\begin{array}{l}\text { Fire in K-3 filter } \\
\text { unit }\end{array}$ & NO & NO & YES \\
\hline & K-3 filter dropped & NO & NO & YES \\
\hline & $\begin{array}{l}\text { Dropped or falling } \\
\text { equipment }\end{array}$ & NO & NO & NO \\
\hline & $\begin{array}{l}\text { Rapid loss of pool } \\
\text { cell shielding } \\
\text { water }\end{array}$ & NO & NO & YES \\
\hline & Fire in truck port & NO & NO & NO \\
\hline & $\begin{array}{l}\text { Cross contamination } \\
\text { from } K-3 \text { to } K-1 \\
\text { ventilation }\end{array}$ & No & NO & NO \\
\hline & Capsule return & NO & NO & No \\
\hline \multirow{5}{*}{$\begin{array}{l}\text { 242-A Evaporator } \\
\text { HNF-SD-WM-SAR-023 } \\
\text { Rev. } 3\end{array}$} & Loss of confinement & NO & NO & YES \\
\hline & $\begin{array}{l}\text { Uncontrolled } \\
\text { chemical reactions }\end{array}$ & NO & NO & NO \\
\hline & $\begin{array}{l}\text { Externa1 } \\
\text { occurrences }\end{array}$ & No & NO & YES \\
\hline & $\begin{array}{l}\text { Radiological } \\
\text { hazards }\end{array}$ & NO & NO & YES \\
\hline & Industrial hazards & NO & No & No \\
\hline
\end{tabular}


HNF-2503, Rev. 0

Table 5-8. Facilities with SARs (3 Sheets)

\begin{tabular}{|c|c|c|c|c|}
\hline FACILITY \& SAR & ACCIDENTS & $\begin{array}{l}\text { CAN INITIATE } \\
\text { TWRS RELEASE? }\end{array}$ & $\begin{array}{l}\text { POIENTIAL DOSE TO } \\
\text { TWRS PERSONNEL ABOVE } \\
\text { RISK GUIDELINES? } \\
\end{array}$ & $\begin{array}{l}\text { CAN DISRUPT } \\
\text { TWRS } \\
\text { OPERATIONS? }\end{array}$ \\
\hline \multirow{9}{*}{$\begin{array}{l}\text { Central Waste } \\
\text { Complex, } \\
\text { WHC-SD-WM-SAR-041 } \\
\text { Rev. } 0\end{array}$} & Seismic event & NO & NO & NO \\
\hline & Wind effects & NO & No & No \\
\hline & $\begin{array}{l}\text { Fire within a } \\
\text { package }\end{array}$ & NO & NO & NO \\
\hline & Range fire & NO & NO & NO \\
\hline & $\begin{array}{l}\text { Fire within a } \\
\text { building. }\end{array}$ & NO & NO & NO \\
\hline & $\begin{array}{l}\text { Material handling } \\
\text { mishaps }\end{array}$ & NO & NO & NO \\
\hline & Criticality & NO & NO & YES \\
\hline & Flood & $N / A$ & NO & $N / A$ \\
\hline & $\begin{array}{l}\text { Toxicological } \\
\text { exposure from } \\
\text { chemical hazards }\end{array}$ & NO & NO & YES \\
\hline \multirow{8}{*}{$\begin{array}{l}\text { PFP/PRF, } \\
\text { WHC-SD-CP-SAR-021 } \\
\text { Rev. } 0\end{array}$} & Explosions & NO & NO & NO \\
\hline & Fire & NO & NO & No \\
\hline & Criticality & NO & NO & NO \\
\hline & Seismic event & No & No & NO \\
\hline & Strong wind & NO & NO & NO \\
\hline & $\begin{array}{l}\text { Hydrogen fluoride- } \\
\text { induced plutonium } \\
\text { release }\end{array}$ & $N / A$ & $N / A$ & $N / A$ \\
\hline & Aircraft accident & NO & No & NO \\
\hline & $\begin{array}{l}\text { Toxic chemical } \\
\text { release } \\
\end{array}$ & NO & NO & NO \\
\hline
\end{tabular}

Note: Natural event phenomena such as high winds and seismic events are listed as "NO" in the columns above. This is because these phenomena are analyzed in the TWRS $A B$ and consequences associated with them are already part of the TWRS hazard profile. 
The facilities that have SARs are:

2 B-Plant (760 m [2500 ft] south of the 241-BX Tank Farm)

- WESF (760 m [2500 ft] south of 241-BX Tank Farm)

- 242A Evaporator (immediately south of 241-A Tank Farm)

- T-P1ant (630 m [2060 ft] east of 241-T Tank Farm)

- 222-S Laboratory (630 m [2060 ft] southeast of 241-SX Tank Farm)

- Central Waste Complex (630 m [2060 ft] west of 241-TX Tank Farm)

- Plutonium Finishing P1ant (503 m [1650 ft] northwest of 241-U Tank Farm)

\subsubsection{Facilities with Hazardous Materials and No SAR}

The facilities listed in Table 5-9 have hazardous materials and no SARs. These facilities need to be evaluated for the potential to initiate a release at TWRS facilities.

Any evaluation must include a method for tracking adjacent facility conditions which may change. For example, the acceptability of the Johnson Controls (JCI) package boiler located near 242-A (across the street from 241-AW tank farm) is based on assumptions made in USQ TF-97-694. There is currently no formal process to ensure that any change JCI makes to this boiTer will generate a TWRS USQ screening. 
HNF-2503, Rev, 0

Table 5-9. Facilities with Hazardous Materials and No SAR

\begin{tabular}{|c|c|c|c|}
\hline FACILITY & MATERIAL & POSSIBLE ACCIDENT & $\begin{array}{l}\text { TWRS ACTION } \\
\text { REQUIRED }\end{array}$ \\
\hline PUREX & \multicolumn{3}{|c|}{$\begin{array}{l}\text { PUREX } A B \text { is in the process of changing from operating } \\
\text { to shutdown. Review will be required when } A B \text { is } \\
\text { finalized. }\end{array}$} \\
\hline 2711-E Garage & Waste oil & Fire & Evaluate \\
\hline $\begin{array}{l}\text { 2721-E Hanford } \\
\text { Patrol HQ }\end{array}$ & $\begin{array}{l}\text { Ammunition, } \\
\text { explosives }\end{array}$ & Fire, explosion & Evaluate \\
\hline Craft shops & $\begin{array}{l}\text { Industrial } \\
\text { chemicals }\end{array}$ & Fire & Evaluate \\
\hline Conoco station & $\begin{array}{l}\text { Gasoline, diesel } \\
\text { fuel }\end{array}$ & Fire & Evaluate \\
\hline $\begin{array}{l}\text { JCI package } \\
\text { boiters }\end{array}$ & Fuel, steam & $\begin{array}{l}\text { Fire, steam } \\
\text { explosion }\end{array}$ & $\begin{array}{l}\text { None; } \\
\text { addressed in } \\
\text { TWRS USQ \#TF- } \\
97-694\end{array}$ \\
\hline $\begin{array}{l}\text { JCI portable } \\
\text { package boilers }\end{array}$ & Fuel, steam & $\begin{array}{l}\text { Fire, steam } \\
\text { explosion }\end{array}$ & $\begin{array}{l}\text { TBD; under } \\
\text { evaluation }\end{array}$ \\
\hline
\end{tabular}




\subsection{AUTHORIZATION BASIS UPGRADE PLANNING}

\subsection{AUTHORIZATION BASIS UPGRADE TASKS}

Tables 6-1 and 6-2 present rough cost estimates and durations for the $A B$ upgrade actions specified in Chapter 5.0 for facilities and IMUSTs, respectively. These cost estimates are only initial rough estimates based on preliminary information. They are subject to change significantly as the work planning process progresses. A11 of the actions specified in Chapter 5.0 are included in the tables, as are some supporting activities not called out explicitly in Chapter 5.0 that are necessary to implement some of the specified $A B$ actions. Cost estimates are more accurate for all tasks that are not dependent on the results of a piece of work that defines the scope of a successive task. For example, Chapter 5.0 calls for characterization of some FTCs for which no information is available. Since the results of the characterization could indicate that there are no hazards, or conversely indicate that there are significant hazards, the costs of the follow-on work to update the $A B$ is highly uncertain. Table 6-1 is arranged in order of the priority shown in Chapter 4.0. Table 6-2 is arranged by IMUST group (refer to Section 5.2). The costs in this table represent totals for all tanks in a given group. In all cases the estimate for the follow-on activity assumes the need to upgrade the authorization basis, but the estimate cannot be validated until the precursor tasks are complete.

\subsection{FISCAL YEAR 1998 REMAINING TASKS}

\subsubsection{Facilities}

The work accomplished to date for TWRS facilities addressed in this report includes identification and categorization, ownership verification, process history review, safety documentation review, risk ranking criteria development, facility walkdowns and hazard assessment, characterization data review, $A B$ strategy development, and status report preparation. Costs to date are estimated to total approximately $\$ 300,000.00$ for Fiscal Year (FY) 1998. Remaining funding of approximately $\$ 60,000.00$ will be utilized to (1) plan and schedule additional AB upgrade work for both facilities and IMUSTs, (2) respond to RL questions and comments on this report, (3) organization of material from this activity into retrievabie files for each FTC evaluated, (4) develop planning interfaces and strategies with the TWRS Facility Deactivation program and the TWRS Characterization Project Office, and (5) Provide change documentation to the WIDS and FacilitiesCORE databases and the TWRS monthly status report (HNF-EP-0182) to reflect information gathered from this activity for facilities and IMUSTs.

\section{2 .2 IMUSTS}

The work accomplished to date for TWRS IMUSTs includes IMUST documentation reviews, identification and categorization of IMUSTs, ownership verification, field walkdowns and hazard assessment, geophysical survey, characterization data review and planning for follow-on characterization activities. Costs to 
date are estimated to total approximately $\$ 67,000.00$ for FY 1998. Remaining funding of approximately $\$ 36,000.00$ will be utilized to develop a modification to the BIO and TSR to list the tanks (IMUST Group No. 1) that are not currently listed or are incorrectly listed in the BIO and TSR.

\subsection{MULTI-YEAR WORK PLANNING}

Currently, TWRS is conducting a review of the multi-year work $p$ lan to better define the interrelationships between the various contractor and subcontractor organizations, and to ensure a clear definition and cost estimate of all committed work. This review is resulting in the development of Technical Basis Review (TBR) packages for all work covered under the Safe Storage portion of the TWRS level 0 schedule. These TBR packages include the technical scope, enabling assumptions, scheduTes, risks, and affected organizations involved in the completion of the scope of work. TWRS Nuclear Safety \& Licensing is involved in this planning process, and has defined interrelationships in several of the work scope area defined in Tables $6-1$ and 6-2. The total funding required to accomplish the identified $A B$ upgrades needs to include the costs of improving the TWRS technical baseline (e.g., sampling and characterization), $A B$ documentation upgrades and $A B$ field implementation (e.g., procedure updates, equipment modifications). Characterization and Operations impacts need to be addressed in their Project Baseline Summaries (PBS) (TWO1 and TW03, respectively). The actual AB documentation upgrade work will be part of the Tank Safety Issue Resolution Project PBS (TWO2).

\subsection{COST-BENEFIT CRITERION FOR TASK PLANNING}

Specific $A B$ upgrade strategies have been developed for the TWRS FTCs addressed in this report, and those strategies have been ranked in order of relative risk (refer to Chapter 4.0). Planning for follow-on activities must address not only the relative risk ranking, but also the cost versus benefit aspects of the tasks proposed. Application of this criterion results in scheduling of follow-on tasks that are not fully in order of relative risk.

The immediate follow-on activity for IMUSTs is to upgrade the BIO to include those IMUSTs that are not currently listed or are incorrectly listed in the $B I 0$ and TSR. This is a funded activity for Fiscal Year 1998, and thus, the $A B$ activities required for these particular IMUSTs will be pursued before the activities for some of the IMUSTs that have been ranked as a higher priority.

The activities specified for some facilities must be evaluated in light of the facility's mission, considering such factors as future planned use of the facility, shutdown/standby status, and accessibility factors. For example, the 242-T Evaporator is listed as the highest priority facility for follow on $A B$ action. The first $A B$ action listed for this facility is the sampling of the tanks and vessels to characterize the materials remaining in the facility. Because the facility is in poor condition, and the tanks needing sampling are in high radiation areas, sampling would be a time consuming and costly effort and would require a safety justification specifically for the sampling activity. The time remaining until the facility is planned for deactivation 
HNF-2503, Rev. 0

and the results of a structural analysis would be factored into a decision as to whether there would be any beneficial gain to sampling at this time.

Interim controls could be considered on the basis of the deactivation planning and any needs identified through structural analysis or a hazards analysis effort. 
HNF-2503, Rev. 0

Table 6-1.

Cost and Duration Estimates for Facility AB Upgrade Activities (4 Sheets)

\begin{tabular}{|c|c|c|}
\hline Required Actions & $\begin{array}{l}\text { Cost Est. } \\
(\$ \times 1000)\end{array}$ & $\begin{array}{l}\text { Duration } \\
\text { (Months) } \\
\end{array}$ \\
\hline \multicolumn{3}{|l|}{ 242-T Evaporator ${ }^{3}$} \\
\hline$A B$ Justification for Entry and Sampling & 50 & 3 \\
\hline DQO, Sample, and Analysis & $\mathrm{CPO}^{1}$ & $\mathrm{CPO}^{1}$ \\
\hline Hazards Evaluation & 70 & 2 \\
\hline Roof Loading Analysis & 30 & 1 \\
\hline Implement Interim Controls as Necessary & $25^{2}+\mathrm{OPS}^{5}$ & $1^{2}+0 \mathrm{PS}^{5}$ \\
\hline Consequence Analysis for New. Credible Accidents & $150^{2}$ & $6^{2}$ \\
\hline Amend Authorization Basis & $60^{2,6,7}$ & $4^{2,6,7,8}$ \\
\hline Remove Shutdown/Standby Report from $A B$ & $--^{4}$ & $--^{4}$ \\
\hline Close Flammable Gas USQ per HNF-SD-WM-ER-680 & $--^{4}$ & $--^{4}$ \\
\hline Total & . 385 & $\begin{array}{l}14^{10}+\text { crot }^{2} \\
\text { ops }\end{array}$ \\
\hline \multicolumn{3}{|l|}{ 244-CR Vault ${ }^{3}$} \\
\hline$A B$ Justification for Sampling & 35 & 2 \\
\hline DQO, Sample, and Analysis & $\mathrm{CPO}^{1}$ & $\mathrm{CPO}^{1}$ \\
\hline Hazards Evaluation & 50 & 2 \\
\hline Continue Tank and Sump Leve] Monitoring & $\mathrm{OPS}^{5}$ & $\mathrm{OPS}^{5}$ \\
\hline Consequence Analysis for New Credible Accidents & $80^{2}$ & $4^{2}$ \\
\hline Implement Interim Controls as Necessary & $10^{2}$ & $1^{2}$ \\
\hline Amend Authorization Basis & $40^{2,6,7}$ & $3^{2,6,7,8}$ \\
\hline Close Flammable Gas USQ per HNF-SD-WM-ER- 680 & $--^{4}$ & $--^{4}$ \\
\hline Total & 215 & $10^{10}+\mathrm{Cpo}^{2}$ \\
\hline
\end{tabular}


HNF-2503, Rev. 0

Table 6-1.

Cost and Duration Estimates for Facility AB Upgrade Activities (4 Sheets)

\begin{tabular}{|c|c|c|}
\hline Required Actions & $\begin{array}{l}\text { Cost Est. } \\
(\$ \times 1000)\end{array}$ & $\begin{array}{l}\text { Duration } \\
\text { (Months) }\end{array}$ \\
\hline \multicolumn{3}{|l|}{ 244-AR Vault ${ }^{3}$} \\
\hline Re-evaluate Sump Level Data/Instrument Performance & 10 & 1 \\
\hline$A B$ Justification for Sampling & 40 & 2 \\
\hline Characterize Vautt Contents & $\mathrm{CPO}^{1}$ & $\mathrm{CPO}^{1}$ \\
\hline Hazards Evaluation & 50 & 2 \\
\hline Consequence Analysis for New Credible Accidents & $25^{2}$ & $1^{2}$ \\
\hline Implement Interim Controls as Necessary & $10^{2}$ & $1^{2}$ \\
\hline Amend Authorization Basis & $40^{2,6,7}$ & $3^{2,6,7,8}$ \\
\hline CTose Flammable Gas USQ per HNF-SD-WM-ER-680 & $--^{4}$ & $--^{4}$ \\
\hline Total & 175. & $8+480$ \\
\hline \multicolumn{3}{|l|}{ 242-S Evaporator ${ }^{3}$} \\
\hline$A B$ Justification for Sampling & 35 & 2 \\
\hline DQO, Sample, and Analysis & CPO ${ }^{1}$ & $\mathrm{CPO} 0^{1}$ \\
\hline Hazards Evaluation & 30 & 1 \\
\hline Implement Interim Controls as Necessary & $10^{2}$ & $1^{2}$ \\
\hline Consequence Analysis for New Credible Accidents & $30^{2}$ & $2^{2}$ \\
\hline Amend Authorization Basis & $40^{2,6}$ & $3^{2,6,7,8}$ \\
\hline Remove Shutdown/Standby $P$ lan from $A B$ & $--^{4}$ & $--^{4}$ \\
\hline Close the Flammable Gas USQ per HNF-SD-WM-ER-680 & $--^{4}$ & $--^{4}$ \\
\hline Total & 145 & $60 \%+p 0$ \\
\hline \multicolumn{3}{|c|}{ ITS-1 In-Tank Solidification System ${ }^{3}$} \\
\hline AB Justification for Sampling & 10 & 1 \\
\hline DQ0/Sample Vapor Space of Components & $\mathrm{CPO}^{1}$ & $\mathrm{CPO}^{1}$ \\
\hline AB Justification for Sampling & $30^{2}$ & $2^{2}$ \\
\hline Inspect/Sample Vessels per Vapor Sample Results & $\mathrm{CPO}^{1,2}$ & $\mathrm{CPO}^{1,2}$ \\
\hline Inspect/Sample Vessels if Significant Mtl. Present & $\mathrm{CPO}^{1,2}$ & $\mathrm{CPO}^{1,2}$ \\
\hline
\end{tabular}


HNF-2503, Rev. 0

Table 6-1.

Cost and Duration Estimates for Facility AB Upgrade Activities (4 Sheets)

\begin{tabular}{|c|c|c|}
\hline Required Actions & $\begin{array}{l}\text { Cost Est. } \\
(\$ X 1000) \\
\end{array}$ & $\begin{array}{c}\text { Duration } \\
\text { (Months) }\end{array}$ \\
\hline \multicolumn{3}{|c|}{ ITS-1 In-Tank Solidification System ${ }^{3}$ (Cont) } \\
\hline Hazards Analysis & 40 & 3 \\
\hline Implement Interim Controls as Necessary & $10^{2}$ & $1^{2}$ \\
\hline Amend Authorization Basis & $40^{2,6,7}$ & $3^{2,6,7,8}$ \\
\hline Total & 130. & $60^{13}+\mathrm{PB}$ \\
\hline \multicolumn{3}{|c|}{ 241-AX-IX Ion Exchange Column ${ }^{3}$} \\
\hline AB Justification for Sampling & 10 & 1 \\
\hline DQ0/Sample Vapor Space of Ion Exc. Column \& Filter & $\mathrm{CPO}^{7}$ & $\mathrm{CPO}^{1}$ \\
\hline AB Justification for Sampling & $25^{2}$ & $2^{2}$ \\
\hline DQO/Inspect/Sample Vessel per Vapor Space Results & $\mathrm{CPO}^{1,2}$ & $\mathrm{CPO}^{1,2}$ \\
\hline Hazards Analysis & 40 & 3 \\
\hline Implement Interim Controls as Necessary & $10^{2}$ & $1^{2}$ \\
\hline Amend Authorization Basis & $40^{2,6,7}$ & $3^{2,6,7,8}$ \\
\hline Total & 125 & $66^{10}+\mathrm{CPO}$ \\
\hline \multicolumn{3}{|c|}{ 204-AR Waste Unloading Facility ${ }^{3}$} \\
\hline Evaluate Waste Transporter & 10 & 1 \\
\hline Resolve Pressure Switch Issue & $15^{7}$ & $2^{7}$ \\
\hline Comp. Modifications per $L C O \quad 3.1 .2 \& 3.1 .4$ req. & $\mathrm{OPS}^{5}$ & $\mathrm{OPS}^{5}$ \\
\hline Amend Authorization Basis & $40^{2,6,7}$ & $3^{2,6,7,8}$ \\
\hline Close Flammable Gas USQ per HNF-SD-WM-ER-680 & $--^{4}$ & $--^{4}$ \\
\hline Total & 65. & . $6.0 \mathrm{PS}$ \\
\hline \multicolumn{3}{|c|}{ 2727-W Sodium Storage Facility ${ }^{3}$} \\
\hline Establish/Confirm Facility Ownership & 5 & 1 \\
\hline Develop MOU with WMH for TWRS Controls (Owned) & $5^{2}$ & $1^{2}$ \\
\hline Remove from $A B$ (Not Owned) & $5^{2}$ & $1^{2}$ \\
\hline Total & 15. & 3. \\
\hline
\end{tabular}


HNF-2503, Rev. 0

Table 6-1.

Cost and Duration Estimates for Facility AB Upgrade Activities

(4 Sheets)

\begin{tabular}{|c|c|c|}
\hline Required Actions & $\begin{array}{l}\text { Cost Est. } \\
(\$ \times 1000)\end{array}$ & $\begin{array}{l}\text { Duration } \\
\text { (Months) }\end{array}$ \\
\hline \multicolumn{3}{|c|}{ Grout Treatment Facility $(\mathrm{GTF})^{3}$} \\
\hline Re-Evaluate Hazard Category Assignment & 15 & 1 \\
\hline Remove WHC-SD-WM-SSP-005 from $A B$ & 5 & 1 \\
\hline Update $A B$ to Include Waste Containing Vault & $5^{6}$ & $1^{6}$ \\
\hline Address Remaining Vaults in Project $W-465$ & $W-465^{9}$ & $W-465^{9}$ \\
\hline Total & 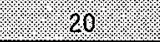 & $3 .+4-465$ \\
\hline \multicolumn{3}{|c|}{ 213-W Dry Waste Compactor Facility ${ }^{3}$} \\
\hline Review Radiation Survey Data & 10 & 1 \\
\hline Re-evaluate Facility Hazard CTassification & 15 & 1 \\
\hline Update Authorization Basis & $5^{2}$ & $1^{2}$ \\
\hline Total & 30 & 3. \\
\hline \multicolumn{3}{|c|}{ 209-E Critical Mass Laboratory ${ }^{3}$} \\
\hline No New Activities Required for Pre-deactivation & -- & - \\
\hline
\end{tabular}

Notes:

1 Characterization Project office (CPO) is responsible for DQO development, sampling, and analysis. $\mathrm{CPO}$ cost and schedule to be incorporated in FY $99 / 00$ MYWP.

2 Cost estimate is uncertain due to dependence on the outcome of preceding tasks.

3 Scope depends upon the schedule for facility deactivation.

4 Cost and duration is considered as part of the $A B$ anendment task.

5 TWRS Operations (OPS) is responsible for cost/schedule to be incorporated in FY $99 / 00 \mathrm{MYWP}$.

6 Cost does not include non-contractor Tier 283 activities.

7 Includes only TWRS Nuclear Safety and Licensing activities.

8 Tier $2 \& 3$ review duration is not included.

9 Project $W-465$ is responsible for cost/schedule to be incorporated in FY $99 / 00$ MYWP.

10 Durations are not additive since some individual activities may be performed concurrently. 
HNF-2503, Rev. 0

Table 6-2.

Cost and Duration Estimates for IMUST Group AB Upgrades

(2 Sheets)

\begin{tabular}{|c|c|c|}
\hline Required Actions & $\begin{array}{l}\text { Cost Est. } \\
(\$ X 1000)\end{array}$ & $\begin{array}{l}\text { Duration } \\
\text { (Months) }\end{array}$ \\
\hline \multicolumn{3}{|l|}{ IMUST Group 1} \\
\hline Determine Flammable Gas Facility Group & 5 & 1 \\
\hline Update $A B$ & 31 & 3 \\
\hline Close Flammable Gas USQ per HNF-SD-WM-ER- 680 & $--^{a}$ & $--^{a}$ \\
\hline Total & 36. & 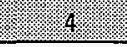 \\
\hline \multicolumn{3}{|l|}{ IMUST Group 2} \\
\hline AB Justification for Sampling & $60^{\mathrm{b}}$ & $4^{b}$ \\
\hline DQ0, Sample, and Analysis & $\mathrm{CPO}^{\mathrm{C}}$ & $\mathrm{CPO}^{\mathrm{C}}$ \\
\hline Continue Current Access Restrictions & -- & -- \\
\hline Continue Process History Evaluation & 50 & 3 \\
\hline Perform Additional $A B$ actions as Required & $60^{d}$ & $5^{d}$ \\
\hline Close Flammable Gas USQ per HNF-SD-WM-ER- 680 & $--^{a}$ & $--^{a}$ \\
\hline Total & 170 & 124.910 \\
\hline
\end{tabular}


HNF-2503, Rev. 0

Table 6-2.

Cost and Duration Estimates for IMUST Group AB Upgrades (2 Sheets)

\begin{tabular}{|c|c|c|}
\hline Required Actions & $\begin{array}{l}\text { Cost Est. } \\
(\$ \times 1000)\end{array}$ & $\begin{array}{l}\text { Duration } \\
\text { (Months) }\end{array}$ \\
\hline \multicolumn{3}{|l|}{ IMUST Group 3} \\
\hline AB Justification for Sampling & $80^{b}$ & $5^{b}$ \\
\hline DQO, Sample, and Analysis & $\mathrm{CPO}$ & $\mathrm{CPO}^{\mathrm{c}}$ \\
\hline Hazards Evaluation & 70 & 3 \\
\hline Perform Additional $A B$ Actions as Required & $60^{d}$ & $5^{d}$ \\
\hline Close Flammable Gas USQ per HNF-SD-WM-ER-680 & $--^{a}$ & $--^{a}$ \\
\hline Total & 216 & $12+920$ \\
\hline \multicolumn{3}{|l|}{ IMUST Group 4} \\
\hline$A B$ Justification for Sampling & $100^{b}$ & $5^{b}$ \\
\hline DQO, Sample, and Analyze & $\mathrm{CPO}^{\mathrm{C}}$ & $\mathrm{CPO}^{\mathrm{c}}$ \\
\hline Continue Access Restrictions & -- & -- \\
\hline Hazards Evaluation & 70 & 3 \\
\hline Perform Additional AB Actions as Required & $60^{d}$ & $5^{d}$ \\
\hline Close Flammable Gas USQ per HNF-SD-WM-ER-690 & $--^{a}$ & $--^{a}$ \\
\hline Total & 230 & $2+190$ \\
\hline
\end{tabular}

Notes:

a Flammable Gas USQ for all IMUSTs will be closed concurrently. Funding is planned separately.

b Cost estimates for each group of IMUSTs strongly depend on the applicability of one safety justification logic which applies to all the tanks in a given group.

c Characterization Project office (CPO) is responsible for DQO development, sampling, and analysis. CPO cost and schedule to be incorporated in FY $99 / 00$ MYWP.

d Cost estimate is uncertain due to dependence on the outcome of preceding tasks. 


\subsection{CONCLUSION}

It has been recognized that certain FTCs that are owned or managed by TWRS are not explicitly addressed in the current TWRS $A B$, or may have not been characterized to the extent that the hazards are fully understood. This report describes a comprehensive activity to evaluate such FTCs and determine the extent and priority of needed $A B$ upgrades to address them. These FTCs may have originally been excluded from the scope of the BI0 due to uncertainties regarding their status (i.e., active or inactive) or ownership. Initial reviews of data available for these FTCs, including IMUSTs, revealed that there was conflicting information in the source documents that described these FTCs. For example, several documents addressing IMUSTs (refer to Table 3-1) have been produced in the last few years containing differences in the list of IMUSTs, both in identification and total number of IMUSTs. Because of the uncertain $A B$ status of these FTCS, there was a need to evaluate the adequacy and effectiveness of current controls, programs, and operational practices to maintain a safe configuration in these FTCs.

To establish the actions necessary to upgrade the AB for the TWRS FTCS addressed in this report, it was necessary to perform a comprehensive review of each FTC to determine accuracy of available information, adequacy of current controls, and understanding of facility hazards. The key activities conducted inciuded:

- Collection of documented information

- Interviews with past and present TWRS personne]

- Field walk-downs of facilities and IMUSTs

- Review of photos, maps, and drawings

- Establishment of interfaces with relevant activities and functions:

- WIDS database

- TWRS Process Engineering

- TWRS Characterization

- Site Chemical Vulnerability Study

- TWRS Month1y Status Report (HNF-EP-0182)

- Flammable gas safety issue resolution

- Organics safety issue resolution

- Site Order Implementation P1 an (HNF-SP-1228)

- Corrections to other data bases, information sources, etc.

- Evaluation of hazards to assess whether any immediate changes in field practices or $A B-l e v e l$ controls were warranted or advised

- Evaluation of $A B$ documentation and assessment of upgrade needs

- Assessment of the need to improve the facility technical baseline (e.g., characterization, structural evaluation) 
HNF-2503, Rev. 0

- Development of a comprehensive Tist of IMUSTs, facilities and other tanks/components owned by TWRS

- Development of path forward for each facility and prioritization on the bases of safety, mission need and cost-benefit.

These activities resulted in the following conciusions:

There are two major components that are not addressed in any part of the current TWRS AB. They are:

241-AX-IX Ion Exchange Column

In-Tank Solidification (ITS-1) system in the 241-BY Tank Farm.

There are four facilities that are inadequately addressed in the current TWRS AB. They are:

242-S Evaporator

242-T Evaporator

244-AR Vault

244-CR Vault.

The facilities evaluated and determined to be adequately addressed in the TWRS $A B$ (although certain updates will be included in an Annual Update) are:

204-AR Waste Unlaading Facility

209-E Critical Mass Laboratory

213-W Dry Waste Compactor

2727-W Sodium Storage Facility

Grout Treatment Facility (GTF).

There are forty three IMUSTs that currently belong to TWRS. These are:

$\begin{array}{llll}200-W-7 & 241-C-301 & 241-Z-8 & 270-W \\ 231-W-151-001 & 241-E R-311 A & 242-T-135 & 209-E-T K-111 \\ 231-W-151-002 & 241-S-302 A & 242-T A-R 1 & 241-A X-151 C T \\ 240-S-302 & 241-S-302 B & 244-B X R-001 & 241-A X-151-T K-D \\ 241-A-302 B & 241-S X-302 & 244-B X R-002 & 241-A X-151-T K-E \\ 241-B-301 & 241-T-301 B & 244-B X R-003 & 241-A X-151-T K-F \\ 241-B-302 B & 241-T X-302 A & 244-B X R-011 & 241-A X-151-T K-G \\ 241-B X-302 A & 241-T X-302 B & 244-T X R-001 \\ 241-B X-302 B & 241-T X-302 B(R) & 244-T X R-002 \\ 241-B X-302 C & 241-T X-302 X B & 244-T X R-003 \\ 241-B Y-I T S 2-T K-1 & 241-T Y-302 A & 216-B Y-201 & \\ 241-B Y-I T S 2-T K-2 & 241-T Y-302 B & 216-T Y-201\end{array}$


HNF-2503, Rev. 0

There are four IMUSTs (all within the 244-UR Vault) that are currently owned by the ER program but are planned for transfer to TWRS. These are:

244-UR-001

244-UR-002

244-UR-003

244-UR-004.

Thirteen IMUSTs are not currently addressed (or are only partially addressed) in the TWRS $A B$. These are:

209-E-TK-111

241-AX-151-TKD

241-AX-151-TKE

241-AX-151-TKF

241-AX-151-TKG

241-BY-ITS2-TK1

241-BY-ITS2-TK2

241-TX-302-B

244-UR-001 (currently ER owned)

244-UR-002 (currently ER owned)

244-UR-003 (currently ER owned)

244-UR-004 (currently ER owned)

241-TX-302B (not listed in B10, Table B2-16).

Eight IMUSTs are addressed in the TWRS $A B$, but may be in an incorrect flammable gas facility group. These are:

241-S-302A

241-ER-311A

241-BX-302A

241-TY-302A

241-Z-8

244-BXR-001

244-TXR-002

244-TXR-003.

Seventeen IMUSTs require further characterization because their contents are unknown. These are:

$$
\begin{aligned}
& 240-S-302 \\
& 241-A-302 B \\
& 241-A X-151 C T \\
& 241-A X-151-T K D \\
& 241-A X-151-T K E \\
& 241-A X-151-T K F \\
& 241-A X-151-T K G \\
& 241-T X-302 B(R) \\
& 241-T T Y-302 A \\
& 241-C-301
\end{aligned}
$$



241-B-301
$241-B-302 B$
$241-B X-302 B$
$241-B X-302 C$
$241-5 X-302$
$241-T X-302 X B$
241-Z-8.

For all of the FTCs facilities where it was determined that the facility is either not addressed in the $A B$ or is not adequately addressed in the $A B$, one of the following two conditions apply:

(1) Available information about the facility; the nature of the activities planned in and around the facility for the near-term, and field observations lead to the conclusion that there are no immediate risks for release of hazardous materials and no identified benefit to immediately imposing new restrictions or controls. It is anticipated that systematic hazards analysis and gathering of more physical data will confirm that existing controls and field practices prudently manage the risks associated with the facility. In some cases, it is anticipated that some facilities will be able to be down-graded from "nuclear" to "radiological."

$\mathrm{OR}$

(2) To some degree, suspected or possible hazards associated with the facility are not well understood. Because the hazards are not well understood, meaningful and effective controls to address them are not identified in this report. In these cases, however, the current role of the facility in the TWRS mission (usually minimal) is judged to be such that ongoing work activities would not initiate accidents, aggravate hazardous conditions, or unduly expose workers to safety risks. It is anticipated that in some of these cases, systematic hazards analysis and gathering of additional physical data will result in the development of new or different controts to better manage the risks posed by the facility. It is also possible that for facilities where nothing is known about contained materials, that additional gathering of physical data will result in relaxation of controls.

In both cases, systematic and disciplined hazards analysis is required; although, the second case warrants priority over the first case. Systematic hazards analysis, in some cases requiring materials sampling and analysis, is the next major step beyond this report in the overall effort to upgrade the TWRS AB. Current approved work scope allows for 7 imited progress, a11 on behalf of upgrading the $A B$ for IMUSTs, for the balance of FY 1998 . FY 1999 and FY 2000 multi-year work planning (MYWP) is in progress. Starting with the information in Chapter 6 of this report, the contractor has begun to incorporate this work scope in FY 1999 and FY 2000 MYWP. 
HNF-2503, Rev. 0

$A B$ upgrade strategies have been presented in this report for the TWRS FTCS identified during the current activity. The priorities for these upgrades, based on perceived or known risk and status of the $A B$, have been established for each facility or IMUST. Although the immediate imposition of new or different controls is not called for in this report, any new work (including sampling) or changes in facility configuration may wel1 require new restrictions. The safety work associated with the gathering of additional physical data on each facility is included in Chapter 6.

Any changes to the TWRS mission which increases the level of worker activity or changes the way a facility is used, may invalidate the conclusions regarding no need for immediate imposition of new or different interim controls. Such changes would be evaluated within the USQ process before taking place.

This report represents the first major step in what is assumed to become an uninterrupted, reasonably expedited process, to accomplish remaining and necessary upgrades to the TWRS $A B$. As long as there is a defined and approved work scope to accomplish the tasks defined in this report, the $A B$ upgrade is in progress and the USQ process is adjusted per the guidance of the NE-70 guidance on implementation of DOE Order 5480.21 (as discussed in Section 2.5). If the $A B$ upgrade effort is interrupted or canceled, however, the contractor must invoke the USQ process to formally re-advise RL of inadequacies in the $A B$. In this case, the inadequacies would be recast as multiple open Discovery USQs requiring closure. 
HNF-2503, Rev. 0

\subsection{REFERENCES}

ARH-MA-119, "242-S Evaporator-Crysta11izer Information Manual, "At1antic Richfield Hanford Co., dated September, 1975.

DOE-STD-1027-92, "Hazard Categorization and Accident Analys is Techniques for Compliance with DOE Order 5480.23, Nuclear Safety Analysis Reports," U.S. Department of Energy, dated December, 1992.

DOE Order 5480.23, "Nuclear Safety Analysis," U. S. Department of Energy, Richland 0perations Office, Richland, Washington, dated Apri1, 1992.

DOE/RL-97-85, "Plutonium Reclamation Facility Incident Response Project Progress Report," Rev. 0, U. S. Department of Energy, Richland Operations Office, Richland, Washington, dated December, 1997.

DOE/RL-91-61, "T Plant Source Aggregate Area Management Study," Rev. 0, dated November, 1992.

HNF-1566, Rev. 0, "Letter Report 200 Area Plateau Inactive Miscellaneous Underground Storage Tanks Locations," Rev. 0, Fluor Daniel Northwest, Richland, Washington, dated November, 1997.

HNF-EP-0182, "Waste Tank Summary Report for Month Ending November 30, 1997," Fluor Daniel Hanford, Inc., Richland, Washington, dated January 8, 1998.

HNF-SD-WM-ER-680, Rev. 0, "Strategy for resolution of the Flammable Gas Safety Issue," Fluor Daniel Hanford, Inc., Richland, Washington, dated May 23, 1997.

HNF-IP-0842, "TWRS Administrative Manual," Volume XI, Section 1.1, Rev. 0-A, Quality Assurance, Fluor Daniel Hanford, Inc., Richland, Washington, dated February 19, 1998 .

HNF-IP-0842, "TWRS Administrative Manual," Volume IV, Section 5.4, Attachment A, Fluor Daniel Hanford, Inc., Richland, Washington, dated July 21, 1997.

HNF-MP-599, Rev. 1, "Project Hanford Quality Assurance Program Description, Fluor Daniel Hanford, Inc., Richland, Washington, dated October 31, 1997.

HNF-PRO-704, Rev. 0, "Hazard and Accident Analysis Process, "Fluor Daniel Hanford, Inc., Richland, Washington, dated December 29, 1997.

HNF-SD-WM-BI0-003, Rev. 0, "B-P1ant Basis for Interim Operation," B\&W Hanford Company, Richland, Washington, dated March 16, 1998.

HNF-SD-WM-BIO-00I, Rev. 0-G, "Tank Waste Remediation System Basis for Interim Operation," Fluor Daniel Hanford, Inc., Richland, Washington, dated February 27, 1998. 
HNF-SD-WM-ER-472, Rev. 0-C, "Best Basis Inventory, Appendix D of Tank Characterization Report," Fiuor Daniel Hanford, Inc., Richland, Washington, dated August 25, 1997.

HNF-SD-WM-ER-637, Rev, OA, "Best Basis Inventory, Appendix D of Tank Characterization Report," Fluor Daniel Hanford, Inc., Richland, Washington, dated August 25, 1997.

HNF-SD-WM-ER-687, Rev. 0, "Best Basis Inventory, Appendix D of Tank Characterization Report," Fluor Daniel Hanford, Inc., Richland, Washington, dated August 25, 1997.

HNF-SD-WM-SAR-023, Rev 3, "242-A Evaporator/Crysta?lizer Safety Analysis Report, "Westinghouse Hanford Company, Richland, Washington, dated March 30, 1998.

HNF-SD-WM-SAR-067, "Tank Waste Remediation System Final Safety Analysis Report," DRAFT, F1uor Daniel Hanford, Inc., Richland, Washington, dated 1997.

HNF-SD-WM-TSR-006, Rev. J, "Tank Waste Remediation System Technical Safety Requirements, " Fluor Daniel Hanford, Inc., Richland, Washington, dated February 26, 1998.

HNF-SD-CP-ISB-002, Rev. 2, "222-S Laboratory Interim Safety Basis," Numatec Hanford Corporation, Richland, Washington, dated Apri1 25, 1997.

HNF-SP-1228, "Quality Assurance Program Implementation Plan for Nuclear Facilities," Fluor Daniel Hanford, Inc., Richland, Washington, dated July $1,1997$.

HSRCM-1, Rev. 2, "Hanford Site Radiological Control Manual, "Westinghouse Hanford Company, Richland, Washington, dated 1995.

Interoffice Memo, Data Assessment and Interpretation to M. J. Sutey, "Data Review of Samples Taken at 242-S and 242-T Evaporator Facilities," 74620-97-208, dated Ju1y 30, 1997.

Interoffice Memo, P. F. Kison, LMHC, to G. L. Dunford, LMHC, "West Tank Farms Facility Chemical Inventory and Vulnerability Evaluation, "Lockheed Martin Hanford Corporation, Richland, Washington, dated July 22, 1997.

Interoffice Memo, East Tank Farms Engineering, to D. G. Baide, "East Tank Farms Facility Chemical Vulnerability Study, "Lockheed Martin Hanford Corporation, Richland, Washington, dated June 30, 1997.

LA-UR-97-311, S. F. Agnew, P. Baca, R.A. Corbin, T.B. Duran, and K.A. Jurgensen, "Waste Status and Transaction Record Summary (WSTRS), Rev. 4," LoS Alamos National Laboratory, Los Alamos, New Mexico, dated 1997. 
Letter, A. M. Umek, FDH, to L. E. Ha11, LMHC, "Subcontract Number 8023734-9-K001; U.S. Department of Energy, Richland Operations Office Request to Devalue Grout Facility Structures and Equipment," FDH-9761499A, Fluor Daniel Hanford, Inc., Richland, Washington, dated December 11, 1997.

Letter, J. K. MCClusky, RL, to H. J. Hatch, FOH, "Contract Number DE-AC06-96RL13200 - U. S. Department of Energy, Richland Operations Office (RL) Request to Devalue Grout Facility Structures and Equipment," 97-WSD-243, U.S. Department of Energy, Richland Operations Office, Richland, Washington, dated December 9, 1997.

Letter, J. E. Kinzer, RL to H. J. Hatch, FDH, "Contracted Number Request to Devalue Grout Facility Structures and Equipment, " 97-TWR-017, U.S. Department of Energy, Richland Operations Office, Richland, Washington, dated August 20, 1997.

Letter, T. N. Turpin, Jr. RL, to H. J. Hatch, FDH, Attachment 1 Appendix $\mathrm{C}$ to WIDS database listing for EM-30 Waste Management Units, "Agreement for and Assignment to Waste Sites for Management by Fluor Daniel Hanford, Inc.," 97-PR0-855, U.S. Department of Energy, Richland Operations Office, Richland, Washington, dated August 20, 1997.

Letter, DOE 1997, "Contract Number DE-AC06-96RL13200 - Declaration of 209-E Unreviewed Safety Question for Deficient Authorization Basis and Institution of Interim Contro1s," 97-WSD-160, 9757083A, U.S. Department of Energy, Richland Operations office, Richland, Washington, dated August 8, 1997.

Letter, E. E. Mayer, LMHC, to A. M. Umek, FDH, "Management of Inactive Miscellaneous Underground Storage Tanks Memorandum," LMHC-9755398, Lockheed Martin Hanford, Corporation, Richland, Washington, dated June 23, 1997.

Letter, J. E. Rasmussen, RL-EAP, to EPA Sherwood and Ecology (Wilson), "Status Report on Inactive Miscellaneous Underground Storage Tanks," 95-PCA-335, dated June 9, 1995.

Letter, A. M. Umek, FDH, to J. E. Kinzer, RL-TWRS, "Management of IMUSTS consistent with Single She11 Tank Program," FDH-9751876aRl, Fluor Daniel Hanford, Inc., Richland, Washington, dated May 15, 1997.

Letter, H. L. Boston, LMHC, to A. M. Umek, FDH, "Inactive Miscellaneous Underground Storage Tanks," 80232764-9-K001, Lockheed Martin Hanford Corporation, Richland, Washington, dated April 16, 1997.

Letter, J. D. Wagoner, RL to Dr. A. L. Trego, WHC, "Recommendation for Declaring an Unreviewed Safety Question (USQ) Regarding Condensed-Phase Organic Nitrate Reactions," 96-WSD-073, U.S. Department of Energy, Richland Operations Office, Richland, Washington, dated May 24, 1996. 
HNF-2503, Rev. 0

Letter, J. L. Lee, WHC TWRS, to A. Sidpara, RL-TOD, Transmitting "Tank Waste Remediation System Management Plan for Hanford 200 Area Inactive Misce]laneous Underground Storage Tanks," 9550687, Westinghouse Hanford Company, Richland, Washington, dated February 6, 1995.

Letter, D. A. Turner, WHC, to R. E. Gerton, RL, "The Department of Energy, Richland Operations Office (DOE-RL), Standby/Shutdown Program Audit December 15-16, 1987," Westinghouse Hanford Company, Rich1and, Washington, dated December 4, 1989.

Letter, R. T. Kimura to R. D. Wojtasek, "Temporary Use of 242-S Evaporator Equipment for U-1/U-2 Crjb Groundwater Treatment Project," 65950-85-350-AX, dated July 29, 1985.

Memorandum, "Interpretation of DOE 5480.21, Unreviewed Safety Questions," DOE NE-70 to Managers, DOE Field Offices, et. al., RL control no. 930020.0F, dated December 29, 1992.

0SD-T-151-00008, Rev. E-2, "Operating Specifications for the 204-AR Waste Unloading Facility," Westinghouse Hanford Company, Richland, Washington, dated January 19, 1995.

OSD-T-151-00014, Rev. A-5, "Operating Specifications for 244-AR Vault Facility," Westinghouse Hanford Company, Richland, Washington, dated February 8, 1996.

OSD-T-151-00015, Rev B-9, "Unclassified Operating Specifications for Miscellaneous Facilities," Westinghouse Hanford Company, Richland, Washington, dated February 8, 1996.

RHO-CD-1410, "242-T Evaporator Facility Shutdown/Standby Plan," Rockwell Hanford Operations, Richland, Washington, dated April 30, 1981.

RHO-RE-SA-116P, "Chemical and Anion Exchange Removal of Uranium From Hanford Groundwater," Rockwell Hanford Operations, Richland, Washington, dated 1986.

SD-HS-SAR-009, Rev. 0, "242-T Evaporator Facility Shutdown/Standby to Condition V Safety Analys is Report," dated February 4, 1983.

SD-WM-SSP-002, "242S Facility Shutdown/Standby Plan," Westinghouse Hanford Company, dated September, 1988.

USQ-TF-96-1000, ReV. 0, "Unreviewed Safety Question; HEPA Fi7ter Change at the 209-E Facility, "Duke Engineering and Services Hanford, Richland, Washington, dated October 29, 1996.

WHC-EP-0775, "Safety Issue Resolution Strategy Plan for Inactive Miscellaneous Underground Storage Tanks," Westinghouse Hanford Company, Richland, Washington, dated September 26, 1994. 
HNF-2503, Rev. 0

WHC-EP-0861, "Status Report for Inactive Miscellaneous Underground Storage Tanks at Hanford Site 200 Areas, "Westinghouse Hanford Company, Richland, Washington, dated October 23, 1995.

WHC-EP-0908, "Strategy for Resolution of the Organic Complexant and Organic Solvent Safety Issues," Westinghouse Hanford Company, Richland, Washington, dated 1996.

WHC-IP-0263-TF, "Tank Farms Building Emergency Plan," Westinghouse Hanford Company, Richland, Washington, dated 1990b.

WHC-IP-0842, "TWRS Administration," Volume IV, Section 5.4, Attachment A, Westinghouse Hanford Company, Richland, Washington, dated September 27, 1996.

WHC-IP-0971, "Tank Waste Remediation System - TWRS - Emergency Preparedness Program Plan," Westinghouse Hanford Company, Richland, Washington, dated November 10, 1994.

WHC-SD-CP-SAR-021, Rev. 0, "Plutonium Finishing Plant Final Safety Analysis Report, "Westinghouse Hanford Company, Richland, Washington, dated March 7, 1995.

WHC-SD-EN-ES-040, Rev 0, "Engineering Study of 50 Miscellaneous Inactive Underground Radioactive Waste Tanks Located at the Hanford Site, Washington," Westinghouse Hanford Company, Richland, Washington, dated May 18, 1994.

WHC-SD-RE-SAP-013, Rev. 6, "Safety Analys is Report for Packaging, Railroad Liquid Waste Tank Cars", Westinghouse Hanford Company, Richland, Washington, dated August 4, 1993.

WHC-SD-TP-SEP-001, Rev. 0, "Safety Evaluation for Packaging for the 222-S Laboratory Cargo Tank," Westinghouse Hanford Company, Richland, Washington, dated July $30,1996$.

WHC-SD-WM-ER-543, Rev. 0, "Assessment of Chemical Vulnerabilities in the Hanford High-Level Waste Tanks, "Westinghouse Hanford Company, Richland, Washington, dated February, 1996.

WHC-SD-WM-FHA-020, Rev. 0, "Tank Farm Fire Hazards Analys is," Westinghouse Hanford Company, Richland, Washington, dated August 29, 1996.

WHC-SD-WM-FHA-022, Rev. 0, "Fire Hazards Analys is for the 242-S Evaporator," Westinghouse Hanford Company, Richland, Washington, dated July 25, 1996.

WHC-SD-WM-FHA-023, Rev. 0, "Fire Hazards Analys is for the 242-T Evaporator," Westinghouse Hanford Company, Richland, Washington, dated July 30, 1996.

WHC-SD-WM-HA-001, "Preliminary Hazards Analys is of the Miscellaneous Underground Storage Tanks," Westinghouse Hanford Company, Rich1and, Washington, dated July 31, 1995. 
HNF-2503, Rev. 0

WHC-SD-WM-HIE-007, "Tank Waste Remediation System FSAR Hazard Identification/Facility Configuration Verification Report, "Westinghouse Hanford Company, Richland, Washington, dated September, 1996.

WHC-SD-WM-SAR-005, Rev 12, "WESF Safety Analysis Report," Westinghouse Hanford, Company, Richland, Washington, dated January 11, 1996.

WHC-SD-WM-SAR-041, Rev 0, "Hanford Central Waste Complex Final Safety Assessment Document," Westinghouse Hanford Company, Richland, Washington, dated Apri1 3, 1991.

WHC-SD-WM-SSP-005, "Grout Treatment Facility Standby P1an," Westinghouse Hanford Company, Richland, Washington, dated September 21, 1994.

WHC-SD-WM-TI-614, Rev. 1, "Waste Status and Transaction Record Summary for the SW Quadrant of the Hanford 200 Area, "Westinghouse Hanford Company, Rich1and, Washington, dated January 29, 1996.

WHC-SD-WM-TI-615, Rev. 1, "Waste Status and Transaction Record Summary for the NE Quadrant of the Hanford 200 Area," Westinghouse Hanford Company, Rich1and, Washington, dated January 29, 1996.

WHC-SD-WM-TI-689, Rev. 1, "Waste Status and Transaction Record Summary for the SE Quadrant of the Hanford 200 Area, "Westinghouse Hanford Company, Rich1 and, Washington, dated January 29, 1996.

WHC-SD-WM-TI-669, Rev. 1, "Waste Status and Transaction Record Summary for the NW Quadrant of the Hanford 200 Area," Westinghouse Hanford Company, Richland, Washington, dated January 26, 1996.

WHC-SD-WM-TI-759, Rev. 0., "Hazards Evaluations for the TWRS Final Safety Analysis Report," Westinghouse Hanford Company, Richland, Washington, dated September 30, 1996.

WHC-SD-WM-TI-789, Rev. 0, "Preliminary Hazards Analysis - 209-E Building Critical Mass Laboratory," Fluor Daniel Hanford, Inc., Richland, Washington, dated November 5, 1996.

WHC-EP-0560/UC-721, "Misce11aneous Underground Radioactive Storage Waste Tanks," Westinghouse Hanford Company, Richland, Washington, dated December, 1992.

WHC-SD-DD-TI-057, "Summary of Radioactive Underground Tanks Managed by Hanford Restoration Operations," Westinghouse Hanford Company, Richland, Wașhington, dated October, 1991.

WHC-SD-SQA-CSA-20326, "CSER 90-008: Reclassification of the Critical Mass Laboratory, Building 209-E As a Limited Control Facility," Rev. 0, Westinghouse Hanford Company, Richland, Washington, dated 1990. 
HNF-2503, Rev. 0

\section{Procedures:}

ARP-T-701-0001 through ARP-T-701-0007, "242-S Evaporator Alarm Response." ARP-T-801-001, Rev. A-3, "Respond To Alarms at 244-TX and 242-T Evaporator." CPS-T-149-00010, Rev. H-0, "Waste Storage in Double-Shel1 Tanks and Associated Equipment."

SW-040-043, "Inspect the CWC and Sodium Storage Building and Associated Equipment."

TF-FT-359-007, Rev. A-0, "Perform Vault Exhauster 244-CR Exhaust Stack Radiation Monitor Functional Test."

TF-OR-EF-C-D, Rev, C-18, "C, CR Tank Farms and 244-A DCRT Lift Station Daily Rounds."

TF-0R-EF-204AR, Rev. C-2, "204AR Rait Car Waste Unloading Building DaiTy Rounds."

TF-OR-ER-244AR, Rev. C-4, "244 AR Vault Rounds."

T0-040-700, Rev. D-1, "Perform Surveillance at 244-AR Vault."

T0-040-710, Rev. C-1, "Perform Routine Surveillance of 204-AR Building and Tank Cars at TC-4."

T0-060-205, Rev. D-8, "Perform Ventilation Control and Surveillance at 244-CR Vault."

T0-290-052, Rev. C-0, "204-AR Unloading Facility Transfers."

T0-290-120, Rev. D-0, "Perform 204-AR Tank Trailer Operations."

T0-290-130, Rev. F-0, "Transfer From 241-A Rail Car to Tank Farm."

T0-720-020, Rev C-4, "Operate 242-S Heating/Ventilation System."

T0-720-140, Rev C-2, "Operate the 242-S Evaporator Compressed Air System."

T0-780-020, Rev C-1, "242-S Shutdown Surveillance and Routines."

T0-820-040, Rev. D-2, "Operate 242-T Process Cell Ventilation." 
HNF-2503, Rev. 0

Appendix A: Facilities, Tanks and Components Matrix 
HNF-2503, Rev. 0

\section{Appendix A}

\section{TABLE OF CONTENTS}

A-1 Historical List of IMUSTs Sorted by Tank Number A-1

A-2 Historical List of IMUSTs Sorted by Current Owner A-3

A-3 Legends and Footnotes for IMUST Tables A-5

A-4 IMUST Additions to the List Since 8/97 Letter to Ecology A-6

A-5 Tanks to be Removed from IMUST List A-6

A-6 Tanks to be Added to the IMUST List A-6

A-7 Observations on the Hanlon Report (Monthly Waste Summary Report) A-7

A-8 Total IMUSTs in the 200 Area A-7

A-9 Current List of TWRS IMUSTS A-8

A-10 Current IMUST List by Tank Number A-10

A-11. Current IMUST List by Tank Owner. A-12

A-12 Facilities, Tanks, and Components With Potential AB Upgrade Needs A-14

A-13 Chemical Tanks Owned by TWRS A-18

A-14 Chemical Tanks in the 200 Area Not Owned by TWRS A-19

A-15 TWRS NITS (TWRS Non-IMUSTS) A-23

A-16 Non-TWRS NITS (Non-TWRS Non-IMUSTs) A-24

A-17 FTCs Having No AB Concern (NABC) A-25

A-18 Facilities Adjacent to TWRS A-26 
APPENDIX A: FACILITIES, TANKS, AND COMPONENTS MATRIX

\begin{tabular}{|c|c|c|c|c|c|c|c|c|c|c|c|c|}
\hline \begin{tabular}{|l|l|}
$A \cdot 1$ & HISTORICAL LIST \\
\end{tabular} & FIMUSTS SORTED & TANK & NUMBER: & & & & & & & & & \\
\hline & & & & & & & & & & & & \\
\hline IMUST & Älternate & Ac- & 1995 & Status & DOE(3) & 1997 & Current & In & In & $\ln$ & Descriptive & Additional \\
\hline TANK & Names & tive? & Ltr(1) & $\operatorname{Rep}(2)$ & WIDS & Ltr(4) & Owner & 040 & $\mathrm{BIO}$ & FSAR & Comments & Comments \\
\hline & & & & & & & & & & & & \\
\hline $1,200-W-7$ & 243-S-TK-1,246L & & XTWRS & XTWRS & XTWRES & XTWRS & TWRS & New & $\gamma$ & $Y$ & Decon Catch Tank & \\
\hline $2213-W-1$ & $213-W-T K-1$ & & $x$ Undet & XTWRS & XTWRS & & TWRS & New & $\bar{Y}$ & $\mathrm{~N}$ & Water & \\
\hline $3216-B C-201$ & & & & $x \in R^{\star}$ & & & ER & & NA & NA & & \\
\hline $4216-B Y-201$ & 241-BY, 216-BY-47 & & XTWRS & XTWRS & XTWRS & XTWRS & TVRS S & New & $Y$ & $Y$ & Flush Tank, Settling Tank & Assume $=216-B Y$ in (1) \\
\hline $5216-T Y-201$ & & & XTWRS & XTWRS & XTWRS & XTWRS ${ }^{*}$ & TWRS S & New & $\bar{Y}$ & $\bar{Y}$ & Supernatant Dispos Flush TK & \\
\hline $6231-W-151-001$ & & & XER & XTWRS. & XTWRS & XTWRS & TWRS & $\bar{Y}$ & $Y$ & $\bar{Y}$ & $\ln 231-W-151$ vault & (1) TWRS ; WIDS=vauft \\
\hline $7231-W-151-002$ & & & XTWRS & XTWRS & XTWRS & XTWRS" & TWRS & $Y$ & $Y$ & $Y$ & In $231-W-151$ vault & WIDS only shows vault \\
\hline $8: 240-5-302$ & & & $X E R$ & X TWRS* & XTWRS & XTWRS* & TWRS & $\bar{Y}$ & $\bar{Y}$ & $\bar{Y}$ & Leaker, TWRS surveills & \\
\hline $9241-A-302 A$ & & $\bar{Y}$ & & & XTWRS. & & TWRS@ & & $Y$ & $Y$ & Catch Tank & \\
\hline $10: 241-\mathrm{A}-302 \mathrm{~B}$ & & & $\times T W R S$ & XTWRS & XTWRS & XTWRS & TWRS & $Y$ & $Y$ & $Y$ & & \\
\hline $11 / 241-A-350$ & & $\bar{Y}$ & & & XTWRS - & & TWRS@ & New & $\mathrm{Y}$ & $\bar{Y}$ & Catch Tank & \\
\hline $12241-\mathrm{A}-417$ & & $Y$ & & & XTWRS. & & TWRS@ & New & $\bar{Y}$ & $\bar{Y}$ & Catch Tank & \\
\hline $13241-A X-151$ & & & XTWRS & XTWRS & XTWRS & XTWRS & TWRS & New & $\bar{Y}$ & $Y$ & Diverter Station with 5 tanks & \\
\hline \begin{tabular}{|l|l|}
14 & $241-A X-152 C T$ \\
\end{tabular} & & $\bar{Y}$ & & & XTWRS - & & TWRS@ & New & $\bar{Y}$ & $\bar{Y}$ & Catch Tank & \\
\hline $15 \mid 241-A Z-151 C T$ & & $\bar{Y}$ & & & XTWRS - & & TWRS@ & New & $Y$ & $\bar{Y}$ & Catch Tank & \\
\hline $16 / 241-\mathrm{B}-301$ & $241-\mathrm{B} \cdot 301 \mathrm{~B}$ & & XTWRS & XTWRS & XTWRS & XTWRS & TWRS & $\bar{Y}$ & $\bar{Y}$ & $Y$ & & \\
\hline $17241-B \cdot 302 B$ & & & XTWRS & XTWRS & XTWRS & XTWRS ${ }^{*}$ & TWRS & $Y$ & $\bar{Y}$ & $\bar{Y}$ & & \\
\hline$1 8 \longdiv { 2 4 1 - 3 - 3 6 1 }$ & & & $X E R$ & XER & + & & ER & $Y$ & NA & NA & & \\
\hline $19241-\mathrm{BX}-302 \mathrm{~A}$ & & & XTWRS & XTWRS & XTWRS & XTWRRS & TWRS & $Y$ & $Y$ & $\bar{Y}$ & & \\
\hline $20 \mid 241-B X-302 B$ & & & XTWRS & XTWRS & XTWRS & XTWRS* & TWRS & $\bar{Y}$ & $Y$ & $\bar{Y}$ & & \\
\hline $21241-\mathrm{BX}-302 \mathrm{C}$ & & & XTWRS & XTWRS & XTWRS & $x$ TWRS & TWRS & $\bar{Y}$ & $\bar{Y}$ & $\bar{Y}$ & & \\
\hline $22 \mid 241 \cdot C \cdot 301$ & $241-\mathrm{C}-301 \mathrm{C}$ & & XTWRS & XTWRS & XTWRS@ & XTWRS & TWRS & $Y$ & $Y$ & $Y$ & & \\
\hline $23 \mid 241-C \times-70$ & & & $x$ ER & XER & & & $E R$ & $\bar{Y}$ & NA & NA & & \\
\hline $24 \mid 241-C \times-71$ & & & $X E R$ & XER & & & $E R$ & $Y$ & NA & NA & & \\
\hline $25241-\mathrm{CX}-72$ & & & $x E R$ & $X E R$ & & & ER & $\bar{Y}$ & NA & NA & & \\
\hline \begin{tabular}{l|l}
$26 \mid 241-E R-311$ \\
\end{tabular} & & $\bar{Y}$ & & & XTWRS. & & TWRS@ & & $\bar{Y}$ & $\bar{Y}$ & Catch Tank & \\
\hline $27241-E R-311 \mathrm{~A}$ & old 241-ER-311 & & XB-Plant & XTWRS & XTWRS & XTWRS" & TWRS & New & $Y$ & $Y$ & & (1) TWRS* \\
\hline $28 \mid 241-E W-151$ & & $\bar{Y}$ & & & XTWRS. & & TWRS@ & & $\bar{Y}$ & $Y$ & Catch Tank & \\
\hline $29 \mid 241-S-302 A$ & & & XTWRS & $x$ TWRS & XTWRS & XTWRS & TWRS & $Y$ & $Y$ & $\bar{Y}$ & Grout; others; leaker & \\
\hline $301241-5-302 \mathrm{~B}$ & & & XTWRS & XTWRS & XTWRS & XTWRS & TWRS & $\bar{Y}$ & $\bar{Y}$ & $\bar{Y}$ & Empty & \\
\hline $31241-5-304$ & & $\bar{Y}$ & & & XTWRS * & & TWRS@. & & $\bar{Y}$ & $Y$ & Catch Tank & \\
\hline $32 \quad 241-S X-302$ & SX-304 & & XTWRS & XTWRS & XTWRS & XTWRS & TWRS & $\bar{Y}$ & $\bar{Y}$ & $\bar{Y}$ & & \\
\hline $33241-T-301 B$ & $241-T-301$ & & XTWRS & XTWRS & XTWRS & XTWRS & THRS & $Y$ & $Y$ & $\bar{Y}$ & & \\
\hline $34241-T-302$ & & & & & XTWRS. & & TWRS & & $\mathbf{N}$ & $N$ & Catch Tank & Does not exist \\
\hline \begin{tabular}{|l|l|}
35 & $241-T-361$ \\
\end{tabular} & & & XER & $x E R$ & & & ER & $\bar{Y}$ & NA & $\mathrm{NA}$ & & \\
\hline \begin{tabular}{l|l|}
36 & $241-T X-302 A$ \\
\end{tabular} & & & XTWRS & $x$ TWRS & XTWRS & XTWRS & TWRS & $\bar{Y}$ & $Y$ & $\bar{Y}$ & & \\
\hline $37241-7 \times-302 \mathrm{~B}$ catch & & & XTWRS & $\times$ TWRS & XTWRS & $x T W R S^{*}$ & TWRS & $Y$ & $\mathrm{~N}$ & $\bar{Y}$ & & \\
\hline $38241-T X-302 B(R)$ & & & XTWRS & XTWRS & XTWRS & XTWRS* & TWRS & $Y$ & $\bar{Y}$ & $Y$ & Unknown & Second TX-302B in (1) \\
\hline
\end{tabular}


APPENDIX A: FACILITIES, TANKS, AND COMPONENTS MATRIX

\begin{tabular}{|c|c|c|c|c|c|c|c|c|c|c|c|c|c|}
\hline \multirow[t]{2}{*}{$A-2$} & \multicolumn{5}{|c|}{ HISTORICAL LIST OFIMUSTS SORTED BY CURRENT OWNER: } & & & & & & & & \\
\hline & & & & & & & & & & & & & \\
\hline & IMUST & Alternate & AC- & 1995 & Status & DOE(3) & 1997 & Current & In & $\ln$ & In & Descriptive & Additional \\
\hline & TANK & Names & tive? & $\operatorname{Ltr}(1)$ & $\operatorname{Rep}(2)$ & WIDS & $\operatorname{Ltr}(4)$ & Owner & 040 & $\mathbf{8 1 0}$ & FSAR & Comments & Comments \\
\hline & & & & & & & & & & & & & \\
\hline & $216-B C-201$ & & & & $x \in R^{*}$ & & & $E R$ & & NA & NA & & \\
\hline & $241-\mathrm{B}-361$ & & & $x E R$ & XER & & & ER & $Y$ & NA & NA & & \\
\hline & $241-C X-70$ & & & $x E R$ & XER & & & ER & $\bar{Y}$ & $\mathrm{NA}$ & NA: & & \\
\hline & $241-\mathrm{CX}-71$ & & & XER & XER & & & ER & $Y$ & NA & NA & & \\
\hline & $241-C \times-72$ & & & XER & XER & & & ER & $Y$ & NA & NA & & \\
\hline & $241-T-364$ & & & $X E R$ & XER & & & ER & $Y$ & NA & NA & & \\
\hline 7 & 241-U-361 & & & $X E R$ & $X E R$ & & & ER & $Y$ & NA & NA & & \\
\hline 8 & 241-WR-001 & & & $x E R$ & $X E R$ & & & ER & $\bar{Y}$ & NA & NA & & \\
\hline 9 & 241.WR-002 & & & $x \in R$ & XER & & & $E R$ & $\bar{Y}$ & NA & $\mathrm{NA}$ & & \\
\hline 10 & 241-WR-003 & & & XER & XER & & & ER & $Y$ & NA & NA & & \\
\hline 11 & $241-\mathrm{WR}-004$ & & & XER & $x E R$ & & & ER & $\bar{Y}$ & NA & NA & & . \\
\hline 12 & $241-W R-005$ & & & XER & XER & & & ER & $\bar{Y}$ & NA & NA & & \\
\hline 13 & 241-WR-006 & & & XER & XER & & & ER & $\bar{Y}$ & NA & NA & & \\
\hline 14 & 241-WR-007 & & & XER & $x E R$ & & & ER & $Y$ & $\overline{N A}$ & NA & & \\
\hline 15 & 241-WR.008 & & & $X E R$ & $X E R$ & & & ER & $\bar{Y}$ & NA & $N A$ & & \\
\hline 16 & 241-WR-009 & & & $X E R$ & XER & & & ER & $Y$ & NA & NA & & \\
\hline 17 & $276-s-14 t$ & $276-S-306 A$ & & XER & XER & & & ER & & NA & NA & & \\
\hline 18 & $276-5-142$ & $276-S-306 B$ & & XER & XER & & & ER & & NA & NA & & \\
\hline 19 & 244-UR-001 & & & XER & $x E R^{*}$ & & & ERS & $\bar{Y}$ & NA & NA & & (1) TWRS ${ }^{*}$ \\
\hline 20 & 244-UR-002 & & & XER & $X E R^{n}$ & & & ERS & $Y$ & NA & $\mathrm{NA}$ & & (1) TWRS \\
\hline 21 & 244-UR-003 & & & $X E R$ & $x E R^{n}$ & & & ERS & $\bar{Y}$ & NA & NA & & (1) TMRS \\
\hline 22 & 244-UR-004 & & & $x E R$ & $X E R^{\prime \prime}$ & & & ERS & $Y$ & NA & NA & Empty & (1) TWRS \\
\hline 23 & $241-Z-361$ & & & XPFP & XPFP & & & TPD/BWHC & $\bar{Y}$ & NA & NA & Settled Solids Moderate Pu & Transition Projects \\
\hline 24 & $270-E-1$ & 270-E_CNT, 216-ER-1 & & XTWRS & XTWRS & & & TPD/BWHC & $\bar{Y}$ & NA & NA & Condensate Neutrallz Tank & EM-60, Transition Projects \\
\hline 25 & $200-W-7$ & 243-S-TK-1,246L & & XTWRS & XTWRS & XTWRS & XTWRS & TWRS & New & $\bar{Y}$ & $\bar{Y}$ & Decon Catch Tank & \\
\hline 26 & $213-W-1$ & $213-$ W-TK-1 & & $x$ Undet & XTWRS & XTWRS & & TWRS & New & $Y$ & $\mathrm{~N}$ & Water & \\
\hline 27 & $231-W-151-001$ & & & $X E R$ & $x$ TWRS & XTWRS & XTWRS* & TWRS & $Y$ & $Y$ & $\bar{Y}$ & In 231-W-151 vault & (1) TWRS ${ }^{*}$; MDS=vault \\
\hline 28 & $231-W-151-002$ & & & XTWRS & XTWRS & XTWRS & XTWRS" & ITWRS & $Y$ & $Y$ & $Y$ & $\ln 231-W-151$ vault & WDS only shows vault \\
\hline 29 & $240-5-302$ & & & $X E R$ & XTWRS* & XTWRS & XTWRS & TWRS & $\bar{Y}$ & $\bar{Y}$ & $\bar{Y}$ & Leaker, TWRS surveills & \\
\hline 30 & $241-A-302 B$ & & & XTWRS & XTWRS & xTMRS & XTWRS & TWRS & $\bar{Y}$ & $\bar{Y}$ & $\bar{Y}$ & & \\
\hline 31 & $241-A \times-151$ & & & XTVRS & XTWRS & XTWRS & XTWRS & TWRS & New & $Y$ & $Y$ & Diverter Station with 5 tanks & \\
\hline 32 & $241-B-301$ & $241-B-3018$ & & $x$ TWRS & XTWRS & $x$ TWRS & TTWRS & TWRS & $\bar{Y}$ & $\bar{Y}$ & $\bar{Y}$ & & \\
\hline 33 & $241-\mathrm{B}-302 \mathrm{~B}$ & & & XTWRS & XTWRS & XTWRS & XTWRS* & TWRS & $Y$ & $\bar{Y}$ & $\bar{Y}$ & & \\
\hline 34 & $241-B X-302 A$ & & & XTWRS & XTWRS & XTWRS & XTWRS & TWRS & $Y$ & $\bar{Y}$ & $Y$ & & \\
\hline 35 & $241-B X-302 B$ & & & XTWRS & XTWRS & XTWRS & XTWRS* & TWRS & $\bar{Y}$ & $Y$ & $\bar{Y}$ & & \\
\hline 36 & $241-\mathrm{BX}-302 \mathrm{C}$ & & & XTWRS & XTWRS & XTWRS & XTWRS & TWRS & $\bar{Y}$ & $Y$ & $Y$ & & \\
\hline 37 & $241-C-301$ & $241-C-301 \mathrm{C}$ & & XTWRS & XTWRS & XTMRSQ & XTWRS & TWRS & $Y$ & $\bar{Y}$ & $Y$ & & \\
\hline 38 & 241-ER-311 & old 241-ER-3 & & $X E$ & XTWRS & XTWRS & XTWRS* & TWRS & New & $\bar{Y}$ & $\bar{Y}$ & & \\
\hline
\end{tabular}


APPENDIX A: FACILITIES, TANKS, AND COMPONENTS MATRIX

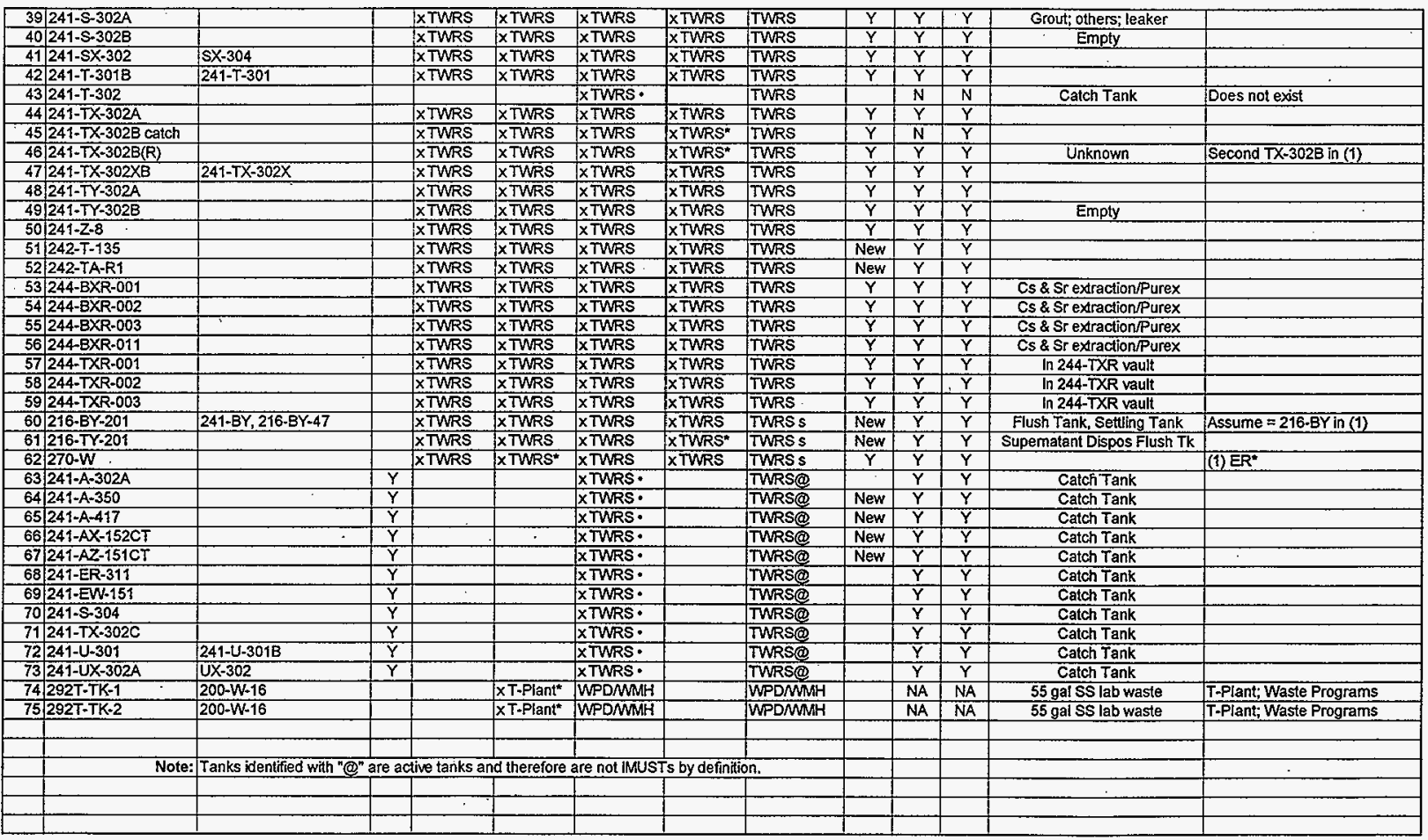


APPENDIX A: FACILITIES, TANKS, AND COMPONENTS MATRIX

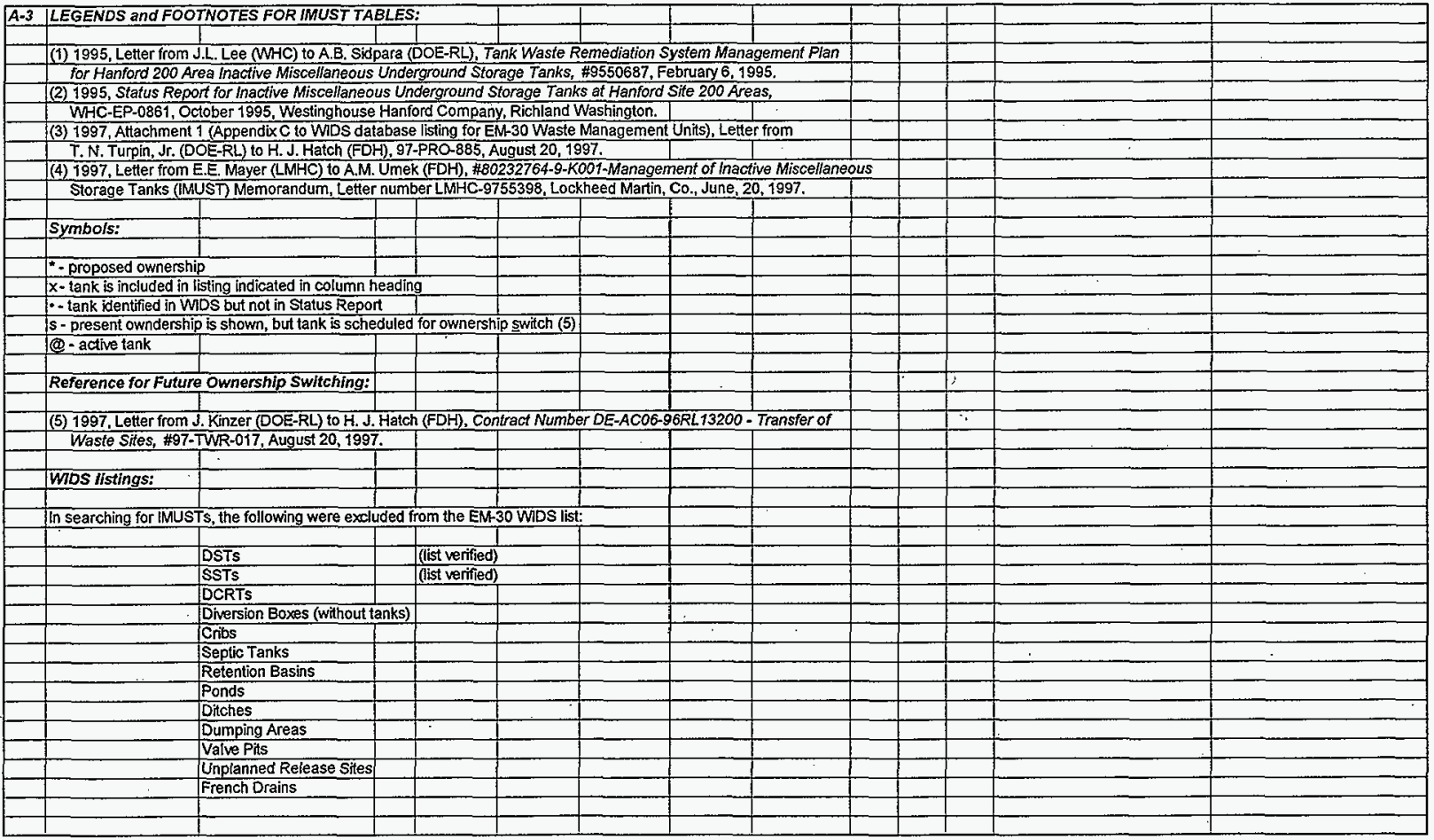




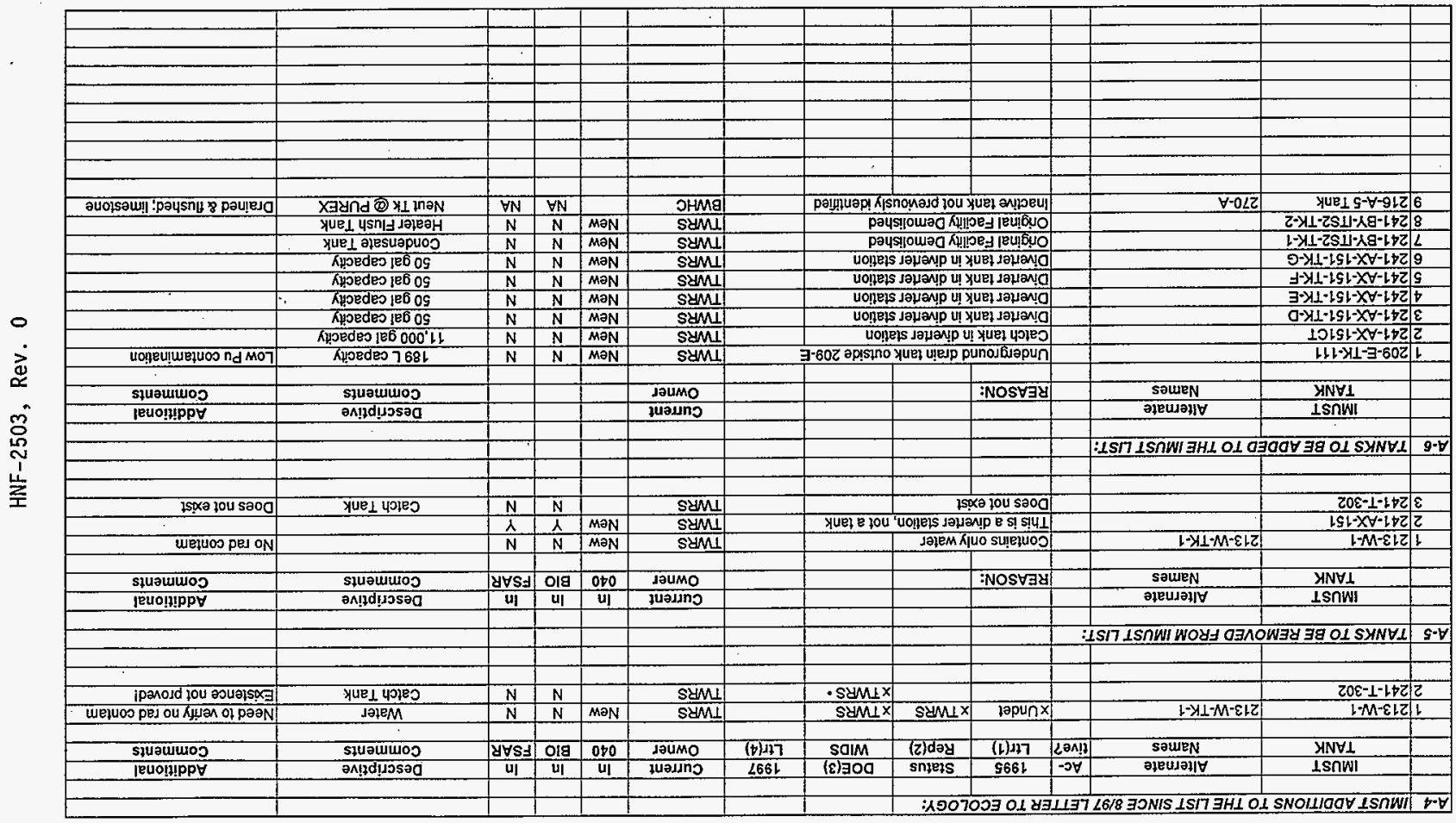

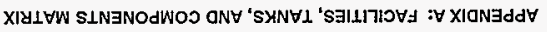

$<$ 
APPENDIX A: FACILITIES, TANKS, AND COMPONENTS MATRIX

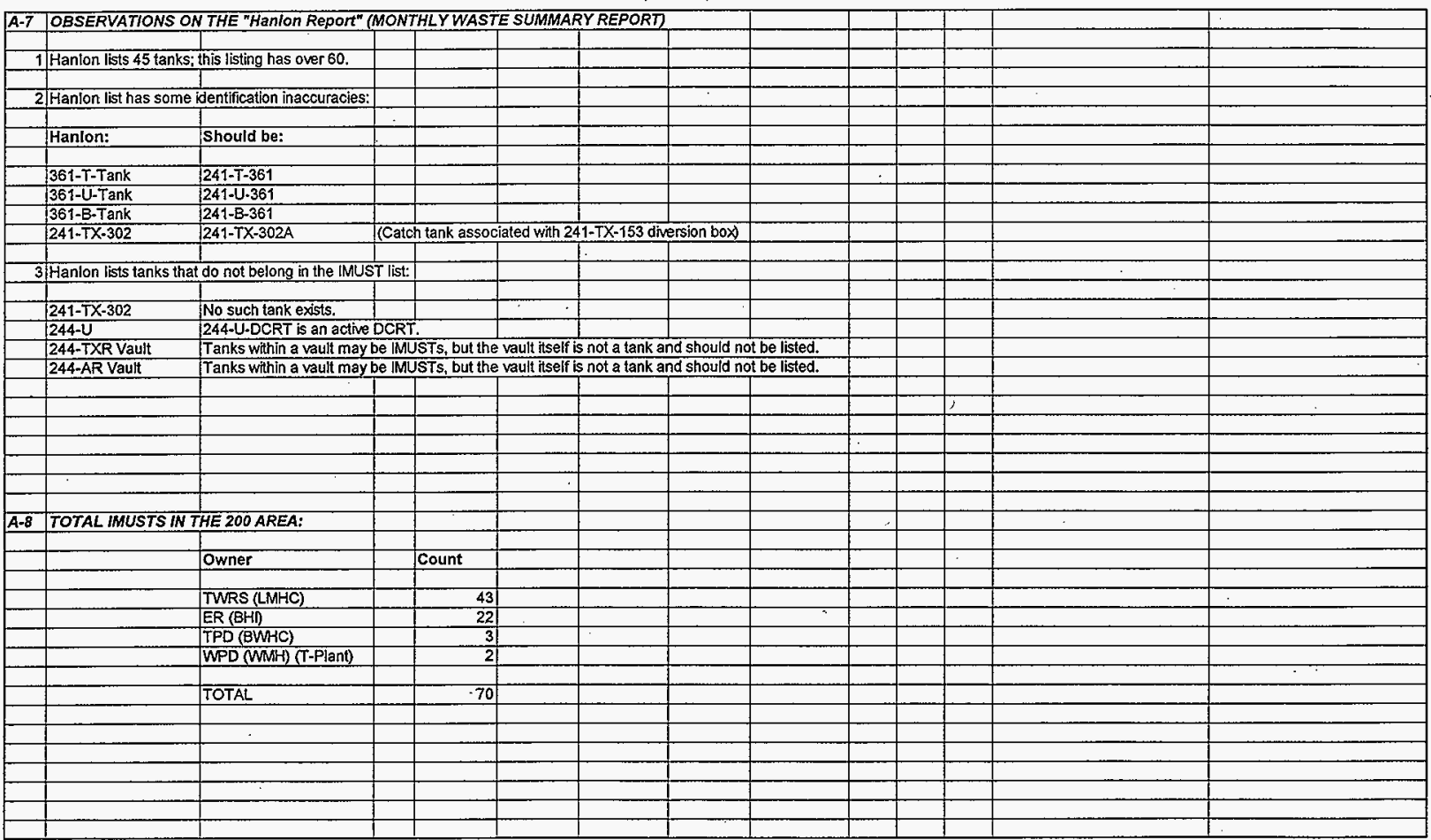


APFENDIX A: FACILITIES, TANKS, AND COMPONENTS MATRIX

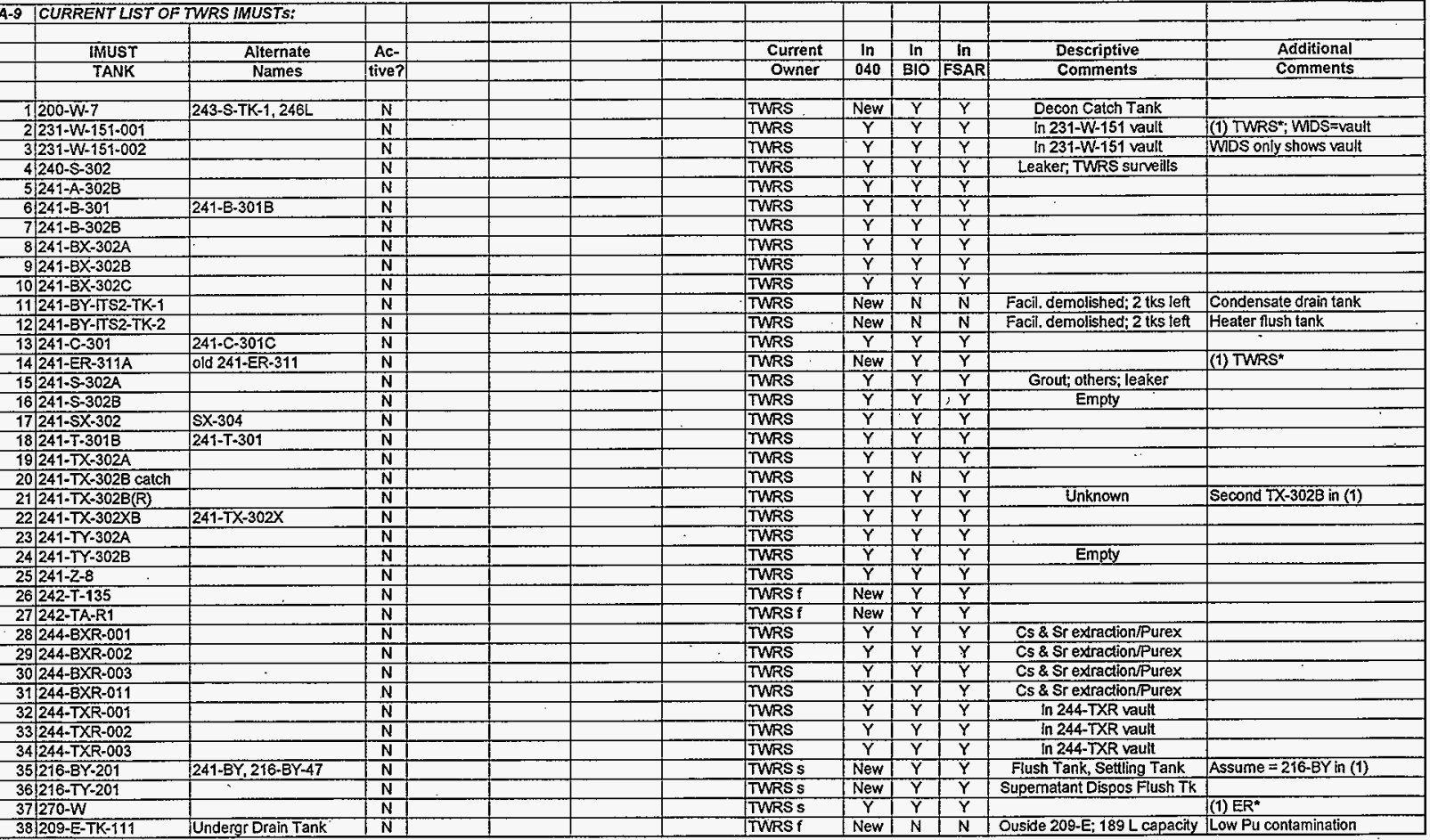




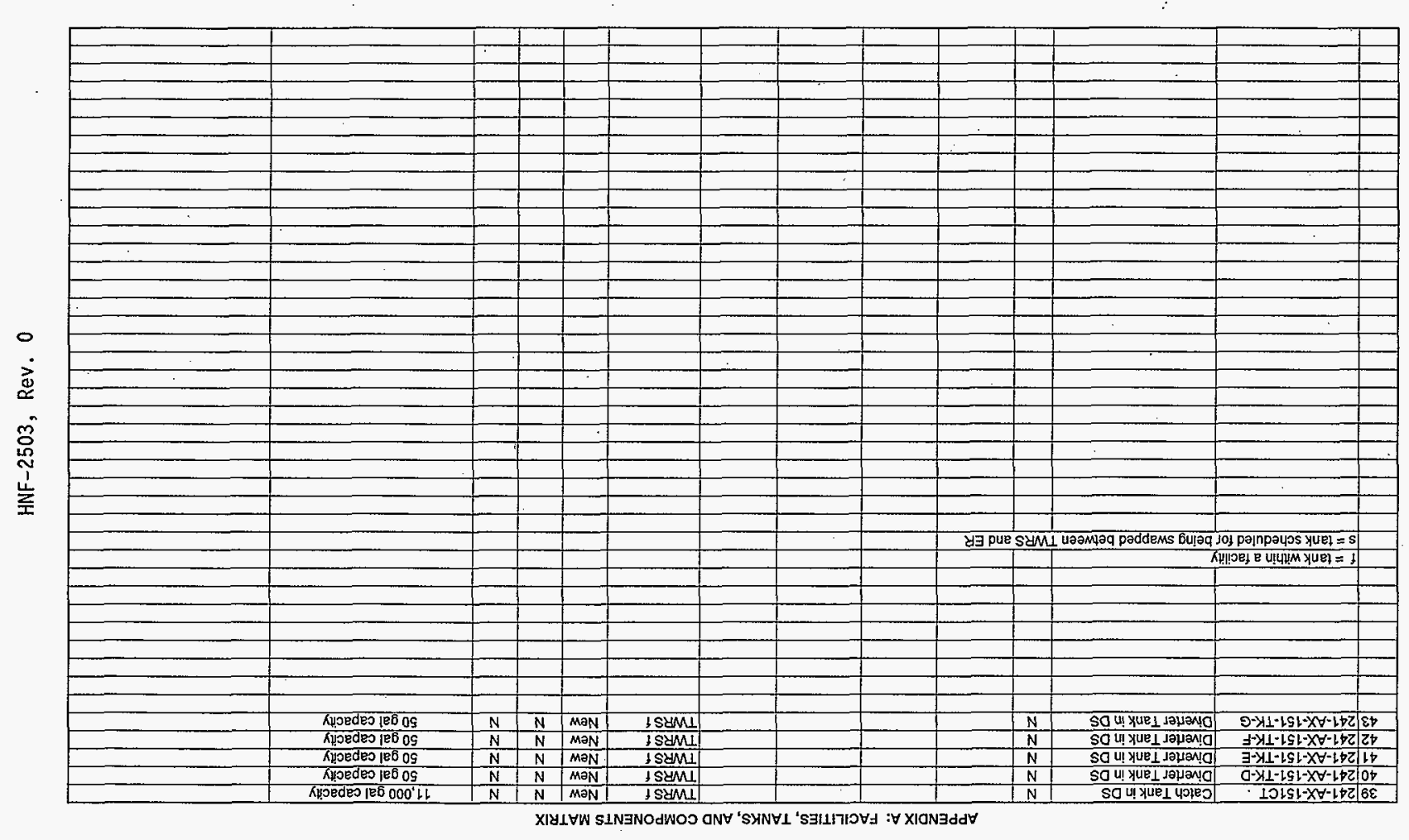

0
1
$<$
0
$\mathscr{8}$
2 
APPENDIX A: FACILITIES, TANKS, AND COMPONENTS MATRIX

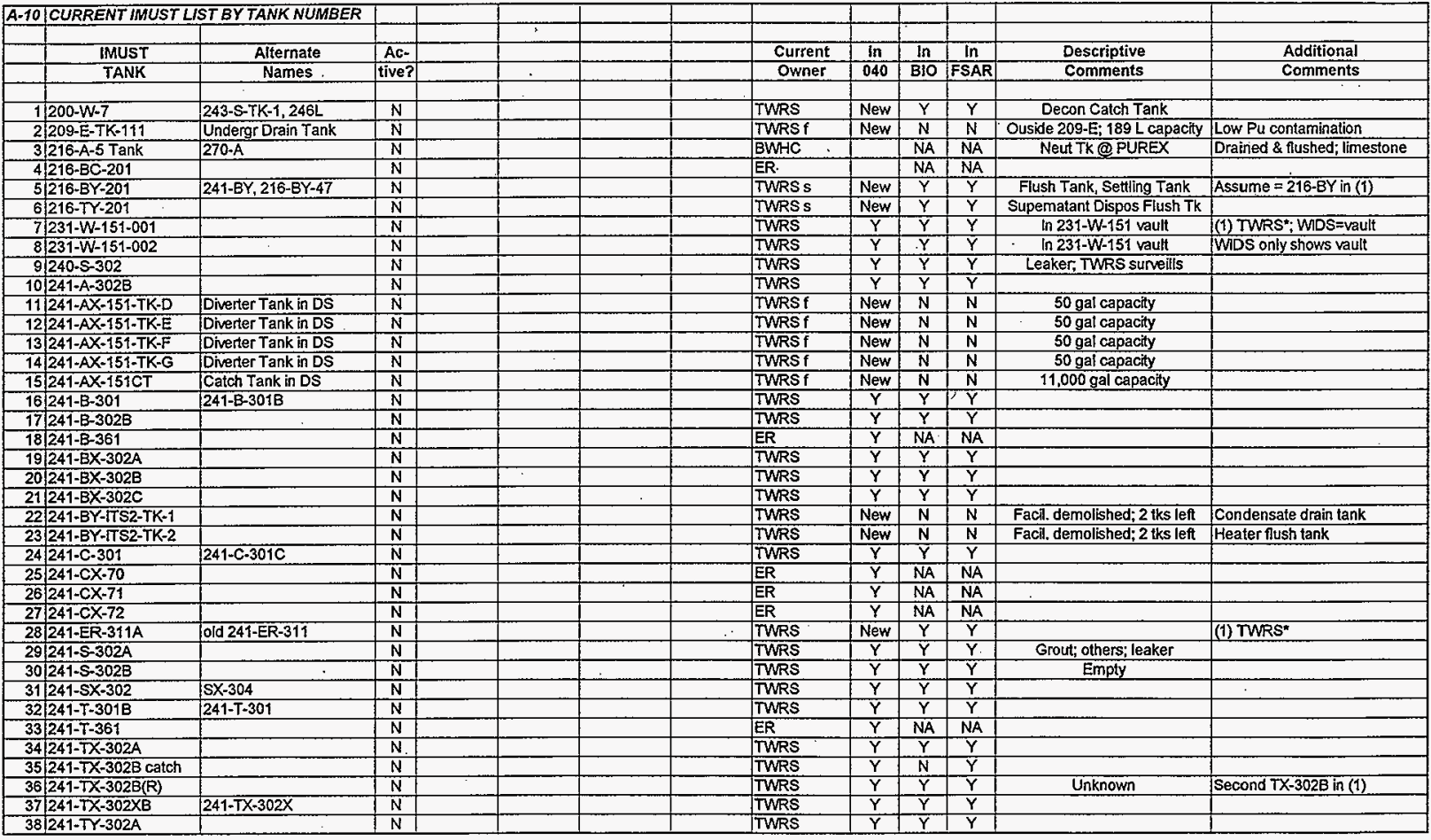


APPENDIX A: FACILITIES, TANKS, AND COMPONENTS MATRIX

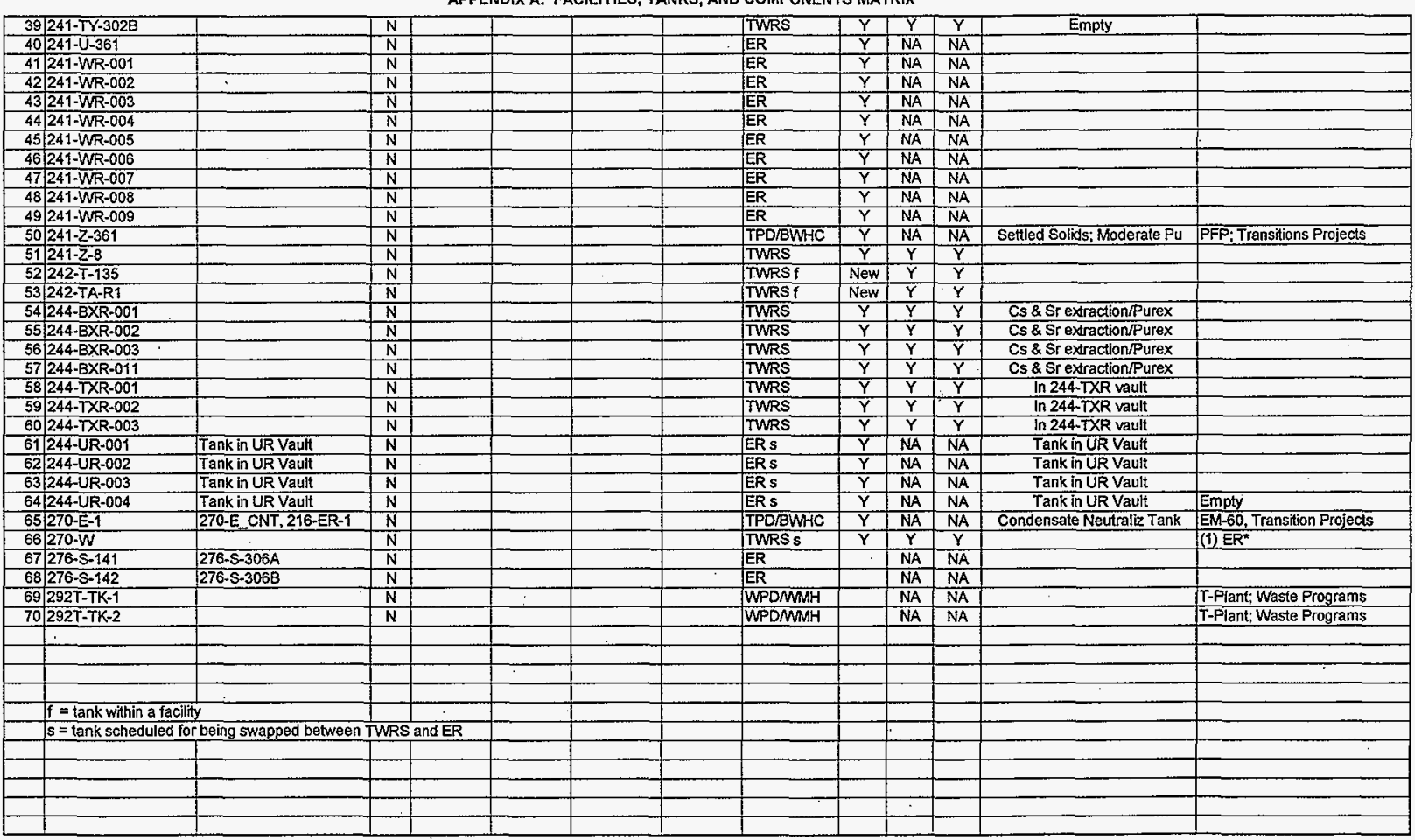


AFPENOIX A: FACILITIES, TANKS, AND COMPONENTS MATRIX

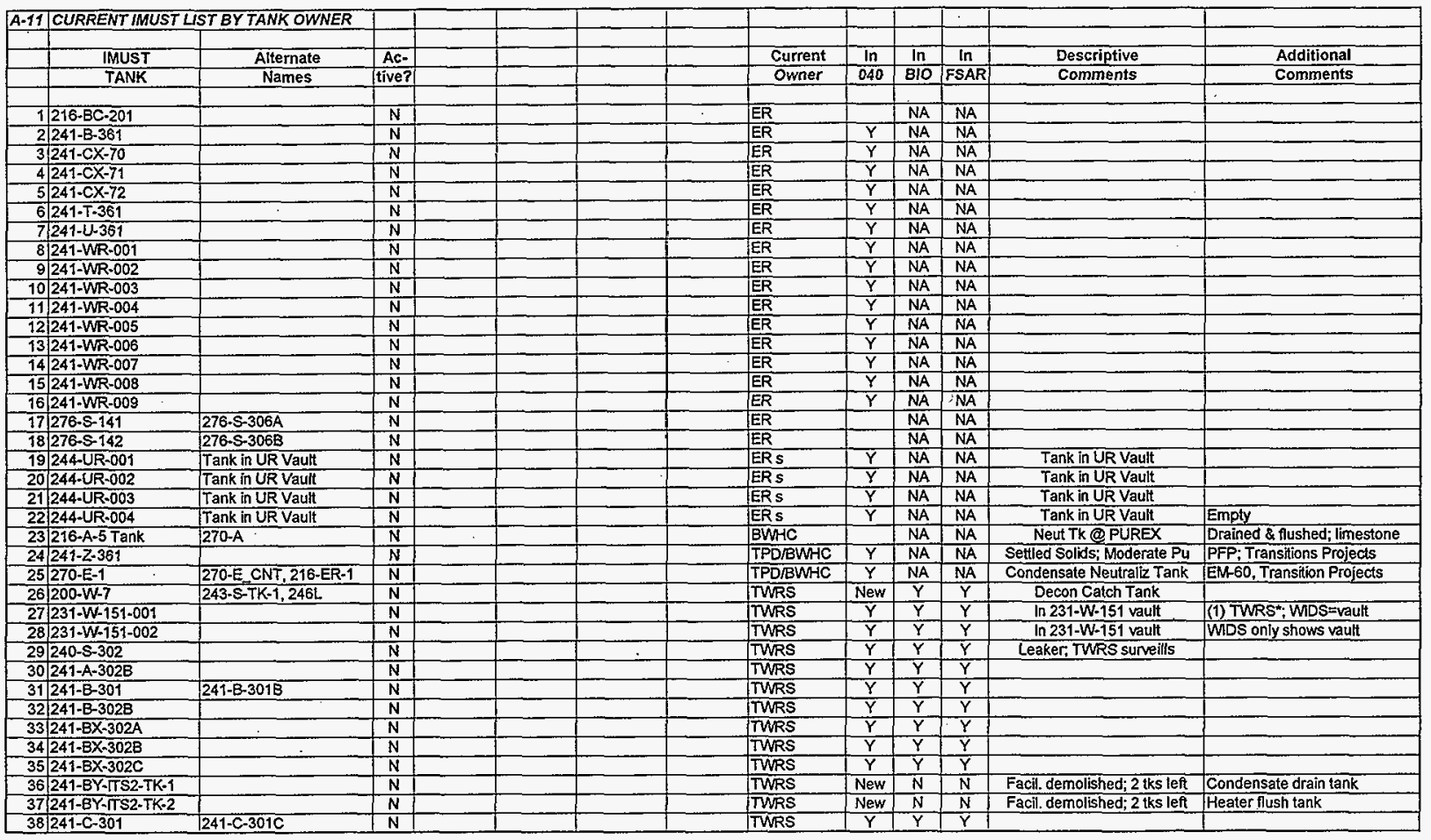


APPENDIX A: FACILITIES, TANKS, AND COMPONENTS MATRIX

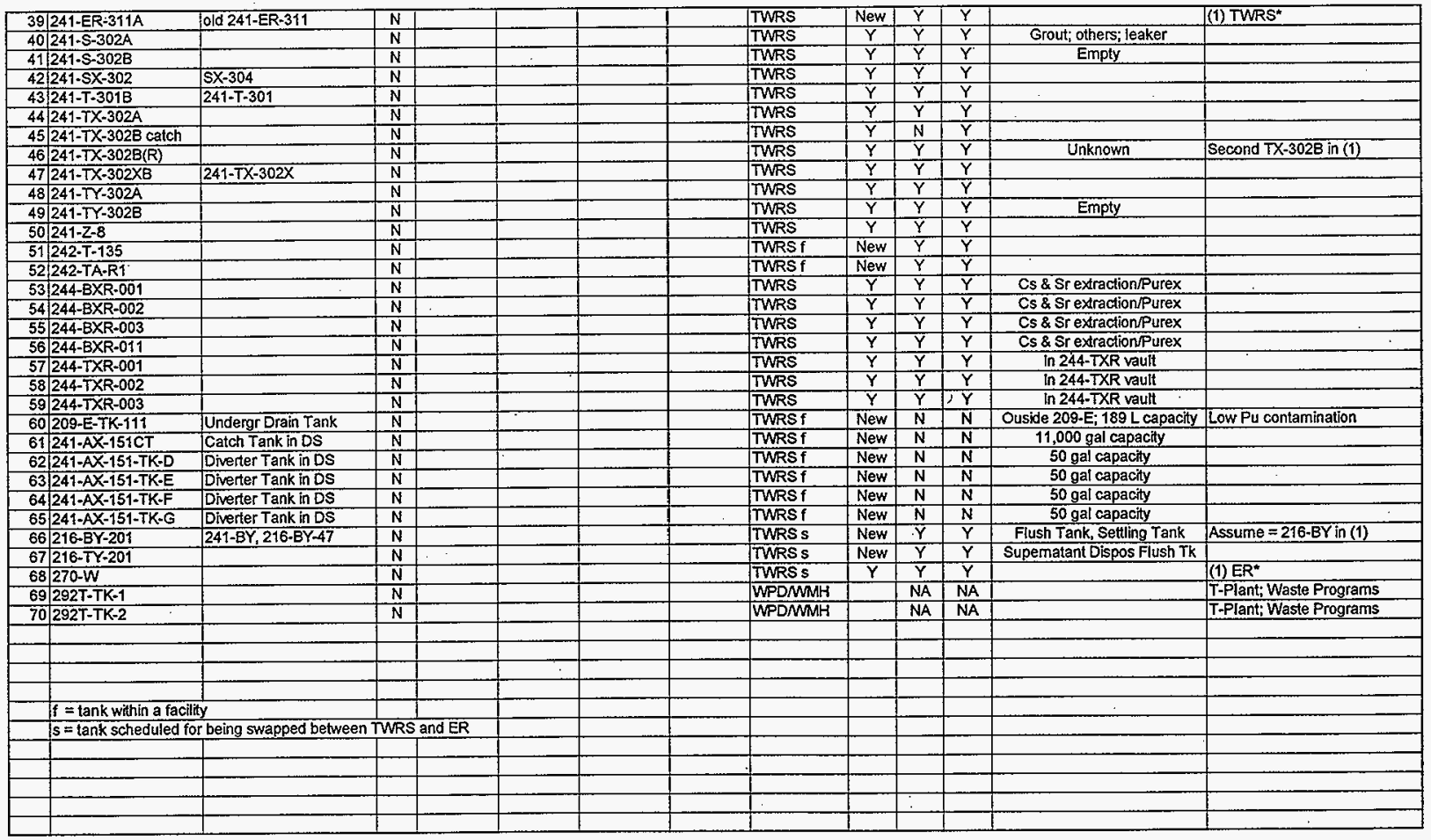


APPENDIX A: FACILITIES, TANKS, AND COMPONENTS MATRIX

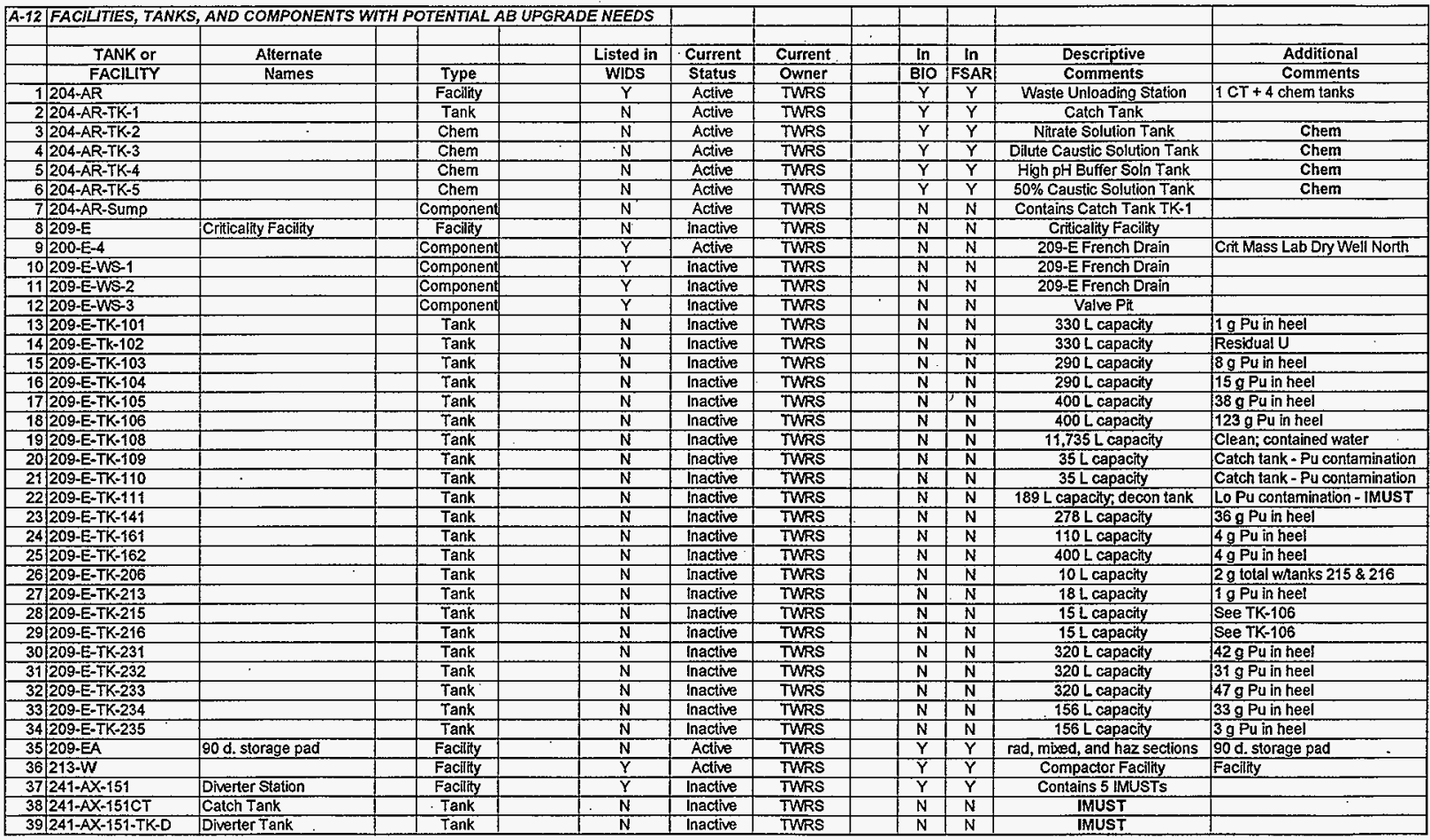


APPENDIX A: FACILITIES, TANKS, AND COMPONENTS MATRIX

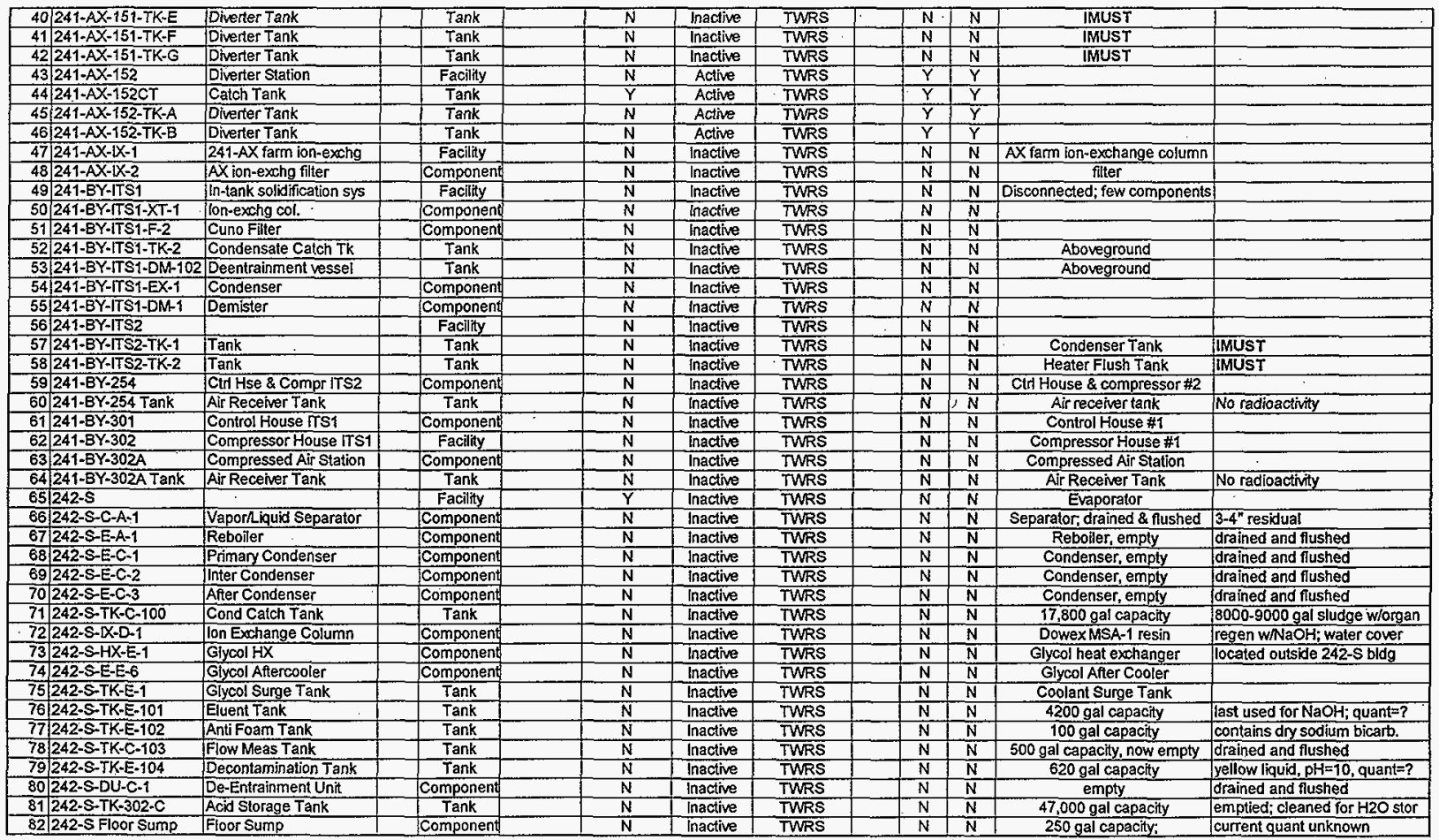


APPENDIX A: FACILITIES, TANKS, AND COMPONENTS MATRIX

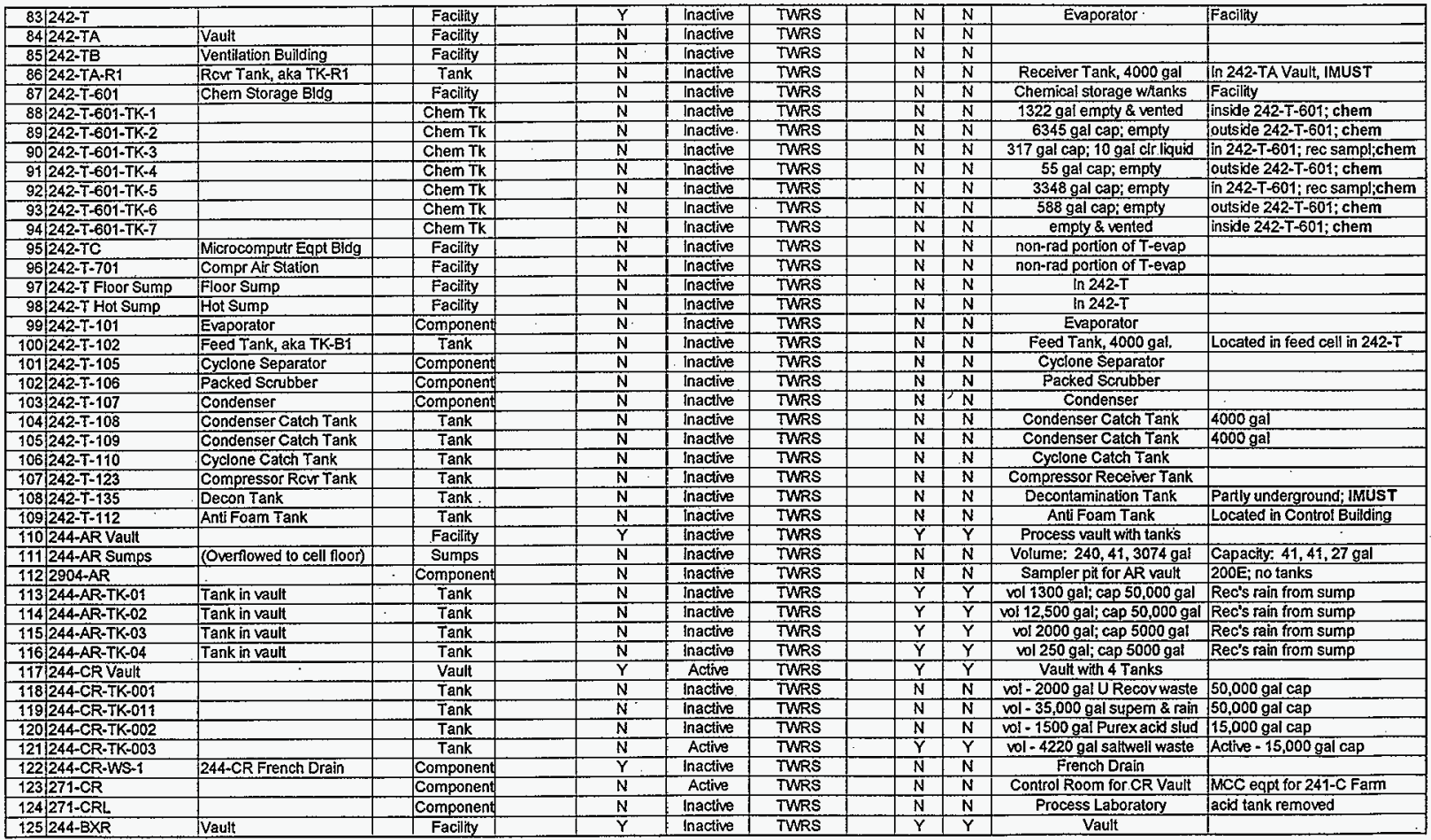


APPENDIX A: FACILITIES; TANKS, AND COMPONENTS MATRIX

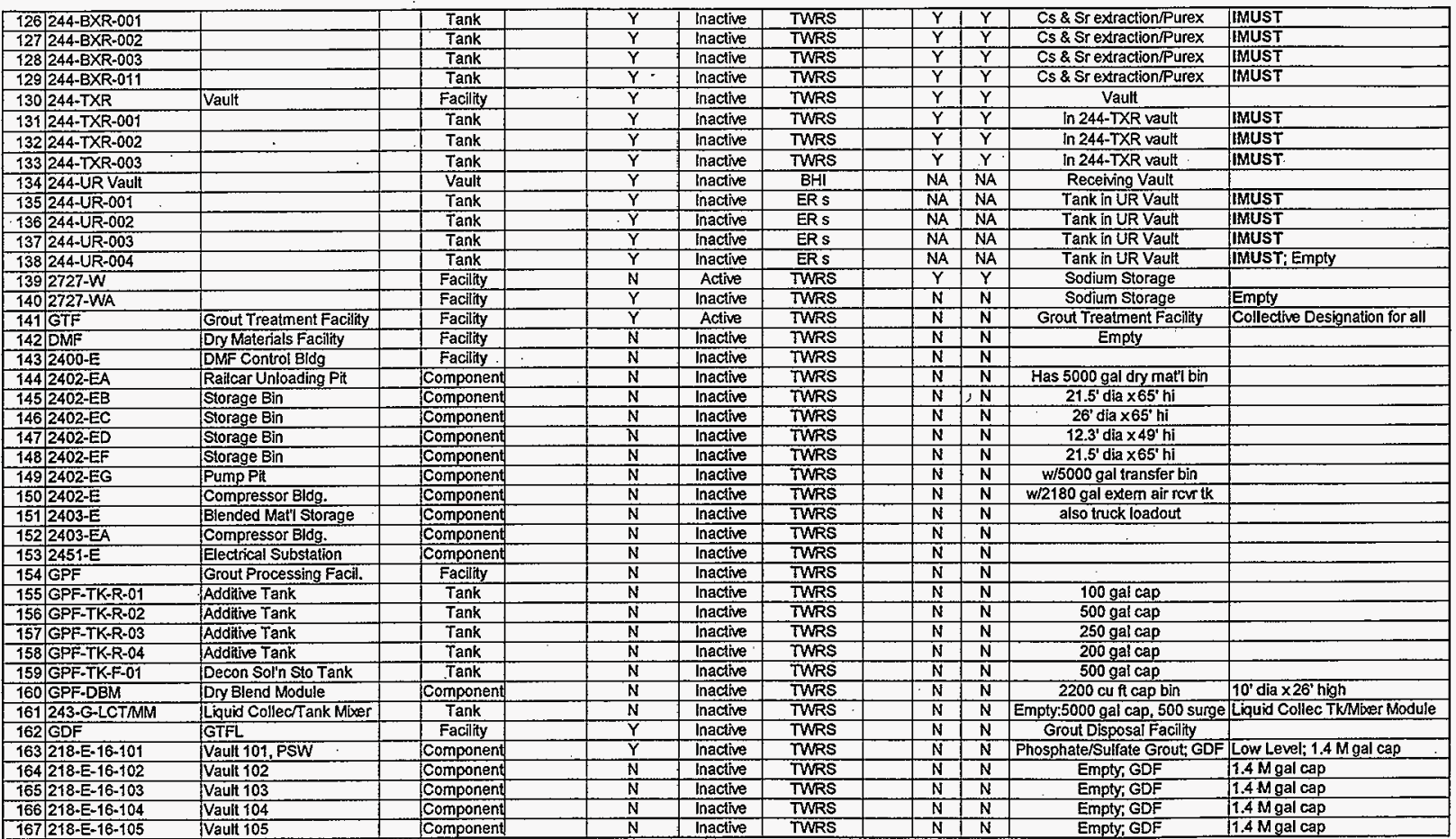


APPENDIX A: FACILITIES, TANKS, AND COMPONENTS MATRIX

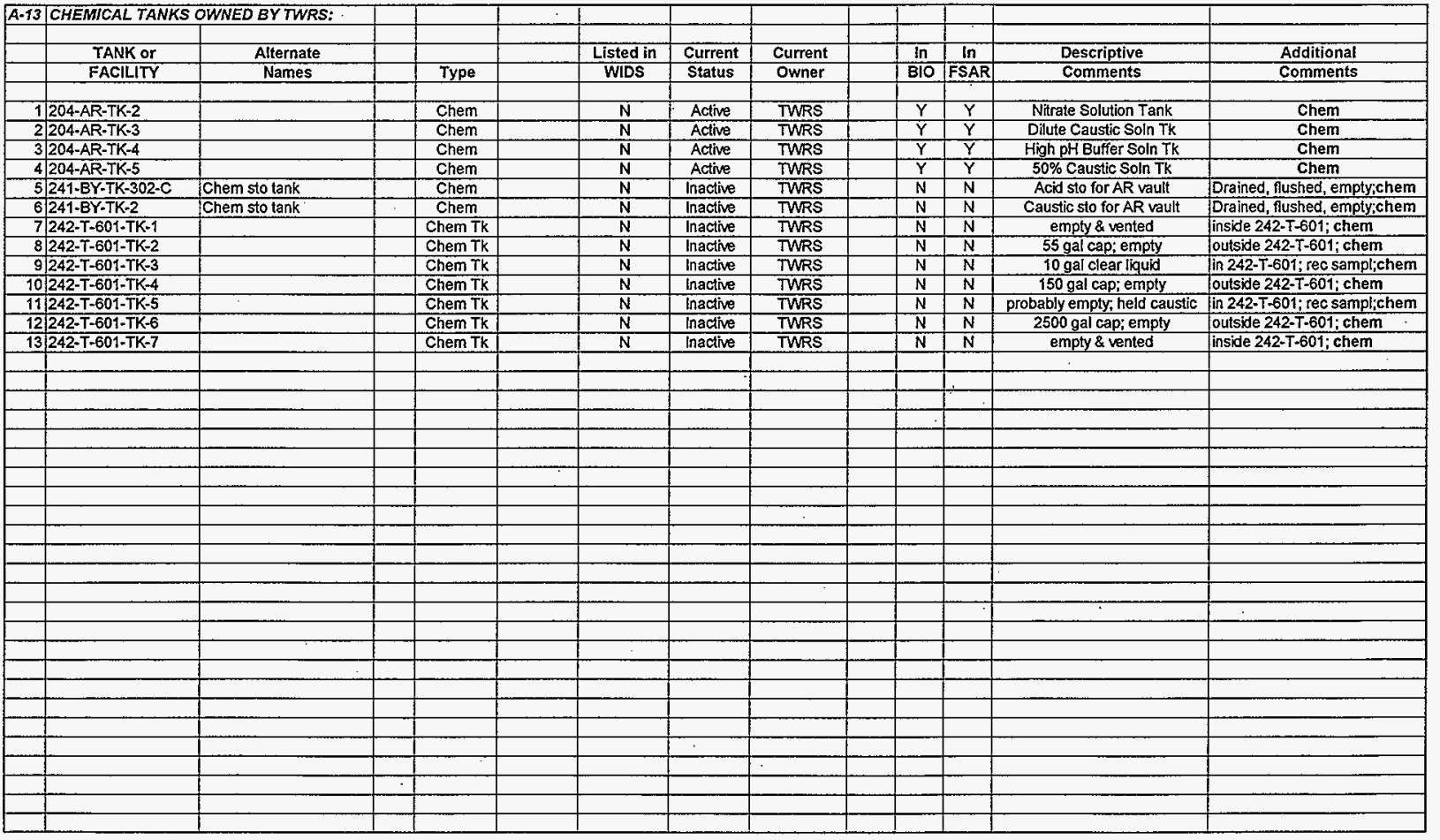


APPENDIXA: FACILITIES, TANKS, AND COMPONENTS MATRIX

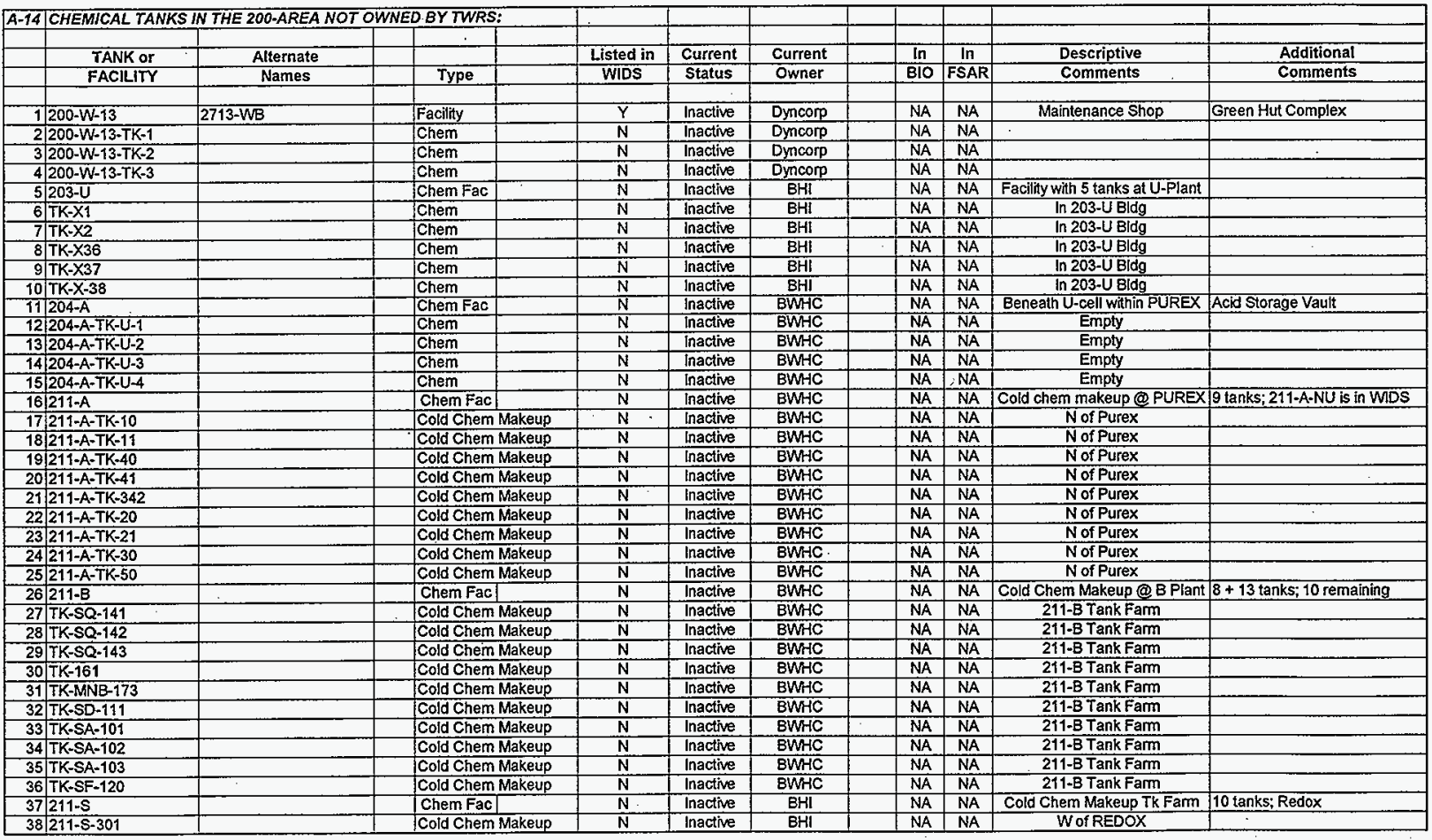


APPENDIX A: FACILITIES, TANKS, AND COMPONENTS MATRIX

\begin{tabular}{|c|c|c|c|c|c|c|c|c|c|}
\hline $39 \mid 21\{-\$-302 A$ & & Cold Chem Makeup & $N$ & Inactive & BH & $\mathrm{NA}$ & $\overline{N A}$ & Wof REDOX & \\
\hline $40 \mid 211-5-302 B$ & & Cold Chem Makeup & $N$ & Inactive & BHI & NA & NA & W of REDOX & \\
\hline $41211-\mathrm{S}-302 \mathrm{C}$ & Not Built? & Cold Chem Makeup & $\mathrm{N}$ & Inactive & $\mathrm{BHI}$ & $\mathrm{NA}$ & NA & Wof REDOX & \\
\hline \begin{tabular}{l|l}
42 & $21.1-5-303 A$
\end{tabular} & 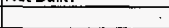 & Cold Chem Makeup & $N$ & Inactive & $\mathrm{BHI}$ & NA & $\mathrm{NA}$ & W of REDOX & \\
\hline $43211-S-303 \mathrm{~B}$ & & Cold Chem Makeup & $N$ & Inactive & $\mathrm{BHI}$ & NA & NA & Wof REDOX & \\
\hline $44 \mid 211-S-303 D$ & & Coid Chem Makeup & $\mathrm{N}$ & Inactive & $\mathrm{BH}$ & NA & $\mathrm{NA}$ & W of REDOX & \\
\hline $45 \mid 211-S-305 A$ & & Cold Chem Makeup & $\mathrm{N}$ & Inactive & $\mathrm{BHI}$ & NA & NA & W of REDOX & \\
\hline \begin{tabular}{l|l}
46 & $211-5-305 B$
\end{tabular} & & Cold Chem Makeup & $\mathrm{N}$ & Inactive & $\mathrm{BHI}$ & NA & NA & W of REDOX & \\
\hline $47211-5-305 C$ & & Cold Chem Makeup & $\mathrm{N}$ & Inactive & $\mathrm{BHI}$ & NA & NA & W Of REDOX & \\
\hline $481211-S-305 D$ & & Cold Chem Makeup & $\mathrm{N}$ & Inactive & $\mathrm{BHI}$ & NA & NA & Wof REDOX & \\
\hline \begin{tabular}{l|l}
$4911-T$ \\
\end{tabular} & & Chem Fac & $\mathrm{Y}$ & Active & WMH & NA & NA & $<90 \mathrm{~d}$. waste storage pad & T Plant; 4 tks orig: 1 remains \\
\hline 50 TK-SQ-141 & & Cold Chem Makeup & $\mathrm{N}$ & Inactive & WMHH & NA & $\mathrm{NA}$ & 211-T Chem Tank Fam & Tank Removed \\
\hline 51|TK-SQ-142 & & Cold Chem Makeup & $\mathrm{N}$ & Inactive & WMit & NA & NA & 211-T Chem Tank Fam & Tank Removed \\
\hline 52) TK-SQ-143 & & Radwaste? & $N$ & Active? & WMH & NA & NA & 211-T Chem Tank Farm & $10-18^{*}$ solid cake; radwaste? \\
\hline \begin{tabular}{r|r}
53 & TK-SQ- 145
\end{tabular} & & Cold Chem Makeup & $N$ & Inactive & WMH & NA & NA & 211-T Chem Tank Farm & TankRemoved \\
\hline $\begin{array}{ll}54 & \text { TK-SY-181A }\end{array}$ & & Cold Chem Makeup & $N$ & Inactive & WMH & NA & NA & At 211-T & Tank Removed \\
\hline \begin{tabular}{l|l}
55 & $211-U$
\end{tabular} & & Chem Facil & $Y$ & Inactive & $\mathrm{BHI}$ & NA & NA & Solvent Recovery Facility & U plant; chem \\
\hline \begin{tabular}{l|l|}
56 & $211-U-301$ \\
\end{tabular} & & Cold Chem Makeup & $N$ & Inactive & $\mathrm{BHI}$ & NA & NA & $\ln 211-U$ Bidg & \\
\hline $57[211-U-302$ & & Cold Chem Makeup & $N$ & inactive & $\mathrm{BHI}$ & NA & $\mathrm{NA}$ & $\ln 211-0$ BIdg & \\
\hline$5 8 \longdiv { 2 1 1 - U - 3 0 3 }$ & & cold Chem Makeup & $N$ & Inactive & BHI & NA & NA & $\ln 211-U$ BIdg & \\
\hline \begin{tabular}{l|l|}
$5911-U-306$ \\
\end{tabular} & & Cold Chem Makeup & $\mathbf{N}$ & Inactive & $\mathrm{BH}$ & NA & NA & $\ln 211-U$ Bldg & \\
\hline $60 \mid 211-U-307$ & & Cold Chem Makeup & $N$ & Inactive & $\mathrm{BH}$ & NA & NA & in 211-U BIdg & \\
\hline \begin{tabular}{l|l}
61 & $211-U-308$
\end{tabular} & & Cold Chem Makeup & $\mathrm{N}$ & Inactive & $\mathrm{BH}$ & NA & NA & $\ln 211.0 \mathrm{U} \mid d g$ & \\
\hline \begin{tabular}{l|l}
62 & $211-U-310$ \\
\end{tabular} & & Cold Chem Makeup & $\mathbf{N}$ & Inactive & BHI & NA & NA & $\ln 211-U$ Bidg & \\
\hline $63211-U-311$ & & Cold Chem Makeup & $N$ & Inactive & BHI & NA & NA & $\ln 211-$ U BIdg & \\
\hline \begin{tabular}{l|l}
$64211-U-312$ \\
\end{tabular} & & Cold Chem Makeup & $N$ & Inactivo & $\mathrm{BH}$ & NA & NA & $\ln 211 . \cup$ Bldg & \\
\hline $65211-U-321$ & & Cold Chem Makeup & $\mathrm{N}$ & Inactive & $\mathrm{BH}$ & NA & NA & $\ln 211.0 \mathrm{Bldg}$ & \\
\hline $66 \sqrt[211-U-322]{6}$ & & Cold Chem Makeup & $N$ & Inactive & $\mathrm{BH}$ & NA & NA & $\ln 211-$ U Bldg & \\
\hline \begin{tabular}{l|l}
67 & $211-U-323$
\end{tabular} & & Cold Chem Makeup & $\mathrm{N}$ & Inactive & $\mathrm{BH}$ & NA & NA & In $211-\mathrm{U}$ Bldg & \\
\hline \begin{tabular}{l|l}
68 & $211-U-324$ \\
\end{tabular} & & Cold Chem Makeup & $\bar{N}$ & Inactive & BHI & NA & NA & $\ln 211-U$ Bldg & \\
\hline $69211-\mathrm{UA}$ & & Chem facill & $\mathrm{N}$ & Inactive & BHI & NA & NA & Addition to 211-U & \\
\hline $70211-\mathrm{UA-312}$ & & Cold Chem Makeup & $\mathrm{N}$ & Inactive & $\mathrm{BH}$ & $\mathrm{NA}$ & NA & UPlant & \\
\hline \begin{tabular}{l|l}
71 & $211-U A-314$
\end{tabular} & & Cold Chem Makeup & $\mathbf{N}$ & Inactive & $\mathrm{BHI}$ & $\mathrm{NA}$ & NA & UPlant & \\
\hline $72211-U A-315$ & & Cold Chem Makeup & $\mathrm{N}$ & Inactive & $\mathrm{BHI}$ & $\mathrm{NA}$ & NA & U Plant & \\
\hline$7 3 \longdiv { 2 1 1 - U A - 3 2 5 }$ & & Cold Chem Makeup & $\mathrm{N}$ & Inactive & $\mathrm{BHI}$ & NA & NA & UPlant & \\
\hline $74 \mid 211-U A-326$ & & Cold Chem Makeup & $\mathrm{N}$ & Inactive & BH & NA & NA & UPlant & \\
\hline $75 \mid 211-\cup A-327$ & & Cold Chem Makeup & $\mathrm{N}$ & Inactive & $\mathrm{BHI}$ & NA & NA & U Plant & \\
\hline \begin{tabular}{l|l}
76 & $211-U A-332$
\end{tabular} & & Cold Chem Makeup & $\mathbf{N}$ & Inactive & $\mathrm{BHI}$ & NA & NA & U Plant & \\
\hline $77276-A$ & & Chem Facil & $\mathrm{N}$ & Inactive & BWHC & NA & NA & Solvent Tanks & Purex chem \\
\hline 78 TK-R1 & & Solvent Tank & N. & Inactive & BWHC & NA & NA & $276-\mathrm{A}$ Bldg & \\
\hline $\begin{array}{ll}7 \overline{9} & \text { TK-R2 } \\
\end{array}$ & & Solvent Tank & $\mathbf{N}$ & Inactive & BWHC & NA & NA & $276-A$ Bldg & \\
\hline 80 TK-R5 & & Solvent Tank & $\mathrm{N}$ & Inactive & BWHC & $\mathrm{NA}$ & NA & $276-\mathrm{A}$ Bldg & \\
\hline 81/TK-R7 & & Solvent Tank & $N$ & Inactive & BWHC & NA & NA & $276-\mathrm{A}$ Bldg & \\
\hline
\end{tabular}


APPENDIX A: FACILITIES, TANKS, AND COMPONENTS MATRIX

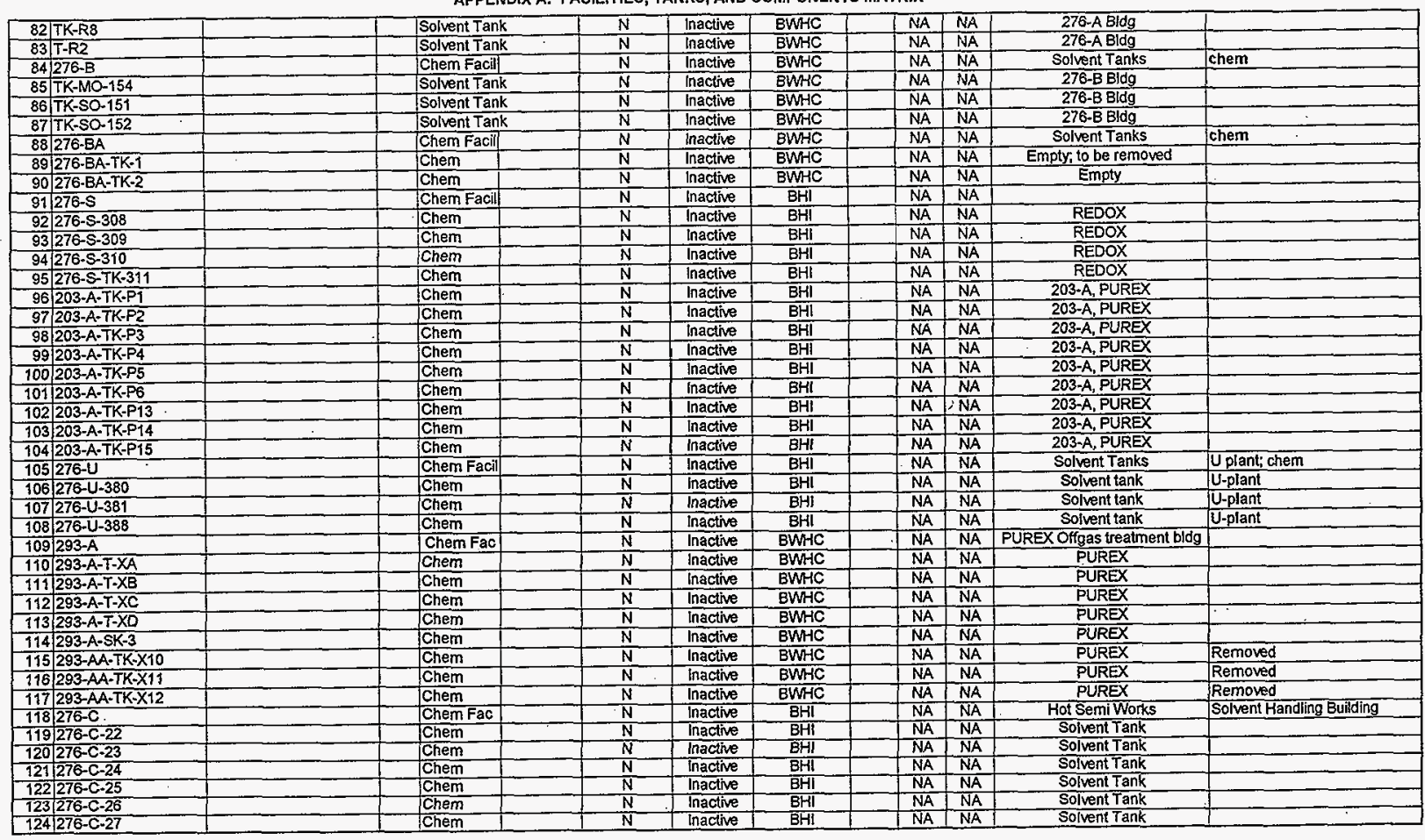


APPENDIX A: FACILITIES, TANKS, AND COMPONENTS MATRIX

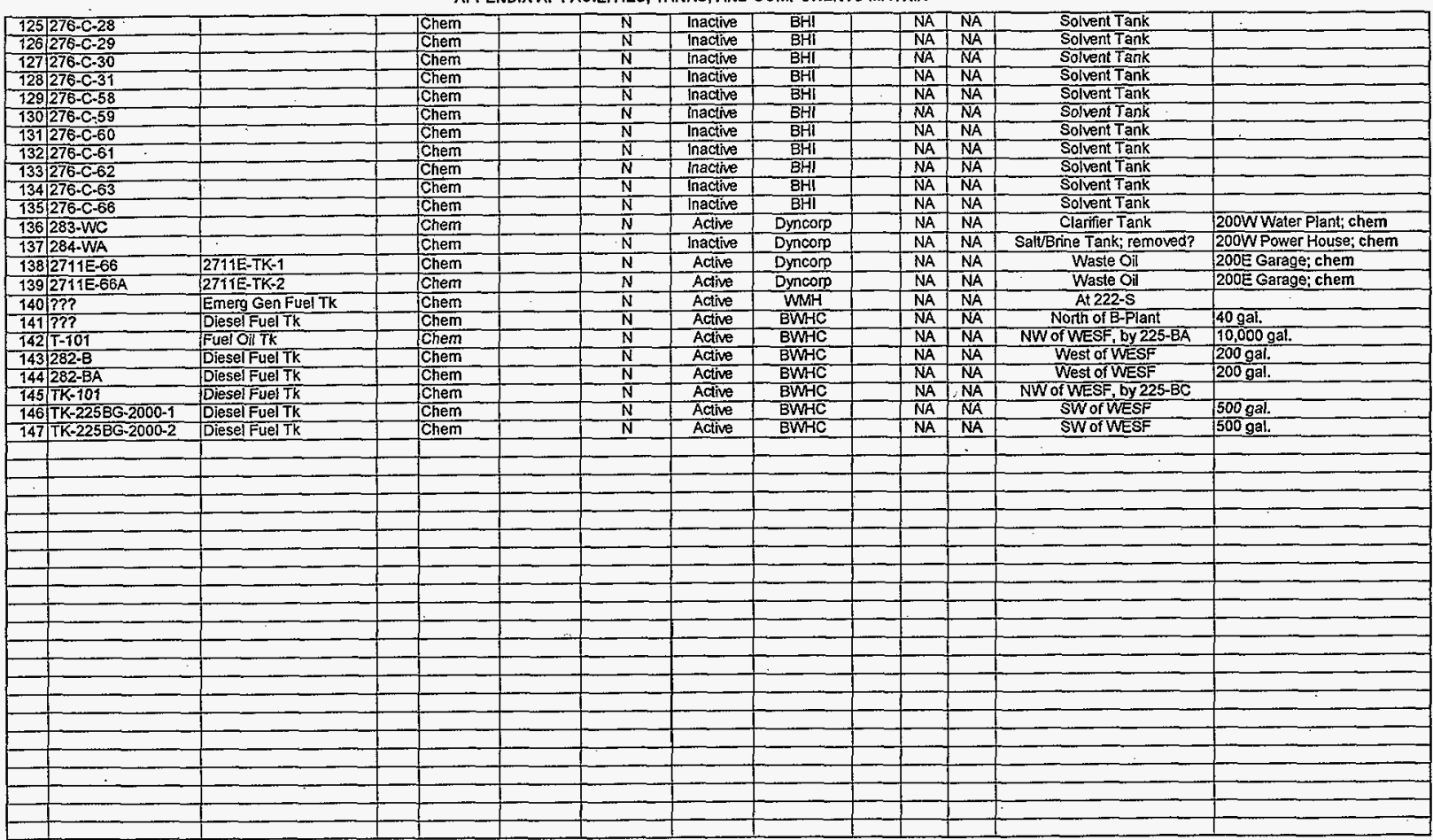


APPENDIX A: FACILITIES, TANKS, AND COMPONENTS MATRIX

\begin{tabular}{|c|c|c|c|c|c|c|c|c|c|c|c|c|}
\hline A-15 & TWRS NITS TTW & NON-IMUSTS) & & & & & & & & & & \\
\hline & TANK or & Alternate & & & Listed in & Current & Current & $\ln$ & In & in & Descriptive & Additional \\
\hline & FACILITY & Names & Type & & WIDS & Status & Owner & 040 & $\mathrm{BIO}$ & FSAR & Comments & Comments \\
\hline & & & & & & & & & & & & \\
\hline 1 & $200-W-48$ & 241-TX 90d Accum Ares & Component & & $\bar{Y}$ & Inactive & TWRS & & $\mathbf{N}$ & $\mathrm{N}$ & <90d Storage Pad & \\
\hline 2 & 241-AZ-154 & Steam conden receiver & Tank & & $\mathbf{N}$ & Active & TWRS & & $\bar{Y}$ & $\bar{Y}$ & Steam condensate rcu tank & \\
\hline$\overline{3}$ & 244-A DCRT & DCRT & Tank & & $\bar{Y}$ & Active & TWRS & & $\bar{Y}$ & $Y$ & & \\
\hline 4 & 244-ALS & 244-AR LS & Component & & $\bar{Y}$ & Active & TWRS & & $\mathrm{N}$ & $\mathrm{N}$ & Control Structure, Lift Station & Part of DCRT equipment \\
\hline 5 & $244-B X$ & DCRT & Tank & & $\bar{Y}$ & Active & TWRS & & $\bar{Y}$ & $\bar{Y}$ & DCRT & \\
\hline 6 & $244-S$ & DCRT & Tank & & $Y$ & Active & TWRS & & $Y$ & $Y$ & DCRT & \\
\hline 7 & $244-T X$ & DCRT & Tank & & $\mathrm{Y}$ & Active & TWRS & & $\bar{Y}$ & $Y$ & DCRT & \\
\hline 8 & 244-U & DCRT & Tank & & $\bar{Y}$ & Active & TWRS & & $\bar{Y}$ & $\bar{Y}$ & DCRT & No rad content yet \\
\hline 9 & $241-\mathrm{A}-302 \mathrm{~A}$ & & Tank & & $\bar{Y}$ & Active & TWRS & & $Y$ & $\bar{Y}$ & Catch Tank & \\
\hline 10 & $241-A-350$ & & Tank & & $\bar{Y}$ & Active & TWRS & New & $\bar{Y}$ & $\bar{Y}$ & Catch Tank & \\
\hline 11 & $241-A-417$ & & Tank & & $\bar{Y}$ & Active & TWRS & New & $\bar{Y}$ & $\bar{Y}$ & Catch Tank & \\
\hline 12 & $241-A X-152 C T$ & & Tank & & 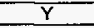 & Active & TWRS & New & $\bar{Y}$ & $Y$ & Catch Tank & \\
\hline 13 & $241-A Z-151 C T$ & & Tank & & $\bar{Y}$ & Active & TWRS & New & $Y$ & $\mathbf{Y}$ & Catch Tank & \\
\hline$\overline{14}$ & 241-ER-311 & & Tank & & $Y$ & Active & TWRS & & $Y$ & $Y$ & Catch Tank & \\
\hline 15 & 241-EW-151 & & Tank & & $\bar{Y}$ & Active & TWRS & & $Y$ & $Y$ & Catch Tank & \\
\hline 16 & $241-5-304$ & & Tank & & $\bar{Y}$ & Active & TWRS & & $Y$ & $\bar{Y}$ & Catch Tank & \\
\hline 17 & $241-\mathrm{TX}-302 \mathrm{C}$ & & Tank & & $\bar{Y}$ & Active & TWRS & & $\bar{Y}$ & $\bar{Y}$ & Catch Tank & \\
\hline 18 & $241-U-301$ & $241-0-3018$ & Tank & & $Y$ & Active & TWRS & & $Y$ & $\bar{Y}$ & Catch Tank & \\
\hline 19 & $241-U X-302 A$ & UXX-302 & Tank & & $\bar{Y}$ & Active & TWRS & & $Y$ & $Y$ & Catch Tank & \\
\hline & & & & & & & & & & & & \\
\hline & & & & & & & & & & & & \\
\hline & & & & & & & & & & & ${ }^{\circ}$ & \\
\hline & & & & & & & & & & & & \\
\hline & & & & & & & & & & & & \\
\hline & & & & & & & & & & & & \\
\hline & & & & & & & & & & & & \\
\hline & & & & & & & & & & & & \\
\hline & & & & & & & & & & & & \\
\hline & & & & & & & & & & & & \\
\hline & & & & & & & & & & & & \\
\hline & & & & & $\therefore$ & & & & & & & \\
\hline & & & & & & . & & & & & & \\
\hline & & & & & & & & & & & & \\
\hline & & & & & & & & & & & & \\
\hline & & & & & & & & & & & & \\
\hline & & & & & & & & & & & & \\
\hline & & & & & & & & & & & & \\
\hline & & & & & & & & & & & & \\
\hline
\end{tabular}




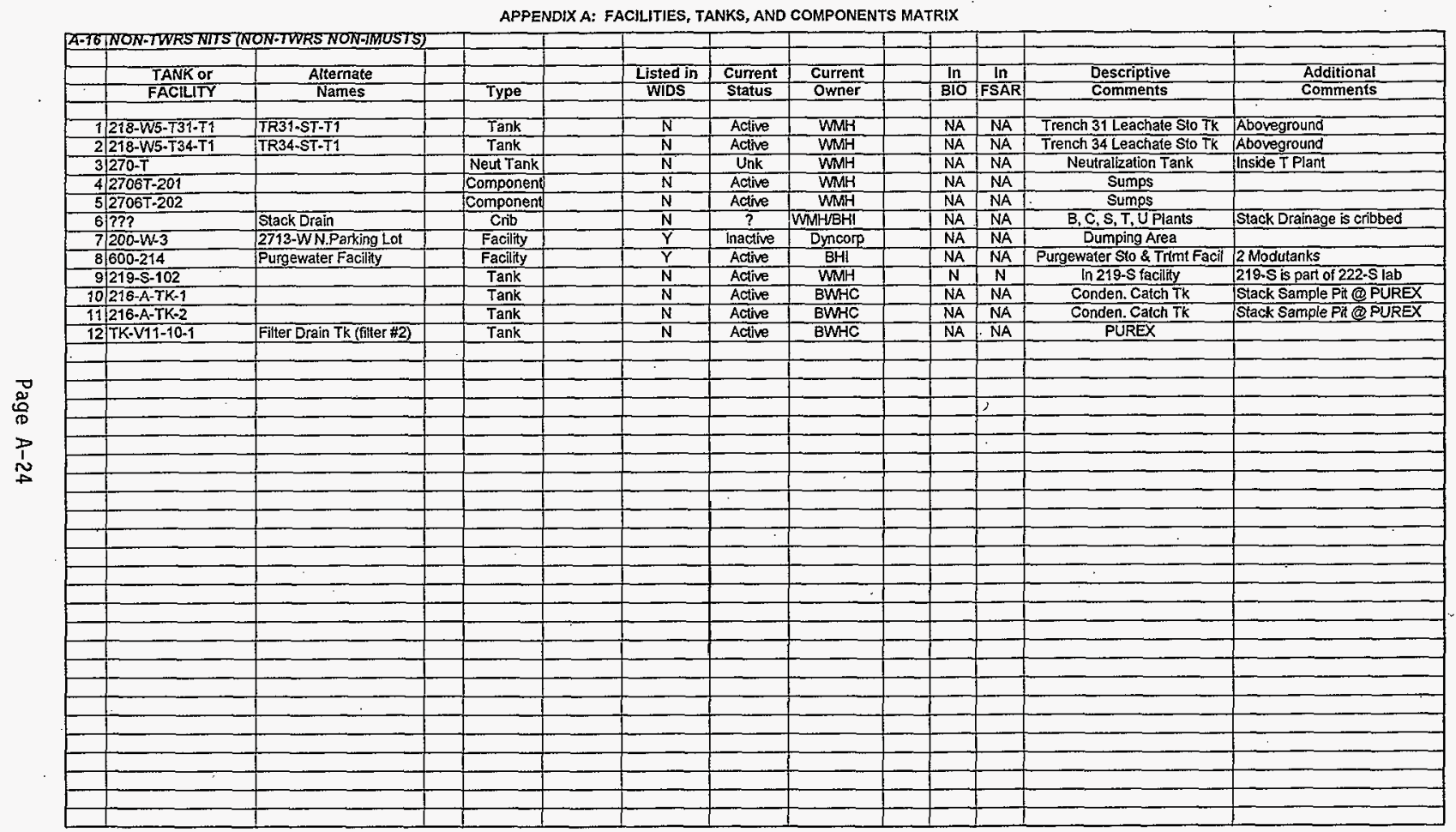


APPENDIX A: FACILITIES, TANKS, AND COMPONENTS MATRIX

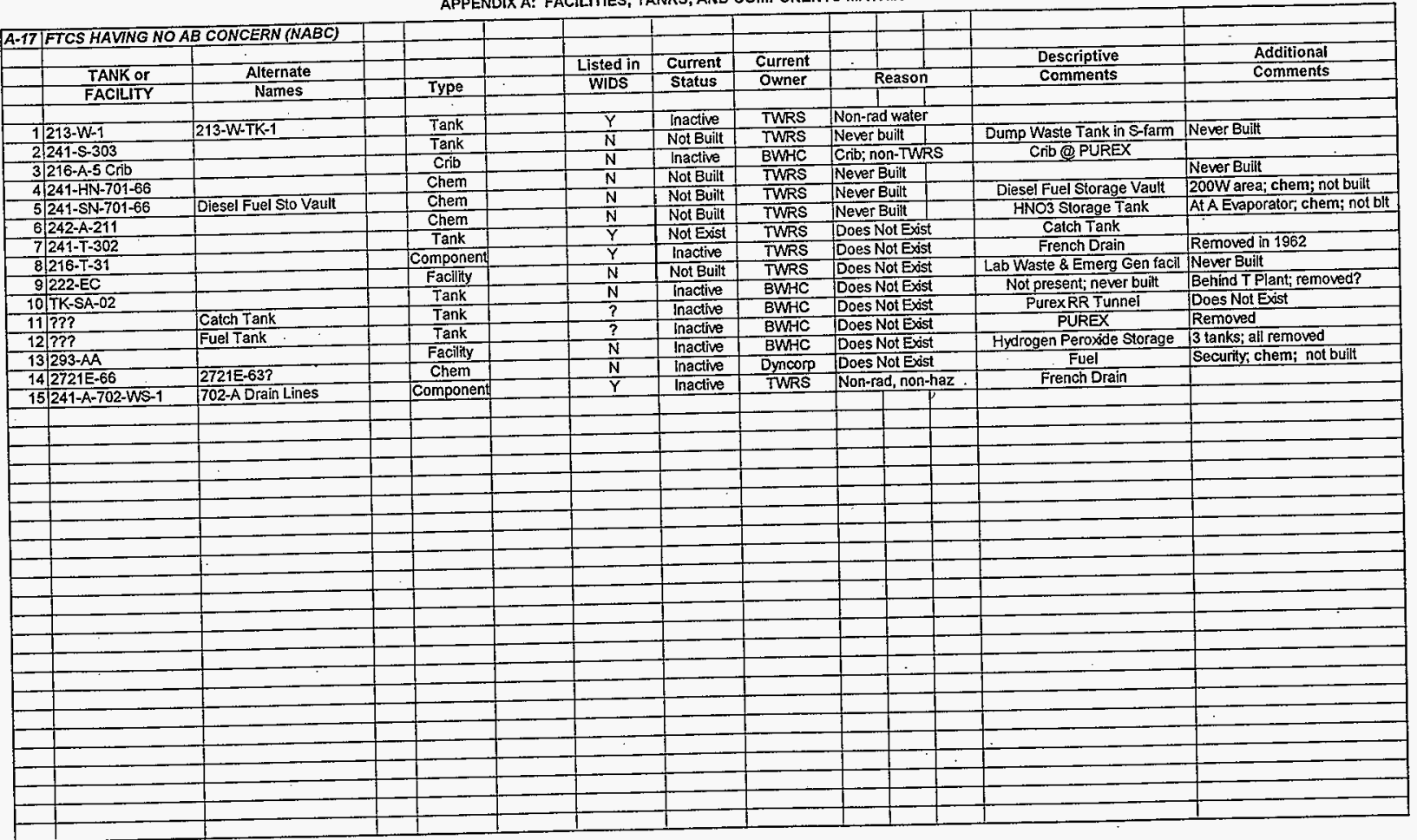


APPENDIX A: FACILITIES, TANKS, AND COMPONENTS MATRIX

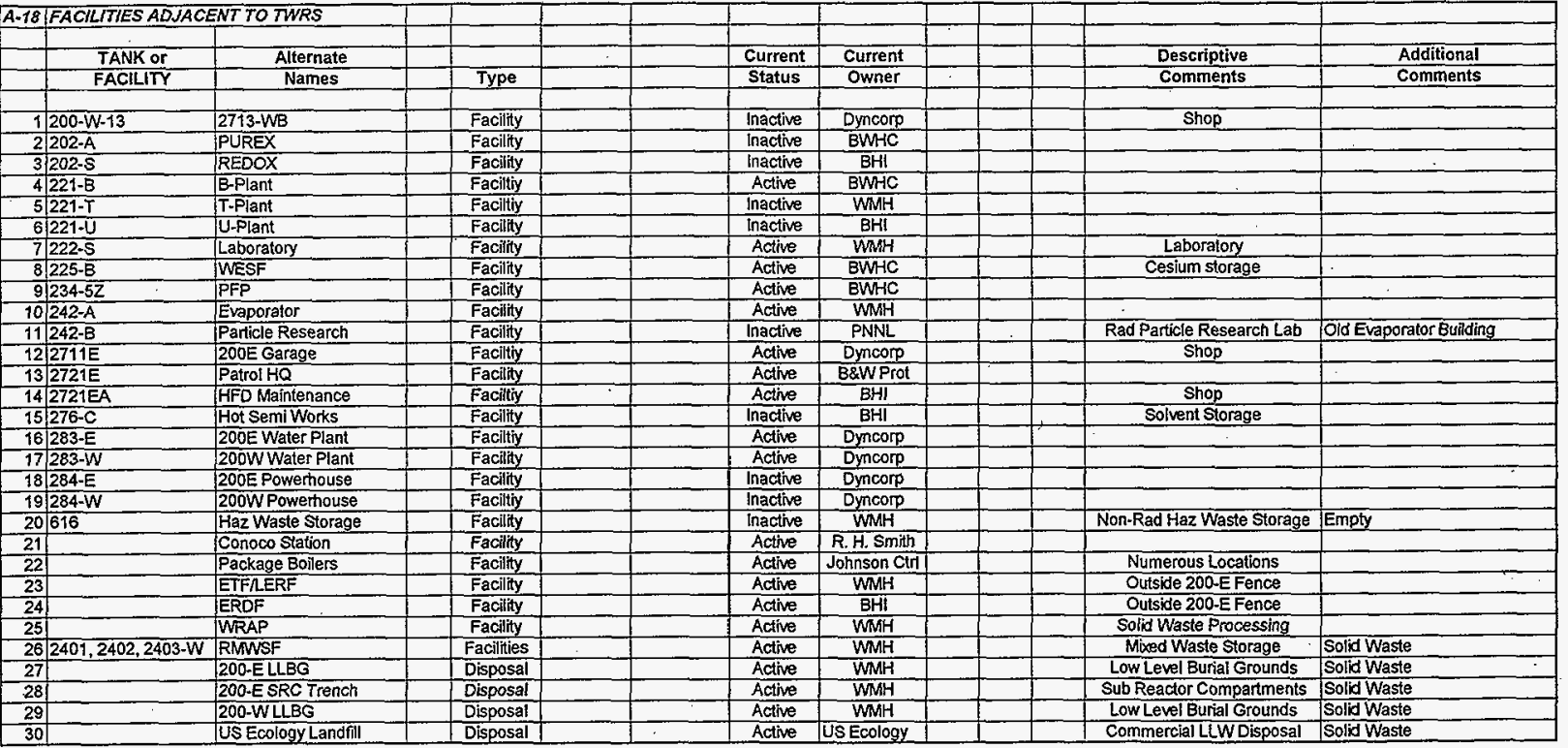




\section{Appendix B: Hazard Profile Sheets}

A "hazard profile sheet" has been prepared for each FTC evaluated in this report, except those addressed in WHC-SD-EN-ES-040. The areas of information contained on the sheets were specifically included in order to assess FTC physical conditions, mission purpose and safety hazards. The hazard profile sheets document the starting point of the FTC evaluations for needed $A B$ upgrades. They are provided in this report to give insight into the process used by the contractor to research each FTC and to communicate the focus of this research.

Once the initial effort was performed to complete the sheets, they were not revisited to incorporate additional technical information unless correction of an error was required. The use of $\underline{a 11}$ information gained from research of the FTCS is evidenced in the main body of this report. The collection of raw data and information supporting the FTC research is being maintained by the TWRS Nuclear Safety \& Licensing Department for use in the follow-on work to upgrade the TWRS AB. 
HNF-2503, Rev. 0

\section{Appendix B}

\section{TABLE OF CONTENTS}

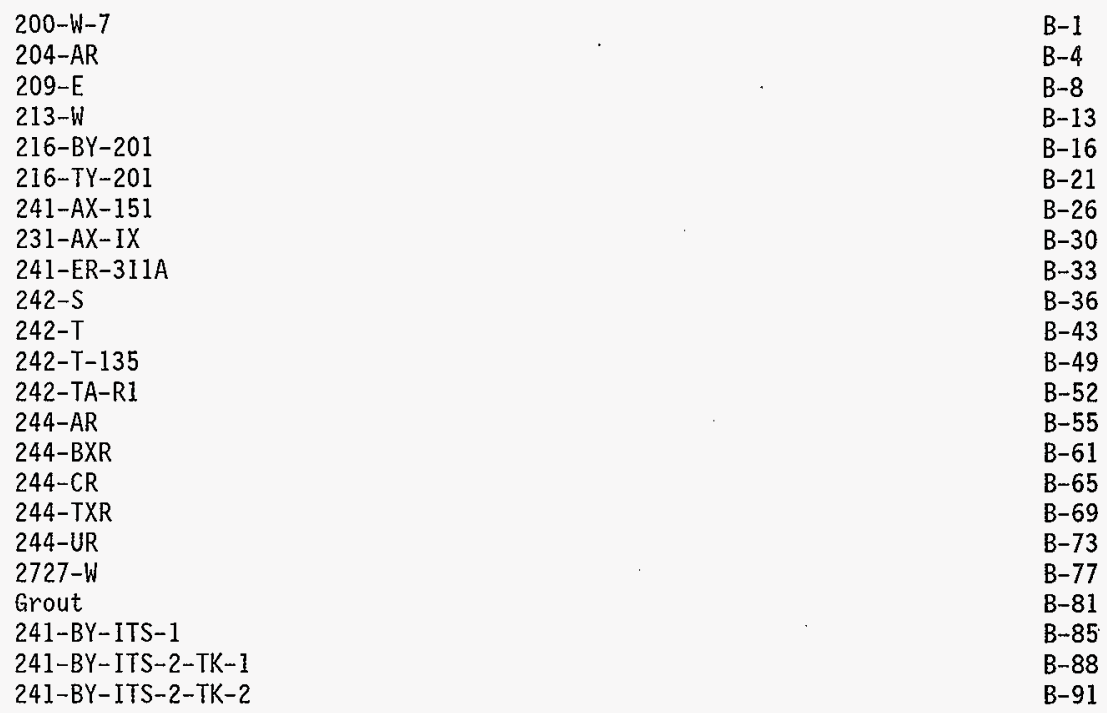


FACILITY HAZARD PROFILE CHECKLIST

Rev, 0, April 20, 1998

\begin{tabular}{|c|c|c|c|c|c|c|c|c|c|}
\hline Facility ID: & 200-W-7 & \multicolumn{2}{|c|}{ Facility Name: } & \multicolumn{6}{|l|}{ Catch Tank } \\
\hline Owner/Operator & Location & Capacity & $\begin{array}{l}\text { Volume of } \\
\text { Contents } \\
\end{array}$ & $\begin{array}{l}\text { Sludge } \\
\text { Volume }\end{array}$ & $\begin{array}{l}\text { Liquid } \\
\text { Volume }\end{array}$ & Risers & $\begin{array}{l}\text { Active/ } \\
\text { Inactive }\end{array}$ & \begin{tabular}{|l} 
Fissile \\
Content \\
\end{tabular} & $\begin{array}{l}\text { Rad } \\
\text { Content } \\
\end{array}$ \\
\hline TWRS & $\begin{array}{l}\text { N134667.406, E566720.5, } \\
200 \mathrm{~W}, \mathrm{NW} \text { of } 242-\mathrm{S} \\
\text { Evaporator }\end{array}$ & $\begin{array}{l}2082 \mathrm{~L} \\
(550 \mathrm{gal})\end{array}$ & Unknown & Unknown & Unknown & $\begin{array}{l}3,10 \mathrm{~cm} \\
\left(4^{\prime \prime}\right) \text { dia. } \\
\text { riser }\end{array}$ & Inactive & Unk & Unknown \\
\hline Geometry & \multicolumn{9}{|c|}{$\begin{array}{l}\text { The tank is } 1.22 \mathrm{~m}\left(4^{\prime}\right) \text { dia. } \times 1.98 \mathrm{~m}\left(6^{\prime} 6^{\prime \prime}\right) \text { long. The tank material is } 8 \mathrm{~mm}\left(5 / 16^{\prime \prime}\right) \text { thick fiberglass, Owens-Corning, Model D-5 } \\
\text { with } 50 \text { Mil corrosion resistant wrapping (Drawing H-2-72885). }\end{array}$} \\
\hline Configuration & \multicolumn{9}{|c|}{$\begin{array}{l}\text { The catch tank is northwest of } 242-S \text { Evaporator and just north of Decontamination Trailer MO-0326: Personnel Decontamination } \\
\text { Facility } 200 \text { West Tank Farms. The decontamination trailer has been removed. The catch tank remains below grade with a minimum of } \\
3^{\prime} \text { of soil overburden. The tank is fiberglass construction. There are three risers extending above ground. One } 10 \mathrm{~cm}\left(4^{\prime \prime}\right) \text { dia. steel riser } \\
\text { has a threaded plug, second } 10 \mathrm{~cm}\left(4^{\prime \prime}\right) \text { steel riser has a thread cap and third } 10 \mathrm{~cm}\left(4^{\prime \prime}\right) \text { dia. PVC vent riser is equipped with a breather } \\
\text { filter and bird house type sheet metal cover. The decontamination water from the decontamination trailer entered above the tank through } \\
\text { a } 10 \mathrm{~cm}\left(4^{\prime \prime}\right) \text { PVC pipe about two feet below grade level. Level gauge has been removed from the riser and riser is plugged. Field walk } \\
\text { down identified a } 10 \mathrm{~cm}\left(4^{\prime \prime}\right) \text { dia. pipe (similar to a clean out located about } 61 \mathrm{~cm}\left(2^{\prime}\right) \text { southwest of vent riser. ) inclined at } 45^{\circ} \text { with a plug } \\
\text { sitting at ground level. The tank drawing did not identify any such connection. It is possible that this piece of pipe may be an abandoned } \\
\text { pipe stuck in the ground. The site is a chained } 3 \mathrm{~m} \times 3 \mathrm{~m}\left(10^{\prime} \times 10^{\prime}\right) \text { area. Tank is also identified as } 243 \mathrm{~S}-\mathrm{TK}-1,243-\mathrm{S}-\mathrm{TKK} 1 \text { and } 246-\mathrm{L} \text {. } \\
\text { The tank has been isolated from the mobile office MO-326 per ECN } 621598 \text {. }\end{array}$} \\
\hline Hardware & \multicolumn{9}{|c|}{ Catch Tank and associated piping. } \\
\hline Contents & \multicolumn{9}{|c|}{ Unknown (Most likely contaminated soap water) } \\
\hline Condition & \multicolumn{9}{|c|}{ Walkdown revealed a clean out type pipe with a plug at grade level. See above Configuration section for more details. } \\
\hline $\begin{array}{l}\text { Original Mission } \\
\text { (Process History) }\end{array}$ & \multicolumn{9}{|c|}{$\begin{array}{l}\text { The site was a personnel decontamination facility used by. West Tank Farms. The tank was in service from late } 1970 \text { s to late } 1980 \mathrm{~s} \text {. } \\
\text { (May have been referred to as } 243 \mathrm{~S}-\mathrm{TK}-1 \text { ) }\end{array}$} \\
\hline Current Mission & \multicolumn{9}{|l|}{ None } \\
\hline Future Mission & \multicolumn{9}{|l|}{ None } \\
\hline Processes & \multicolumn{9}{|c|}{ No processing was performed. } \\
\hline Input Streams & \multicolumn{9}{|c|}{ Effluent stream from personnel decontamination. Expect soap, water, and low levels of contamination. } \\
\hline
\end{tabular}




\begin{tabular}{|c|c|c|}
\hline - & pəIg़̣uəp! əuoN & 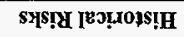 \\
\hline & əüN & 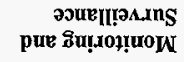 \\
\hline & 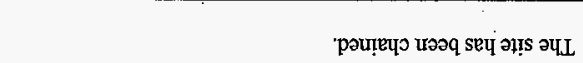 & 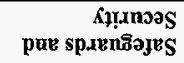 \\
\hline & 2ưN & 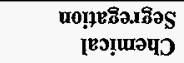 \\
\hline & 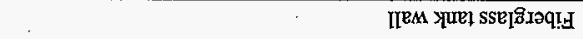 & S.ạudeg \\
\hline & axoN & $\begin{array}{l}\text { s[o.juop } \\
\text { pəaukyd }\end{array}$ \\
\hline & 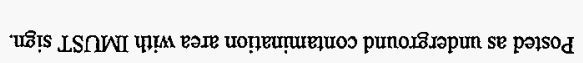 & $\begin{array}{l}\text { spodquop } \\
\text { pua.t.m }\end{array}$ \\
\hline & umouryu & s[odjuop 1sed \\
\hline & $\mathrm{V} / \mathrm{N}$ & $\begin{array}{l}\text { uo!!!puop } \\
\text { əo.dnos }\end{array}$ \\
\hline & $\mathrm{V} / \mathrm{N}$ & sme+S A8.doug \\
\hline & axoN & 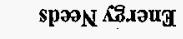 \\
\hline & auoN & səo.mos AR.xәu \\
\hline & 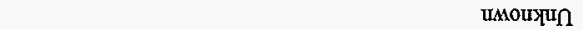 & suoppedaquI \\
\hline & uмkourun & ио:н!риор \\
\hline & usorryu & 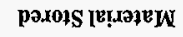 \\
\hline & umouryu $\Omega$ & Kł!ฺนeno \\
\hline & นmoư⿰彳口 & วе.xeqD/ux.xog \\
\hline$\cdot$ & uMotryu & 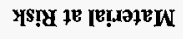 \\
\hline & sureəns indự se əures & 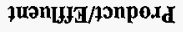 \\
\hline
\end{tabular}




\begin{tabular}{|c|c|}
\hline $\begin{array}{l}\text { Current or } \\
\text { Future Risks }\end{array}$ & Unknown \\
\hline $\begin{array}{l}\text { Occurrence } \\
\text { History }\end{array}$ & None identified \\
\hline Root Cause & N/A \\
\hline $\begin{array}{l}\text { Records } \\
\text { Location }\end{array}$ & Contact operations \\
\hline Records Access & N/A \\
\hline $\begin{array}{l}\text { Adjacent Facility } \\
\text { Location }\end{array}$ & $242-\mathrm{S}$ is about $91.5 \mathrm{~m}(100 \mathrm{yd}) \mathrm{SE}$ of the tank. $272-\mathrm{S}$ maintenance shop is about $91.5 \mathrm{~m}$ (100 yd) south of the tank. \\
\hline $\begin{array}{l}\text { Underground } \\
\text { Facilities }\end{array}$ & None \\
\hline $\begin{array}{l}\text { Aboveground } \\
\text { Facilities }\end{array}$ & None \\
\hline BIO Coverage & Yes under 243S-TK-1 name. \\
\hline FSAR Coverage & Yes under 243S-TK-1 name. \\
\hline $\begin{array}{l}\text { Information } \\
\text { Source }\end{array}$ & $\begin{array}{l}\text { Drawing H-2-72885, Decontamination Trailer \& Radiation Monitoring Tank. Out standing changes to the drawing: CEO \# } 044770, \mathrm{ECN} \\
\text { \# } 101299 \text { and } 621598 \text {. } \\
\text { Field walk down on } 3 / 25 / 98 \text { by Sohan Gahir and Jim Williams }\end{array}$ \\
\hline
\end{tabular}


FACUITY HAZARD PROFUL CHECKLIST

Rev. 0, April 20, 1998

\begin{tabular}{|c|c|c|c|c|c|c|c|c|c|}
\hline \multicolumn{10}{|l|}{$\mathrm{Fa}$} \\
\hline Owner/Operator & Location & Capacity & $\begin{array}{l}\text { Volume of } \\
\text { Contents }\end{array}$ & $\begin{array}{l}\text { Sludge } \\
\text { Volume }\end{array}$ & $\begin{array}{l}\text { Liquid } \\
\text { Volume }\end{array}$ & Risers & $\begin{array}{l}\text { Active/ } \\
\text { Inactive }\end{array}$ & $\begin{array}{l}\text { Fissile } \\
\text { Content }\end{array}$ & $\begin{array}{l}\text { Rad } \\
\text { Content }\end{array}$ \\
\hline TWRS & South of 244-AR Vault & See below & See below & None & See below & N/A & Active & None & Low-level \\
\hline Geometry & \multicolumn{9}{|c|}{ Rectangular; $19.8 \mathrm{~m}(65 \mathrm{ft})$ long by $12.2 \mathrm{~m}(40 \mathrm{ft})$ wide by $7.6 \mathrm{~m}(25 \mathrm{ft})$ high. } \\
\hline Configuration & \multicolumn{9}{|c|}{$\begin{array}{l}\text { The facility is a two-story reinforced concrete structure. The first floor contains the rail tank car unloading canyon and mechanical } \\
\text { equipment room. The second floor contains the control room, locker room, and airlock leading to the rail car access balcony. A catch } \\
\text { tank is located below grade and an air compressor is located in an outdoor enclosure. The mechanical equipment room contains four } \\
\text { tanks storing chemicals which ensure tank car waste can be treated to meet tank farm acceptance criteria. The mechanical room also } \\
\text { contains pumps and piping asssociated with waste treatment operations. Separate HVAC systems are provided for personnel areas and } \\
\text { radiation zones. A diesel generator is located approximately } 15.25 \mathrm{~m} \text { ( } 50 \mathrm{ft}) \text { northwest of the facility. }\end{array}$} \\
\hline Hardware & \multicolumn{9}{|c|}{$\begin{array}{l}\text { Tank TK-1 (catch tank) - Located in below-grade sump in rail car unloading canyon. Stainless steel, } 5678 \mathrm{~L} \text { (1500 gal) capacity. } \\
\text { Provides temporary storage of liquids from floor drains. Tank contents are periodically pumped to the tank farms. Tank overflow is } \\
\text { collected in the sump. The tank is connected to the ventilation exhaust system through a HEPA filter. } \\
\text { Tank TK-2 (sodium nitrite storage) - Located in mechanical equipment room. Carbon steel, } 1893 \mathrm{~L} \text { (500-gal) capacity. Connected to } \\
\text { raw water and steam supply lines. } \\
\text { Tank TK-3 (dilute caustic storage) - Located in mechanical equipment room. Stainless steel, } 1893 \mathrm{~L} \text { (500-gal) capacity. Connected to } \\
\text { steam and raw water supply lines. } \\
\text { Tank TK-4 (high pH buffer storage) - Located in mechanical equipment room. Stainless steel, } 757 \mathrm{~L} \mathrm{(200-gal)} \mathrm{capacity.} \mathrm{Connected} \mathrm{to} \\
\text { raw water supply line. } \\
\text { Tank TK-5 (50\% caustic storage) - Located in mechanical equipment room. Carbon steel, } 6814 \mathrm{~L} \text { (1800-gal) capacity. Connected to } \\
\text { steam supply line. Fill line penetrates wall and terminates outside building. } \\
\text { Pumps, related piping and valves, rad and non-rad HVAC systems. } \\
3.7 \mathrm{~kW} \text { ( } 5 \text { hp) instrument air compressor. } \\
\text { Diesel generator and } 2082 \mathrm{~L} \text { ( } 550 \text { gal.) fuel tank. }\end{array}$} \\
\hline Contents & \multicolumn{9}{|c|}{$\begin{array}{l}\text { TK-1 currently contains water and a dilute amount of caustic material. } \\
\text { TK-2 contains a residual amount of sodium nitrite solution. }\end{array}$} \\
\hline
\end{tabular}

Tank TK-2 (sodium nitrite storage) - Located in mechanical equipment room. Carbon steel, 1893 L (500-gal) capacity. Connected to Tank TK-3 (dilute caustic storage) - Located in mechanical equipment room. Stainless steel, $1893 \mathrm{~L}$ (500-gal) capacity. Connected to Tank TK-4 (high pH buffer storage) - Located in mechanical equipment room. Stainless steel, $757 \mathrm{~L}$ (200-gal) capacity. Connected to

Tank TK-5 (50\% caustic storage) - Located in mechanical equipment room. Carbon steel, $6814 \mathrm{~L}$ (1800-gal) capacity. Connected to Pumps, related piping and valves, rad and non-rad HVAC systems.

$7 \mathrm{~kW}(5 \mathrm{hp})$ instrument air compressor. 


\begin{tabular}{|c|c|}
\hline & $\begin{array}{l}\text { TK-3 contains a residual amount of } 5.4 \mathrm{M} \text { ( } 18 \mathrm{wt} \% \text { ) sodium hydroxide solution. } \\
\text { TK-4 is currently empty, but had been used to store high pH buffer solution (sodium hydroxide and disodium phosphate) used for pH } \\
\text { probe calibrâtion. } \\
\text { TK- } 5 \text { is currently empty, but had been used to store } 50 \% \text { sodium hydroxide solution. } \\
\text { Diesel generator fuel tank contains diesel fuel. }\end{array}$ \\
\hline Condition & Facility is regularly inspected and maintained in a good state of repair. \\
\hline $\begin{array}{l}\text { Original Mission } \\
\text { (Process } \\
\text { History) }\end{array}$ & $\begin{array}{l}\text { The unit received wastes generated from decontamination and regeneration operations in the } 100 \text { and } 200 \text { Areas, from recovery, fuel } \\
\text { fabrication, and laboratory operations in the } 200 \text { and } 300 \text { Areas; and from decontamination operations in the } 400 \text { Area. }\end{array}$ \\
\hline Current Mission & The facility continues to receive waste delivered via railroad tank car. \\
\hline Future Mission & Modification to accommodate LR-56 truck trailer. \\
\hline Processes & $\begin{array}{l}\text { The structure allows the pumping, sampling, and sluicing of tank cars. The waste is chemically adjusted in-line during pump-out to } \\
\text { double-shell underground storage tanks to meet corrosion specifications. }\end{array}$ \\
\hline Input Streams & 222-S and 340 (PNNL) laboratory waste. \\
\hline Product/Effluent & Low-level wäste meeting tank farms acceptance criteria. \\
\hline Material at Risk & $\begin{array}{l}\text { T-Plant, } 340 \text {, and } 222-S \text { facility wastes (heavy metal, process chemical, and radioactive waste), sodium nitrate, sodium hydroxide, diesel } \\
\text { fuel, potentially contaminated HEPA filters. }\end{array}$ \\
\hline Form/Charac & Described under "Contents" above. \\
\hline Quantity & Described under "Contents" above. \\
\hline Material Stored & Process materials remain in the process vessels. Diesel fuel remains in the generator fuel tank. \\
\hline Condition & Storage vessels are inspected and well maintained. \\
\hline Interactions & $\begin{array}{l}\text { Interaction of process chemicals and tank car waste would dilute the waste and not increase the existing hazard if the waste is non-acidic. } \\
\text { Interaction of acidic waste with process chemicals should be evaluated. }\end{array}$ \\
\hline Energy Sources & Facility is served with steam and electrical power. \\
\hline Energy Needs & $\begin{array}{l}\text { Facility requires steam for tank heating and sampling, and electrical power for instrument air compressor, mixers, pumps, } \\
\text { instrumentation, HVAC, lighting, control room functions, and radiation monitors. }\end{array}$ \\
\hline Energy Status & Electrical power is active. \\
\hline
\end{tabular}




\begin{tabular}{|c|c|}
\hline $\begin{array}{l}\text { Source } \\
\text { Condition }\end{array}$ & Steam supply is blanked off. Electrical power is maintained for use. \\
\hline Past Controls & $\begin{array}{l}\text { Radiation probes are located in the rail car unloading canyon, the balcony, and the main floor. These alarm locally and in the control } \\
\text { room. Heat and smoke detectors and a sprinkler system are installed throughout the facility. }\end{array}$ \\
\hline $\begin{array}{l}\text { Current } \\
\text { Controls }\end{array}$ & $\begin{array}{l}\text { Fire suppression system is active. Ventilations systems, CAMs, and stack high radiation alarms are active. Facility is inspected daily. } \\
\text { Raw water backflow preventer is inspected annually. Operating controls are applied to the instrument and control functions in the } \\
\text { facility. Normal radiological and criticality control, industrial safety, and hazardous materials controls apply. Administrative controls } \\
\text { are placed on composition of incoming waste shipments and transfers to tank farms. Other administrative controls are placed on HEPA } \\
\text { filter pressure drop, HEPA filter efficiency, and HEPA filter inlet temperature. Catch tank level is limited to } 80 \% \text { of capacity. }\end{array}$ \\
\hline $\begin{array}{l}\text { Planned } \\
\text { Controls }\end{array}$ & No planned changes to existing controls. \\
\hline Barriers & $\begin{array}{l}\text { Doors are closed during waste unloading operations. Ventilation systems are operating during unloading operations. Doors are closed } \\
\text { and locked when not staffed. }\end{array}$ \\
\hline $\begin{array}{l}\text { Chemical } \\
\text { Segregation } \\
\end{array}$ & Chemicals are segregated by being contained in the process vessels which are physically separated. \\
\hline $\begin{array}{l}\text { Monitoring and } \\
\text { Surveillance }\end{array}$ & Connected to Computer Automated Surveillance System (CASS). Facility is inspected daily. \\
\hline Fistorical Risks & $\begin{array}{l}\text { Original facility SAR analyzed for leaks, waste misrouting, backflow from tank farms, HEPA failure, contamination spread, personnel } \\
\text { radiation exposure, criticality, earthquake, tornado, high winds, thunderstorm, fire, loss of utilities, aircraft strike, and normal industrial } \\
\text { hazards. }\end{array}$ \\
\hline $\begin{array}{l}\text { Current or } \\
\text { Future Risks }\end{array}$ & $\begin{array}{l}\text { Current TWRS FSAR analyzes this facility for caustic spray leaks, HEPA failure, rail car leaks, spray leaks from waste transfer system, } \\
\text { and surface leaks resulting in pool. }\end{array}$ \\
\hline $\begin{array}{l}\text { Occurrence } \\
\text { History }\end{array}$ & No unplanned releases have been reported from this facility. \\
\hline Root Cause & N/A \\
\hline
\end{tabular}




\begin{tabular}{|c|c|}
\hline $\begin{array}{l}\text { Underground } \\
\text { Facilities }\end{array}$ & 51-mm (2-in.) raw water, 51-mm (2-in.) sanitary water, 152-mm (6-in.) raw water, septic tank, electrical. \\
\hline $\begin{array}{l}\text { Aboveground } \\
\text { Facilities }\end{array}$ & 152-mm (6-in.) steam line (capped). \\
\hline BIO Coverage & The facility is extensively described in the TWRS BIO. \\
\hline FSAR Coverage & The facility is extensively described in the TWRS FSAR. \\
\hline
\end{tabular}


FACILITY HAZARD PROFILE CHECKLIST

Rev. 0, April 20, 1998

\begin{tabular}{|l|l|l|l|l|l|l|l|l|l|l|}
\hline Facility ID: & 209-E & Facility Name: & \multicolumn{2}{|l|}{ 209-E Building } \\
\hline Owner/Operator & Location & Capacity & $\begin{array}{l}\text { Volume of } \\
\text { Contents }\end{array}$ & $\begin{array}{l}\text { Sludge } \\
\text { Volume }\end{array}$ & $\begin{array}{l}\text { Liquid } \\
\text { Volume }\end{array}$ & Risers & $\begin{array}{l}\text { Active/ } \\
\text { Inactive }\end{array}$ & $\begin{array}{l}\text { Fissile } \\
\text { Content }\end{array}$ & $\begin{array}{l}\text { Rad } \\
\text { Content }\end{array}$ \\
\hline TWRS/WMI & $\begin{array}{l}\text { 200-E Area, 7th Street, } \\
\text { Between B-Plant and 241- } \\
\text { C tank farm }\end{array}$ & $\begin{array}{l}\text { Detailed } \\
\text { below }\end{array}$ & $\begin{array}{l}\text { Detailed } \\
\text { below }\end{array}$ & Unknown & $\begin{array}{l}\text { Detailed } \\
\text { below }\end{array}$ & N/A & Inactive & $\begin{array}{l}\text { Detailed } \\
\text { below } \\
\vdots\end{array}$ & $\begin{array}{l}\text { Detailed } \\
\text { below }\end{array}$ \\
\hline
\end{tabular}

Geometry The 209-E Building is an L-shaped building consisting of the Critical Assembly Room (CAR), Mix Room, Equipment Room, a change room, and office space. The CAR is $10.67 \mathrm{~m}(35 \mathrm{ft})$ by $10.67 \mathrm{~m}(35 \mathrm{ft})$ with a $6.1 \mathrm{~m}(20 \mathrm{ft})$ high ceiling. The Mix room is approximately $6.7 \mathrm{~m}(22 \mathrm{ft})$ by $9.75 \mathrm{~m}(32 \mathrm{ft})$ with a $3 \mathrm{~m}(10 \mathrm{ft})$ ceiling. The Equipment Room is $7.92 \mathrm{~m}(26 \mathrm{ft})$ by $8.53 \mathrm{~m}(28 \mathrm{ft})$ with $3 \mathrm{~m}$ (10 ft) ceilings. The change room is $6.1 \mathrm{~m}(20 \mathrm{ft})$ by $9.75 \mathrm{~m}(32 \mathrm{ft})$ with $3 \mathrm{~m}(10 \mathrm{ft})$ ceilings. The office space is apptoximately $24.38 \mathrm{~m}$ $(80 \mathrm{ft})$ by $10.67 \mathrm{~m}(35 \mathrm{ft})$ with $3 \mathrm{~m}$ ( $10 \mathrm{ft})$ ceilings. Geometry of individual vessels within the facility is described under "Hardware" below.

The facility is not connected to other TWRS facilities. There are twelve tanks within the CAR, nine tanks within the Mix Room, and a drain tank located adjacent to the CAR that was used to send low level solutions to a crib.

Configuration

As metioned above, there are twelve tanks within the CAR, nine tanks within the Mix Room, and a drain tank located adjacent to the CAR. All of these tanks, are inactive and are slated to be decommisioned during facility decontamination and decommisioning. These tanks therefore have no future use. Support systems at the 209-E Building include an air purge system, an exhaust ventilation system, and a fire suppression system.

Twelve process tanks were used for solution handing. These tanks include TK-101, TK-102, TK-103, TK-104, TK-105, TK-106, located in the CAR and TK-213, TK-231, TK-232, TK-233, TK-234, and TK-235, located in the Mix Room. Per the PNNL status report, these tanks were flushed, are tied into the exhaust ventilation system, and have an air purge system to remove any generated hydrogen.

Another tank, TK-111, was used as a drain tank and is located underground, adjacent to the south end of the facility. This passively ventilated tank was sampled routinely, where it was determined that plutonium levels were below limits for discharging the contents to a crib. A recent vapor sample of the drain tank (TK-111) identified no detectable flammable gas within the tank.

One tank, TK-108, contained water and not process solution; it is open to room atmosphere, is located in the CAR, and is considered flushed since it only contained water.

The experimental vessels, TK-141, TK-161, and TK-162, have a bottom drain and are vented to the exhaust ventilation system for hydrogen removal. These tanks are all located in the CAR. As stated in the status report, TK-141 was thoroughly flushed. The status report states that an NDA was performed to provide "before" plutonium quantities (i.e., baseline indications prior to decontamination efforts). This was used as a guide to perform limited decontamination on certain experimental vessels. TK-161 and TK-162, each assayed by NDA to contain $4 \mathrm{~g}$ of plutonium, fell into this realm. 


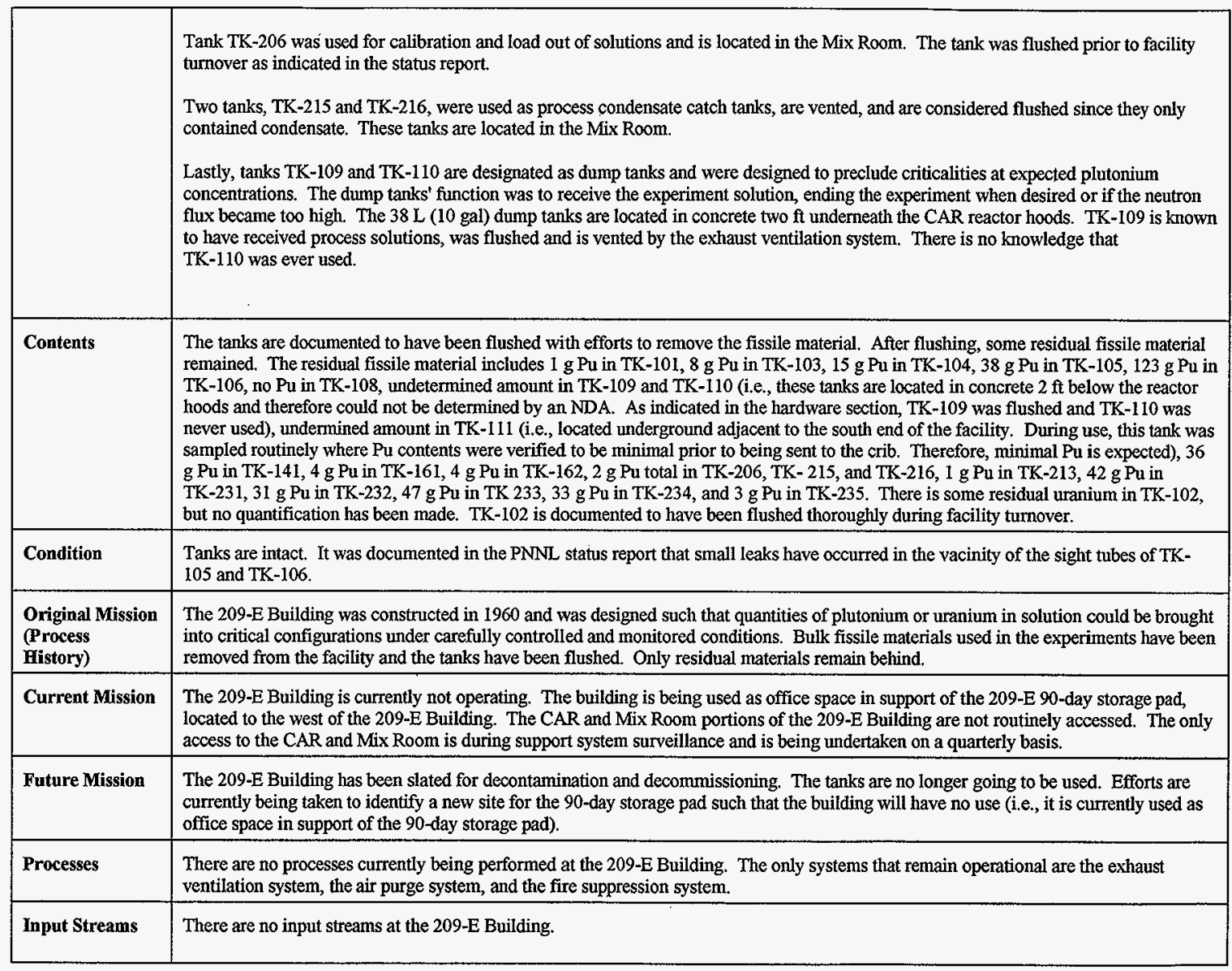




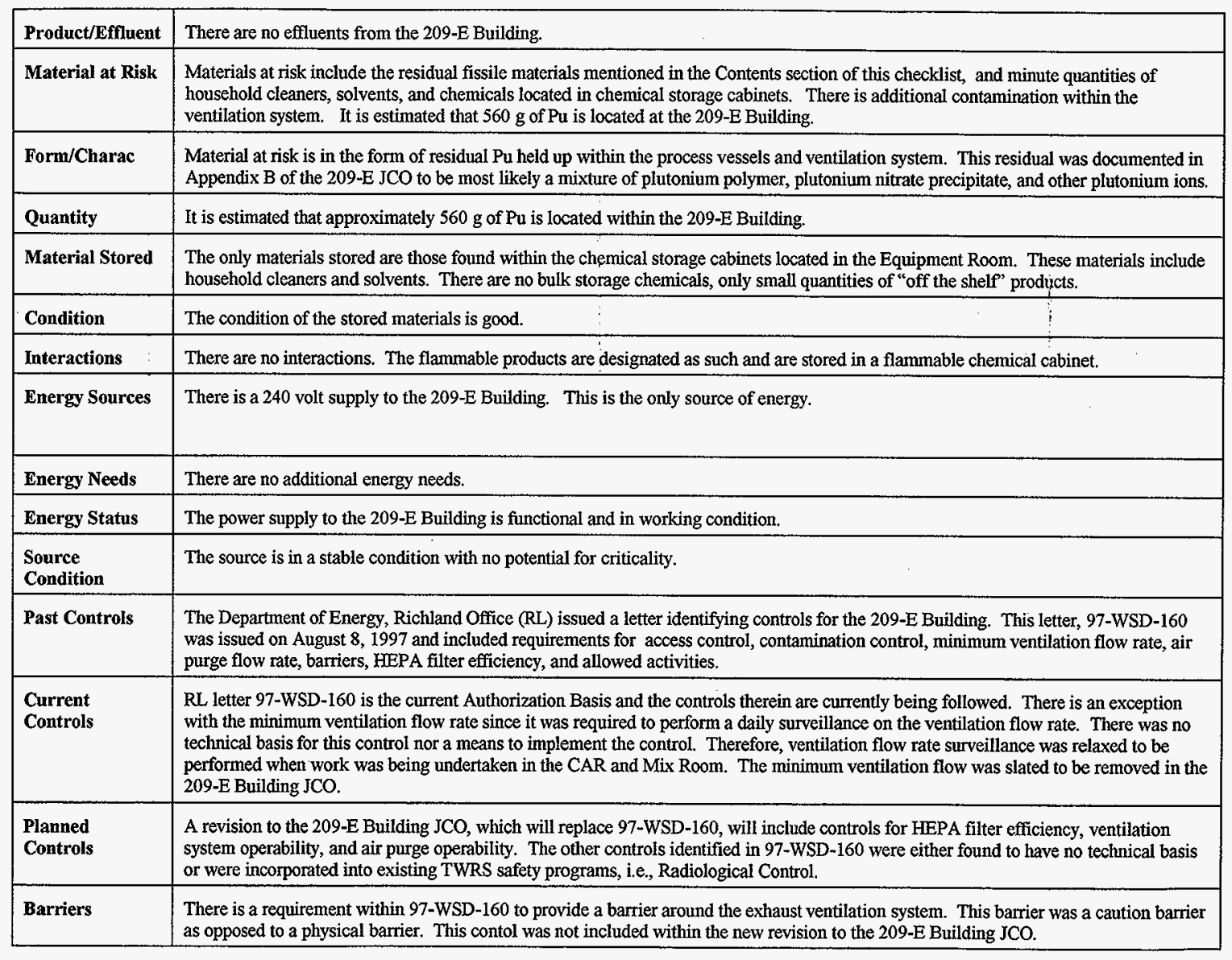




\begin{tabular}{|c|c|}
\hline $\begin{array}{l}\text { Chemical } \\
\text { Segregation }\end{array}$ & $\begin{array}{l}\text { As noted in the Materials at Risk section of this checklist, the chemicals are segrated depending on whether they are flammable or not. } \\
\text { These chemicals are only household products and are in limited quantitiy. There are no bulk chemicals stored. }\end{array}$ \\
\hline $\begin{array}{l}\text { Safeguards and } \\
\text { Security }\end{array}$ & $\begin{array}{l}\text { Access to the CAR and Mix Room is controlled through the facility manager. Additionally, there is a sign-in sheet to ensure that all } \\
\text { visitors are accounted for in case of an emergency. }\end{array}$ \\
\hline $\begin{array}{l}\text { Monitoring and } \\
\text { Surveillance }\end{array}$ & $\begin{array}{l}\text { Currently, the exhaust ventilation system's operability is being verified daily, the air purge systems operability is being verified } \\
\text { quarterly, and the HEPA filter efficiency is being verified annually. These verifications are being performed per } 97 \text {-WSD-160. Once the } \\
209-\mathrm{E} \text { Building JCO gains RL approval, the exhaust ventilation system's operability and air purge system's operability will be verified } \\
\text { every } 90 \text { days and the HEPA filter efficiency will be verified annually. }\end{array}$ \\
\hline $\begin{array}{l}\text { Current or } \\
\text { Future Risks }\end{array}$ & $\begin{array}{l}\text { Since the facility is in a shut down mode and will not be operated again, and also because the configuration of remaining fissile material } \\
\text { precludes a criticality, criticalities are not a current or future risk. }\end{array}$ \\
\hline $\begin{array}{l}\text { Occurrence } \\
\text { History }\end{array}$ & $\begin{array}{l}\text { Occurrence History at the } 209 \text {-E Building includes two missed surveillances that were required by the Authorization Basis. The } \\
\text { surveillances were regained shortly thereafter. No additional USQs resulted from the missed surveillances. }\end{array}$ \\
\hline $\begin{array}{l}\text { Records } \\
\text { Location }\end{array}$ & $\begin{array}{l}\text { The cognizant engineer of the facility has many of the safety documents including original operational documents and more recent shut } \\
\text { down status reports. Many of the experiments and records of past operations are still classified since they involved criticalities. } \\
\text { However, sufficient information is known about the process. Information was also obtained during conversations with a past facilility } \\
\text { manager. Subsequent information was obtained during recent entries into the CAR and Mix Room. }\end{array}$ \\
\hline Records Access & With the exception to the classified information, the cognizant engineer of the facility can provide the access to the records. \\
\hline $\begin{array}{l}\text { Adjacent } \\
\text { Facility Location }\end{array}$ & $\begin{array}{l}\text { Adjacent facilities include the } 90 \text {-day storage pad to the west of the 209-E Building, building } 2718 \text { located to the southwest of the } 209-\mathrm{E} \\
\text { Building, Hot Semi-Works located to the east of the } 20 \mathrm{p}-\mathrm{E} \text { Building, and a mobile office MO-434 located to the northeast of the } 209-\mathrm{E} \\
\text { Building. }\end{array}$ \\
\hline $\begin{array}{l}\text { Underground } \\
\text { Facilities }\end{array}$ & $\begin{array}{l}\text { The only underground facility at the } 209-\mathrm{E} \text { Building is TK-111 which is discussed in the Hardware and Contents sections of this } \\
\text { checklist. }\end{array}$ \\
\hline
\end{tabular}


The 209-E Building is not within the TWRS BIO. The current Authorization Basis is RL letter 97-WSD-160, which is soon to be replaced by revision 2 of the 209-E Justification for Continued Operation. It should be noted that no plans have been made to amend the $\mathrm{BIO}$ and incorporate the $\mathrm{JCO}$. The JCO is a stand alone Authorization Basis and will serve as the Authorization Basis until a Safety Analysis Report for deactivation has gained RL approval.

FSAR Coverage Like the BIO, there are no plans to incoroporate the 209-E Building into the FSAR. The JCO will adequately serve as the Authorization Basis for the 209-E Building until a Safety Analsis Report for Deactivation is approved by RL. Efforts are currently planned to deactivate the facility within a few years, provided funding and resources remain intact. 
FACILITY HAZARD PROFLE CHECKLIST

Rev 0, April 24, 1998

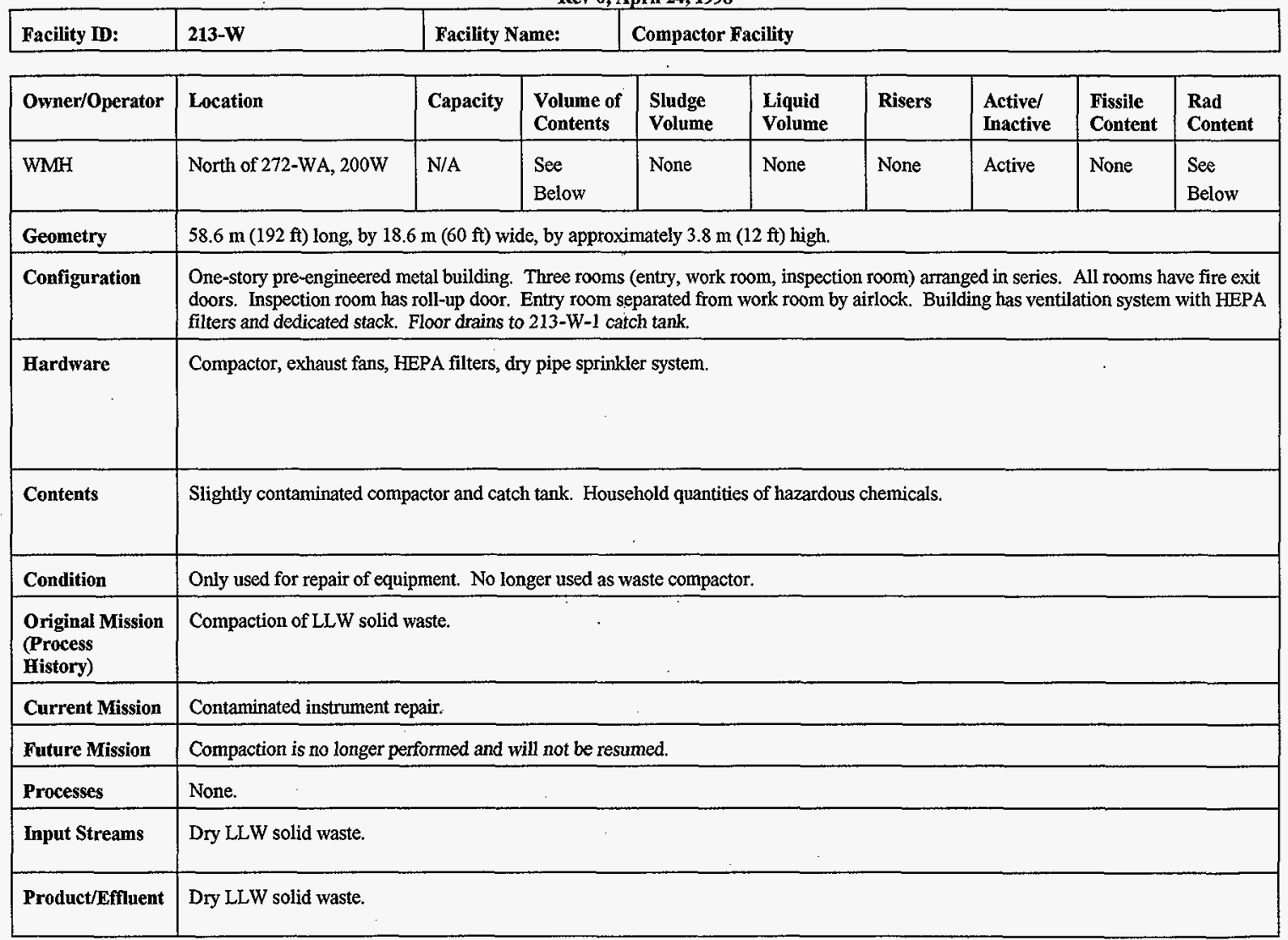




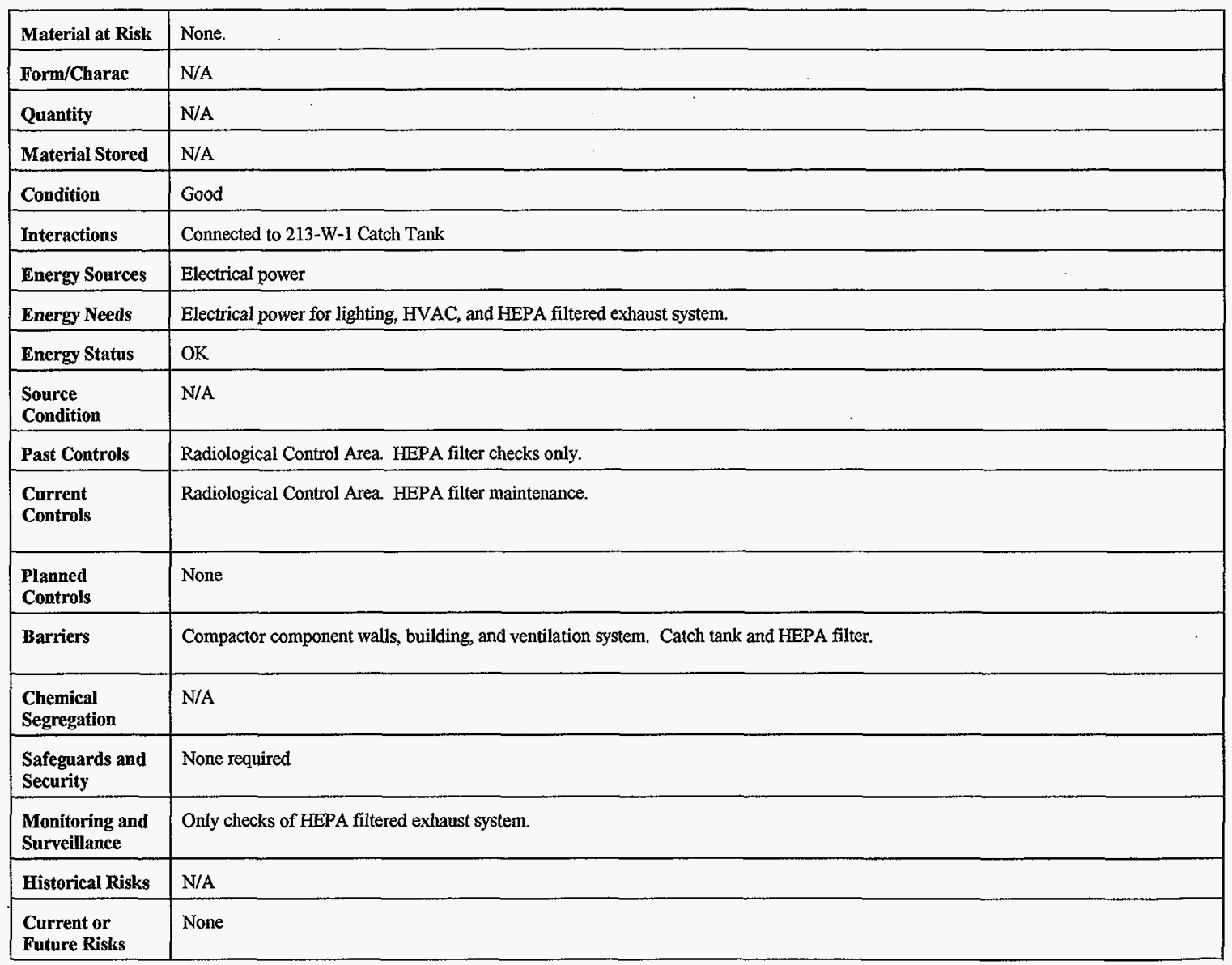




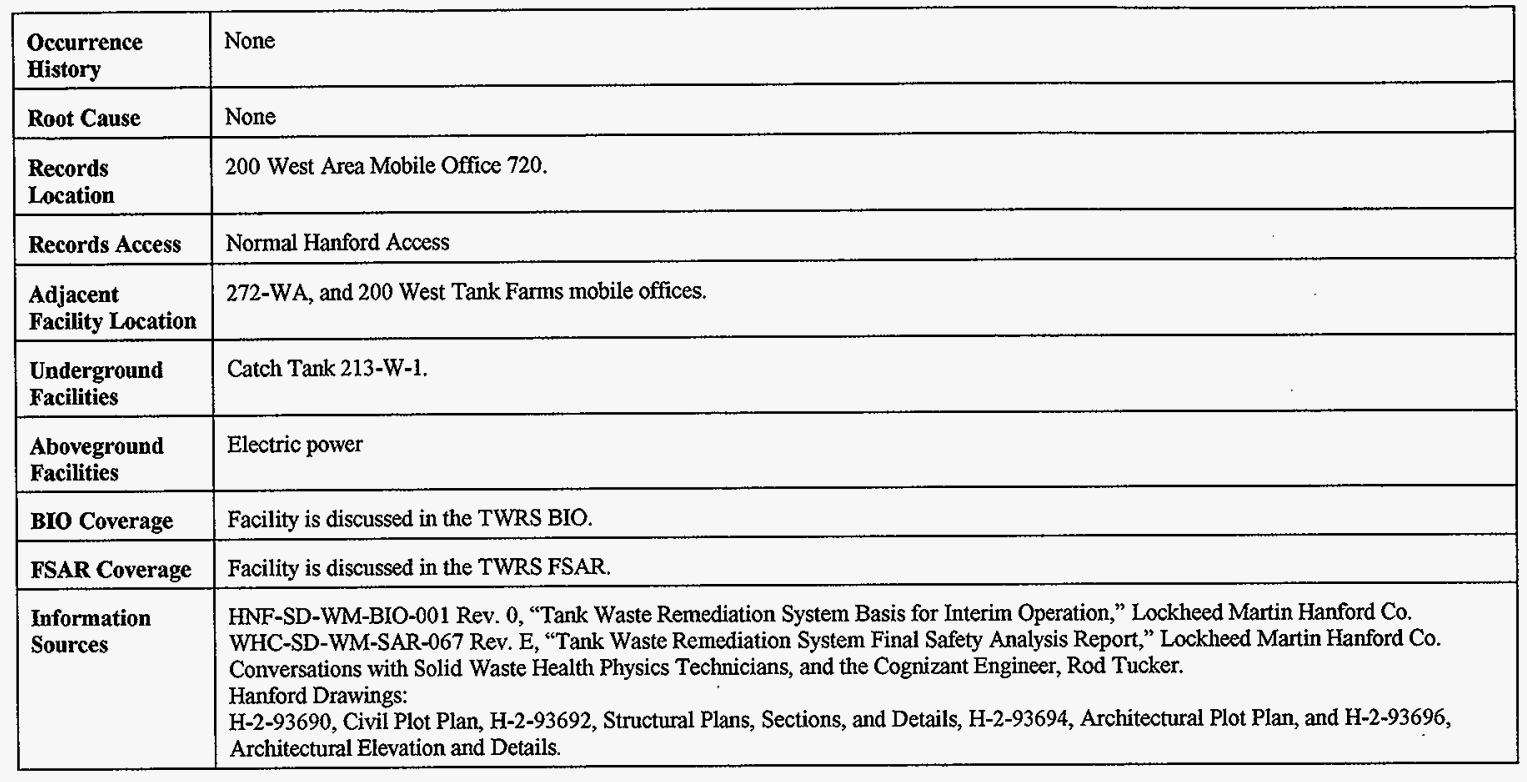


FACUITY HAZARD PROFLE CHECKLIST

Rev. 0, April 20, 1998

\begin{tabular}{|l|l|l|l}
\hline Facility D: & 216-BY-201 & Facility Name: & Supernatant Dispasal Flush Tank \\
\hline
\end{tabular}

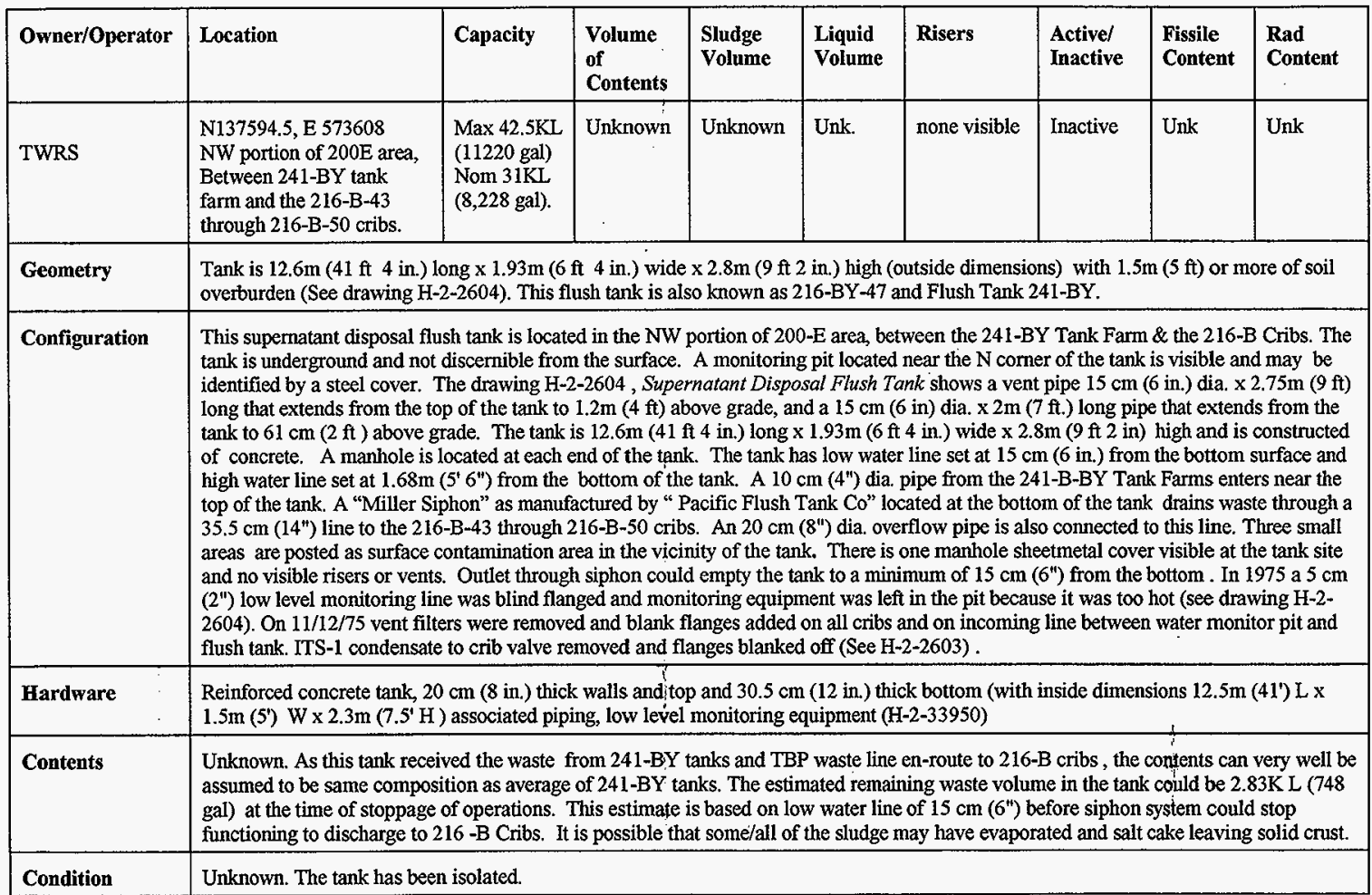




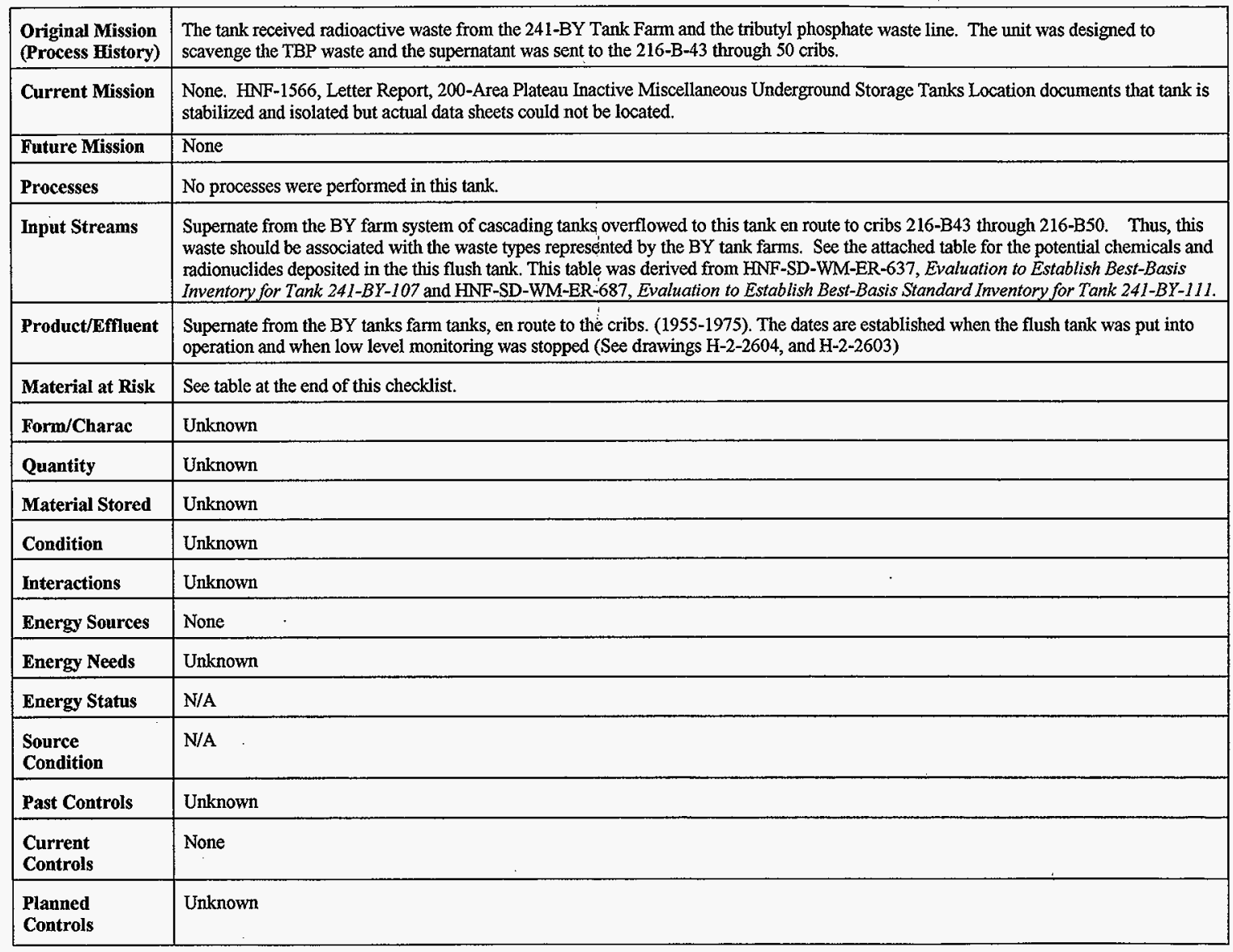




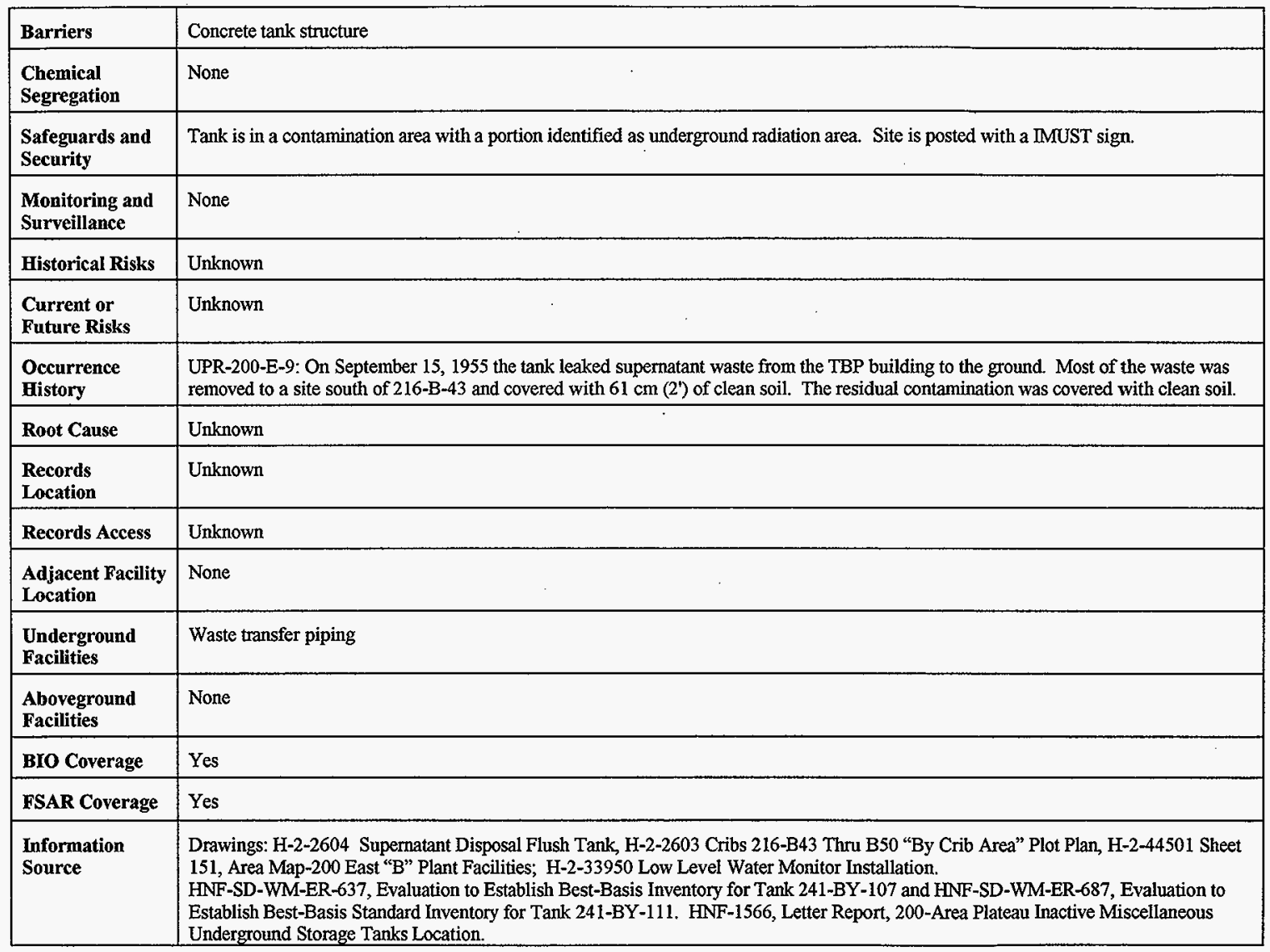


Table 1. Tank 216-8Y-201 Engineering Assessment-Based Solid and Liquid Compositions (Same as average 241-BY Tank Farm).

\begin{tabular}{|c|c|c|}
\hline 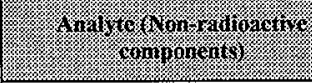 & 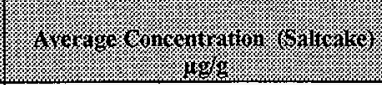 & 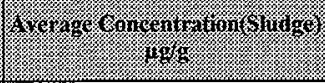 \\
\hline Al & 17,633 & 29,550 \\
\hline $\mathrm{Bi}$ & $<52.4$ & NR \\
\hline $\mathrm{Ca}$ & 308 & 11,175 \\
\hline Chloride & 1,736 & 3,570 \\
\hline $\mathrm{Cr}$ & 1,359 & 1,670 \\
\hline Fluoride & 4,883 & 4,220 \\
\hline $\mathrm{Fe}$ & 538 & 26,500 \\
\hline $\mathrm{Pb}$ & 82 & 1,880 \\
\hline $\mathrm{Mn}$ & 39.1 & 228 \\
\hline $\mathrm{Ni}$ & 106 & 6,815 \\
\hline Nitrate & 335,000 & 111,000 \\
\hline Nitrite & 24,037 & 43,200 \\
\hline Oxalate & 11,297 & 5,870 \\
\hline Phosphate & 8,120 & 32,100 \\
\hline$P$ & 2,231 & 15,500 \\
\hline $\mathrm{K}$ & 1,704 & 2,930 \\
\hline $\mathrm{Si}$ & 272 & 1,190 \\
\hline $\mathrm{Na}$ & 213,000 & 145,500 \\
\hline $\mathrm{Sr}$ & 64 & 6,840 \\
\hline Sulfate & 13,433 & 18,400 \\
\hline TIC & 19,580 & 6,005 \\
\hline TOC & 3,890 & 15,750 \\
\hline$U$ & 374 & 20,900 \\
\hline $\mathrm{Zr}$ & 8.64 & 304.35 \\
\hline Density $(\mathrm{g} / \mathrm{mL})$ & 1.71 & 1.76 \\
\hline $\mathrm{wt} \% \mathrm{H}_{2} \mathrm{O}$ & 21.6 & 33.9 \\
\hline
\end{tabular}


Table 1. Tank 216-BY-201 Engineering Assessment-Based Solid and Liquid Compositions (Same as average 241-BY Tank Farm).

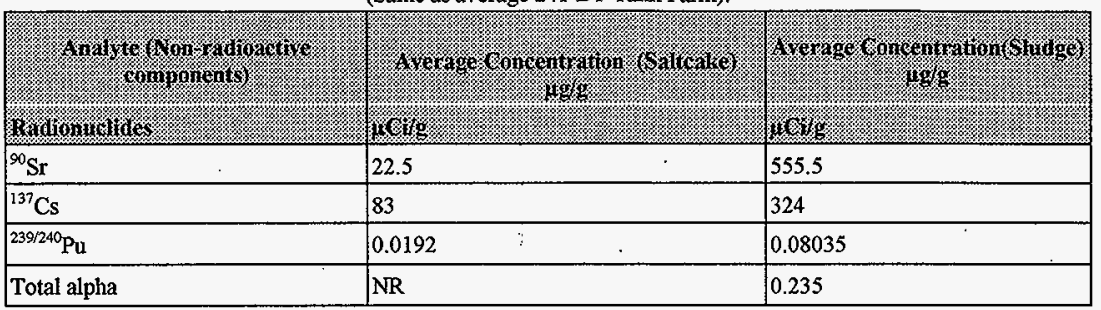

NR: Not reported 
FACILITY HAZARD PROFILE CHECKLIST

Rev. 0, April 20, 1998

\begin{tabular}{|c|c|c|c|c|c|c|c|c|c|}
\hline Facility W: & 216-TY-201 & \multicolumn{2}{|c|}{ Facility Name: } & \multicolumn{6}{|c|}{ Supernatant Disposal Flush Tank } \\
\hline Owner/Operator & Location & Capacity & $\begin{array}{l}\text { Volume } \\
\text { of } \\
\text { Contents }\end{array}$ & $\begin{array}{l}\text { Sludge } \\
\text { Volume }\end{array}$ & $\begin{array}{l}\text { Liquid } \\
\text { Volume }\end{array}$ & Risers & $\begin{array}{l}\text { Active/ } \\
\text { Inactive }\end{array}$ & $\begin{array}{l}\text { Fissile } \\
\text { Content }\end{array}$ & $\begin{array}{l}\text { Rad } \\
\text { Content }\end{array}$ \\
\hline TWRS & $\begin{array}{l}\text { N } 136417 \text {, E } 566946, \\
200 W \text { area, East of } 24 \mathrm{I}- \\
\text { TY tank farm, approx } \\
65.5 \mathrm{~m}\left(215^{\prime}\right) \text { E of Camden } \\
\text { Ave and } 152 \mathrm{~m}\left(500^{\prime}\right) \mathrm{N} \text { of } \\
\text { 22nd Street. }\end{array}$ & $\begin{array}{l}\text { Max. Cap: } \\
36.24 \mathrm{~K} \mathrm{~L} \\
\text { (9573 gal) } \\
\text { Nom. Cap: } \\
26.57 \mathrm{~K} \mathrm{~L} \\
(7020 \text { gal })\end{array}$ & Unknown & Unknown & Unknown & $\begin{array}{l}3-20 \mathrm{~cm} \\
\left(8^{\prime \prime}\right) \text { risers }\end{array}$ & Inactive & Unknown & Unknown \\
\hline Geometry & \multicolumn{9}{|c|}{ Tank is $7.11 \mathrm{~m}\left(23^{\prime} 4^{\prime \prime}\right)$ long $\times 3 \mathrm{~m}\left(10^{\prime}\right)$ wide $\times 2.9 \mathrm{~m}\left(9.5^{\prime}\right)$ high (outside), $1.5 \mathrm{~m}\left(5^{\prime}\right)$ of soil overburden (Drawing \# H-2-2670) } \\
\hline Configuration & \multicolumn{9}{|c|}{ 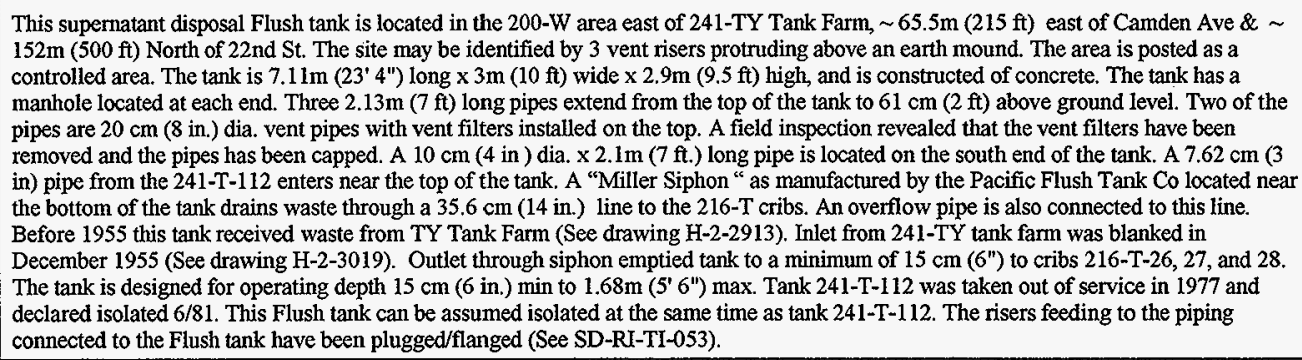 } \\
\hline Hardware & \multicolumn{9}{|c|}{$\begin{array}{l}\text { Reinforced concrete rectangular tank, } 30.5 \mathrm{~cm}\left(1^{\prime \prime}\right) \text { thick (with inside dimensions of } 6 . \mathrm{m}\left(21^{\prime} 4^{\prime \prime}\right) \mathrm{L} \times 2.44 \mathrm{~m}\left(8^{\prime}\right) \mathrm{W} \times 2.29 \mathrm{~m}\left(7.5^{\prime}\right) \mathrm{H} \text {. Three } \\
\text { risers and } 7.62 \mathrm{~cm}\left(3^{\prime \prime}\right) \text { sched. } 40 \text { inlet, } 20 \mathrm{~cm}\left(8^{\prime \prime}\right) \text { sched } 40 \text { siphon (trap) under tank and leading to } 35.6 \mathrm{~cm} \text { (14") sched } 40 \text { pipe to cribs. } \\
\text { Piping from } 241-\mathrm{T}-112 \text { tank to this Flush tank and piping from Flush tank to the } 216 \mathrm{cribs} \text {. }\end{array}$} \\
\hline Contents & \multicolumn{9}{|c|}{$\begin{array}{l}\text { Unknown. As this tank was en route from } 241-\mathrm{T}-112 \text { in the T Tank farm, the contents can very well be assumed to be same as in the } 241- \\
\text { T-112 Tank. The estimated remaining waste volume in the tank could be } 2.4 \mathrm{~K} \mathrm{~L}(638 \text { gal) at the time of isolation. This estimate is based } \\
\text { on low water line of } 15 \mathrm{~cm}\left(6^{\prime \prime}\right) \text { before siphon system could stop functioning to discharge to } 216-\mathrm{T} \text { Cribs. It is possible that some/all of } \\
\text { the liquid may have evaporated and salt cake or sludge crust is left in the tank. }\end{array}$} \\
\hline
\end{tabular}

in) pipe from the 241-T-112 enters near the top of the tank. A "Miller Siphon" as manufactured by the Pacific Flush Tank Co located near The tank is designed for operating depth $15 \mathrm{~cm}\left(6 \mathrm{in}\right.$.) $\min$ to $\left.1.68 \mathrm{~m} \mathrm{(5^{ \prime }} 6^{\prime \prime}\right)$ max. Tank 241-T-112 was taken out of service in 1977 and

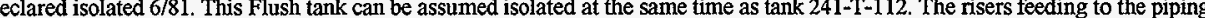

risers and $7.62 \mathrm{~cm}\left(3^{\prime \prime}\right)$ sched. 40 inlet, $20 \mathrm{~cm}\left(8^{\prime \prime}\right)$ sched 40 siphon (trap) under tank and leading to $35.6 \mathrm{~cm}$ (14") sched 40 pipe to cribs.

T-112 Tank. The estimated remaining waste volume in the tank could be $2.4 \mathrm{~K} \mathrm{~L} \mathrm{(638} \mathrm{gal)} \mathrm{at} \mathrm{the} \mathrm{time} \mathrm{of} \mathrm{isolation.} \mathrm{This} \mathrm{estimate} \mathrm{is} \mathrm{based}$ the liquid may have evaporated and salt cake or sludge crust is left in the tank.

Condition 


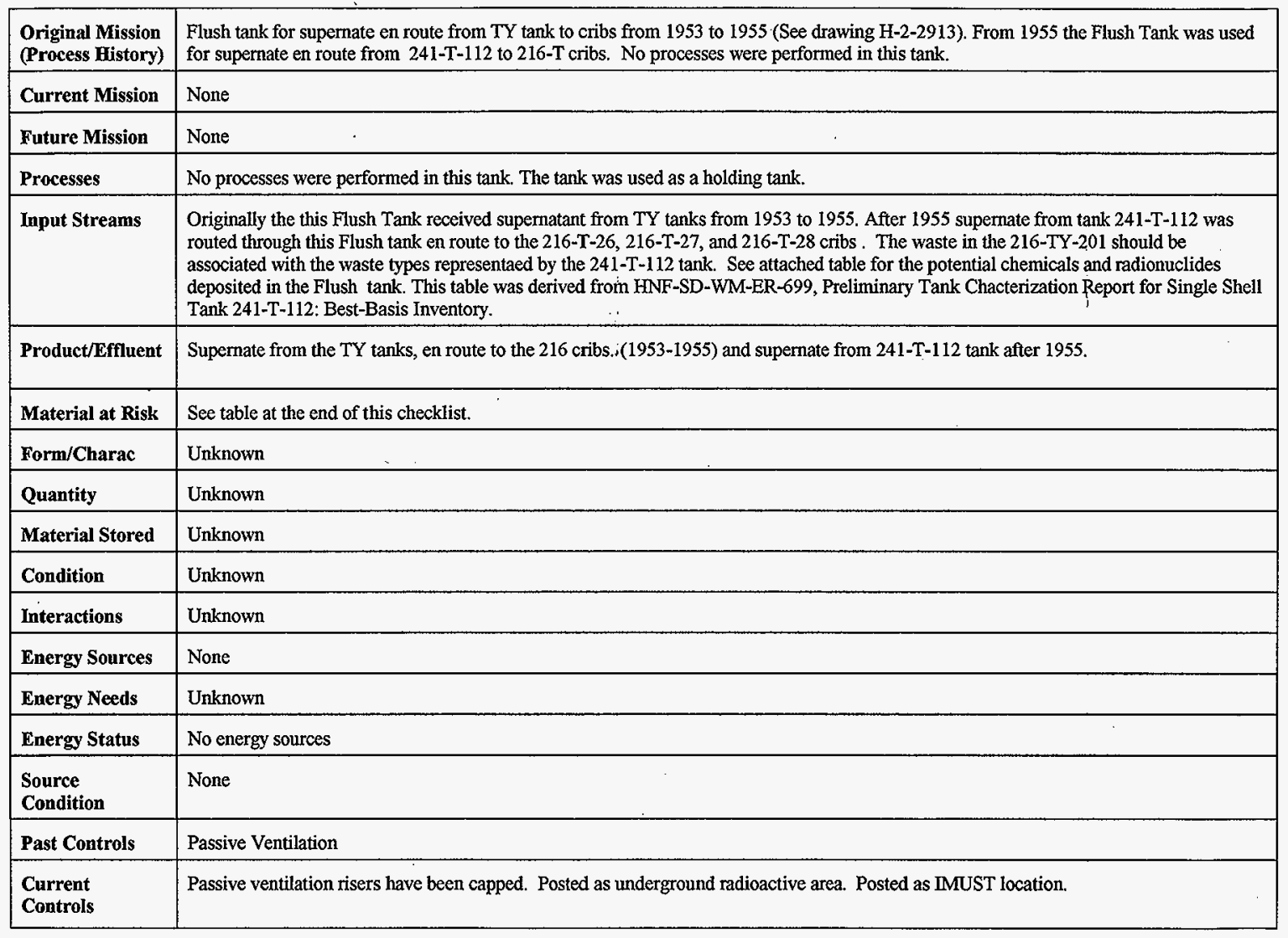




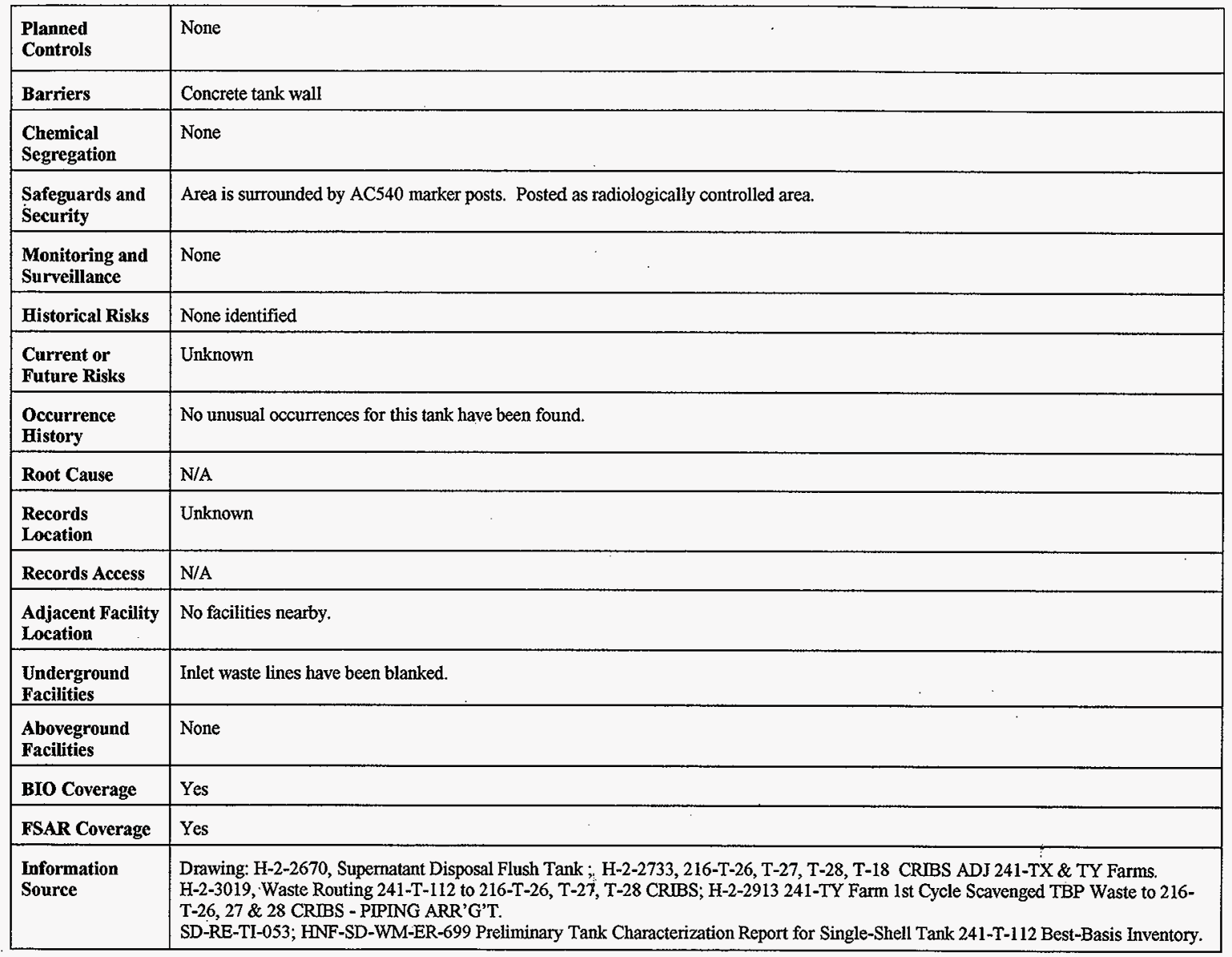


Table 1. Tank 216-TY-201 Engineering Assessment-Based Solid and Liquid Compositions (Same as 241-T-112)

\begin{tabular}{|c|c|c|}
\hline \multirow[b]{2}{*}{ Analyte } & \multicolumn{2}{|c|}{ 216-TY-201 concentration } \\
\hline & $\begin{array}{l}\text { Solids } \\
(\mu \mathrm{g} / \mathrm{g})\end{array}$ & $\begin{array}{c}\text { Supernatant } \\
(\mu \mathrm{g} / \mathrm{mL})\end{array}$ \\
\hline $\mathrm{Al}$ & 5,110 & $<10$ \\
\hline $\mathrm{Bi}$ & 28,800 & 44 \\
\hline $\mathrm{Ca}$ & $<1,890$ & $<20$ \\
\hline $\mathrm{Cr}$ & 2,110 & 691 \\
\hline $\mathrm{Fe}$ & 16,400 & $<10$ \\
\hline $\mathrm{Hg}$ & 2 & $\mathrm{NR}$ \\
\hline $\mathrm{K}$ & 1,270 & 603 \\
\hline $\mathrm{La}$ & 4,800 & $<10$ \\
\hline Mn & 5,970 & $<20$ \\
\hline $\mathrm{Na}$ & 41,000 & 57,200 \\
\hline $\mathrm{Ni}$ & 150 & 24 \\
\hline $\mathrm{Pb}$ & 395 & 46 \\
\hline $\mathrm{Si}$ & 8,810 & $<10$ \\
\hline $\mathrm{Sr}$ & 313 & $<20$ \\
\hline $\mathrm{U}$ & 3,100 & $<20$ \\
\hline $\mathrm{Zr}$ & $\leq 172$ & 8 \\
\hline $\mathrm{CO} 3$ & 4,960 & NR \\
\hline $\mathrm{Cl}$ & 428 & 511 \\
\hline F & 339 & 439 \\
\hline $\mathrm{OH}$ & 36,600 & 9,800 \\
\hline $\mathrm{NO}_{3}$ & 17,300 & 23,300 \\
\hline $\mathrm{NO}_{2}$ & 28,100 & 38,800 \\
\hline $\mathrm{P}$ as $\mathrm{PO}_{4}$ & 12,350 & 2,004 \\
\hline
\end{tabular}


Table 1. Tank 216-TY-201 Engineering Assessment-Based Solid and Liquid Compositions (Same as 241-T-112)

\begin{tabular}{|c|c|c|}
\hline & \multicolumn{2}{|c|}{ 216-TY-201 concentration } \\
\hline Analyte & $\begin{array}{l}\text { Solids } \\
(\mu g / g)\end{array}$ & $\begin{array}{l}\text { Supernatant } \\
(\mu \mathrm{g} / \mathrm{mL})\end{array}$ \\
\hline $\mathrm{S}_{2}$ as $\mathrm{SO}_{4}$ & 9,030 & 9,500 \\
\hline TOC & 3,160 & 3,000 \\
\hline Percent water & 73.9 & 85.1 \\
\hline $\mathrm{SpG}, \mathrm{kg} / \mathrm{L}$ & 1.28 & 1.10 \\
\hline Radionuclides $^{d}$ & $\mu \mathrm{Ci} / \mathrm{g}$ & $\mu \mathrm{Ci} / \mathrm{g}$ \\
\hline${ }^{137} \mathrm{Cs}$ & 0.184 & NR \\
\hline${ }^{90} \mathrm{Sr}$ & 6.0 & NR \\
\hline${ }^{99} \mathrm{Tc}$ & 0.0088 & NR \\
\hline${ }^{238} \mathrm{Pu}^{\mathrm{c}}$ & $5.71 \mathrm{E}-04$ & 0 \\
\hline${ }^{239} \mathrm{Pu}$ & 0.0709 & 0 \\
\hline${ }^{240} \mathrm{Pu}$ & 0.00692 & 0 \\
\hline${ }^{241} \mathrm{Am}$ & $1.0 \mathrm{E}-04$ & $9.0 \mathrm{E}-06$ \\
\hline Total alpha & 0.256 & 0.0233 \\
\hline
\end{tabular}

$N R=$ Not reported 
FACIITY HAZARD PROFILE CHECKLIST

Rev. 0, April 20, 1998

\begin{tabular}{|c|c|c|c|c|c|c|c|c|c|}
\hline Facility W: & 241-AX-151 & \multicolumn{2}{|c|}{ Facility Name: } & \multicolumn{6}{|c|}{ Diverter Station } \\
\hline Owner/Operator & Location & Capacity & $\begin{array}{l}\text { Volume of } \\
\text { Contents }\end{array}$ & $\begin{array}{l}\text { Sludge } \\
\text { Volume }\end{array}$ & $\begin{array}{l}\text { Liquid } \\
\text { Volume }\end{array}$ & Risers & $\begin{array}{l}\text { Active/ } \\
\text { Inactive }\end{array}$ & $\begin{array}{l}\text { Fissile } \\
\text { Content }\end{array}$ & $\begin{array}{l}\text { Rad } \\
\text { Content }\end{array}$ \\
\hline TWRS & $\begin{array}{l}200 \text { E Area, SW of } 241-A \\
\text { tank farm, N40980 } \\
\text { W48050 }\end{array}$ & $\begin{array}{l}\text { See } \\
\text { Hardware }\end{array}$ & Unknown & Unknown & Unknown & $\begin{array}{l}\text { see } \\
\text { config. } \\
\text { below }\end{array}$ & Inactive & Unk. & Unk. \\
\hline Geometry & \multicolumn{9}{|c|}{$\begin{array}{l}\text { The diverter station is } 13.4 \mathrm{~m}(44 \mathrm{ft}) \text { long } \times 3 \mathrm{~m}(10 \mathrm{ft}) \text { wide } \times 7.62 \mathrm{~m} .(25 \mathrm{ft}) \text { high, reinforced concrete structure (See } \mathrm{drawing} \mathrm{H}-2-44752 \\
\text { and } \mathrm{H}-2-44753) \text {. }\end{array}$} \\
\hline Configuration & \multicolumn{9}{|c|}{ 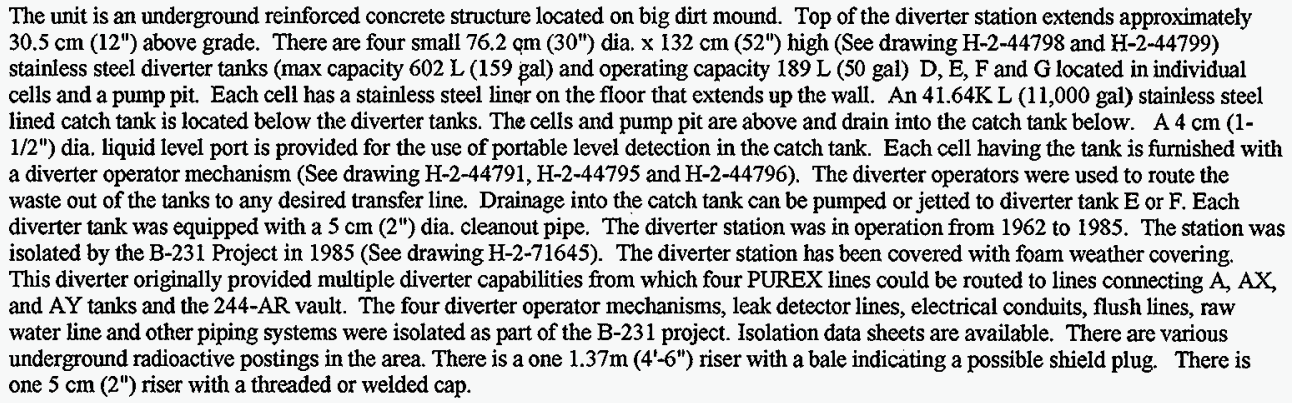 } \\
\hline Hardware & \multicolumn{9}{|c|}{$\begin{array}{l}\text { Catch Tank } 241-A X-151 \mathrm{CT}-42 \mathrm{~K} \text { L (11,000 gal) capacity (See drawing H-2-44612) with normal operating limit of } 20.8 \mathrm{~K} \text { L (5,500 gal) } \\
\text { Catch tank pump (P-AX-151) - 379 L (100 gal) pm (See drawing H-2-44612) } \\
\text { Diverter Tank 241-AX-151TKD - } 189 \mathrm{~L} \text { (50 gal) operating capacity (See drawing H-2-44798 and H-2-44799) } \\
\text { Diverter Tank 241-AX-151TKE - } 189 \mathrm{~L} \text { (50 gal) operating capacity (See drawing H-2-44798 and H-2-44799) } \\
\text { Diverter Tank 241-AX-151TKF - } 189 \mathrm{~L} \text { (50 gal) operating capacity (See drawing H-2-44798 and H-2-44799) } \\
\text { Diverter Tank 241-AX-151TKG - } 189 \mathrm{~L} \text { (50 gal) operating capacity (See drawing H-2-44798 and H-2-44799) } \\
\text { Associated internal piping systems } \\
\text { Diverter Station Spout (See drawing H-2-44795) }\end{array}$} \\
\hline
\end{tabular}




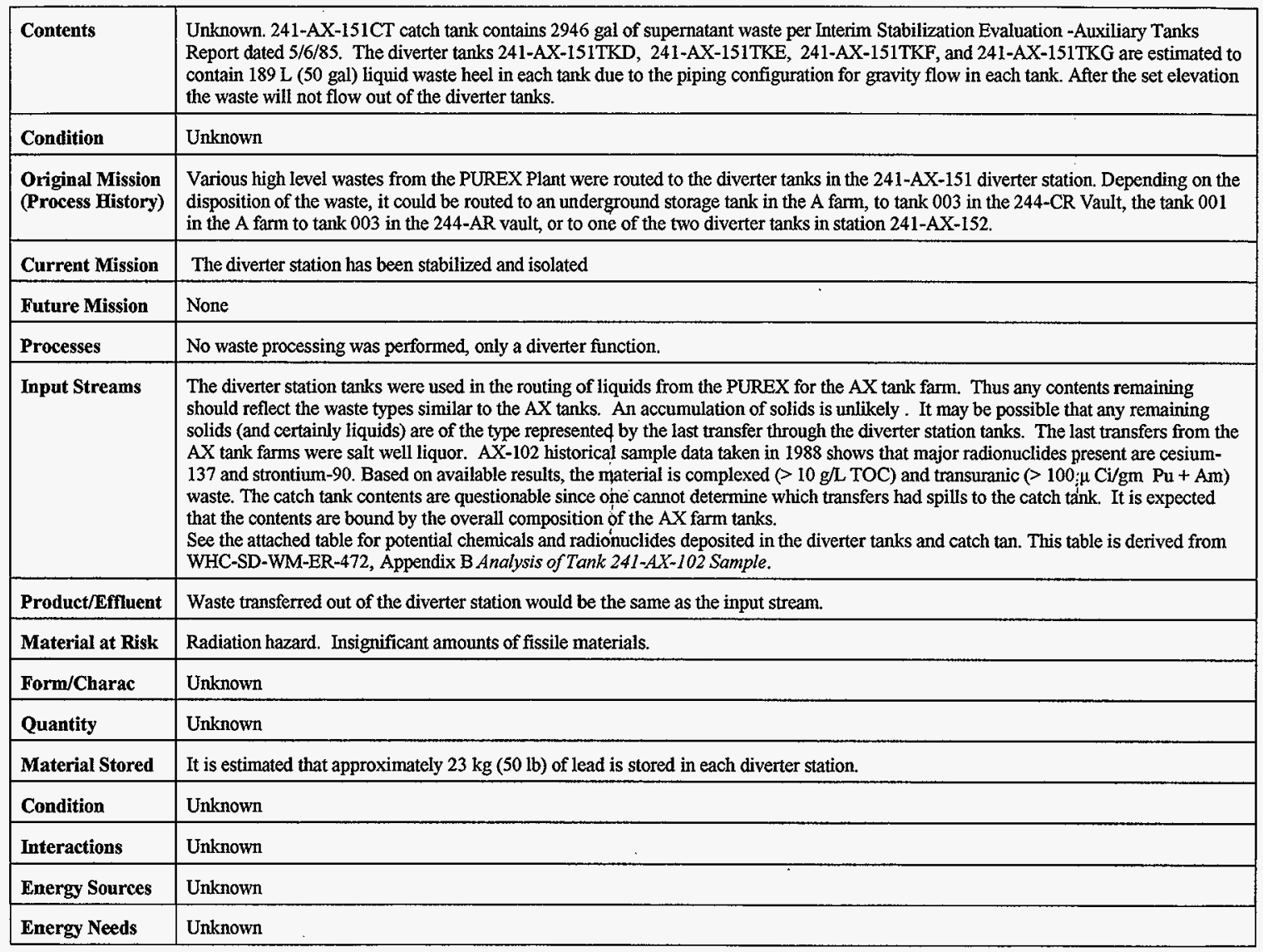




\begin{tabular}{|c|c|}
\hline Energy Status & Unknown \\
\hline $\begin{array}{l}\text { Source } \\
\text { Condition }\end{array}$ & Unknown \\
\hline Past Controls & Unknown \\
\hline $\begin{array}{l}\text { Current } \\
\text { Controls }\end{array}$ & None \\
\hline $\begin{array}{l}\text { Planned } \\
\text { Controls }\end{array}$ & None \\
\hline Barriers & Concrete tank wall and stainless steel liner. \\
\hline $\begin{array}{l}\text { Chemical } \\
\text { Segregation }\end{array}$ & None \\
\hline $\begin{array}{l}\text { Safeguards and } \\
\text { Security }\end{array}$ & The diverter station is located in a contamination area. \\
\hline $\begin{array}{l}\text { Monitoring and } \\
\text { Surveillance }\end{array}$ & None \\
\hline Historical Risks & None identified \\
\hline $\begin{array}{l}\text { Current or } \\
\text { Future Risks }\end{array}$ & Unknown \\
\hline $\begin{array}{l}\text { Occurrence } \\
\text { History }\end{array}$ & None identified \\
\hline Root Cause & N/A \\
\hline $\begin{array}{l}\text { Records } \\
\text { Location }\end{array}$ & Unknown \\
\hline Records Access & N/A \\
\hline $\begin{array}{l}\text { Adjacent Facility } \\
\text { Location }\end{array}$ & \\
\hline $\begin{array}{l}\text { Underground } \\
\text { Facilities }\end{array}$ & Waste transfer lines \\
\hline
\end{tabular}




\begin{tabular}{|l|l|}
\hline $\begin{array}{l}\text { Aboveground } \\
\text { Facilities }\end{array}$ & None \\
\hline BIO Coverage & Yes \\
\hline FSAR Coverage & Yes \\
\hline $\begin{array}{l}\text { Information } \\
\text { Source }\end{array}$ & $\begin{array}{l}\text { Drawings: H-2-44752, H-2-44753, H-2-44798, H-2-44799, H-2-44791, H-2-44795, H-2-44796, H-2-44612, H-2-71645 } \\
\text { WHC-SD-WM-ER-472, Appendix B Analysis of Tank 241-AX-102 Sample. }\end{array}$ \\
\hline
\end{tabular}

Table 1. Estimated Composition of 241-AX-151 Catch Tank Based on 241-AX-102 Sample

\begin{tabular}{|c|c|}
\hline Component & Value \\
\hline $\mathrm{pH}$ & 11.3 \\
\hline $\mathrm{NO}_{3}$ & $3.7 \mathrm{M}$ \\
\hline $\mathrm{NO}_{2}$ & $1,4 \mathrm{M}$ \\
\hline $\mathrm{TOC}$ & $36.8 \mathrm{~g} / 1$ \\
\hline $\mathrm{Na}$ & $7.32 \mathrm{M}$ \\
\hline $\mathrm{Am}$ & $1000 \mu \mathrm{Ci} / 1$ \\
\hline $\mathrm{Pu}$ & $97 \mu \mathrm{Ci} / 1$ \\
\hline $\mathrm{Cs}^{137}$ & $3.5 \mathrm{E}+05 \mu \mathrm{Ci} / 1$ \\
\hline $\mathrm{Co}^{60}$ & $7.1 \mathrm{E}+02 \mu \mathrm{Ci} / 1$ \\
\hline $\mathrm{Eu}^{154}$ & $3.5 \mathrm{E}+03 \mu \mathrm{Ci} / 1$ \\
\hline $\mathrm{Eu}^{155}$ & $4.7 \mathrm{E}+03 \mu \mathrm{Ci} / 1$ \\
\hline $\mathrm{Sr}^{90}$ & $1.7 \mathrm{E}+05 \mu \mathrm{Ci} / 1$ \\
\hline
\end{tabular}


FACILITY HAZARD PROFUL CHECKLIST

Rev. 0, April 20, 1998

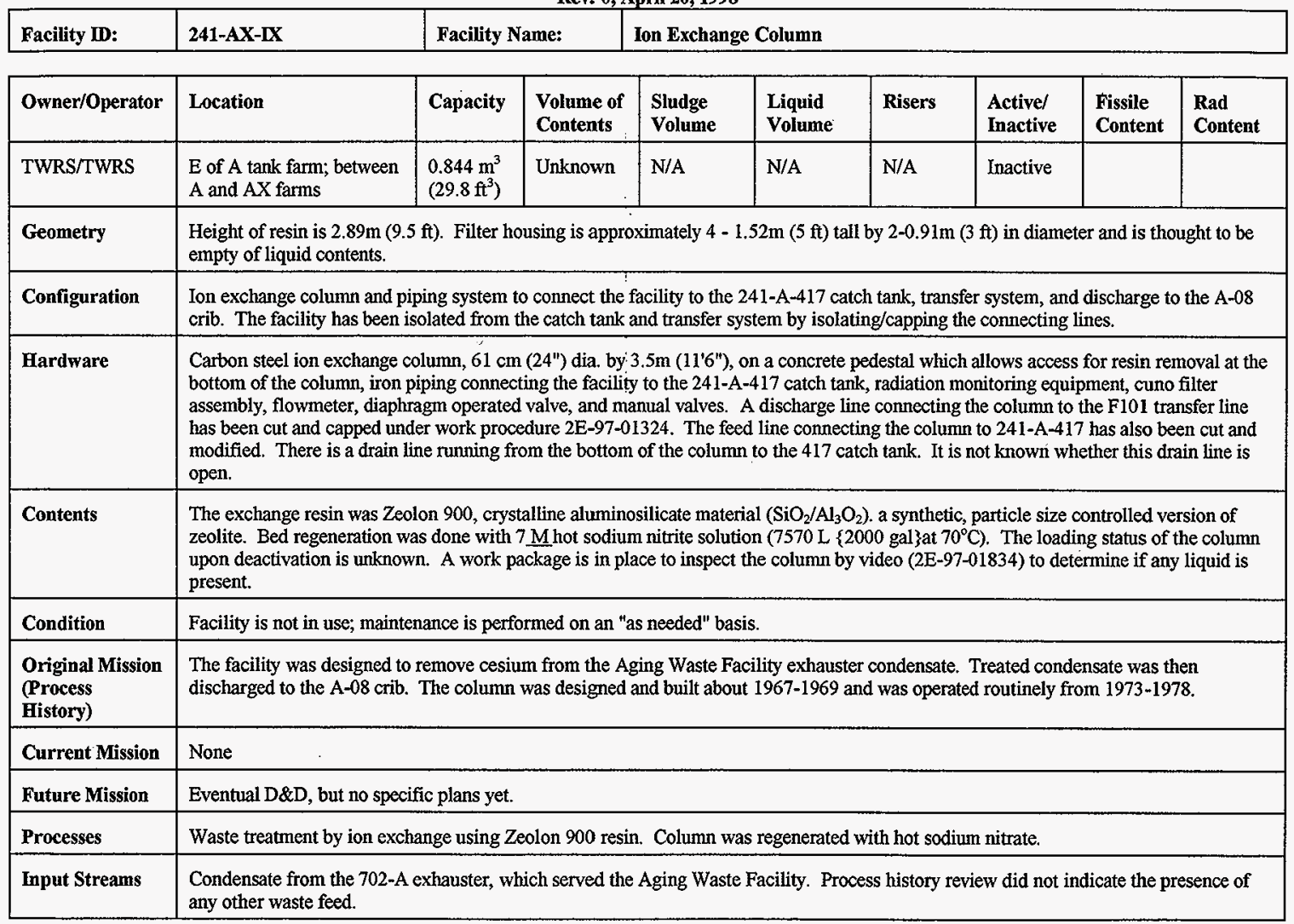




\begin{tabular}{|c|c|}
\hline Product/Effluent & $\begin{array}{l}\text { Treated condensate was discharged through a discharge line to the A-08 crib. Waste material from recharging the column was returned } \\
\text { to the F-101 transfer line to the 501-AY valve pit. }\end{array}$ \\
\hline Material at Risk & $\begin{array}{l}\text { Material used in the facility process is described above. No known hazardous material currently present. There is radioactive } \\
\text { contamination present from past operation. }\end{array}$ \\
\hline Form/Charac & Work packages are currently being completed to determine if any liquid waste remains in the system. None is expected. \\
\hline Quantity & Radioactive material dose rate data will be provided by the cognizant engineer. \\
\hline Condition & None \\
\hline Interactions & None apparent \\
\hline Energy Sources & $\begin{array}{l}\text { There is electrical power supply to the facility, which was used to power a } 2 \mathrm{kw} \text { electrical heater at the bottom of the column. The power } \\
\text { has not been disconnected at the junction box feeding the facility, however it has been confirmed that there is no amperage through the } \\
\text { facility circuit. There are no connections to steam lines. }\end{array}$ \\
\hline $\begin{array}{l}\text { Source } \\
\text { Condition }\end{array}$ & Electrical system appears to be sound. Cable are in conduit, and there are no exposed wires of obvious potential for short circuits. \\
\hline Past Controls & Have not identified past operating limits. \\
\hline $\begin{array}{l}\text { Current } \\
\text { Controls }\end{array}$ & $\begin{array}{l}\text { The area is in a posted rad zone and is surrounded by a radiological buffer area. Standard RWP requirements imposed on the A- } \\
\text { Complex are applicable to this facility. }\end{array}$ \\
\hline $\begin{array}{l}\text { Planned } \\
\text { Controls }\end{array}$ & No planned future use of the facility other than D\&D. \\
\hline Barriers & $\begin{array}{l}\text { The column is within a fenced area in the A Tank Farm complex. The column and filter housing are constructed of carbon steel, } \\
\text { containing any remaining radioactive material. There is contamination in the concrete base of the column. }\end{array}$ \\
\hline $\begin{array}{l}\text { Chemical } \\
\text { Segregation }\end{array}$ & No chemicals stored. \\
\hline
\end{tabular}




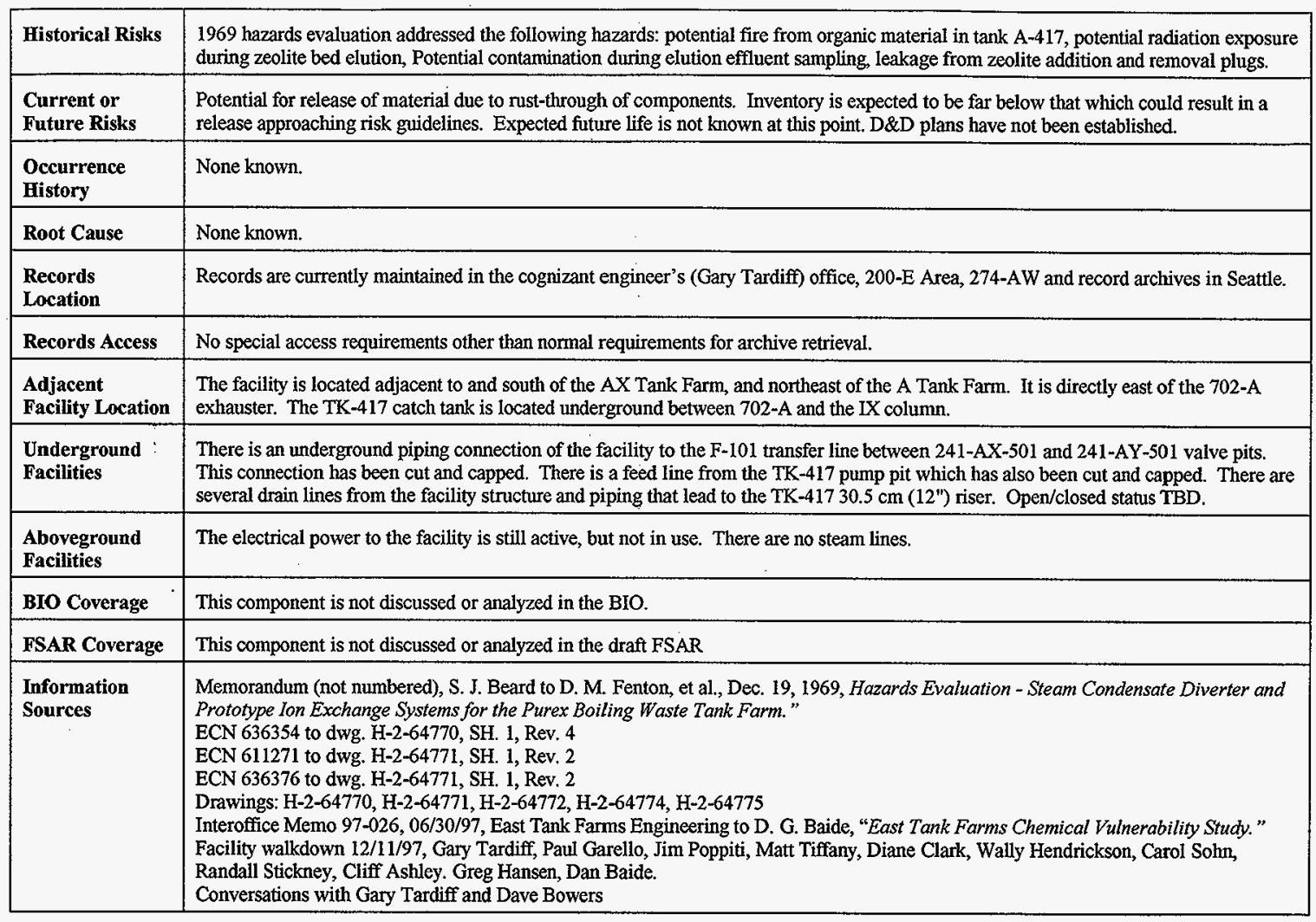


FACILITY HAZARD PROFILE CHECKLIST

Rev. 0, April 20, 1998

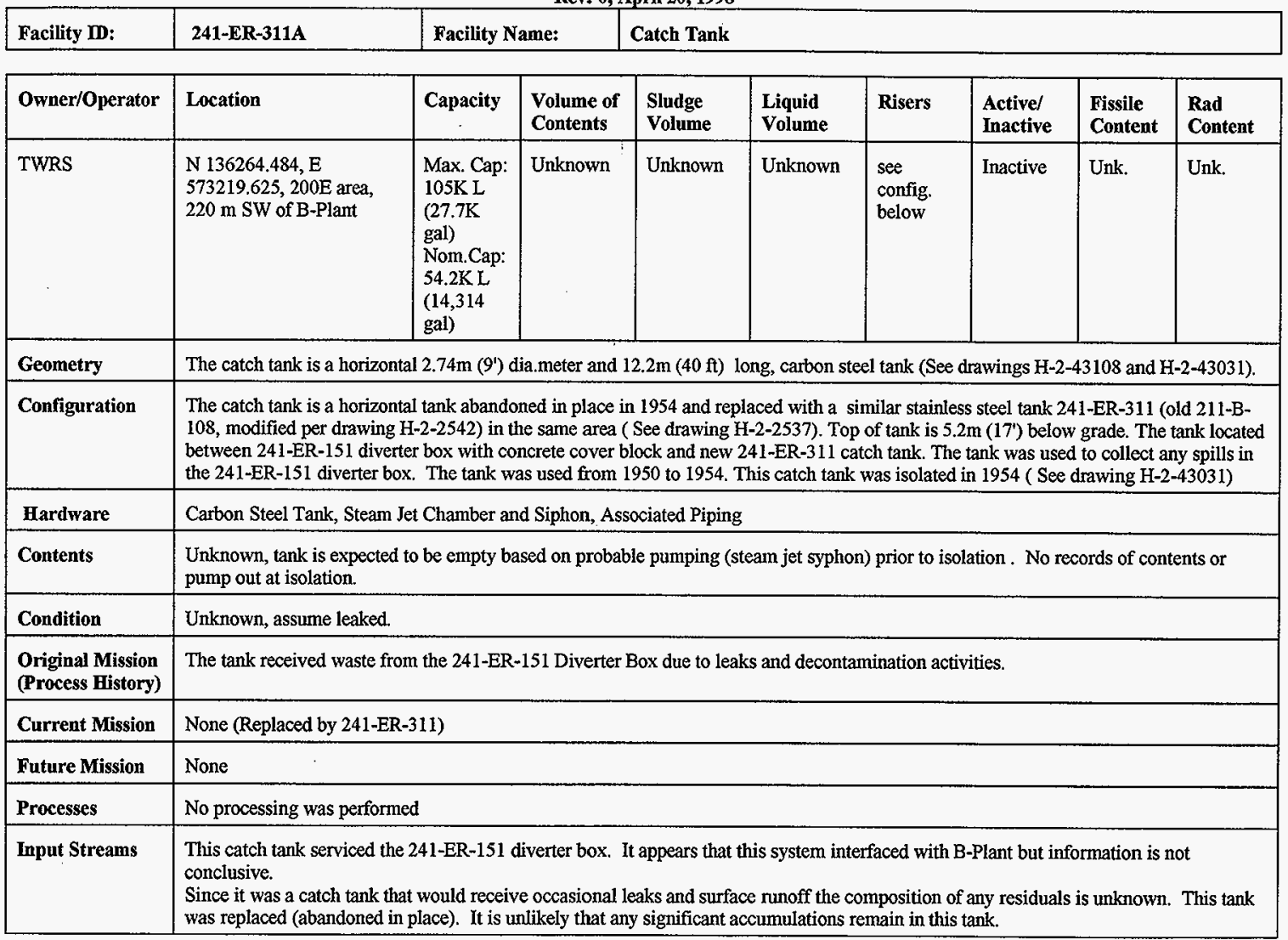




\begin{tabular}{|c|c|}
\hline pəI!!uәp! әuоN & 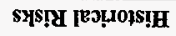 \\
\hline 2UON & 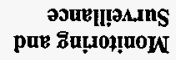 \\
\hline 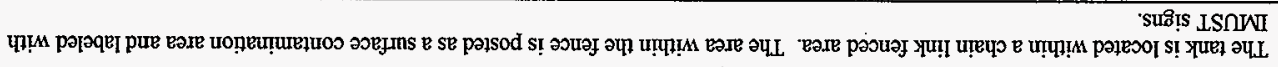 & $\begin{array}{r}\text { Ky!umas } \\
\text { pue sp.reniojes }\end{array}$ \\
\hline$\nabla / N$ & 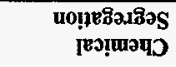 \\
\hline IIEM YUR」 & sıวฺ.reg \\
\hline วu०N & $\begin{array}{l}\text { spo.nutuo, } \\
\text { pəuueld }\end{array}$ \\
\hline əUON & $\begin{array}{l}\text { slo.juop } \\
\text { pua.sin? }\end{array}$ \\
\hline umourun & s[0גjuop 1sed \\
\hline$\forall / \mathbf{N}$ & $\begin{array}{r}\text { uoṇ!puos } \\
\text { วэ.InoS }\end{array}$ \\
\hline$\nabla / N$ & 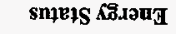 \\
\hline DUON & 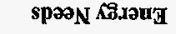 \\
\hline 2ưoN & 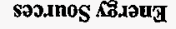 \\
\hline umourun & 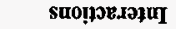 \\
\hline umouryun & иo!ฺ!puор \\
\hline uмourun & 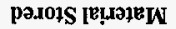 \\
\hline uмоurun & 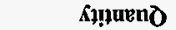 \\
\hline แмоч⿻й & 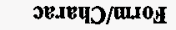 \\
\hline uмошч⿻् & 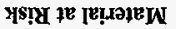 \\
\hline uмоurqu & fuənLug/asnpoxd \\
\hline
\end{tabular}




\begin{tabular}{|l|l|}
\hline $\begin{array}{l}\text { Current or } \\
\text { Future Risks }\end{array}$ & Unknown \\
\hline $\begin{array}{l}\text { Occurrence } \\
\text { History }\end{array}$ & Unknown \\
\hline Root Cause & Unknown \\
\hline $\begin{array}{l}\text { Records } \\
\text { Location }\end{array}$ & None located \\
\hline Records Access & N/A \\
\hline $\begin{array}{l}\text { Adjacent Facility } \\
\text { Location }\end{array}$ & \\
\hline $\begin{array}{l}\text { Underground } \\
\text { Facilities }\end{array}$ & None \\
\hline $\begin{array}{l}\text { Aboveground } \\
\text { Facilities }\end{array}$ & None \\
\hline BIO Coverage & Yes \\
\hline FSAR Coverage & Yes \\
\hline $\begin{array}{l}\text { Information } \\
\text { Source }\end{array}$ & Drawings: $\mathrm{H}-2-43108 ; \mathrm{H}-2-2537 ; \mathrm{H}-2-2542 ; \mathrm{H}-2-43031, \mathrm{H}-2-2538 ; \mathrm{H}-2-71670 ; \mathrm{H}-2-43034$ \\
\hline
\end{tabular}


FACILITY HAZARD PROFLE CHECKLIST

Rev. 0, April 20, 1998

\begin{tabular}{|c|c|c|c|c|c|c|c|c|c|}
\hline Facility $\mathbf{~ W :}$ & 242-S & Facility & Ime: & 42-S Evapo & tor Facility & & & & \\
\hline Owner/Operator & Location & Capacity & $\begin{array}{l}\text { Volume of } \\
\text { Contents }\end{array}$ & $\begin{array}{l}\text { Sludge } \\
\text { Volume }\end{array}$ & $\begin{array}{l}\text { Liquid } \\
\text { Volume }\end{array}$ & Risers & $\begin{array}{l}\text { Active/ } \\
\text { Inactive }\end{array}$ & $\begin{array}{l}\text { Fissile } \\
\text { Content }\end{array}$ & $\begin{array}{l}\text { Rad } \\
\text { Content }\end{array}$ \\
\hline TWRS & $\begin{array}{l}200-\text { W Area, North of } \\
241-S \text { tank farm and West } \\
\text { of } 241-S Y \text { tank farm }\end{array}$ & $\begin{array}{c}{ }^{*} \text { see } \\
\text { below }\end{array}$ & *see below & *see below & *see below & $\begin{array}{l}\text { not } \\
\text { applicable }\end{array}$ & $\begin{array}{l}\text { shutdown/ } \\
\text { standby } \\
\text { condition } \\
\text { III }\end{array}$ & TBD & TBD \\
\hline
\end{tabular}

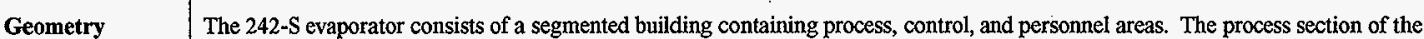
facility is approximately $22.86 \mathrm{~m}(75 \mathrm{ft}$.) long by $15.24 \mathrm{~m}(50 \mathrm{ft}$.) wide and $18.29 \mathrm{~m}(60 \mathrm{ft})$. high. The process portions of the facility contain the condenser and evaporator rooms and a separate vault for the ion exchange column. Geometry of individual vessels within the facility is described under "Hardware" below. The control room, lunch room, change room, and cold storage room are located in a onestory service building on the west side of the process rooms. The service building is approximately $13.72 \mathrm{~m}$ ( $45 \mathrm{ft}$ ). square.

In its original configuration, the facility was connected by piping to 241-S-102 (and later to 241-SY-102), which was the feed and blending tank for the evaporator and $241-\mathrm{S}-103$ which was the effluent tank for concentrated waste and other byproducts of the process. Tank 241-S-103 received the concentrated waste returned from the evaporation process and other facility effluents.; Treated condensate was routed to the $216-\mathrm{S}-25 \mathrm{crib}$. The facility was upgraded after shutdown with several piping connections to Tank 241-SY-103 to facilitate future waste concentration missions. The connecting lines to the 241-S Tank Farm were isolated so that the facility could no longer utilize single shell tanks. In 1985 several configuration changes were made to $242-\mathrm{S}$ to support a groundwater treatment campaign from the U1 and U2 cribs. Changes included routing from the cribs to tank TK-302-C outside of the facility, and through the ion exchange column. The building is ventilated by two ventilation systems serving the "hot" and "cold" sides of the facility. The hot side of the facility is maintained at a negative pressure relative to the cold side.

Hardware $\quad$ The facility consists of a number of components for evaporation of the liquid from the feed/staging tank 241-S-102 (or 241-SY-102) and return of the concentrated waste to Tank 241-S-103. Following is a listing of the major vessels within the facility, comprising the primary process components capable of containing significant quantities of liquids. Pumps, instrumentation systems, compressed air systems, utilities and the majority of the piping are not included in this list.

C-A-1 (Vapor/Liquid Separator) - Approximately $12.19 \mathrm{~m}$ (40 ft. ) high and $4.57 \mathrm{~m}$ (15 ft.) dia. $134.75 \mathrm{~K} \mathrm{~L} \mathrm{(35,600} \mathrm{gal.)} \mathrm{total} \mathrm{capacity,}$ $94.63 \mathrm{~K} \mathrm{~L}(25,000 \mathrm{gal}$.) normal operating capacity. C-A-1 is connected by $71.12 \mathrm{~cm}(28$-in.) recirculation line with E-A-1. Working liquid level approximately $5.18 \mathrm{~m}$ (17 ft.) from bottom. A $107 \mathrm{~cm}$ (42-in.) vapor line connects to E-C-1. Feed line from $241-\mathrm{S}-102$ (later 241-SY-102) connects to recirculation loop.

E-A-1 (Reboiler) - Approximately $4.57 \mathrm{~m}$ ( $15 \mathrm{ft}$.) high and $1.07 \mathrm{~m}$ ( $3.5 \mathrm{ft}$.) dia. E-A-1 is connected by $71.12 \mathrm{~cm}$ ( 28 -in.) recirculation line with C-A-1, $186 \mathrm{~m}^{2}\left(2000 \mathrm{ft}^{2}\right)$ surface area, $2.5 \times 10^{7} \mathrm{BTU} / \mathrm{hr}$. 
E-C-1 (Primary Condenser) - Vessel is approximately $5.5 \mathrm{~m}\left(18 \mathrm{ft}\right.$ ) long $2.13 \mathrm{~m}\left(7 \mathrm{ft}\right.$.) dia. $697 \mathrm{~m}^{2}\left(7,500 \mathrm{ft}^{2}\right)$ condenser surface area. $107 \mathrm{~cm}$ (42-in. ) vapor feed from C-A-1, connected to E-C-2, E-C-3, vessel vent system and TK-C-100. $2.2 \times 10^{7} \mathrm{BTU} / \mathrm{hr}$.

E-C-2 (Inter Condenser) - Approximately $2.13 \mathrm{~m}$ (7 ft.) long $0.46 \mathrm{~m}\left(1.5 \mathrm{ft}\right.$.) dia. $18.58 \mathrm{~m}^{2}\left(200 \mathrm{ft}^{2}\right)$ surface area. Connected to E-C-1, E$\mathrm{C}-3$, vessel vent system, and TK-C-100. $1 \times 10^{6} \mathrm{BTU} / \mathrm{hr}$.

E-C-3 (After Condenser) - Approximately $2.29 \mathrm{~m}$ ( $7.5 \mathrm{ft})$ long $25.4 \mathrm{~cm}\left(10 \mathrm{in}\right.$.) dia. $9.29 \mathrm{~m}^{2}\left(100 \mathrm{ft}^{2}\right)$ surface area. Connected to E-C-1, E-C-2, vessel vent system, and TK-C-100. $7 \times 10^{5} \mathrm{BTU} / \mathrm{hr}$.

TK-C-100 (Condensate Catch Tank) - 67.373K L (17,800 gal. ) approx 4.27m (14 ft.) dia. and 6.1m (20 ft). high. Connected to condensers and provides feed to LX-D-1 by $60 \mathrm{gpm}$ pump.

IX-D-1 (Ion Exchange Column) - Approx 1.22m (4 ft.) dia. and 4.88m (16 ft) high. $4288 \mathrm{~L}$ (1133 gal.) capacity. Process feed from TKC-100, effluent to 216-S-25 crib through diverter R-C-3 (diverts to TK-C-100) Eluent line from TK-E-01, Eluted waste drains to 241-S103. Reconfigured in 1985 to drain to Tank 241-SY-102.

TK-E-101 (Eluent Tank) - 15,897 L (4,200 gal.) approx 2.74m (9 ft. dia.) and 2.74m (9 ft.) high. Eluent line to IX-D-1, overflow line routed to tank 241-S-103. Reconfigured in 1985 to route overflow to Tank 241-SY-102.

TK-E-102 (Anti-Foam Tank) - $379 \mathrm{~L}$ (100 gal.), approx $76.2 \mathrm{~cm}$ (30 in) dia. and $81.28 \mathrm{~cm}(32 \mathrm{in}$.) high. Connected to raw water supply , C-A-1, overflow drain routed to tank 241-S-103.

TK-C-103 (Flow Measurement Tank) - $1893 \mathrm{~L}$ ( $500 \mathrm{gal}$ ) ) approx $1.83 \mathrm{~m}$ (6 ft.) long and $0.915 \mathrm{~m}(3 \mathrm{ft}$. )square. Connected to steam condensate line from $\mathrm{E}-\mathrm{A}-1$.

TK-E-104 (Decontamination Tank) - $2347 \mathrm{~L}$ (620 gal. ) approx $1.52 \mathrm{~m}$ (5 ft.) dia and $1.52 \mathrm{~m}$ ( $5 \mathrm{ft}$.) high. Connected to raw water supply, condensate catch tank, and process equipment and loadout room.

DU-C-1 (De-Entrainment Unit ) - Removes moisture from vessel vent system connected to condensers, drains to TK-C-100.

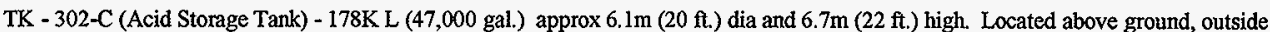
of the facility and was used for feed storage in the U1/U2 ground water clean-up campaign.

Floor Sump in hot side of facility $-3,785 \mathrm{~L}(1,000 \mathrm{gal}$.) capacity. approx $1.52 \mathrm{~m}(5 \mathrm{ft}$.) by $1.52 \mathrm{~m}(5 \mathrm{ft}$.) and $1.83 \mathrm{~m}(6 \mathrm{ft}$.) deep. Original routing to Tank $241-\mathrm{S}-102$. Configured during project B-464 for touting to Tank 241-SY-103. Collects all drainage from the hot side of the facility, currently contains some liquid. 

shutdown. According to the Operations representative, there is a residual of about 3-10.16 $\mathrm{cm}$ (4 in) of unidentified liquid remaining.

E-A-1 (Reboiler) - According to the shutdown plan (SD-WM-SSP-002) this vessel was drained and flushed during shutdown and is not thought to contain any residual liquids.

E-C-1 (Primary Condenser) - According to the shutdown plan (SD-WM-SSP-002) this vessel was drained and flushed during shutdown and is not thought to contain any residual liquids.

E-C-2 (Inter Condenser) - According to the shutdown plan (SD-WM-SSP-002) this vessel was drained and flushed during shutdown and is not thought to contain any residual liquids.

E-C-3 (After Condenser) - According to the shutdowri plan (SD-WM-SSP-002) this vessel was drained and flushed during shutdown and is not thought to contain any residual liquids.

TK-C-100 (Condensate Catch Tank) - The condensate patch tank was last used during the U1/U2 groundwater treatment campaign in 1985. It was not re-used. The tank contains approximately $8-34,065 \mathrm{~L}(9,000$ gal.) [approximately $8-3 \mathrm{~m}$ (10 ft.) depth] of residual waste (walkdown notes). The amount of sludge in this waste is unknown. Since the resin in the ion exchange column was organic, the tank likely also contains some organic materials.

IX-D-1 (ion exchange column) - The column originally contained Zeolon 900 ion exchange medium (ARH-MA-119). To support the U1/U2 groundwater treatment campaign in 1985, Dowex MSA-1 ion exchange resin was added to the ion exchange column (letter, 65950-85-350-AX; SD-WM-SSP-002). After the U1/U2 treatment the resin was regenerated with sodium hydroxide and the column was filled with water to cover the resin. The column is not vented, but opened and inspected periodically.

TK-E-101 (Eluent Tank) - Tank originally contained sodium nitrate for regeneration of the ion exchange column, ahd was later used in the U1/U2 treatment campaign to contain sodium hydroxide for regeneration of the ion exchange column. The tank is assumed empty.

TK-E-102 (Anti-Foam Tank) - The tank was used in the U1/U2 treatment campaign. It contains a white power and is labeled as "Sodium Bicarbonate." The tank was sampled in 1997 (74620-97-208) and the analysis confirmed the tank contained sodium bicarbonate.

TK-C-103 (Flow Measurement Tank) - According to the shutdown plan (SD-WM-SSP-002) this vessel was drained and flushed during shutdown and is not thought to contain any residual liquids.

TK-E-104 (Decontamination Tank) - The tank was sampled in 1997 (74620-97-208). It currently contains a minimal heel of yellowtinted water. Analysis determined a pH of 10.0 and sp gr of 1.028 .

DU-C-1 (De-Entrainment Unit) - According to the shutdown plan (SD-WM-SSP-002) this vessel was drained and flushed during shutdown and is not thought to contain any residual liquids. The vessel vent system has been shutdown and isolated.

TK-302-C - This tank was originally an acid addition tank for injection of dilute nitric acid in the process stream, and was more recently used during the U1/U2 treatment campaign as lag storage for the U1/U2 crib groundwater. This tank has been emptied and cleaned for use as a raw water storage and chemical addition tark for the cross site transfer system.

Pump Room Floor Sump - This sump contains floor drainage from the hot side of the facility. 


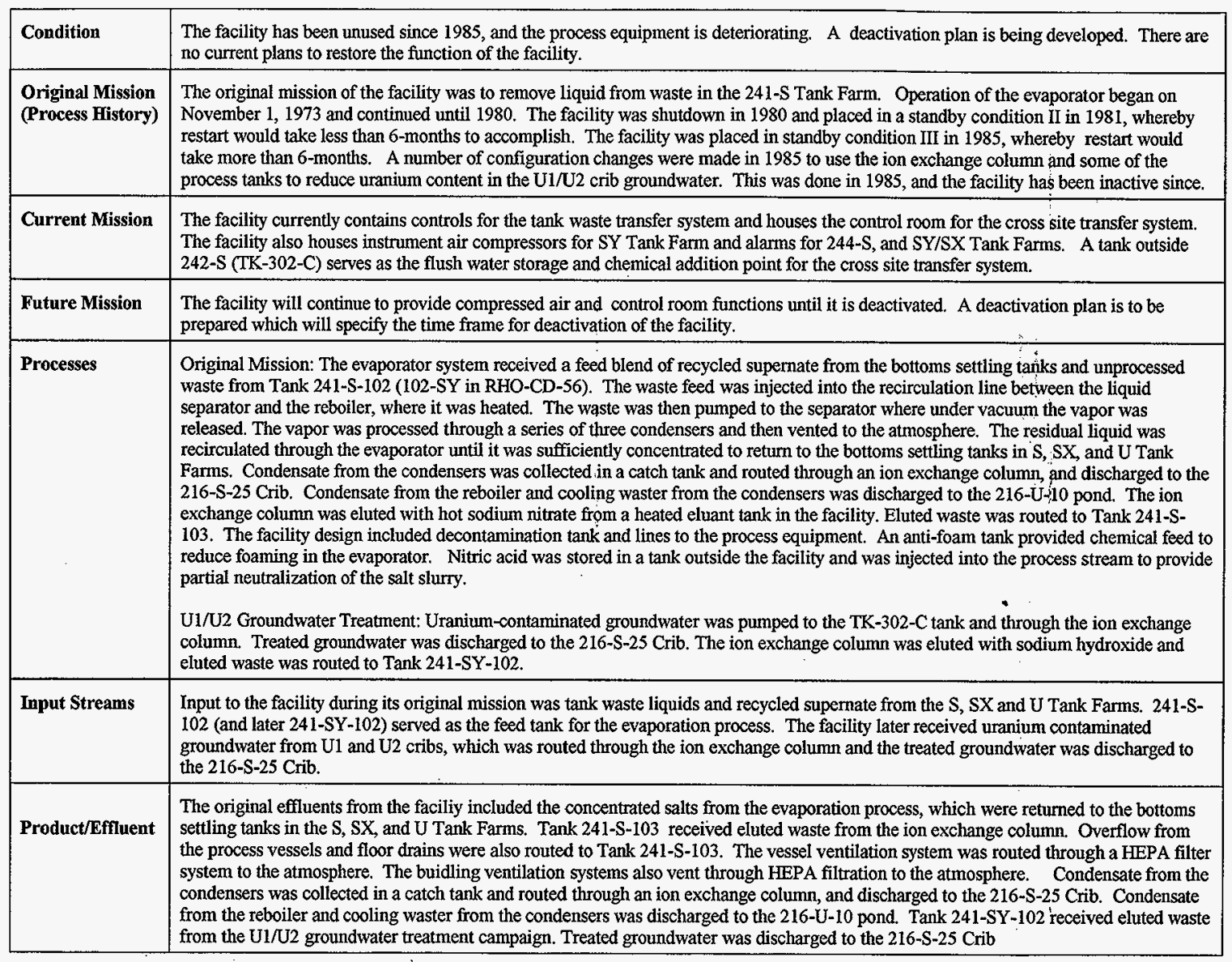

A deactivation plan is to be 


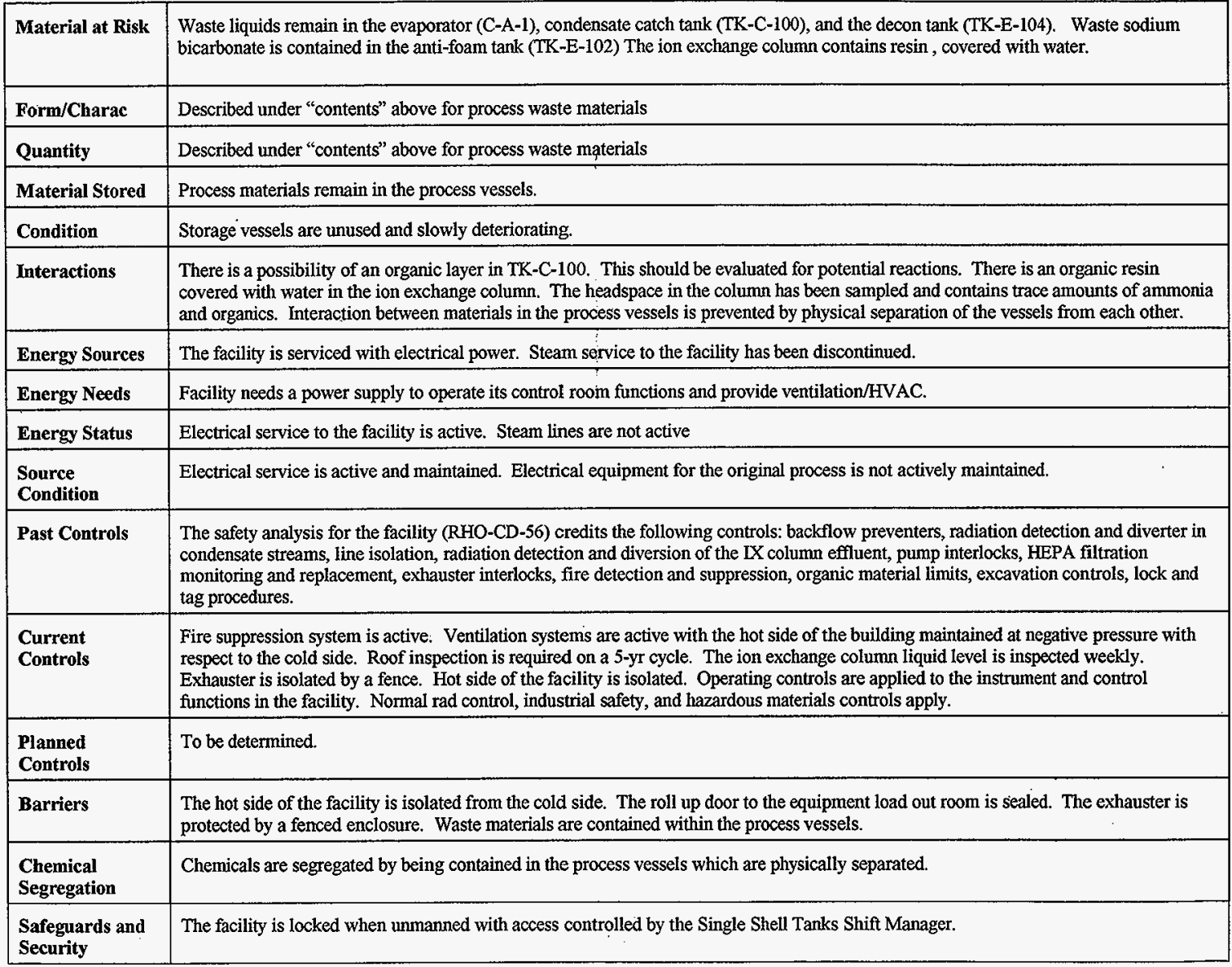




\begin{tabular}{|c|c|}
\hline $\begin{array}{l}\text { Monitoring and } \\
\text { Surveillance }\end{array}$ & $\begin{array}{l}\text { Periodic inspection of the ion exchange column liquid level is performed. Routine readings are taken in the Evaporator Control Room of } \\
\text { condensate tank level, exhauster operating parameters, and compressor operating parameters. }\end{array}$ \\
\hline Historical Risks & $\begin{array}{l}\text { The safety documentation for the facility (RHO-CD-56) addressed } 6 \text { postulated accidents: Siphoning or backflow of contaminated } \\
\text { process solution into personnel areas; Excessive foaming of process solution, accompanied be entrainment of foam in the process } \\
\text { condensate system; Organic distillate fire or explosion of organic vapors in the condensate collection tank; Failure of the vessel vent } \\
\text { system exhaust filters; Failure of reboiler tubes, with simultaneous failure of the steam condensate monitor/diverter station; Rupture of an } \\
\text { underground waste transfer line during processing or power shovel operation. }\end{array}$ \\
\hline $\begin{array}{l}\text { Current or } \\
\text { Future Risks }\end{array}$ & $\begin{array}{l}\text { Potential energy sources (electrical). Potential for flammable gasses (organics and ammonia) in IX column. Potential for flammable } \\
\text { gasses (organics) in the condensate collection tank }\end{array}$ \\
\hline $\begin{array}{l}\text { Occurrence } \\
\text { History }\end{array}$ & $\begin{array}{l}\text { Three relatively significant occurrences are listed below } \\
\text { 1. The hot side of the facility flooded when a break in the emergency shower water system occurred. } \\
\text { 2. A break in the transfer line occurred which resulted in a surface pool of waste. } \\
\text { 3. Ventilation to the hot side of the facility was lost several times after shutdown. }\end{array}$ \\
\hline Root Cause & $\begin{array}{l}\text { 1. The event was caused by a failure of a backflow preventer. } \\
\text { 2. The event was caused by corrosion/aging of the transfer line. } \\
\text { 3. The event was caused by general area power outages. }\end{array}$ \\
\hline Records Access & No special access requirements except the normal for archived records. \\
\hline $\begin{array}{l}\text { Adjacent Facility } \\
\text { Location }\end{array}$ & The 242-S facility is adjacent to the S and SY Tank Farms. \\
\hline $\begin{array}{l}\text { Underground } \\
\text { Facilities }\end{array}$ & $\begin{array}{l}\text { There are underground piping connections from the facility to the S, SY, SX and U Tank Farms. All piping connections to single-shell } \\
\text { tank farms have been cut and capped to isolate them from the facility. There is a piping connection to } 216-\mathrm{S}-25 \text { crib which may not be } \\
\text { isolated, connections to the U1/U2 cribs. }\end{array}$ \\
\hline $\begin{array}{l}\text { Aboveground } \\
\text { Facilities }\end{array}$ & Electrical power connections to the facility are active. Steam lines are inactive. \\
\hline BIO Coverage & This facility is not currently described or analyzed in the TWRS BIO. \\
\hline
\end{tabular}




\begin{tabular}{|l|l|}
\hline WHC-MR-0132, A History of the 200 Area Tank Farms \\
& RHO-RE-SA-116P, 1986, Chemical and Anion Exchange Removal of Uranium From Hanford Groundwater \\
& Interoffice Memo, 07/22/1997, P. F. Kison to G. L. Dunford, West Tank Farms Facility Chemical Inventory and Vulnerability Evaluation \\
& Drawings: H-2-46320, H-2-46322, H-2-46323, H-2-46324, H-2-46325, H-2-46326, H-2-46327, H-2-46335, H-2-46336, H-2-46342, H- \\
& 2-46343, H-2-46347, H-2-46355, H-2-46357, H-2-46361, H-2-46365, H-2-46366, H-2-46367, H-2-46369, H-2-46370, H-2-46371, H-2- \\
& $822350, \mathrm{H}-2-822351, \mathrm{H}-2-822409$ \\
& Facility walkdown 8/15/97; Ron Tucker, Jeff Doeler, Carole Leach, Jim Poppiti, Kim Beacher, Carol Sohn, Ken Wade \\
& Conversations with Mike Sutey (Engineering), Paul Kison (Engineering) and Ron Tucker (Operations) \\
\hline
\end{tabular}


FACILITY HAZARD PROFILE CHECKLIST

Rev. 0, April 20, 1998

\begin{tabular}{|c|c|c|c|c|c|c|c|c|c|}
\hline Facility ID: & 242-T Evaporator & \multicolumn{2}{|c|}{ Facility Name: } & \multicolumn{6}{|c|}{ 242-T Evaporator } \\
\hline Owner/Operator & Location & Capacity & $\begin{array}{l}\text { Volume of } \\
\text { Contents }\end{array}$ & $\begin{array}{l}\text { Sludge } \\
\text { Volume }\end{array}$ & & Risers & & $\begin{array}{l}\text { issile } \\
\text { ontent }\end{array}$ & $\begin{array}{l}\text { Rad } \\
\text { Content }\end{array}$ \\
\hline LMHC & 200W near PFP & $\begin{array}{l}\text { Detailed } \\
\text { below }\end{array}$ & $\begin{array}{l}\text { Detailed } \\
\text { below }\end{array}$ & Unknown & & N/A & Inactive & & \\
\hline Geometry & \multicolumn{9}{|c|}{$\begin{array}{l}\text { A rectangular concrete building with a divided process area (radiological area, or "hot"), a control area (non-radiological, or "cold"), and } \\
\text { a stand alone chemical storage tank building. The process area has two ft of concrete shielding and is approximately } 13.1 \mathrm{~m}(43 \mathrm{ft} .) 10 n g \text {, } \\
12.8 \mathrm{~m} \text { ( } 42 \mathrm{ft} \text {.) wide, with } 6.7 \mathrm{~m} \text { ( } 22 \mathrm{ft} \text {.) tall walls, and a } 12.7 \mathrm{~cm}(5 \mathrm{in} \text {.) thick cover block (flat) roof, reinforced with external steel } \\
\text { trusses. The process area roof cover blocks have been foamed over. The building is built on a concrete slab floor. } \\
\text { The attached single story control area has a pitched roof. This cold area originally contained a lunch room, wash room and lavatory, a } \\
\text { change room, a control room, instrument air dryers; and an anti-foam tank and pump. } \\
\text { The processing area consists of a "Feed Cell", and "Evaporator Cell", and a "Condensate Cell" that are separated by one ft concrete } \\
\text { walls. One corner of the Condensate Cell holds the sample gallery and the decontamination sink. A small in-ground decontamination } \\
\text { tank (hot) (242-T-135) is adjacent to the building. } \\
\text { The tanks in } 242-T-601 \text {, a small chemical storage tank building, are empty. Outside there are three empty tanks, including a } 24,000 \mathrm{~L} \\
(6,345 \text { gal) capacity nitric acid tank.. }\end{array}$} \\
\hline $\mathrm{Co}$ & \multicolumn{9}{|c|}{$\begin{array}{l}\text { The facility was modified in } 1973 \text { from the original design of taking feed from Tank } 118 \text {-TX, to also be able to take feed from Tank D-5 } \\
\text { in the } 241-Z \text { building of the Plutonium Finishing Plant, or Tank 242-TA-R1 in the 242-TA Receiver Tank Vault. } \\
\text { The "Bottoms Storage" tanks ( } 113-\mathrm{TX} \text {, 116-TX, or 117-TX) receive concentrated effluent from the evaporator process. Acceptable } \\
\text { "condensate" from the condenser was sent to the } 216-\mathrm{T}-19 \text { crib, or could be recycled by routing back to Tank 118-TX. Sludge from the } \\
\text { evaporator was sent to Tank 109-TX, via the 242-T-151 diverter box. } \\
\text { The } 242-\mathrm{T}-601 \text { building chemical tanks (Ferrocynide, HNO3, NaOH, and NiSO4) are empty. } \\
\text { The } 10.16 \mathrm{~cm} \text { (4 in.) raw water line has been blanked off inside the control building. } \\
\text { The } 242-\mathrm{TA} \text { vault has been made an IMUST item, and not part of this facility. }\end{array}$} \\
\hline
\end{tabular}




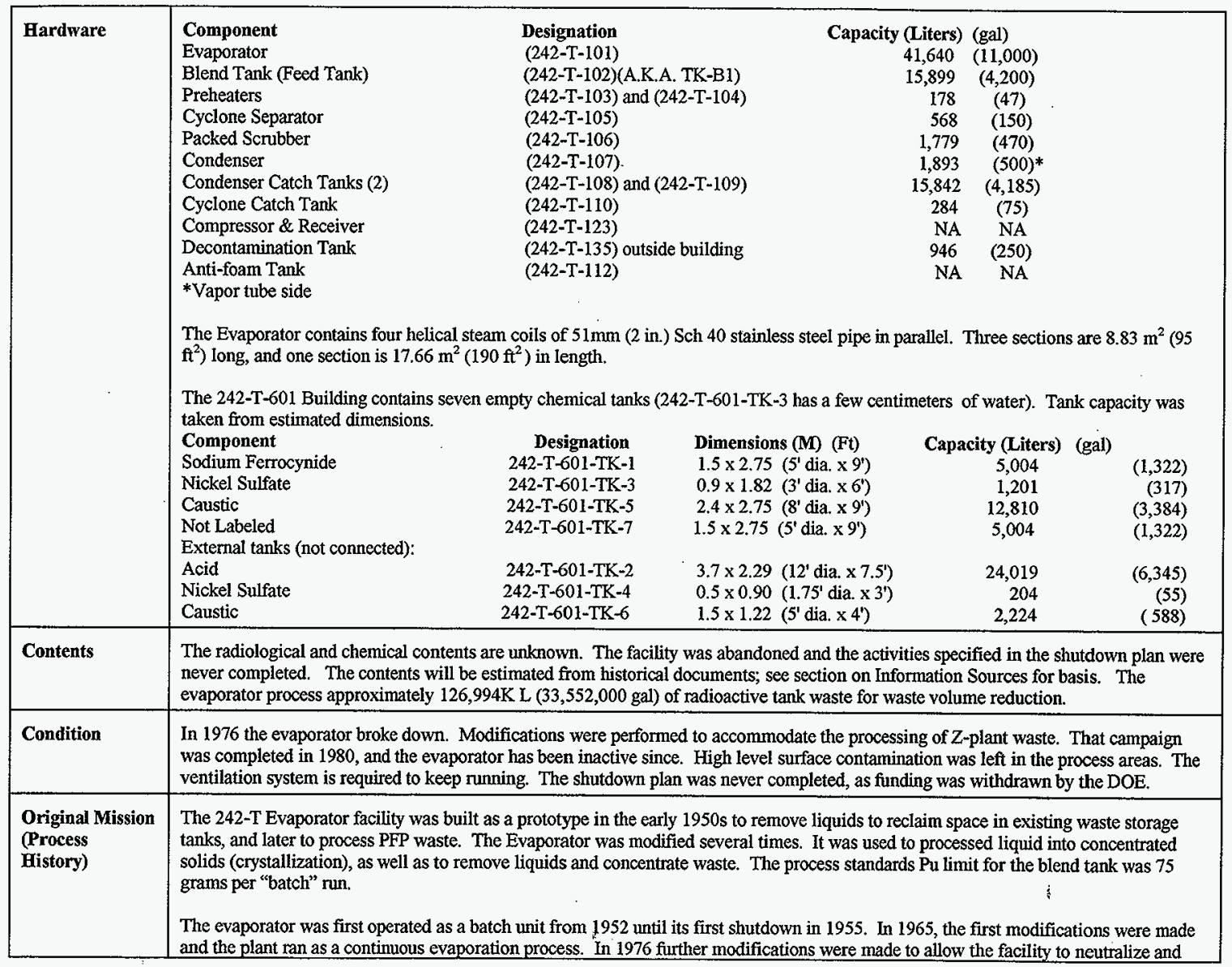


The evaporator Blend Tank (also called the Feed Tank) was filled with waste from the source tank. The amount of Feed Tank overflow back to the source tank controlled the process rate. Over the life of the facility, feed came from three sources. The facility was feed from either underground storage tank 118-TX, Tank D-5 in the 241-Z building of the Plutonium Finishing Plant, or 242-TA-R1 in the 242-TA Receiver Tank Vault.

The facility was designed to run with control on the feed rate, based on condensate output. Overflow feed was routed back to the source tank. This allowed full capacity operation, with efficiency tied to the amount of solids (concentration) in the feed liquids. Process output came from the condenser, usually low-level "condensate", and the evaporator or condenser, as concentrated waste. Vapor was also removed. Liquid vapor was pulled from the evaporator, through a cyclone separator, then a screened scrubber, and off of a cooled and low vacuum condenser. Finally the now "dry" air was routed through a deentrainer, then warmed by heaters, and sent through pre-filters and two stages of HEPA filters to a building stack exhaust. Acceptable "condensate" from the condenser was sent to the 216-T-19 crib, and concentrated solids from the evaporator were routed to bottom storage tanks. Unacceptable condensate and process drains were routed back to the source tank for recycle. Sludge from the evaporator was sent through the 242-T-151 diverter box to Tank 109-TX.

There were two operating processes, evaporation (with precipitation), and crystallization. For crystallization, the feed tank inside the evaporator facility was called a blend tank because the crystallization process required a small amount of solids to "seed" the supernate. Waste feed was pumped from Tank 118-TX through a jet valve to siphon the blend tank and send the blended stream through the evaporator. When used for crystallization, the dried solids, termed "bottoms" or "salt cake" were sent to one of several "Bottoms Storage Tanks" (116-TX, 117-TX, or 113-TX) through the 242-T-151 diverter box.

In evaporation, the hot concentrated waste was sent back to a storage tank and allowed to cool. As the concentrated waste cooled, the solids precipitated out of suspension and the remaining supernatant liquid was decanted and sent back through the process again. Tank 118-TX was used to receive supernatant liquids (and fed the evaporator) from a decant tank.

The facility used nitric acid $\left(\mathrm{HNO}_{3}\right)$ and caustic $(\mathrm{NaOH})$ for $\mathrm{pH}$ adjustment. Caustic was also used for decontamination as some components were made of mild steel. TBP scavenging used ferrocyanide and nickel sulfate, $\mathrm{NiSO}_{4}$.

\begin{tabular}{l|l} 
Current Mission & Shutdown, with controls requiring active ventilation, and annual building structural inspection.
\end{tabular}

Future Mission

\section{None}

\begin{tabular}{l|l} 
Processes & See section on Process History. \\
\hline
\end{tabular}

Input Streams

Tank 118-TX, Tank D-5 in the 241-Z building of the Plutonium Finishing Plant, or Tank R-1 in the 242-TA Receiver Tank Vault.

Product/Effluent Hot side effluent was salt cake or concentrated waste. The salt cake was sent to bottom storage tanks, 116-TX, 117-TX, or 113-TX. The concentrated waste was sent to waste storage tanks 114-TX, or 116-TX. Cold side effluent was low level radionuclide "condensate" which was sent to the $216-\mathrm{T}-19 \mathrm{crib}$, and vapor which was first filtered and then sent up the exhaust stack. Sludge from the evaporator was sent to tank 109-TX. 


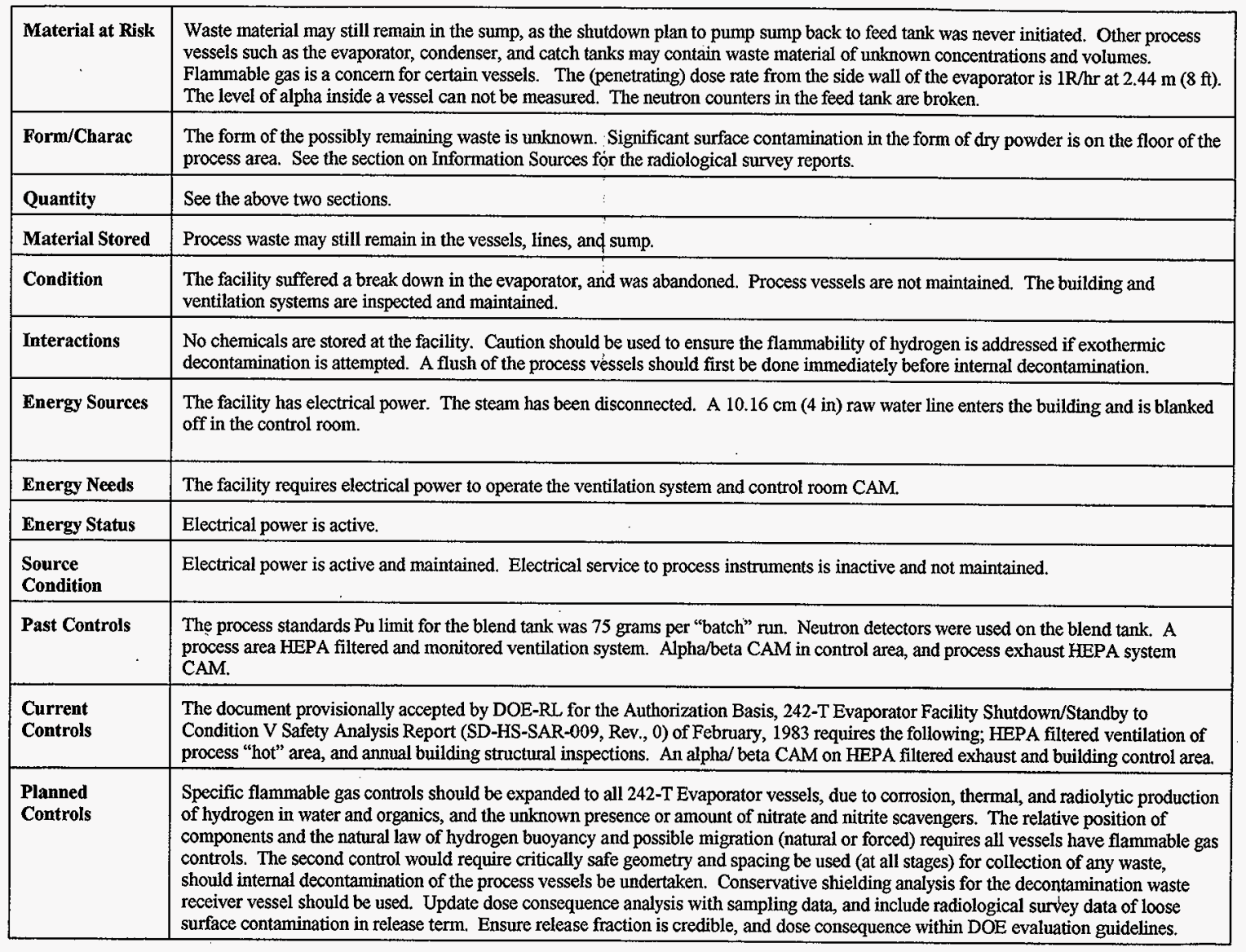




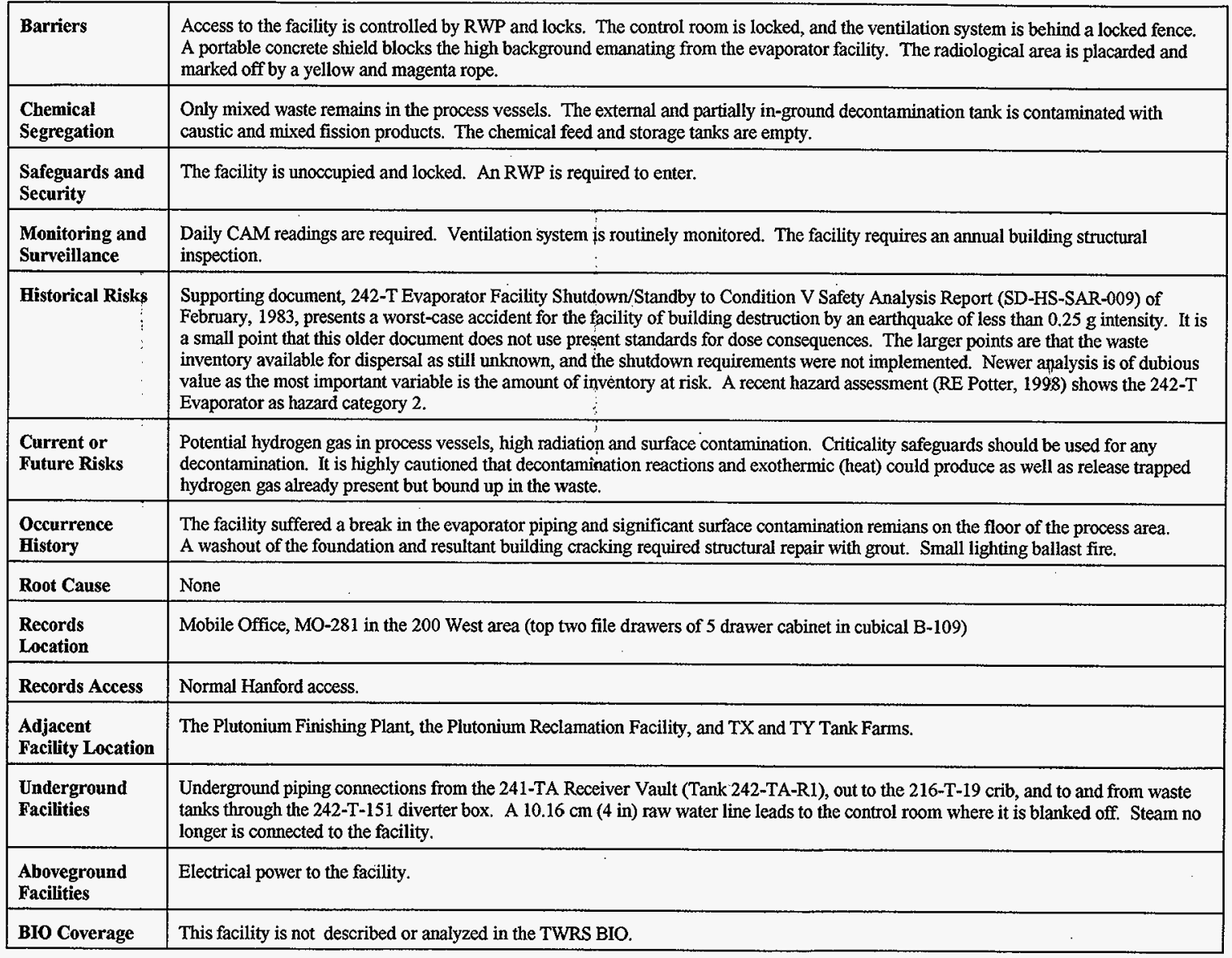



February, 1983. It should be noted that Luis Williamson, the last operating cognizant engineer reports that the work referenced in this document was never completed.

\section{Information}

Sources
The transition to shutdown Cognizant Engineer was Luis Williamson. Current Cognizant Engineer is Kevin Hull. The last process to be documented is discussed in ARH-CD-178, Operational Safety Analysis 242-T Waste Evaporator, Nov, 18, 1974. Past historical Pu limit of 75 grams per batch was taken from Process Specifications and Standards for the 242-T Evaporator Facility, RL-SEP-649, September $1,1965$.

Original operating logs for final years (1976-1980) of operation (custody of Kevin Hull - soon to record storage)

RHO-CD-1410 242-T Evaporator Facility Shutdown/Standby Plan, April 1981, calls for the Hot Cell Sump to be pumped to Feed Tank, work never completed as funding withdrawn by the DOE.

OSD-T-151-00015 Rev/Mod B-6 Safety Based Specifications Support for the OSD is provided in Technical Basis for OSD-T-15100015, SD-WM-TI-352, September 30, 1988.

242-T Evaporator Facility Shutdown/Standby to Condition V Safety Analysis Report (SD-HS-SAR-009) of February, 1983 (work not completed according to discussion with Luis Williamson.

Project B-106 provided ventilation improvements which are documented in Building Effluent Improvements Conceptual Design Description 242-T Facility Building, ARH-2943, December 6, 1973.

The supporting document, Structural Inspection 242-T Evaporator Facility, SD-WM-PRS-008, February, 1989 called for roof reinforcing. Analysis of foundation (prompted by repairs to cracks due to wash out) was documented in Structural Assessment of the 242-T Evaporator Facility, WHC-SD-WM-ER-194, Rev., 0, March, 1993.

Radiological Survey Report 196474 of June 13, 1995, covered an entry to the condenser room, average dose rate was $7 \mathrm{R} / \mathrm{hr}$. Radiological Survey Report 196477 of June 23, 1995, covered an entry to the Feed Tank room, average was $\sim 150 \mathrm{mR} / \mathrm{hr}$. Radiological Survey Report 196498 of June 29,1995 , covered an entry to the Feed Tank room, average was $\sim 800 \mathrm{mR} / \mathrm{hr}$.

Field verified HEPA ventilation system and control room CAM were in operation, at 1:43pm on March 9, 1998.

Hanford Drawings:

The year 1965 TBP Modifications are on SK-2-1821.

Preheaters (H-2-1847), Condenser (H-2-1849), Condenser Catch Tanks (H-2-1850), Cyclone Separator (H-2-1851), Decontamination

Tanks (H-2-1852), Feed Tank (H-2-1853), Packed Scrubber (H-2-1880), Evaporator (H-2-1882), 242- T Evaporator Plan (H-2-1895), Cyclone Catch Tanks (H-2-2012), 
FACMITY HAZARD PROFILE CHECKLIST

Rev. 0, April 20, 1998

\begin{tabular}{|l|l|l|l|}
\hline Facility ID: & 242-T-135 & Facility Name: & Decontaminant Storage Tank \\
\hline
\end{tabular}

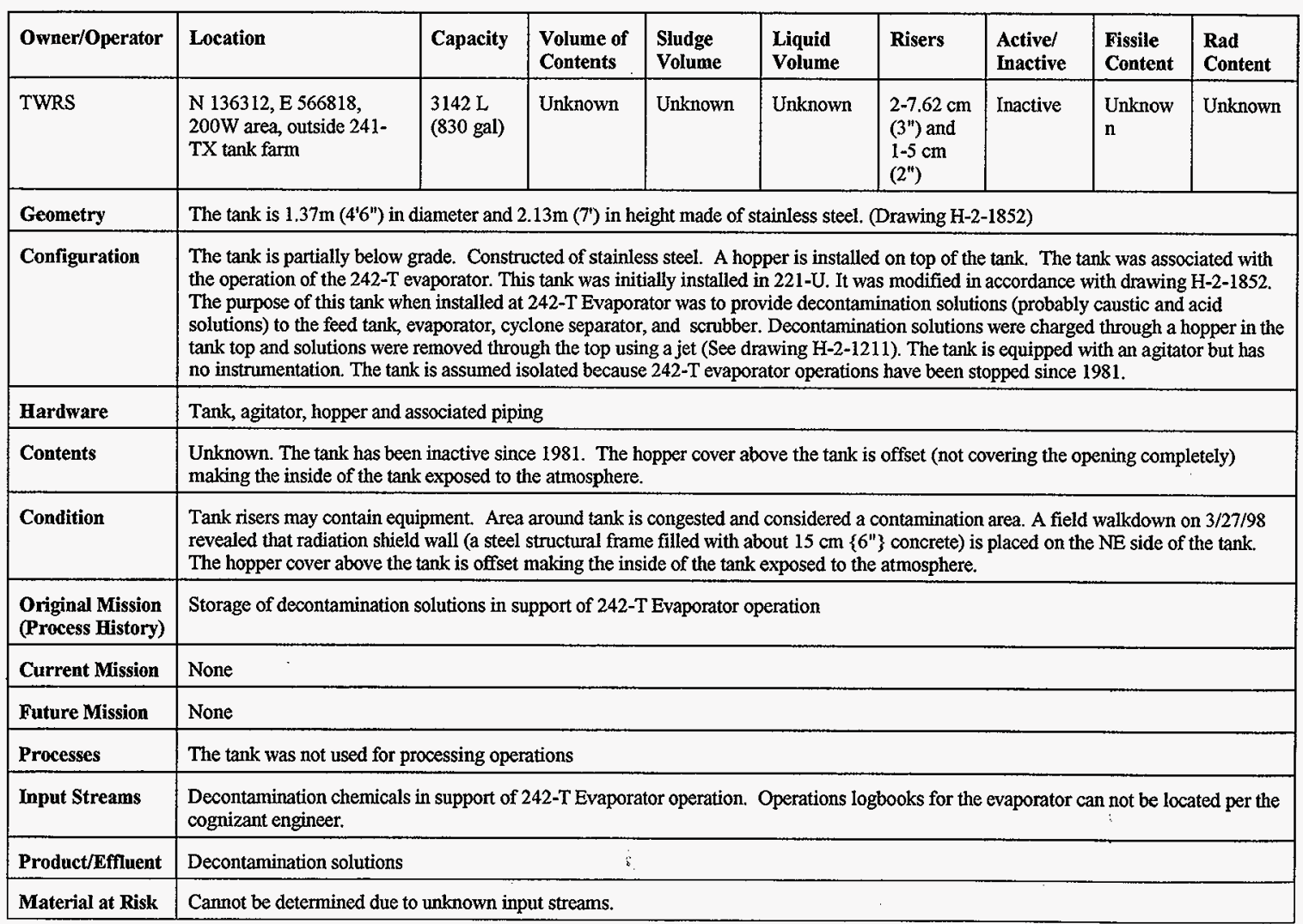




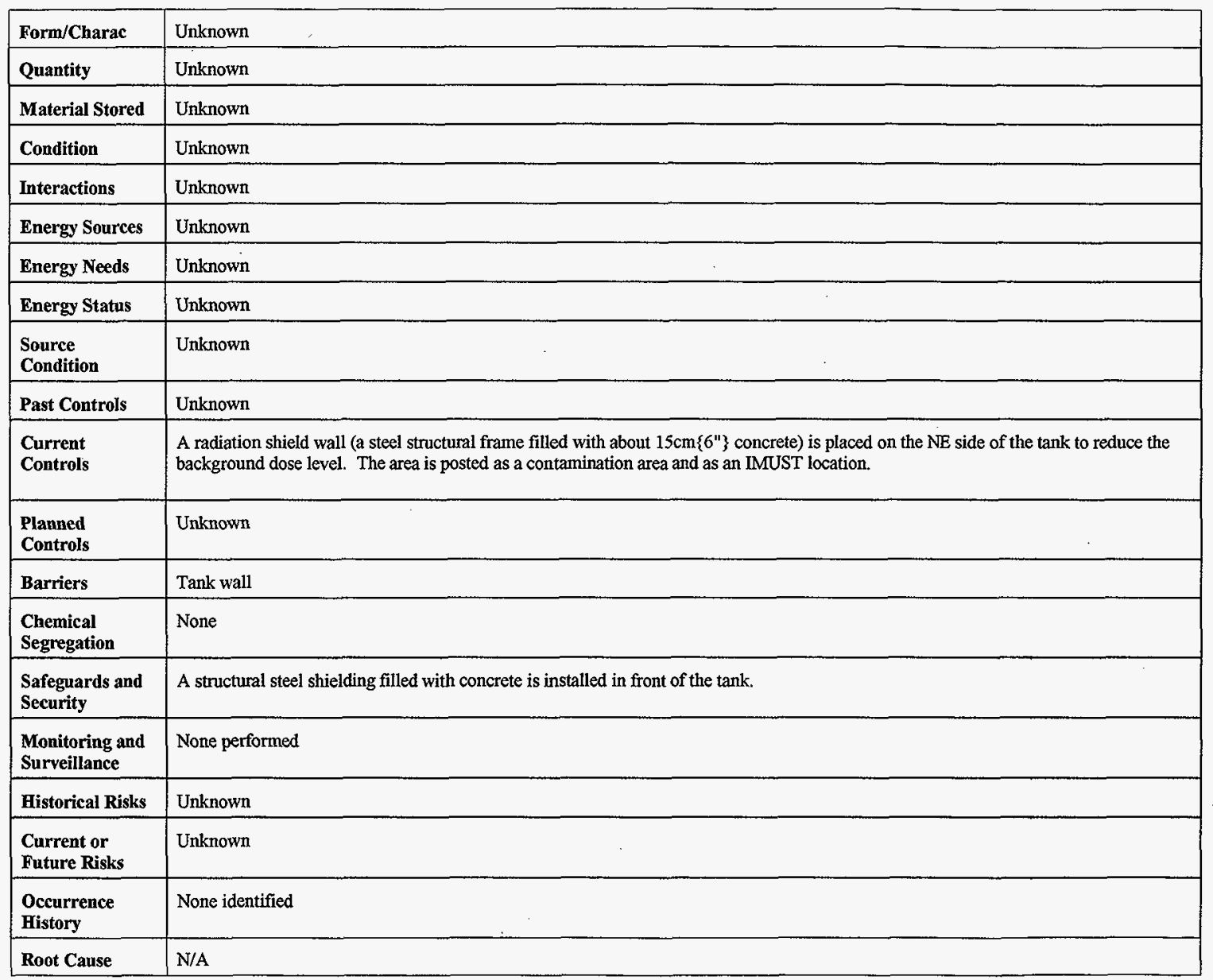




\begin{tabular}{|l|l|}
\hline $\begin{array}{l}\text { Records } \\
\text { Location }\end{array}$ & Not available \\
\hline Records Access & N/A \\
\hline $\begin{array}{l}\text { Adjacent Facility } \\
\text { Location }\end{array}$ & $242-$ T evaporator \\
\hline $\begin{array}{l}\text { Underground } \\
\text { Facilities }\end{array}$ & None \\
\hline $\begin{array}{l}\text { Aboveground } \\
\text { Facilities }\end{array}$ & None \\
\hline BIO Coverage & Yes \\
\hline FSAR Coverage & Yes \\
\hline $\begin{array}{l}\text { Information } \\
\text { Source }\end{array}$ & \begin{tabular}{l} 
Drawing H-2-1852, H-2-1208, H-2-1209, H-2-1211, H-2-37256 Sht 3. \\
RL-SEP-396, 242-T Evaporator Facility Information Manual (June, 1965); HNF-1566, "Letter Report 200-Area Plateau Inactive \\
\hline
\end{tabular} \\
\hline
\end{tabular}


FACILITY HAZARD PROFLE CHECKLIST

Rev. 0, April 20, 1998

\begin{tabular}{|l|l|l|l|}
\hline Facility W: & 242-TA-R1 & Facility Name: & Receiver Tank \\
\hline
\end{tabular}

\begin{tabular}{|c|c|c|c|c|c|c|c|c|c|}
\hline Owner/Operator & Location & Capacity & $\begin{array}{l}\text { Volume of } \\
\text { Contents }\end{array}$ & $\begin{array}{l}\text { Sludge } \\
\text { Volume }\end{array}$ & $\begin{array}{l}\text { Liquid } \\
\text { Volume }\end{array}$ & Risers & $\begin{array}{l}\text { Active/ } \\
\text { Inactive }\end{array}$ & $\begin{array}{l}\text { Fissile } \\
\text { Content }\end{array}$ & $\begin{array}{l}\text { Rad } \\
\text { Content }\end{array}$ \\
\hline TWRS & $\begin{array}{l}\text { N } 136296.203, \mathrm{E} \\
566804.5,200 \mathrm{~W} \text { area, } \\
\text { within } 241-\mathrm{TX} \text { tank farm, } \\
\text { SW of } 242-\mathrm{T} \text { bldg. }\end{array}$ & $\begin{array}{l}15.9 \mathrm{~K} \mathrm{~L} \\
(4200 \mathrm{gal})\end{array}$ & Unknown & Unknown & Unknown & None & Inactive & $\begin{array}{l}\text { Unknow } \\
\mathrm{n}\end{array}$ & Unknown \\
\hline Geometry & \multicolumn{9}{|c|}{$\begin{array}{l}\text { Receiver Vault: } 4.88 \mathrm{~m}\left(16^{\prime}\right) \text { dia., } 6 \mathrm{~m}\left(20^{\prime}\right) \text { height, below grade (See drawing H-2-27275). Receiver Tank: } 2.74 \mathrm{~m}\left(9^{\prime}\right) \text { dia., } 2.95 \mathrm{~m}\left(9^{\prime} 8^{\prime \prime}\right) \\
\text { height stainless steel (See drawing H-2-27344). This receiver tank is known as 242-TA, Receiver TK-Vault, } 242-\mathrm{TA} \text { Receiver Tank } \\
\text { Vault, Receiver Tank TK-Rl. }\end{array}$} \\
\hline Configuration & \multicolumn{9}{|c|}{$\begin{array}{l}\text { The receiver tank is located at the bottom of the } 242-\mathrm{TA} \text { receiver vault. The vault is concrete lined pit with an octagonal concrete cover } \\
\text { at grade level and the tank is stainless steel. The tank has seventeen nozzles including } 6 \text { spare nozzles. The tank overflows to a sump at } \\
\text { the receiver vault bottom. The tank is equipped with a pump and agitator A-R1-1 (See drawings H-2-27345, and H-2-27339). The } \\
\text { sump is also equipped with a pump. The receiver tank along with blending tank were used for neutralization of Z-Plant acid waste. Use } \\
\text { of } 242-\mathrm{T} \text { Evaporator Facility to neutralize Z-Plant waste was concluded with the anticipated startup of } 244-\mathrm{TX} \text {, a double shell receiver } \\
\text { tank (See RHO-CD-1410). Transfer line was re-routed to a different receiver tank (244-TX Vault) in } 1980 \text { (See drawing H-2-73901). } \\
\text { In April } 1981 \text {, a document was generated by Rockwell International, Rockwell Hanford Operations, Energy System Group, titled } 242-T \\
\text { Evaporator Facility Shutdown/Standby Plan (RHO CD-14l0). The plan detailed a comprehensive plan to be carried out that would place } \\
\text { the entire } 242-\mathrm{T} \text { Evaporator Facility, including } 242-\mathrm{TA}-\mathrm{R} 1 \text { tank in a condition wherein all process lines would be blanked, equipment } \\
\text { would be disabled, and instruments disconnected, to effectively isolate } 242-T \text { process area. The } 242-\mathrm{T} \text { Evaporator Facility } \\
\text { Shutdown/Standby plan was never implemented. This fact is documented in correspondence no. 8956942, R. E. Gerton, Director Waste } \\
\text { Management Division, DOE-RL, dated December } 4 \text {, 1989, regarding the DOE-RL, Standby/Shutdown Program audit December } 15-16 \text {, } \\
\text { I987. This letter further recommended that the plan be deleted. Examination of existing documentation provides no proof that any part of } \\
\text { the plan was ever actually completed. It is estimated the receiver tank was in operation from } 1972-1980 \text {. }\end{array}$} \\
\hline Hardware & \multicolumn{9}{|c|}{$\begin{array}{l}\text { Receiver Vault } \\
\text { Receiver Tank 242-TA-R1 and associated piping. } \\
\text { Tank Pump } \\
\text { Tank Agitator } \\
\text { Sump Pump }\end{array}$} \\
\hline Contents & \multicolumn{9}{|c|}{$\begin{array}{l}\text { The contents, amount, and residual heel remaining are unknown. The tank must be sampled with emphasis on catching the very bottom } \\
\text { layers, as this tank was used to receive plutonium bearing wastes. The drawing H-2-27332 shows the process flow and waste streams } \\
\text { along with the waste stream composition. The waste stream composition is based on design criteria established for the process. The } \\
\text { mixed aqueous waste stream no. } 3 \text { was used for processing High Salt waste from } 236-Z \text { and } 242-Z \text { after it was treated in tank D-5 located } \\
\text { in } 241-Z \text { building. This waste stream was routed from tank D-5 to } 242-T A-R 1 \text {, blending tank TK-B1 and then to } 242-T \text { building. Waste } \\
\text { stream no. } 3 \text { composition as listed on drawing H-2-27332 consists of the following: }\end{array}$} \\
\hline
\end{tabular}




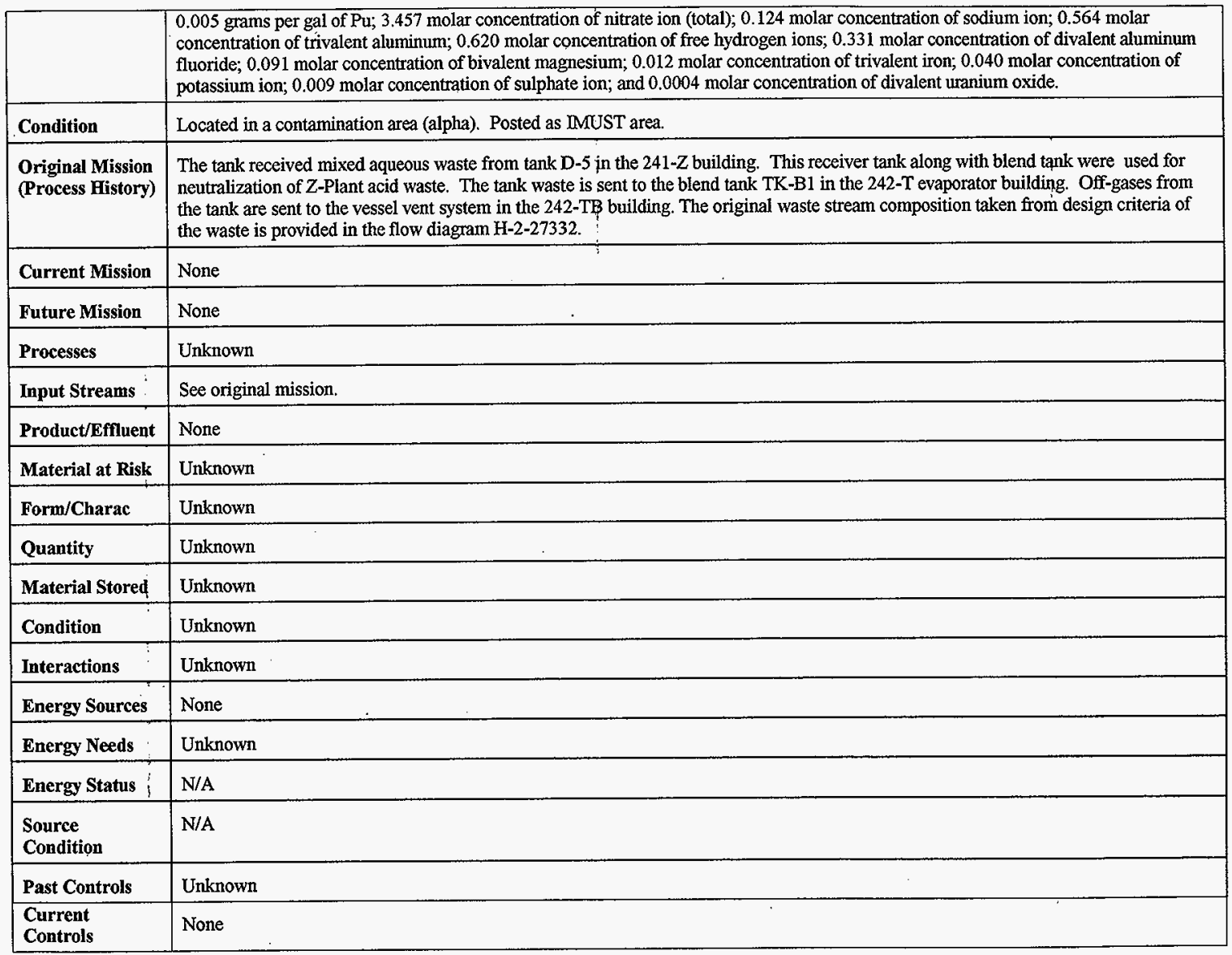




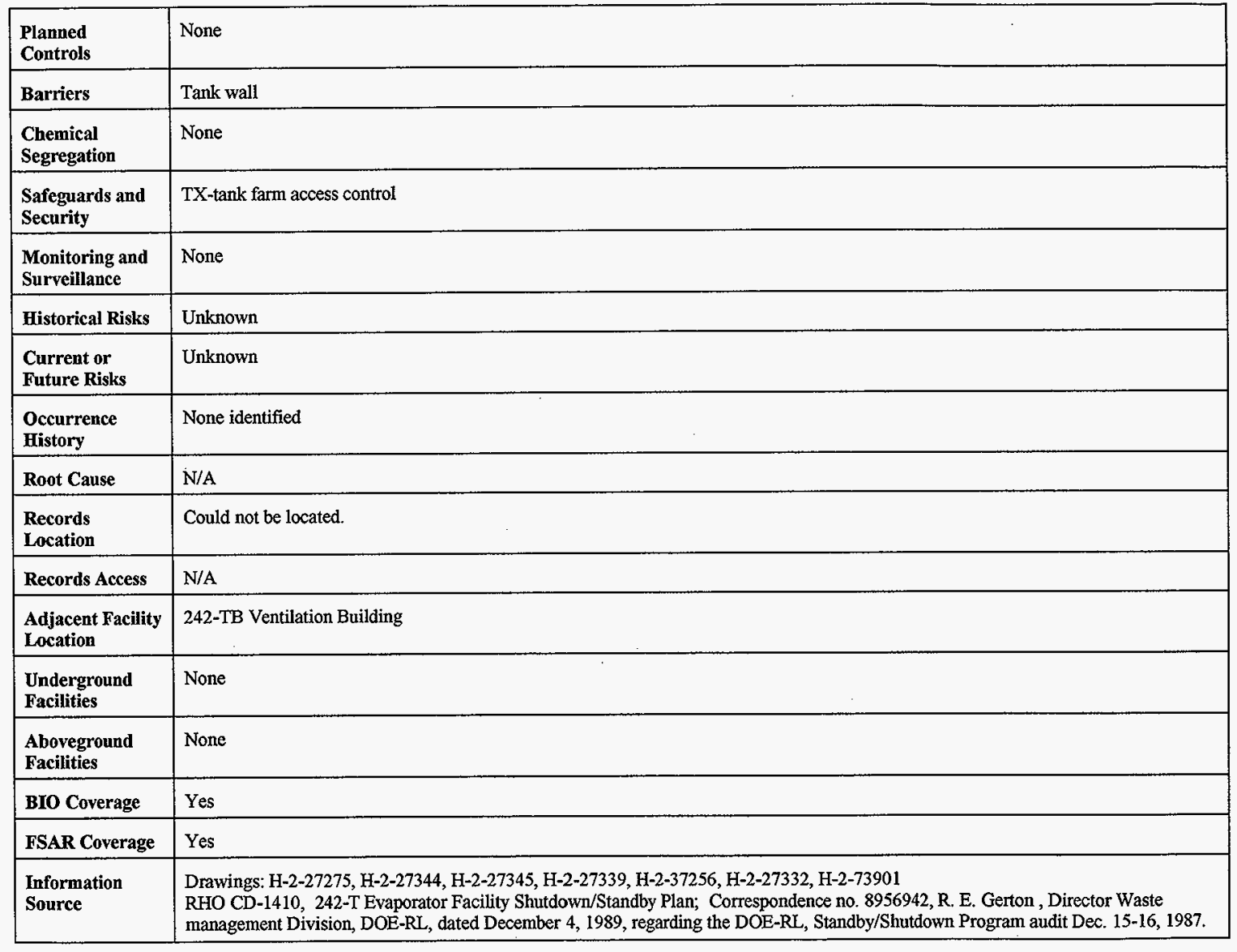


FACILITY HAZARD PROFILE CHECKLIST

Rev. 0, April 20, 1998

\begin{tabular}{|c|c|c|c|c|c|c|c|c|c|}
\hline Facility ID: & 244-AR & \multicolumn{2}{|c|}{ Facility Name: } & \multicolumn{6}{|c|}{ AR Vault Complex } \\
\hline Owner/Operator & Location & Capacity & $\begin{array}{l}\text { Volume } \\
\text { of } \\
\text { Contents }\end{array}$ & $\begin{array}{l}\text { Sludge } \\
\text { Volume }\end{array}$ & $\begin{array}{l}\text { Liquid } \\
\text { Volume }\end{array}$ & isers & & & $\begin{array}{l}\text { Rad } \\
\text { Content }\end{array}$ \\
\hline TWRS & $\begin{array}{l}\text { 10 East; N of PUREX } \\
\text { dd W of 241A Tank Farm }\end{array}$ & See below. & See below. & See below. & See below. & ב. & e. & Unk & $\mathrm{Jn}$ \\
\hline Geometry & \multicolumn{9}{|c|}{ The AR Vault is $28.66 \mathrm{~m}$ ( $94 \mathrm{ft}$ ) long by $5.5 \mathrm{~m}$ (18ft) wide by $12.5 \mathrm{~m}(41 \mathrm{ft}$ ) high. } \\
\hline Configuration & \multicolumn{9}{|c|}{$\begin{array}{l}\text { The 244-AR Complex consists of the } 244-\mathrm{AR} \text { canyon/service building; the } 2704-\mathrm{AR} \text { lunchroom/changeroom; the 244-AR-712 Wind } \\
\text { Reduction Facility; the } 291-\mathrm{AR} \text { filter vault and addition; the } 292-\mathrm{AR} \text { instrument building, prefilter vault, and filter vault; the } 701-\mathrm{AR} \\
\text { building; the 715-AR Closed Loop Cooling System building; the 2904-AR cooling warter sample building; and the air compressor } \\
\text { building. } \\
\text { The } 244-\mathrm{AR} \text { canyon building is a reinforced concretestructure housing three process cells and a failed equipment cell. The process cells } \\
\text { contain sumps with an intercell sump overflow. Cell \#1 contains tank } 244-\mathrm{AR}-001 \text {. Cell \#2 contains tank } 244-\mathrm{AR}-002 \text {. Cell \#3 } \\
\text { contains tanks } 244-\mathrm{AR}-003 \text { and } 244-\mathrm{AR}-004 \text {. The canyon vent filter vaults drain to cell \#1. The vessel vent system seal pot drains to } \\
\text { cell \#3. The process cells and failed equipment cell are covered with } 1.53 \mathrm{~m}(5 \mathrm{ft}) \text { thick concrete shielding blocks. The } 244-\mathrm{AR}-712 \\
\text { Wind Reduction Facility is a prefabricated metal building adjoining the east end of the } 244-\mathrm{AR} \text { canyon building. } \\
\text { The } 244-\mathrm{AR} \text { service building is a steel frame structure with a concrete roof which contains the control room, sample room, and lavatory. } \\
\text { It adjoins the south wall of the } 244-\mathrm{AR} \text { canyon building. The } 2704-\mathrm{AR} \text { lunchroom/changeroom is a prefabricated metal building } \\
\text { adjoining the south side of the service building. The crane control room is on the east side of the service building. }\end{array}$} \\
\hline Ha & \multicolumn{9}{|c|}{$\begin{array}{l}\text { Tank } 244-\mathrm{AR}-001 \text { is a } 189,250 \mathrm{~L}(50,000 \mathrm{gal}) \text { capacity tank constructed of } 9.5-\mathrm{mm}(0.374 ") \text { thick Type } 304 \mathrm{~L} \text { stainless steel plate. It is } \\
6.1 \mathrm{~m}(20 \mathrm{ft}) \text { in diameter and } 6.0 \mathrm{~m}\left(19^{\prime}-9^{\prime \prime}\right) \text { high with a flat bottom. It has upper and lower cooling coils, a transfer pump, a transfer jet, } \\
\text { an agitator, spray rings, a purge air system, a sampler, vessel vent and chemical addition lines, instrumentation, and three spare nozzles. } \\
\text { Tank } 244-\mathrm{AR}-002 \text { is a } 189,250 \mathrm{~L}(50,000 \mathrm{gal}) \text { capacity tank constructed of } 9.5-\mathrm{mm}\left(0.374^{\prime \prime}\right) \text { thick Type } 304 \mathrm{~L} \text { stainless steel plate. It is } \\
6.1 \mathrm{~m}(20 \mathrm{ft}) \text { in diameter and } 6.0 \mathrm{~m}\left(19^{\prime} 9^{\prime \prime}\right) \text { high with a flat bottom. It is equipped with upper and lower dual service heating/cooling } \\
\text { coils, a transfer pump, a sluice pump, a transfer jet, an agitator, spray rings, a purge air system, a sampler, vessel vent and chemical } \\
\text { addition lines, a radiation monitoring dry well, instrumentation, three spare nozzles, and a spare permanent piping line. } \\
\text { Tank } 244-\mathrm{AR}-003 \text { is a } 18,925 \mathrm{~L}(5,000 \mathrm{gal}) \text { capacity tank constructed of } 13-\mathrm{mm} \text { (1/2-in.) thick Type } 18-8 \mathrm{Cb} \text { stainless steel plate. It is } 2.9 \\
\mathrm{~m}\left(9^{\prime}-6^{\prime \prime}\right) \text { in diameter and } 2.7 \mathrm{~m}(9 \mathrm{ft} \text { high) with a sloped bottom. It is equipped with a cooling coil, two transfer jets, a transfer pump, an } \\
\text { agitator, a spray ring, a purge air system, a sampler, vessel ventilation and chemical addition lines, instrumentation, and three spare } \\
\text { nozzles. } \\
\text { Tank } 244-\mathrm{AR}-004 \text { is a } 18,925 \mathrm{~L}(5,000 \mathrm{gal}) \text { capacity tank and is identical to } 244-\mathrm{AR}-003 \text {. }\end{array}$} \\
\hline
\end{tabular}




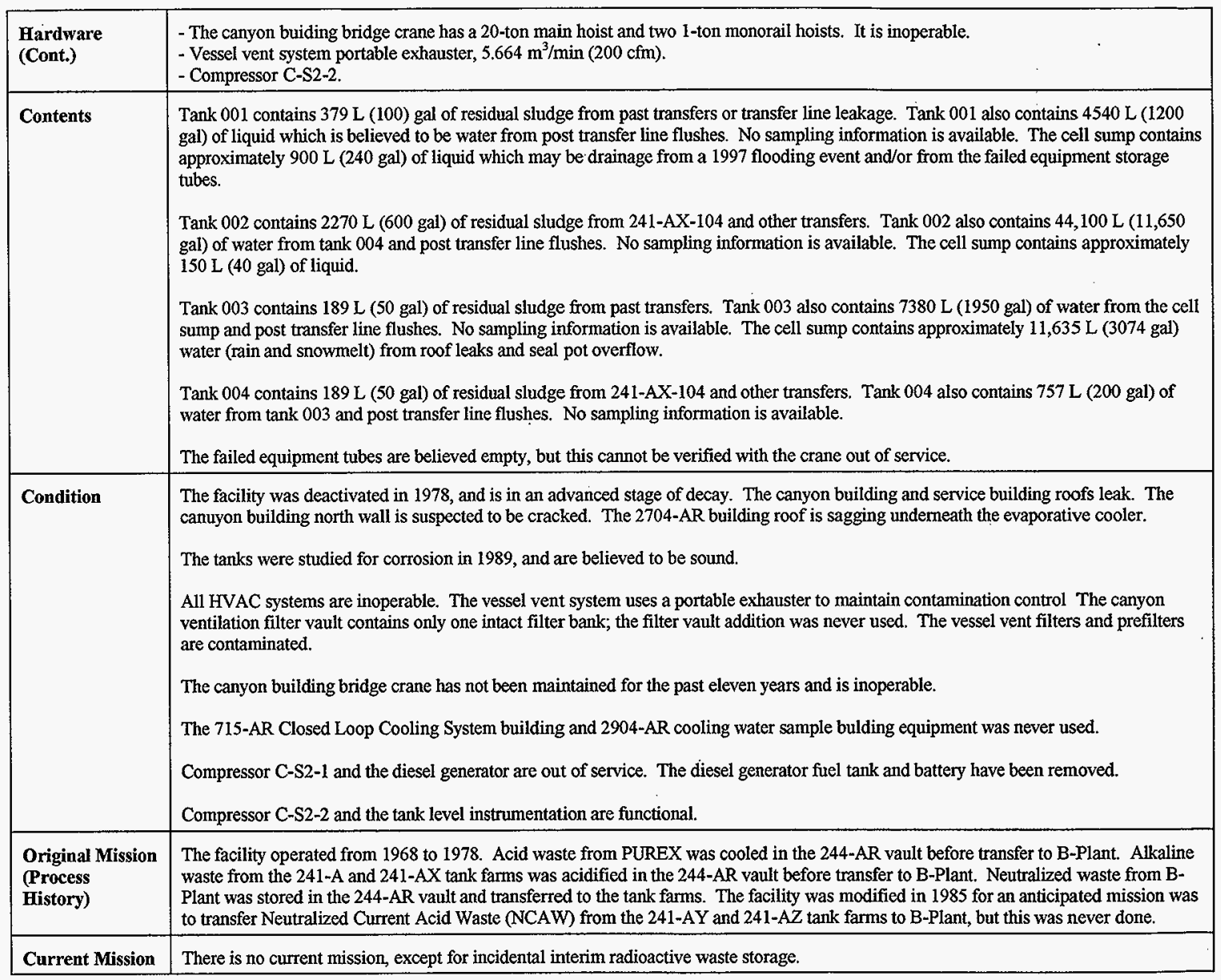




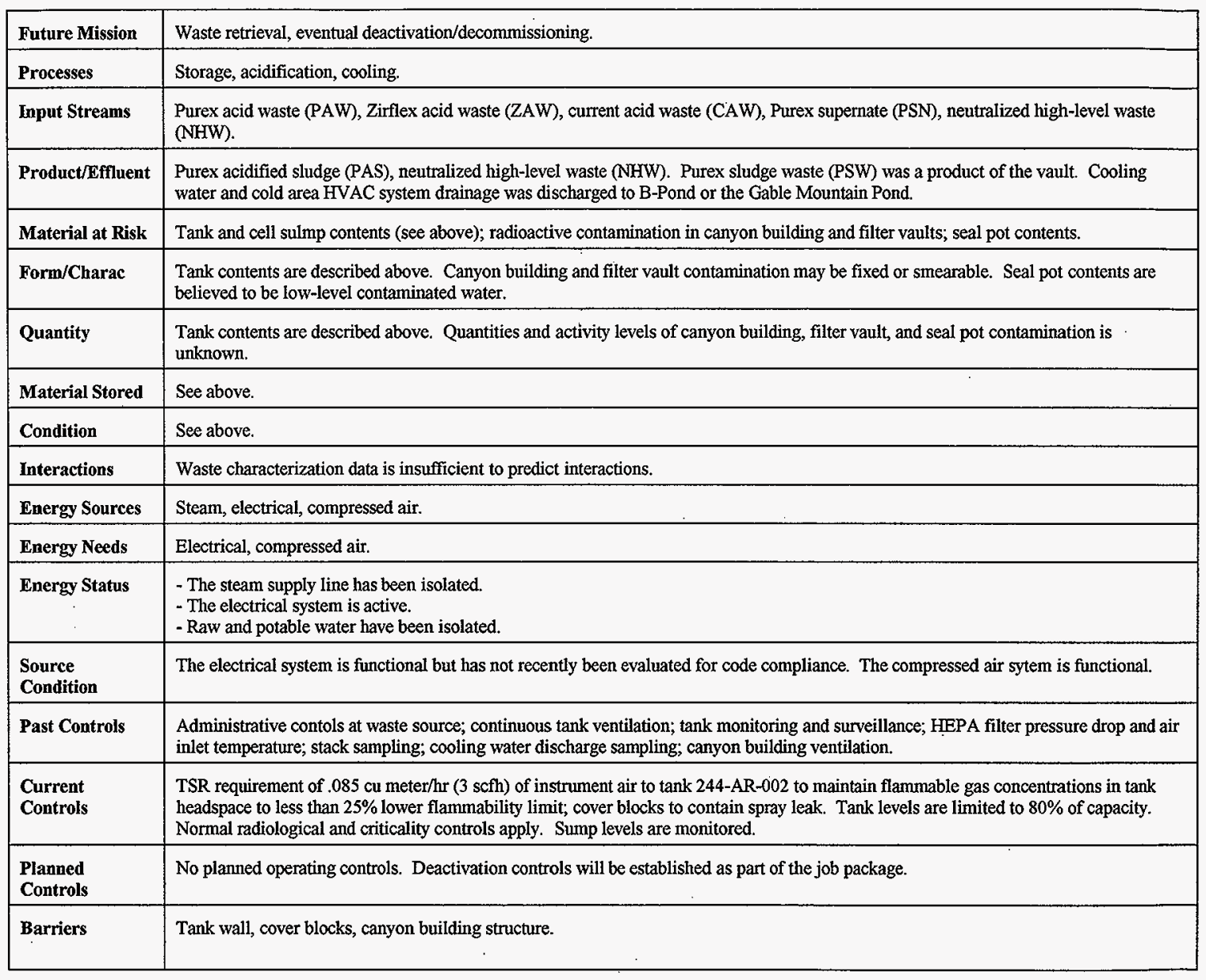




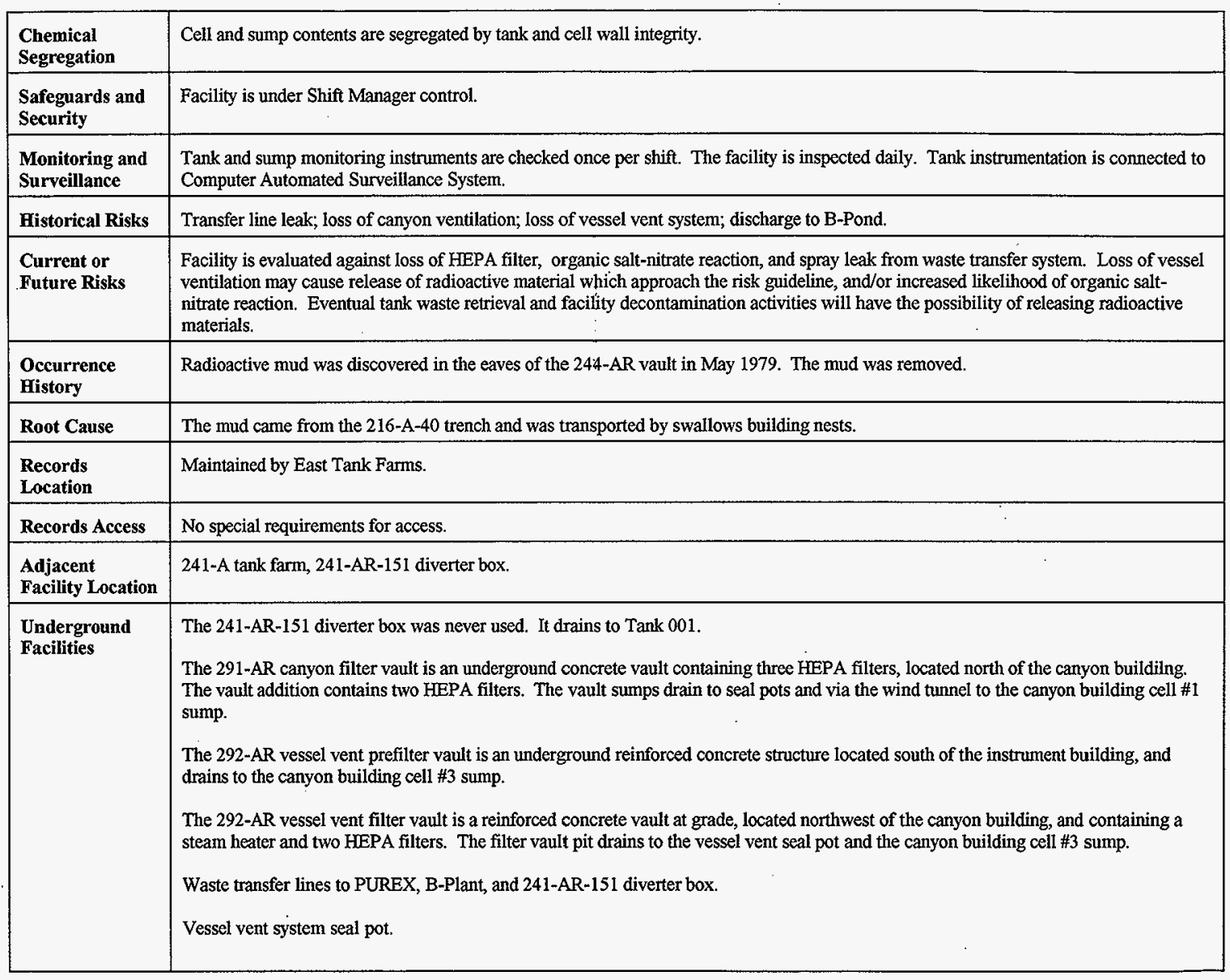




\begin{tabular}{|c|c|}
\hline $\begin{array}{l}\text { Underground } \\
\text { Facilities (Cont.) }\end{array}$ & $\begin{array}{l}\text { Electrical wiring. } \\
\text { Raw and potable water lines (isolated). } \\
\text { Septic tank. }\end{array}$ \\
\hline $\begin{array}{l}\text { Aboveground } \\
\text { Facilities }\end{array}$ & $\begin{array}{l}\text { The } 244-A R-715 \text { Closed Loop Cooling System building is a prefabricated metal building located west of the canyon building. It } \\
\text { contains electrical MCCs, an annunciator panel, pumps and motors, piping and valves, water conditioners, and backflow preventers. } \\
\text { Two chillers are outside the building. } \\
\text { The } 2904-A R \text { cooling water sampling building is a prefabricated metal building on the north side of the complex. It contains an } \\
\text { automated sample system with associated piping and valves. It was to be used to sample liquid discharges from } 244-A R \text { before release } \\
\text { to B-Pond. } \\
\text { The air compressor buildings are fabricated metal buildings located west of the canyon building. They contain compressors C-S2-1 and } \\
\text { C-S2-1. Only C-S2-2 is operable. } \\
\text { The 701-AR building is a fabricated metal building which originally housed the backup diesel generator. It currently contains electrical } \\
\text { MCCs and a transformer. } \\
\text { 291-AR canyon vent stack and fans. } \\
\text { The } 292-A R \text { instrument building is a prefabricated metal building located north of the canyon building. } \\
\text { Vessel vent system portable exhauster and stack. } \\
\text { Steam line (isolated). } \\
\text { Electrical lines. } \\
\text { Diesel generator (deactivated). }\end{array}$ \\
\hline Bro Coverage & Facility is described in the TWRS BIO. \\
\hline FSAR Coverage & Facility is described in the TWRS FSAR. The vessel vent system is identified as a safety-class system. \\
\hline $\begin{array}{l}\text { Information } \\
\text { Sources }\end{array}$ & $\begin{array}{l}\text { WIDS General Summary Report } \\
\text { Ficklin, J.W., "Condition Assessment of the 244AR Complex," 3/7/97. } \\
244-A R \text { Vault fact sheet prepared by Terry Laney, 1/29/98. } \\
\text { Facility walkdown 3/18/98. } \\
\text { Conversation with Terry Laney 3/23/98. } \\
\text { WHC-SD-WM-ES-135 Rev. 0, December 1989, "Corrosion Study of the 244-AR Vault Tanks 001, 002, 003, \& 004," Carlos, W.C. } \\
\text { FDM-T-280-00001 Rev. A-0, September 1986, "244-AR Vault Facility Description Manual," Koerner, J.A. } \\
\text { HNF-SD-WM-BIO-001 Rev. 0, "Tank Waste Remediation System Basis for Interim Operation," Lockheed Martin Hanford Co. } \\
\text { HNF-SD-WM-TSR-006 Rev. 0-J, "Tank Waste Remediation System Technical Safety Requirements," Lockheed Martin Hanford Co. }\end{array}$ \\
\hline
\end{tabular}


HNF-SD-WM-SAR-067 Rev. G, "Tank Waste Remediation System Final Safety Analysis Report," Lockheed Martin Hanford Co.

WHC-SD-WM-HIE-007, May 1996, "Tank Waste Remediation System FSAR Hazard Identification/Facility Configuration Verification

Report," Science Applications International Corporation.

Procedure TF-OR-EF-244AR, Rev. C-4, "244 AR Vault Rounds," 1/20/98.

Procedure TO-040-700, Rev. D-1, "Perform Surveillance at 244-AR Vault," 9/22/97.

Procedure OSD-T-151-00014, Rev. A-5, "Operating Specifications for 244-AR Vault Facility," 12/21/94. 
FACUITY HAZARD PROFLE CHECKLIST

Rev. 0, April 20, 1998

\begin{tabular}{|l|l|l|l|}
\hline Facility ID: & 244-BXR & Facility Name: & 244-BXR Vault \\
\hline
\end{tabular}

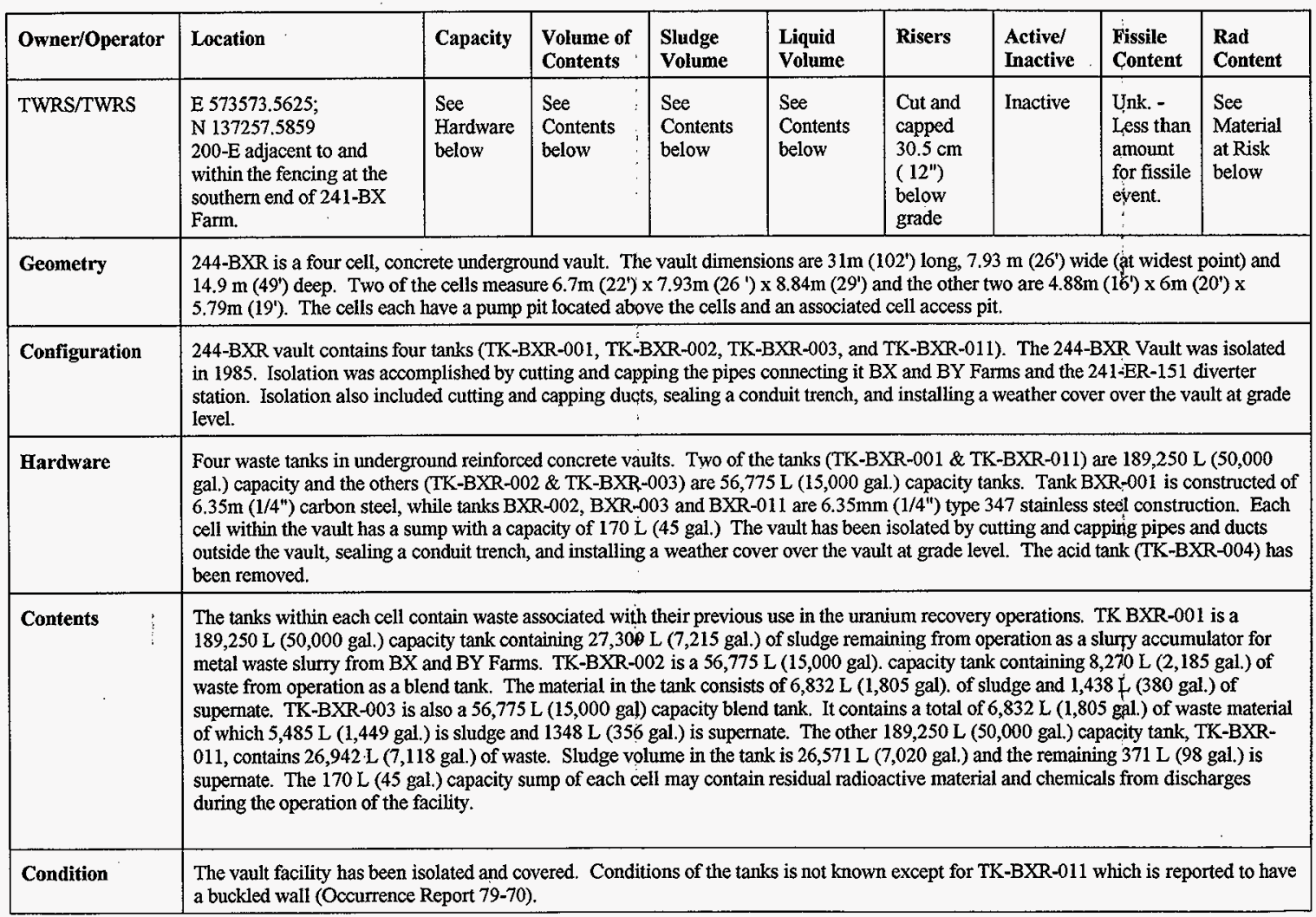




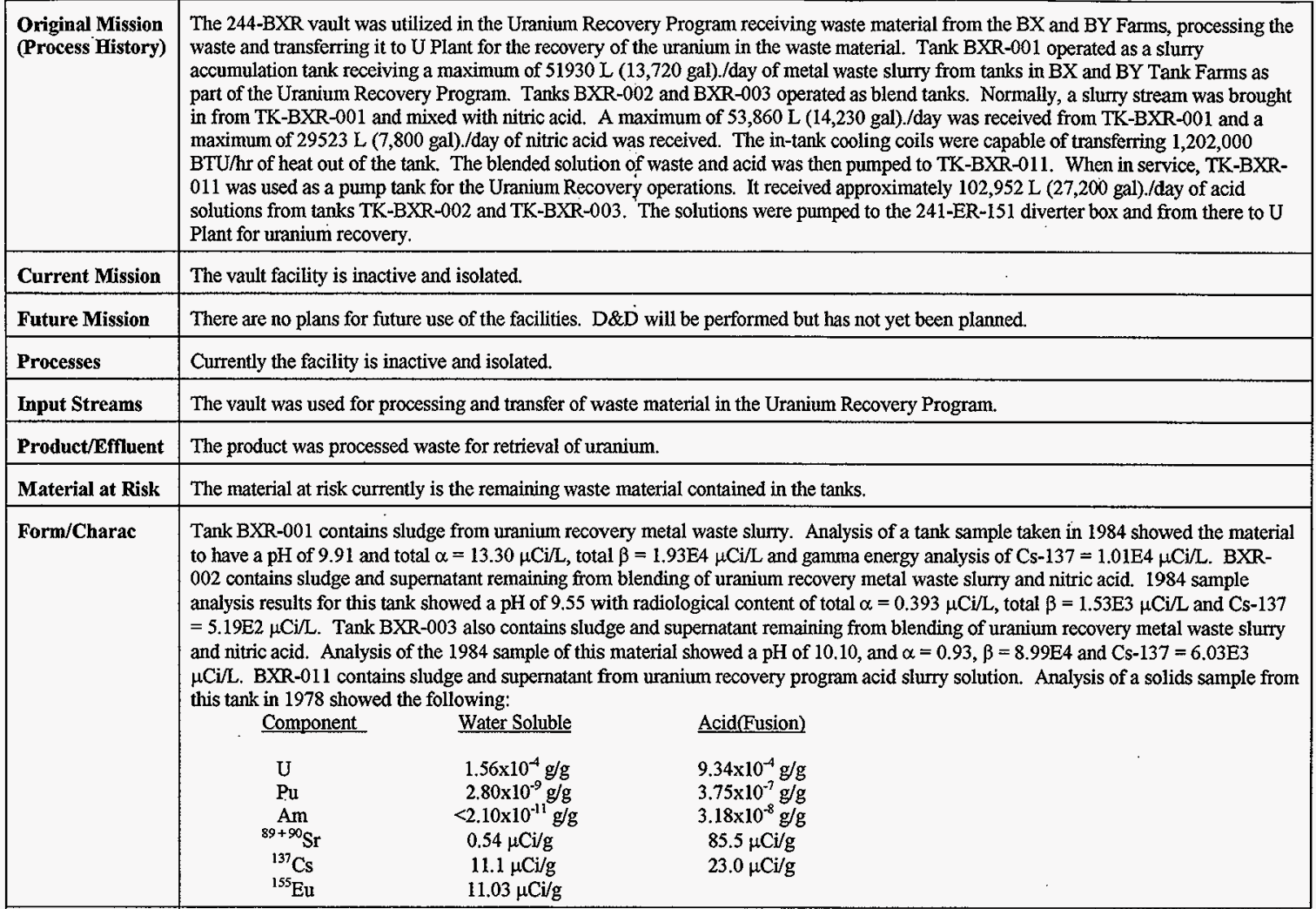

Quantity

TK-BXR-001: 27,309 L (7,215 gal.) of sludge remaining from operation as a slurry accumulation tank receiving a maximum of $51,930 \mathrm{~L}$ $(13,720 \mathrm{gal}$.$) / day of metal waste slurry from tanks in BX and BY Tank Farms.$

TK-BXR-002: 6,832 L (1,805 gal.) of sludge and 1,438 L (380 gal.) of supernatant remaining from operation as a blend tank for mixing waste from TK-BXR-001 with nitric acid. 


\begin{tabular}{|c|c|}
\hline & $\begin{array}{l}\text { TK-BXR-003: 5,485 L (1,449 gal.) of sludge and 1,348 L (356. gal.) of supernatant remaining from operation as a blend tank for mixing } \\
\text { waste from TK-BXR-001 with nitric acid. } \\
\text { TK-BXR-011: } 26,571 \mathrm{~L}(7,020 .) \text { of sludge and } 371 \mathrm{~L} \text { (98 gal.) of supernatant remaining from operation as a pump tank for the Uranium } \\
\text { Recovery operations. }\end{array}$ \\
\hline Material Stored & $\begin{array}{l}\text { The material is contained in the tanks within BXR Vault. The cell sumps have a capacity of } 170 \mathrm{~L} \text { ( } 45 \text { gal.) and may contain } \\
\text { radiologically and/or chemically contaminated liquid. }\end{array}$ \\
\hline Condition & $\begin{array}{l}\text { The overall condition of the vault cannot currently be observed since the facility has been isolated and covered with a weather seal. The } \\
\text { conditions of the tanks cannot be observed, however, tanks BXR-001, } 002 \text { and } 003 \text { are assumed to be sound. TK-BXR-011 is reported to } \\
\text { be buckled from overpressurization of the tank exterior. }\end{array}$ \\
\hline Interactions & $\begin{array}{l}\text { There are no identified interactions of materials located within the facility. Feed material to the tanks originated in tanks containing } \\
\text { materials that may produce toxic vapors when combined, thus tank contents may produce toxic vapors. }\end{array}$ \\
\hline Energy Sources & The facility has been isolated from all energy sources. \\
\hline Energy Needs & None. \\
\hline Past Controls & Past controls include the facility and tank ventilation system and radiological controls related to entry into the components of the facility. \\
\hline $\begin{array}{l}\text { Current } \\
\text { Controls }\end{array}$ & $\begin{array}{l}\text { Currently, the TSR Controls related to Flammable Gas ignition (AC 5.10) and tank dome loading (AC 5.16) apply to the facility since the } \\
\text { tanks in it are identified as IMUSTs referred to in the BIO. }\end{array}$ \\
\hline $\begin{array}{l}\text { Planned } \\
\text { Controls }\end{array}$ & No additional controls are anticipated or planned. \\
\hline Barriers & The facility has been isolated and sealed. \\
\hline $\begin{array}{l}\text { Chemical } \\
\text { Segregation }\end{array}$ & $\begin{array}{l}\text { Materials within the facility are contained within the four tanks each located within individual reinforced concrete cells which provide } \\
\text { physical separation of the contents. }\end{array}$ \\
\hline
\end{tabular}




\begin{tabular}{|c|c|}
\hline $\begin{array}{l}\text { Current or } \\
\text { Future Risks }\end{array}$ & No current or future risks have been identified other than potential presence of toxic vapors in the tanks. \\
\hline $\begin{array}{l}\text { Occurrence } \\
\text { History }\end{array}$ & $\begin{array}{l}\text { Occurrence Report } 79-70 \text { provides information that the wall of TK-BXR-011 is buckled. The failure was due to an overpressure } \\
\text { condition from a higher than allowed liquid level in the cell. }\end{array}$ \\
\hline Root Cause & No root cause analysis for the occurrence has been identified. \\
\hline $\begin{array}{l}\text { Records } \\
\text { Location }\end{array}$ & $\begin{array}{l}\text { Records regarding the facility are located in Engineering Files, operational reports files and Discrepancy Report files located within } \\
\text { TWRS Engineering and Operations organizations. Some of the tecords may be located in Records Holding locally and at the records } \\
\text { repository. }\end{array}$ \\
\hline Records Access & No special access requirements for facility documentation have been identified. \\
\hline $\begin{array}{l}\text { Adjacent Facility } \\
\text { Location }\end{array}$ & The 244-BXR Vault is located adjacent to and within the fencing of 241-BX Tank Farm. \\
\hline $\begin{array}{l}\text { Underground } \\
\text { Facilities }\end{array}$ & $\begin{array}{l}\text { Isolation of the facility included cutting and capping pipes and ducts. Isolation drawings indicate risers and lines were cut and capped } \\
30.5 \mathrm{~cm}\left(12^{\prime \prime}\right) \text { below grade. }\end{array}$ \\
\hline BIO Coverage & $\begin{array}{l}\text { 244-BXR Vault is not discussed in the BIO. The Individual tanks within the Vault are identified in the BIO Table B2-16 as IMUSTs that } \\
\text { are radiologically contaminated. As such, BIO discussions of IMUSTs includes these tanks. }\end{array}$ \\
\hline FSAR Coverage & $\begin{array}{l}\text { 244-BXR Vault is not discussed in the draft FSAR. The Individual tanks within the Vault are identified in the FSAR Table 2-16 as } \\
\text { IMUSTs that are radiologically contaminated. As such, FSAR discussions of IMUSTs includes these tanks. }\end{array}$ \\
\hline $\begin{array}{l}\text { Information } \\
\text { Sources }\end{array}$ & $\begin{array}{l}\text { J.A. Crawford - Cognizant Engineer } \\
\text { HNF-SD-WM-BIO-001, REV 0 - Tank Waste Remediation System Basis for Interim Operation } \\
\text { WHC-SD-EN-ES-040, REV 0 - Engineering Study of } 50 \text { Miscellaneous Inactive Underground Radioactive Waste Tanks Located at the } \\
\text { Hanford Site WA } \\
\text { WHC-SD-WM-HIE-007, REV } 0 \text { - Tank Waste Remediation System FSAR Hazard Identification/Facility Configuration Verification } \\
\text { Report } \\
\text { WHC-SD-WM-HA-001, REV 0 - Preliminary Hazards Analysis of the Miscellaneous Underground Storage Tanks } \\
\text { WHC-EP-0861, REV 0 - Status Report for Inactive Miscellaneous Underground Storage Tanks at Hanford Site } 200 \text { Areas } \\
\text { Drawings - H-2-71638, H-2-42485, H-2-42486, H-2-42487, H-2-42488, H-2-71655, H-2-71656. }\end{array}$ \\
\hline
\end{tabular}


FACILITY HAZARD PRÖFLE CHECKLIST

Rev. 0, April 20, 1998

\begin{tabular}{|c|c|c|c|c|c|c|c|c|c|}
\hline Facility $\mathbf{m}$ & 44-CR & \multicolumn{2}{|c|}{ Facility Name: } & \multicolumn{6}{|l|}{ 44-CR Vault } \\
\hline Owner/Operator & Location & Capacity & $\begin{array}{l}\text { Volume of } \\
\text { Contents }\end{array}$ & $\begin{array}{l}\text { Sludge } \\
\text { Volume }\end{array}$ & $\begin{array}{l}\text { Liquid } \\
\text { Volume }\end{array}$ & Risers & $\begin{array}{l}\text { Active/ } \\
\text { nactive }\end{array}$ & $\begin{array}{l}\text { Fissile } \\
\text { Content } \\
\end{array}$ & $\begin{array}{l}\text { Rad } \\
\text { Content }\end{array}$ \\
\hline TWRS/TWRS & $\begin{array}{l}575150 ; N 135450 \\
0-E \text {, adjacent to and } \\
\text { thin the fencing at the } \\
\text { athern end of } C \text { farm. }\end{array}$ & $\begin{array}{l}\text { See } \\
\text { Hardware } \\
\text { below }\end{array}$ & $\begin{array}{l}\text { See } \\
\text { Contents } \\
\text { below }\end{array}$ & $\begin{array}{l}\text { Unknown - } \\
\text { cf. Content } \\
\text { and Mat'l at } \\
\text { Risk below }\end{array}$ & $\begin{array}{l}\text { Unknown - } \\
\text { cf. Content } \\
\text { and Mat'l at } \\
\text { Risk below }\end{array}$ & $\begin{array}{l}\text { See } \\
\text { Hardware } \\
\text { below }\end{array}$ & $\begin{array}{l}\text { See } \\
\text { Current } \\
\text { Mission } \\
\text { below } \\
\end{array}$ & Unk. & Unknown \\
\hline Geometry & \multicolumn{9}{|c|}{$\begin{array}{l}\text { 244-CR is a four cell, concrete underground vault. The vault dimensions are } 31 \mathrm{~m}\left(102^{\prime}\right) \text { long, } 7.93 \mathrm{~m}\left(26^{\prime}\right) \text { wide (at widest point) and } \\
14.94 \mathrm{~m}\left(49^{\prime}\right) \text { deep. Two of the cells measure } 6.7 \mathrm{~m}\left(22^{\prime}\right) \times 7.93 \mathrm{~m}\left(26^{\prime}\right) \times 8.84 \mathrm{~m}\left(29^{\prime}\right) \text { and the other two are } 4.88 \mathrm{~m}\left(16^{\prime}\right) \times 6 \mathrm{~m}\left(20^{\prime}\right) \times \\
5.79 \mathrm{~m}\left(19^{\prime}\right) \text {. The cells each have a pump pit located above the cells and an associated cell access pit. TK-CR-001 is a } 189,250 \mathrm{~L}(50,000 \\
\text { gal.) tank located in a reinforced concrete cell } 6.7 \mathrm{~m}\left(22^{\prime}\right) \times 7.93 \mathrm{~m}\left(26^{\prime}\right) \times 8.84 \mathrm{~m}\left(29^{\prime}\right) \text {. Tanks TK-CR-002 and TK-CR-003 are } 56,775 \mathrm{~L} \\
\left(15,000 \text { gal.) tanks located in reinforced concrete cells } 4.88 \mathrm{~m}\left(16^{\prime}\right) \times 6 \mathrm{~m}\left(20^{\prime}\right) \times 5.79 \mathrm{~m}\left(19^{\prime}\right) \text {. TK-CR-011 is a } 189,250 \mathrm{~L}(50,000 \text { gal). }\right. \\
\text { tank located in a reinforced concrete cell } 6.7 \mathrm{~m}\left(22^{\prime}\right) \times 7.93 \mathrm{~m}\left(26^{\prime}\right) \times 8.84 \mathrm{~m}\left(29^{\prime}\right) \text {. Adjacent to the Vault is the } 271-\mathrm{CR} / \mathrm{CRL} \text { facility. } \\
271-\mathrm{CR} \text { operated as the control room/shift office for the } 244-\mathrm{CR} \text { uranium recovery and ferrocyanide programs and housed the saltwell } \\
\text { pumping alarm panels. } 271-\mathrm{CRL} \text { was used as a shielded laboratory facility for reactor coolant studies. } 271-\mathrm{CR} \text { is a wood frame building } \\
9.75 \mathrm{~m}\left(32^{\prime}\right) \text { wide and } 19 \mathrm{~m}\left(62^{\prime} 7^{\prime \prime}\right) \text { long. } 271-\mathrm{CRL} \text { is a metal \& concrete building } 9.75 \mathrm{~m}\left(32^{\prime}\right) \text { wide and } 15.75 \mathrm{~m}\left(51^{\prime} 8^{\prime \prime}\right) \text { long. }\end{array}$} \\
\hline on & \multicolumn{9}{|c|}{$\begin{array}{l}244-\mathrm{CR} \text { vault contains four tanks (TK-CR-001, TK-CR-002, TK-CR-003 and TK-CR-011). The tanks provided interim storage and } \\
\text { transfer of liquid waste. Piping connecting the vault to C Farm and the } 241-\mathrm{CR}-151 \text { Diverter Box is still connected and electric lines and } \\
\text { ventilation systems are operational. 271-CR contains the Motor Control Center (MCC) for C Farm and both electrical and fire protection } \\
\text { water systems are connected and active. }\end{array}$} \\
\hline Hardware & \multicolumn{9}{|c|}{$\begin{array}{l}\text { Two of the four tanks (TK-CR-001 \& TK-CR-011) are } 189,250 \mathrm{~L} \text { ( } 50,000 \text { gal) capacity, and the others (TK-CR-002 \& TK-CR-003) are } \\
56,775 \mathrm{~L}(15,000 \text { gal.) capacity tanks. Only TK-CR-003 is currently in use. All above ground piping and lines have been removed } \\
\text { except for the following: the Air Intake for the ventilation system, Cell } 003 \text { Heat Trace and Water Drip Cabinet, the Temporary Power } \\
\text { Supply and the exhaust ventilation system fan and Stack. The Cell } 003 \text { sample pit manual tape and zip cord have also been left in place. } \\
\text { The ventilation system filter pit containing the stack gas filter is operable. All of the cell access pits and pump pits are covered with } \\
\text { cover blocks which have been sealed for cells } 001,002 \text { and } 011 \text {. } 271-\mathrm{CR} \text { is active as the MCC and CASS for C Farm. An } 30,280 \mathrm{~L} \\
(8000 \text { gal.) tank previously used for nitric acid tank has been removed. The CRL facility is empty and is not currently in use. }\end{array}$} \\
\hline Contents & \multicolumn{9}{|c|}{$\begin{array}{l}\text { The tanks within each cell in the vault contain waste associated with their previous use as interim storage and transfer of liquid process } \\
\text { waste. TK-CR-003 contains approximately } 15,973 \mathrm{~L} \text { ( } 4220 \text { gal.) of saltwell waste with an unknown amount of solids associated with it. } \\
\text { The contents of the other tanks are not verified but estimated to be: } 7.570 \mathrm{~L}(2,000 \text { gal.) of Uranium Recovery Program solids in TK-001; } \\
56,775 \mathrm{~L} \text { ( } 1,500 \text { gal.) of waste solids from PUREX acidified sludge in TK-002; and } 132,475 \mathrm{~L} \text { ( } 35,000 \text { gal.) of supernatant and rainwater } \\
\text { in TK-011. (Source: Discussions with cognizant individuals.) Each cell has a } 170 \mathrm{~L} \text { ( } 45 \text { gal.) capacity sump with the possibility of } \\
\text { containing standing liquids which would contain contamination. Within the } 271-\mathrm{CR} / \mathrm{CRL} \text { complex, only the MCC instrumentation and } \\
\text { piping for the fire suppression system remain as operational equipment. The buildings themselves contain radiological contamination } \\
\text { and entry is controlled. }\end{array}$} \\
\hline
\end{tabular}




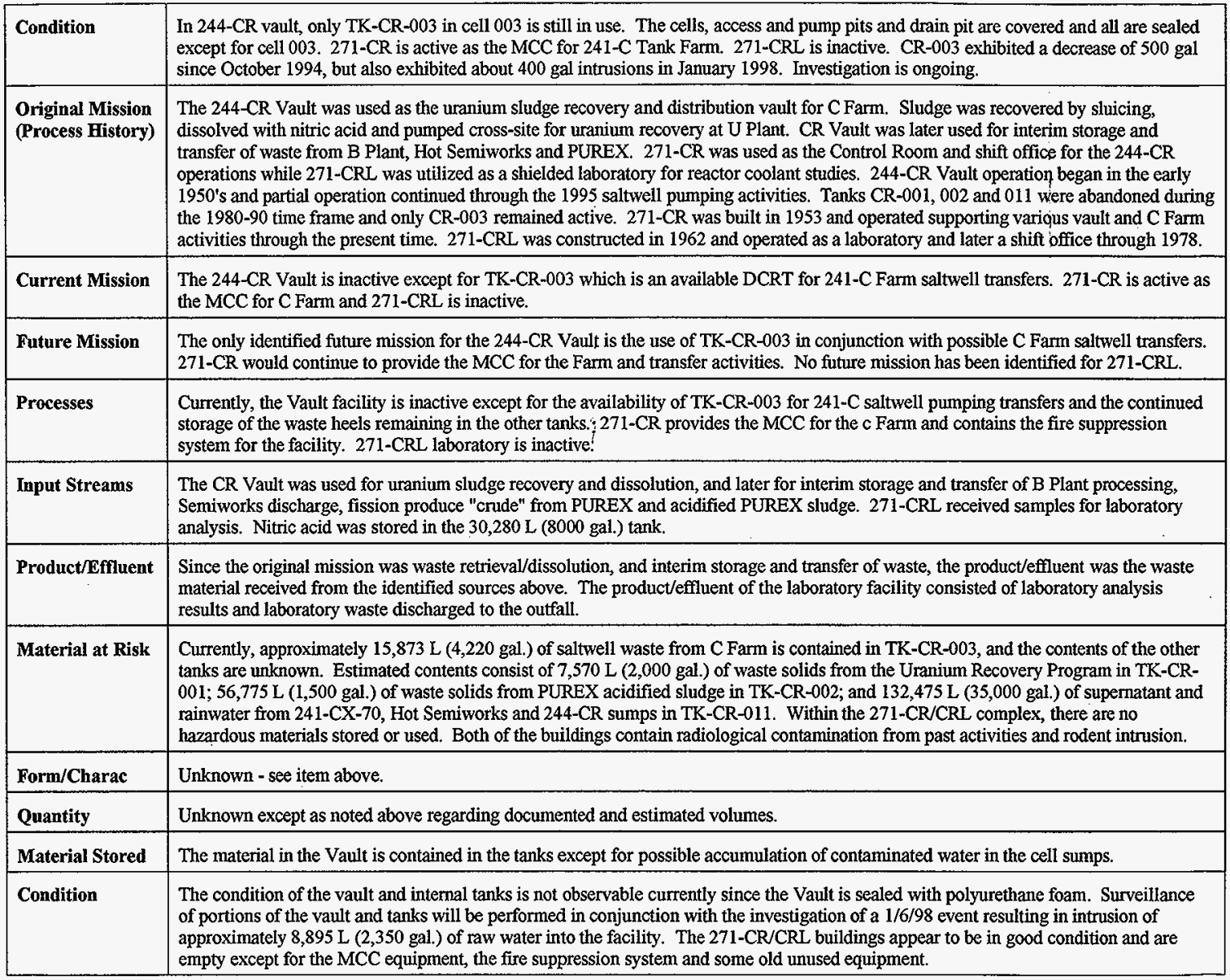




\begin{tabular}{|c|c|}
\hline Interactions & $\begin{array}{l}\text { There are no identified interactions of materials located within the vault facility. However, based on the previous use of the } 244-\mathrm{CR} \\
\text { Vault in conjunction with B Plant, there is the potential for organic materials to be in the tank contents. The tank contents are potentially } \\
\text { capable of producing flammable gas. There is no identified interactions associated with } 271-\mathrm{CR} / \mathrm{CRL} \text {. }\end{array}$ \\
\hline Energy Sources & $\begin{array}{l}\text { Currently the only energy source active in the vault is the electrical system for operation of the ventilation fan. Electrical power is also } \\
\text { supplied to } 271-\mathrm{CR} \text { to operate the } 241-\mathrm{C} \text { MCC equipment. } 271-\mathrm{CR} \text { also has a connection to raw water for the fire protection sprinkler } \\
\text { system in the facility. }\end{array}$ \\
\hline Energy Needs & $\begin{array}{l}\text { Electricity for operation of the vault ventilation system and the C Farm MCC. Water for the fire suppression system, however, this } \\
\text { system is being considered for deactivation based on the current value of the facility and its contents. }\end{array}$ \\
\hline $\begin{array}{l}\text { Source } \\
\text { Condition }\end{array}$ & The electrical system and raw water system for the fire suppression system appears sound. \\
\hline Past Controls & $\begin{array}{l}\text { Past controls include the facility and tank ventilation systems, radiological controls related to entry into the components of the facility } \\
\text { and the fire suppression system for the } 2371-C R / C R L \text { complex. }\end{array}$ \\
\hline $\begin{array}{l}\text { Planned } \\
\text { Controls }\end{array}$ & There are no controls anticipated other than those noted above. \\
\hline Barriers & $\begin{array}{l}\text { Currently, all of the vault cell access pits and pump pits are covered with cover blocks which have been sealed for cells } 001,002 \text { and } 011 \text {. } \\
\text { Cell } 003 \text { is sealed but will be opened to allow video surveillance and observation for associated with investigation of the consequences of } \\
\text { a } 1 / 6 / 98 \text { introduction of raw water and the observed level decrease from } 10 / 95 \text { to } 11 / 97 \text {. The tanks are assumed to be sound and the } \\
\text { ventilation system is operational. The } 271-\text { CR/CRL complex is within the Tank Farm fenced area and are closed to entry except as } \\
\text { specifically authorized. }\end{array}$ \\
\hline $\begin{array}{l}\text { Chemical } \\
\text { Segregation }\end{array}$ & $\begin{array}{l}\text { Materials within the vault facility are contained in the four tanks which are contained in individual cells which provides physical } \\
\text { separation of the contents unless deliberate transfer of the tank contents is initiated. }\end{array}$ \\
\hline
\end{tabular}




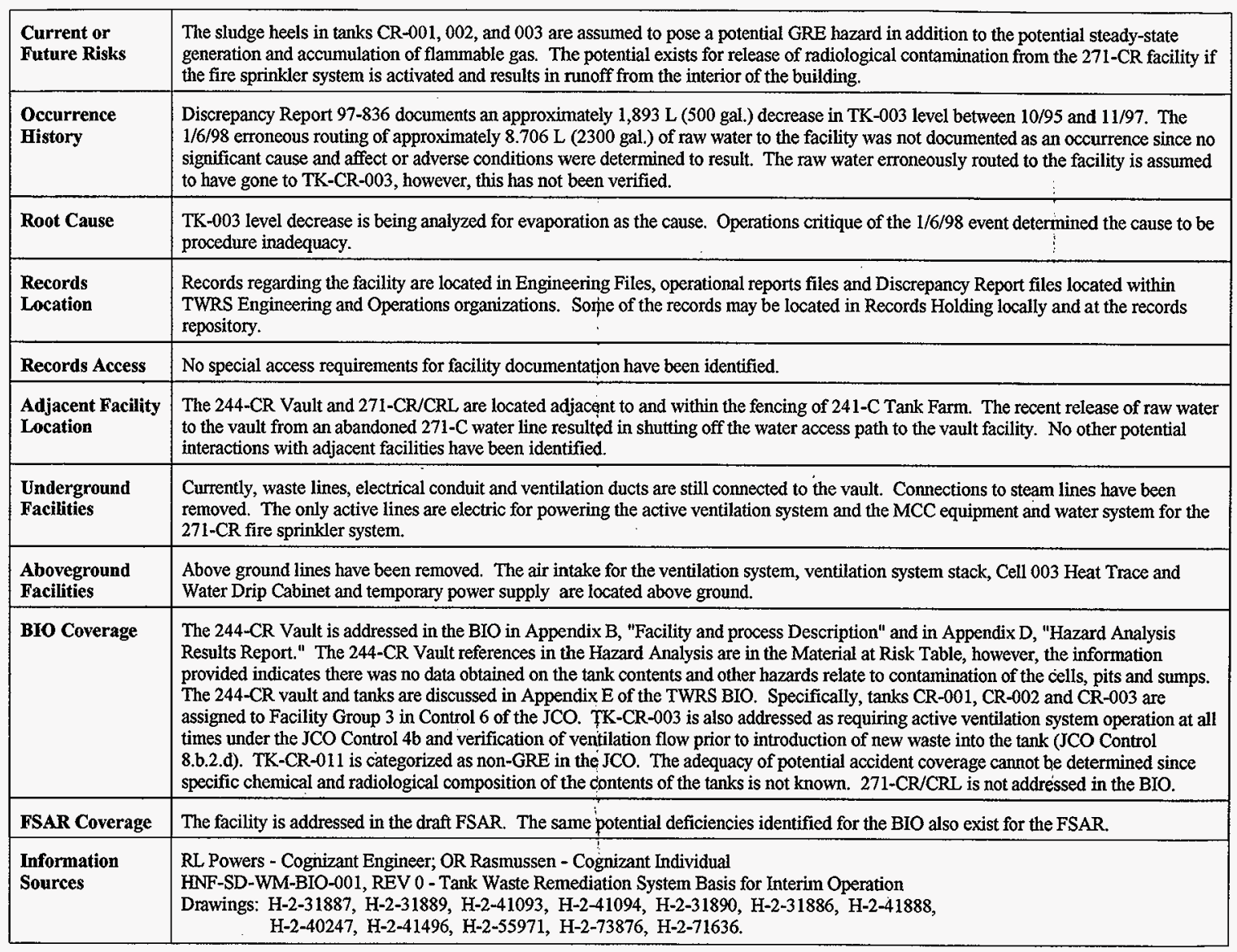


FACLITY HAZARD PROFILE CHECKLIST

Rev 0, April 20, 1998

\begin{tabular}{|c|c|c|c|c|c|c|c|c|c|}
\hline Facility D: & 244-TXR & \multicolumn{2}{|c|}{ Facility Name: } & \multicolumn{6}{|c|}{ 244-TXR Vault } \\
\hline Owner/Operator & Location & Capacity & $\begin{array}{l}\text { Volume of } \\
\text { Contents }\end{array}$ & $\begin{array}{l}\text { Sludge } \\
\text { Volume }\end{array}$ & $\begin{array}{l}\text { Liquid } \\
\text { Volume }\end{array}$ & Risers & $\begin{array}{l}\text { Active/ } \\
\text { Inactive }\end{array}$ & $\begin{array}{l}\text { Fissile } \\
\text { Content }\end{array}$ & $\begin{array}{l}\text { Rad } \\
\text { Content }\end{array}$ \\
\hline TWRS/TWRS & $\begin{array}{l}\text { E } 573573.5625 \\
\text { N } 137257.5859 \\
200-E \text { adjacent to and } \\
\text { within the fencing at the } \\
\text { South end of } 241-\mathrm{TX} \\
\text { Farm. }\end{array}$ & $\begin{array}{l}\text { See } \\
\text { Hardware } \\
\text { below }\end{array}$ & $\begin{array}{l}\text { See } \\
\text { Contents } \\
\text { below }\end{array}$ & $\begin{array}{l}\text { See } \\
\text { Contents } \\
\text { below }\end{array}$ & $\begin{array}{l}\text { See } \\
\text { Contents } \\
\text { below }\end{array}$ & $\begin{array}{l}\text { Cut and } \\
\text { capped, } \\
\text { some } \\
\text { below } \\
\text { grade }\end{array}$ & Inactive & $\begin{array}{l}\text { Unk. - } \\
\text { Less than } \\
\text { amount } \\
\text { for fissile } \\
\text { event. }\end{array}$ & $\begin{array}{l}\text { See } \\
\text { Material } \\
\text { at Risk } \\
\text { below }\end{array}$ \\
\hline Geometry & \multicolumn{9}{|c|}{$\begin{array}{l}\text { 244-TXR is a three cell, underground reinforced concrete vault. The vault dimensions are } 22.6 \mathrm{~m}\left(74^{\prime}\right) \text { long, } 7.93 \mathrm{~m}\left(26^{\prime}\right) \text { wide }(\text { at widest } \\
\text { point) and } 14.9 \mathrm{~m}\left(49^{\prime}\right) \text { deep. One cell measures } 6.7 \mathrm{~m}\left(22^{\prime}\right) \times 7.93 \mathrm{~m}\left(26^{\prime}\right) \times 8.84 \mathrm{~m}\left(29^{\prime}\right) \text { and the other two are } 4.88 \mathrm{~m}\left(16^{\prime}\right) \times 6.1 \mathrm{~m}\left(20^{\prime}\right) \times \\
5.79 \mathrm{~m}\left(19^{\prime}\right) \text {. The cells each have a pump pit located above the cells and an associated cell access pit. }\end{array}$} \\
\hline Configuration & \multicolumn{9}{|c|}{$\begin{array}{l}\text { The 244-TXR Vault contains three tanks with capacities of: TK-TXR-001: } 189.25 \mathrm{~K} \text { L (50,000 gal.); Tanks TK-TXR-002 and TXR-003: } \\
56.775 \mathrm{~K} \mathrm{~L} \mathrm{(15,000} \mathrm{gal).} \mathrm{The} \mathrm{Vault} \mathrm{was} \mathrm{taken} \mathrm{out} \mathrm{of} \mathrm{regular} \mathrm{service} \mathrm{in} 1957 \text { and underwent stabilization in } 1984 \text {. }\end{array}$} \\
\hline Hardware & \multicolumn{9}{|c|}{$\begin{array}{l}\text { Three tanks in reinforced concrete cells. Tank TXR-001 is a } 189.25 \mathrm{~K} \mathrm{~L}(50,000 \text { gal.) steel plate tank, tanks TK-TXR-002 and TXR-003 } \\
\text { are } 56.775 \mathrm{~K} \mathrm{~L}(15,000 \mathrm{gal}) \text { stainless steel tanks. Cells TXR-001, } 002 \text { and } 003 \text { each contain a } 170 \mathrm{~L} \text { ( } 45 \text { gal.) capacity sump. }\end{array}$} \\
\hline Contents & \multicolumn{9}{|c|}{ 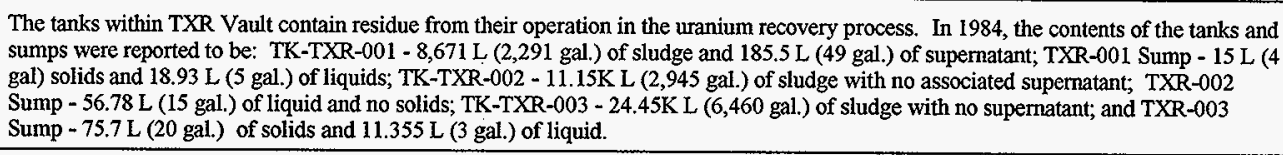 } \\
\hline Condition & \multicolumn{9}{|c|}{$\begin{array}{l}\text { The condition of the vault is not known. Hanford Occurrence Report } 79-68 \text { relates to TK-TXR-001 and concludes that the tank is of } \\
\text { questionable integrity. The conditions of the two blend tanks is unknown. }\end{array}$} \\
\hline $\begin{array}{l}\text { Original Mission } \\
\text { (Process History) }\end{array}$ & \multicolumn{9}{|c|}{$\begin{array}{l}\text { The Vault was in service from } 1951 \text { to } 1956 \text {, receiving metal waste from tanks TX-103 through TX-108 and T-101 through T-103. The } \\
\text { metal waste was received in TK-TXR-00I and the waste slurry was pumped to TK-TXR-002 and/or TK-TXR-003 for acidification and } \\
\text { blending. The processed waste was then pumped to U Plant as feed for the uranium recovery process. }\end{array}$} \\
\hline Current Mission & \multicolumn{9}{|l|}{ None. } \\
\hline Future Mission & \multicolumn{9}{|c|}{ None. D\&D will be performed in the future but has not yet been planned. } \\
\hline rocesses & \multicolumn{9}{|c|}{ The facility is currently isolated and stabilized. } \\
\hline
\end{tabular}




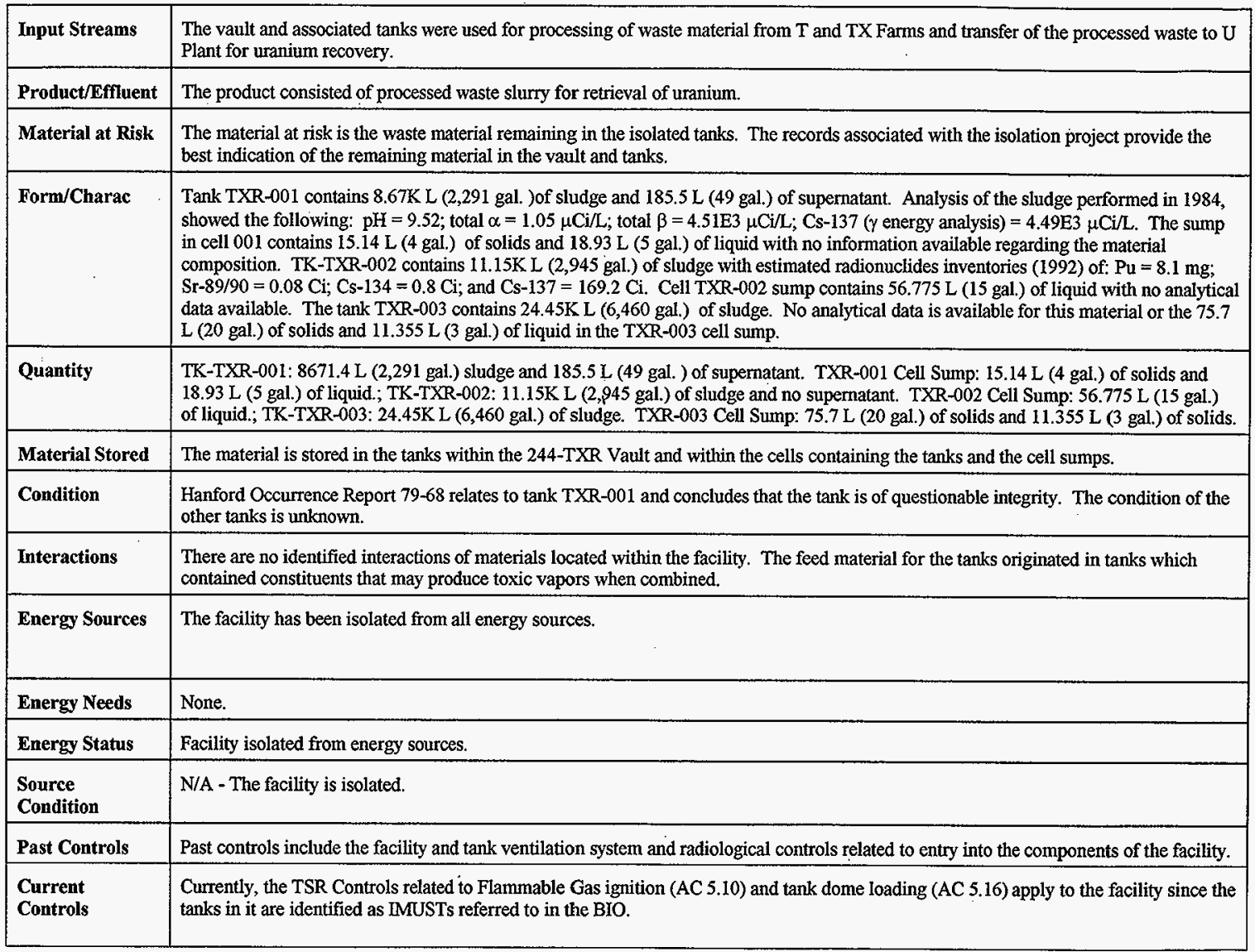




\begin{tabular}{|c|c|}
\hline $\begin{array}{l}\text { Planned } \\
\text { Controls }\end{array}$ & No additional controls are anticipated or planned. \\
\hline Barriers & The facility has been isolated and stabilized. \\
\hline $\begin{array}{l}\text { Chemical } \\
\text { Segregation }\end{array}$ & $\begin{array}{l}\text { Materials within the facility are contained within the four tanks each located within individual reinforced concrete cells which provide } \\
\text { physical separation of the contents. }\end{array}$ \\
\hline $\begin{array}{l}\text { Monitoring and } \\
\text { Surveillance }\end{array}$ & The facility is not currently routinely monitored. \\
\hline Historical Risks & No safety documentation of historical risks or postulated accidents has been identified. \\
\hline $\begin{array}{l}\text { Current or } \\
\text { Future Risks }\end{array}$ & No current or future risks have been identified other than potential presence of toxic vapors in the tanks. \\
\hline Root Cause & No root cause of the liquid level decrease was determined. \\
\hline $\begin{array}{l}\text { Records } \\
\text { Location }\end{array}$ & $\begin{array}{l}\text { Records regarding the facility are located in Engineering Files, operational reports files and Discrepancy Report files located within } \\
\text { TWRS Engineering and Operations organizations. Some of the records may be located in Records Holding locally and at the records } \\
\text { repository. }\end{array}$ \\
\hline Records Access & No special access requirements for facility documentation have been identified. \\
\hline $\begin{array}{l}\text { Adjacent Facility } \\
\text { Location }\end{array}$ & The 244-TXR Vault is located adjacent to and within the fencing of 241-TX Tank Farm. \\
\hline $\begin{array}{l}\text { Underground } \\
\text { Facilities }\end{array}$ & Isolation of the facility included cutting and capping pipes and ducts. \\
\hline
\end{tabular}




\section{FSAR Coverage}

Information

Sources
244-TXR Vault is not discussed in the draft FSAR. The Individual tanks within the Vault are identified in the FSAR Table 2-16 as IMUSTs that are radiologically contaminated. As such, FSAR discussions of IMUSTs includes these tanks.

KJ Hull - Cognizant Engineer

HNF-SD-WM-BIO-001, REV 0 - Tank Waste Remediation System Basis for Interim Operation

WHC-SD-EN-ES-040, REV 0 - Engineering Study of 50 Miscellaneous Inactive Underground Radioactive Waste Tanks Located at the Hanford Site WA

WHC-SD-WM-HIE-007, REV 0 - Tank Waste Remediation System FSAR Hazard Identification/Facility Configuration Verification

Report

WHC-SD-WM-HA-001, REV 0 - Preliminary Hazards Analysis of the Miscellaneous Underground Storage Tanks

WHC-EP-0861, REV 0 - Status Report for Inactive Miscellaneous Underground Storage Tanks at Hanford Site 200 Areas

Drawings - H-2-42300, H-2-42301, H-2-42302, H-2-42303, H-2-42707, H-2-44511, H-2-71661, H-2-71662, H-2-73112 
FACILITY HAZARD PROFILE CHECKLIST

Rev. 0, April 20, 1998

\begin{tabular}{|c|c|c|c|c|c|c|c|c|c|}
\hline Facility ID: & 244-UR & \multicolumn{2}{|c|}{ Facility Name: } & \multicolumn{6}{|c|}{ 244-UR Vault } \\
\hline Owner/Operator & Location & Capacity & $\begin{array}{l}\text { Volume of } \\
\text { Contents }\end{array}$ & $\begin{array}{l}\text { Sludge } \\
\text { Volume } \\
\end{array}$ & $\begin{array}{l}\text { Liquid } \\
\text { Volume }\end{array}$ & Risers & $\begin{array}{l}\text { Active/ } \\
\text { Inactive }\end{array}$ & $\begin{array}{l}\text { Fissile } \\
\text { Content }\end{array}$ & $\begin{array}{l}\text { Rad } \\
\text { Content }\end{array}$ \\
\hline $\begin{array}{l}\text { ERS (To be } \\
\text { TWRS) }\end{array}$ & $\begin{array}{l}\text { E } 566793.2678 \text {; } \\
\text { N } 135162.4158 \\
200 \text { W, adjacent to and } \\
\text { within the fencing at the } \\
\text { north end of } 241 U \text { Tank } \\
\text { Farm }\end{array}$ & $\begin{array}{l}\text { See } \\
\text { Hardware } \\
\text { below }\end{array}$ & $\begin{array}{l}\text { See } \\
\text { Contents } \\
\text { and } \\
\text { Quantity } \\
\text { below }\end{array}$ & $\begin{array}{l}\text { See } \\
\text { Contents } \\
\text { and } \\
\text { Quantity } \\
\text { below }\end{array}$ & $\begin{array}{l}\text { See } \\
\text { Contents } \\
\text { and } \\
\text { Quantity } \\
\text { below }\end{array}$ & $\begin{array}{l}\text { Cut and } \\
\text { capped } \\
\text { and } \\
\text { weather } \\
\text { cover } \\
\text { installed }\end{array}$ & Inactive & $\begin{array}{l}\text { None - } \\
\text { Trace } \\
\text { amounts } \\
\text { only }\end{array}$ & $\begin{array}{l}\text { See Form/ } \\
\text { Charac } \\
\text { below }\end{array}$ \\
\hline Geometry & \multicolumn{9}{|c|}{$\begin{array}{l}\text { 244-UR Vault is a four cell reinforced concrete underground structure } 27.43 \mathrm{~m} \text { (90 ft.) long, } 7.93 \mathrm{~m}(26 \mathrm{ft} \text {.) wide at its widest point and } \\
14 \mathrm{~m}\left(46 \mathrm{ft} \text { ) deep at the deepest cell. The cell containing TK-UR-001 has internal dimensions of } 7.93 \mathrm{~m}\left(26^{\prime}\right) \times 6.7 \mathrm{~m}\left(22^{\prime}\right) \times 9.0 \mathrm{~m}\left(29.5^{\prime}\right)\right. \\
\text { with } 61 \mathrm{~cm}\left(2^{\prime}\right) \text { thick walls, ceiling and floor. Above the cell is a } 3.81 \mathrm{~m}\left(12.5^{\prime}\right) \text { deep pump pit. The cells containing tanks TK-UR-002 } \\
\text { and } 003 \mathrm{measure} 6 \mathrm{~m}\left(20^{\prime}\right) \times 4.88 \mathrm{~m}\left(16^{\prime}\right) \times 5.95 \mathrm{~m}\left(19.5^{\prime}\right) \text { internally and also have a pump pit located above them. The cell containing } \\
\text { TK-UR-004 measures } 4.27 \mathrm{~m}\left(14^{\prime}\right) \times 4.88 \mathrm{~m}\left(16^{\prime}\right) \times 5.49 \mathrm{~m}\left(18^{\prime}\right) \text {, internal dimensions and has the pump pit located above it also. }\end{array}$} \\
\hline Hardware & \multicolumn{9}{|c|}{$\begin{array}{l}\text { Four tanks in underground reinforced concrete vault cells. Tank TK-UR-001 is a } 189,250 \mathrm{~L} \text { ( } 50,000 \text { gal.) steel plate tank, tanks TK-UR- } \\
002 \text { and UR-003 are } 56,775 \mathrm{~L} \text { ( } 15,000 \text { gal.) stainless steel tanks and TK-UR-004 is a } 31,151 \mathrm{~L}(8,230 \text { gal). stainless steel tank. Cells UR- } \\
001,002 \text { and } 003 \text { each contain a } 170 \mathrm{~L} \text { ( } 45 \text { gal.) capacity sump. }\end{array}$} \\
\hline Contents & \multicolumn{9}{|c|}{$\begin{array}{l}\text { The tanks within UR Vault contain residue from their operation in the uranium recovery process. TK-UR-001 contains } 7,010 \mathrm{~L}(1,852 \\
\text { gal.) of sludge and } 1,476 \mathrm{~L} \text { ( } 390 \text { gal.) of supernatant from its use as a slurry accumulator tank for the U Tank Farm. Tank UR-002 } \\
\text { contains } 8,721 \mathrm{~L}(2,304 \text { gal.) of sludge and either } 810 \mathrm{~L}(214 \text { gal.) or } 2,158 \mathrm{~L} \text { ( } 570 \text { gal.) of supernatant (conflicting liquid level data). } \\
\text { TK-UR-003 contains } 5,935 \mathrm{~L} \text { ( } 1,568 \text { gal.) of sludge. Tank UR-004 is reported to be empty. The sumps in cells UR-001,002 and } 003 \\
\text { also contain volumes of waste. }\end{array}$} \\
\hline Condition & \multicolumn{9}{|c|}{$\begin{array}{l}\text { The vault facility has been isolated and covered. Conditions of the tanks is not known. No evidence of leakage during the operating life } \\
\text { of the tanks has been located. Design life of the tanks has been exceeded. }\end{array}$} \\
\hline $\begin{array}{l}\text { Original Mission } \\
\text { (Process History) }\end{array}$ & \multicolumn{9}{|c|}{$\begin{array}{l}\text { The 244-UR Vault was built in } 1951 \text { for use in the uranium recovery process. The vault received uranium bearing waste slurries from } \\
\text { tanks in U Tank Farm, blended the slurry, added acid for } \mathrm{pH} \text { adjustment and conditioned the material as feed for the TBP uranium } \\
\text { extraction process in U Plant. }\end{array}$} \\
\hline
\end{tabular}




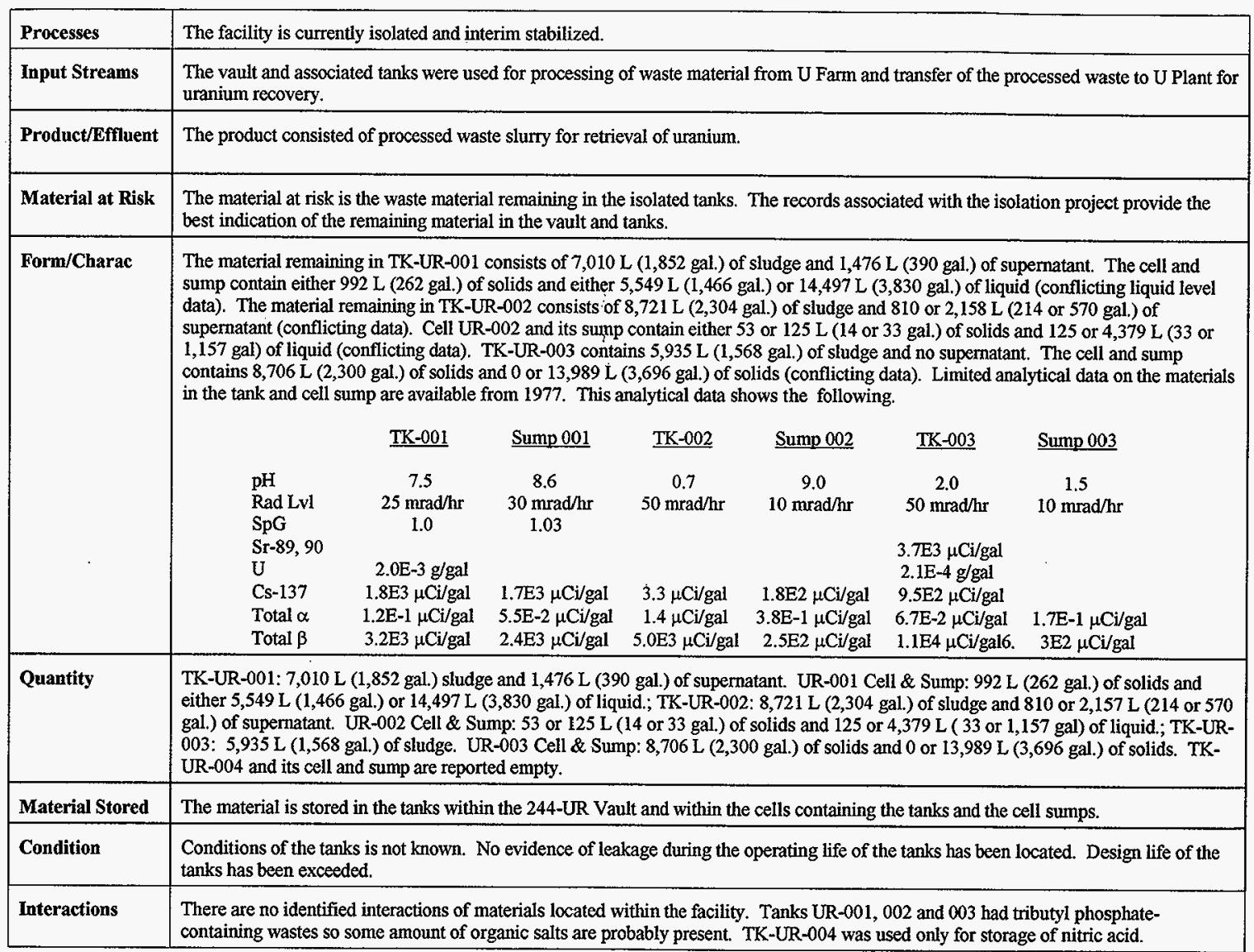




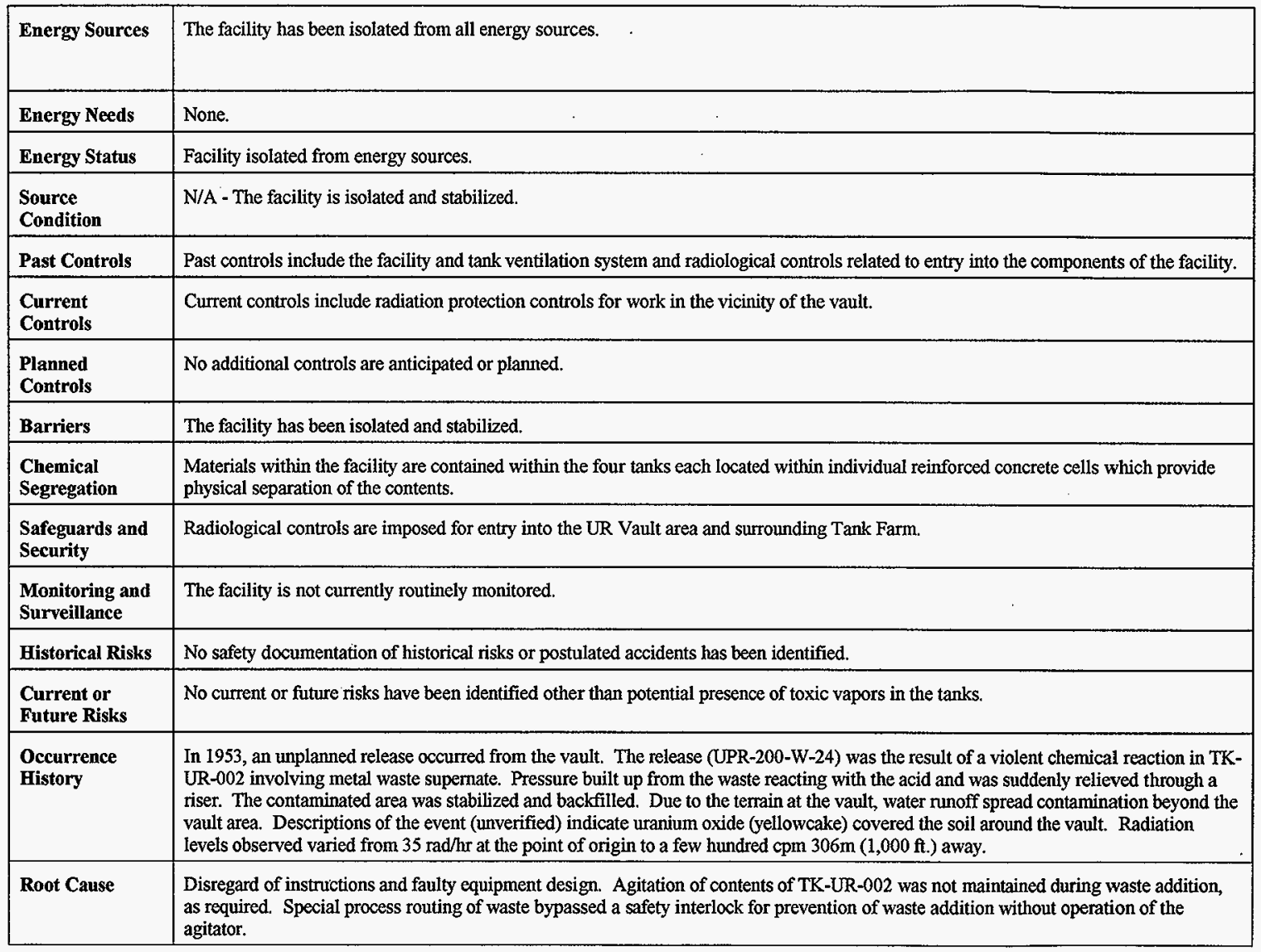




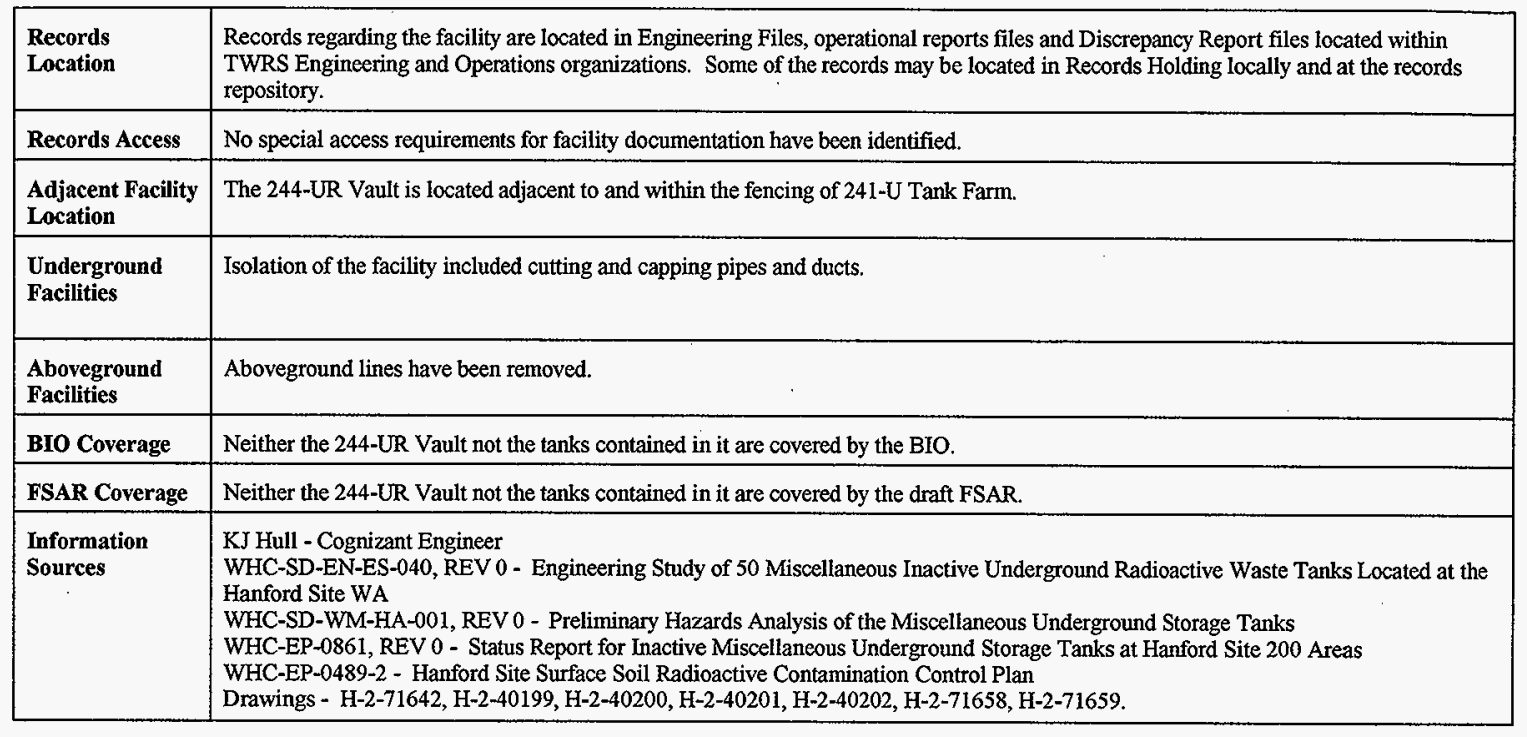


FACILITY HAZARD PROFILE CHECKLIST

Rev 0, April 20, 1998

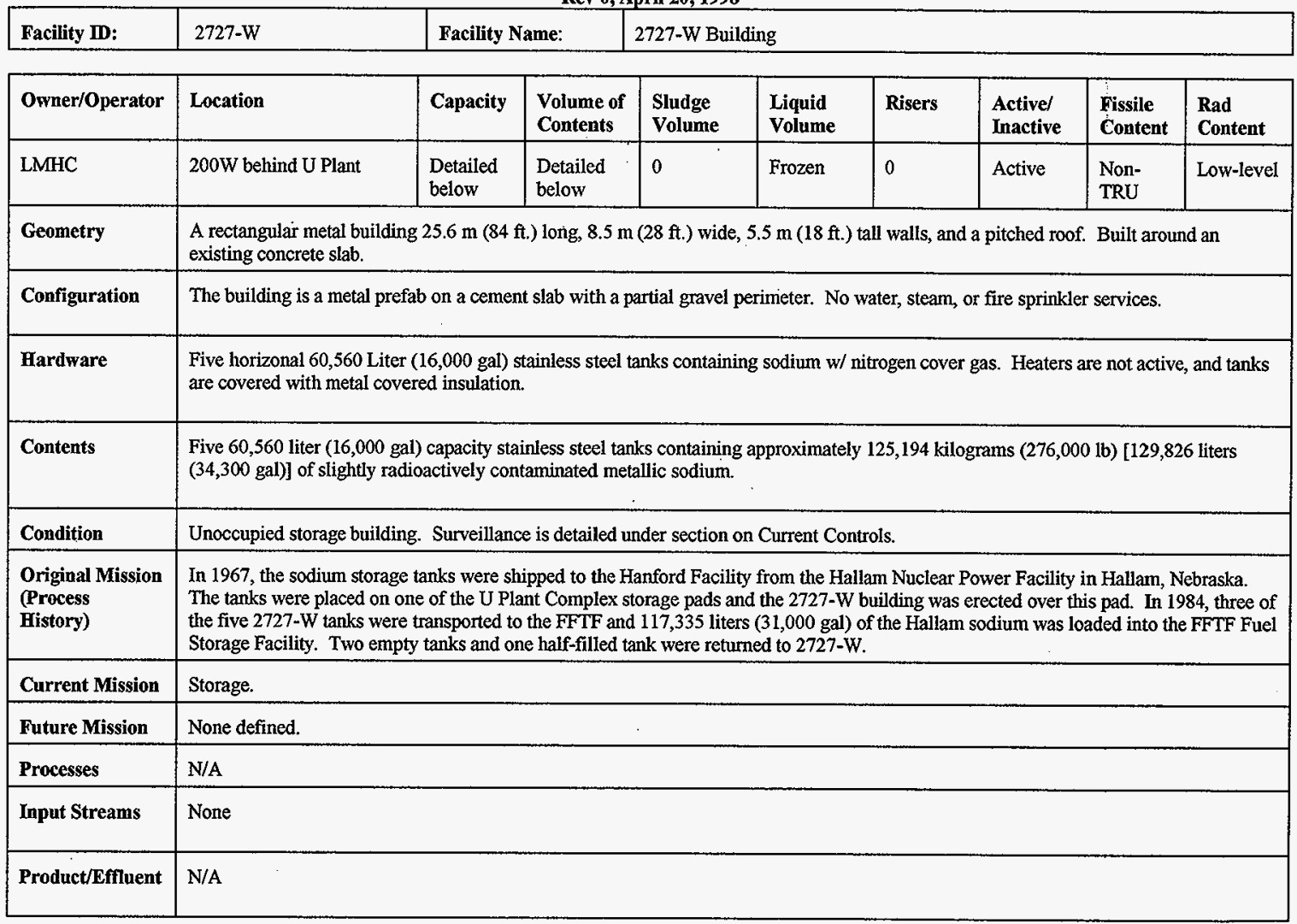




\begin{tabular}{|c|c|}
\hline Material at Risk & Slightly contaminated sodium metal. \\
\hline Form/Charac & Frozen solid in five SS tanks with nitrogen cover gas. \\
\hline Quantity & 129,826 Liters $(34,300$ gal) remaining in 5 tanks. Two of the tanks are nearly empty. \\
\hline Material Stored & Metallic sodium. \\
\hline Condition & Frozen in SS tanks with nitrogen cover gas. \\
\hline Interactions & Only connected to nitrogen cover gas bottles when adding gas, and when doing the semi-annual PM on the pressure switch. \\
\hline Energy Sources & Electrical power only, for lights, bottle pressure alarm, and fire detectors. \\
\hline Energy Needs & Electrical power only, for lights, bottle pressure alarm, and fire detectors. \\
\hline Energy Status & Connected to electrical power. \\
\hline $\begin{array}{l}\text { Source } \\
\text { Condition }\end{array}$ & Electrical OK \\
\hline Past Controls & Same as current checks. \\
\hline $\begin{array}{l}\text { Current } \\
\text { Controls }\end{array}$ & $\begin{array}{l}\text { Ionizing smoke detectors are installed to give advanced warning of threat to tanks from a fire (not to detect a sodium fire). } \\
\text { Operator checklist "Sodium Storage Building } 2727 \text {-W and SAMSM Check List" is contained in Solid Waste Management plant } \\
\text { operating procedure SW-04-043, Inspect the CWC and Sodium Storage Building and Associated Equipment. This checklist assures: } \\
\text { Chemicals (other than fire extinguisher) are greater than } 30.5 \mathrm{~m} \text { (100 ft) from building. Combustibles are greater than } 15.24 \mathrm{~m} \\
\text { (50 ft.) from building. (except for motor vehicle parking). Building lighting operable, fire alarms undisturbed, moisture not } \\
\text { present, roof not leaking, wind damage not present, suspicious objects or packages not present, and building secured. Tank } \\
\text { condition check specifies; "Leaks not present". }\end{array}$ \\
\hline $\begin{array}{l}\text { Planned } \\
\text { Controls }\end{array}$ & $\begin{array}{l}\text { The following controls are recommended: } \\
\text { Annual building integrity and foundation wall height } 0.9 \mathrm{~m} \text { ( } 3 \mathrm{ft} \text {.) above grade, as per Section } 4.4 .3 .4 \text { of Tank Waste Remediation } \\
\text { System Final Safety Analysis Report (HFN-SD-WM-SAR-067) should be implemented. } \\
\text { Pull sample from tank and analyze for radiological content for input into accident consequences. } \\
\text { Formalize limit on combustibles and chemicals to help pre-fire plan. Limits should be marked on building sign and surveillance sheet. } \\
\text { Prohibit vehicles from within } 15.24 \mathrm{~m}(50 \mathrm{ft} \text { ) of building (prohibit source of fuel and ignition). Placard building and add to surveillance } \\
\text { checklist. }\end{array}$ \\
\hline
\end{tabular}




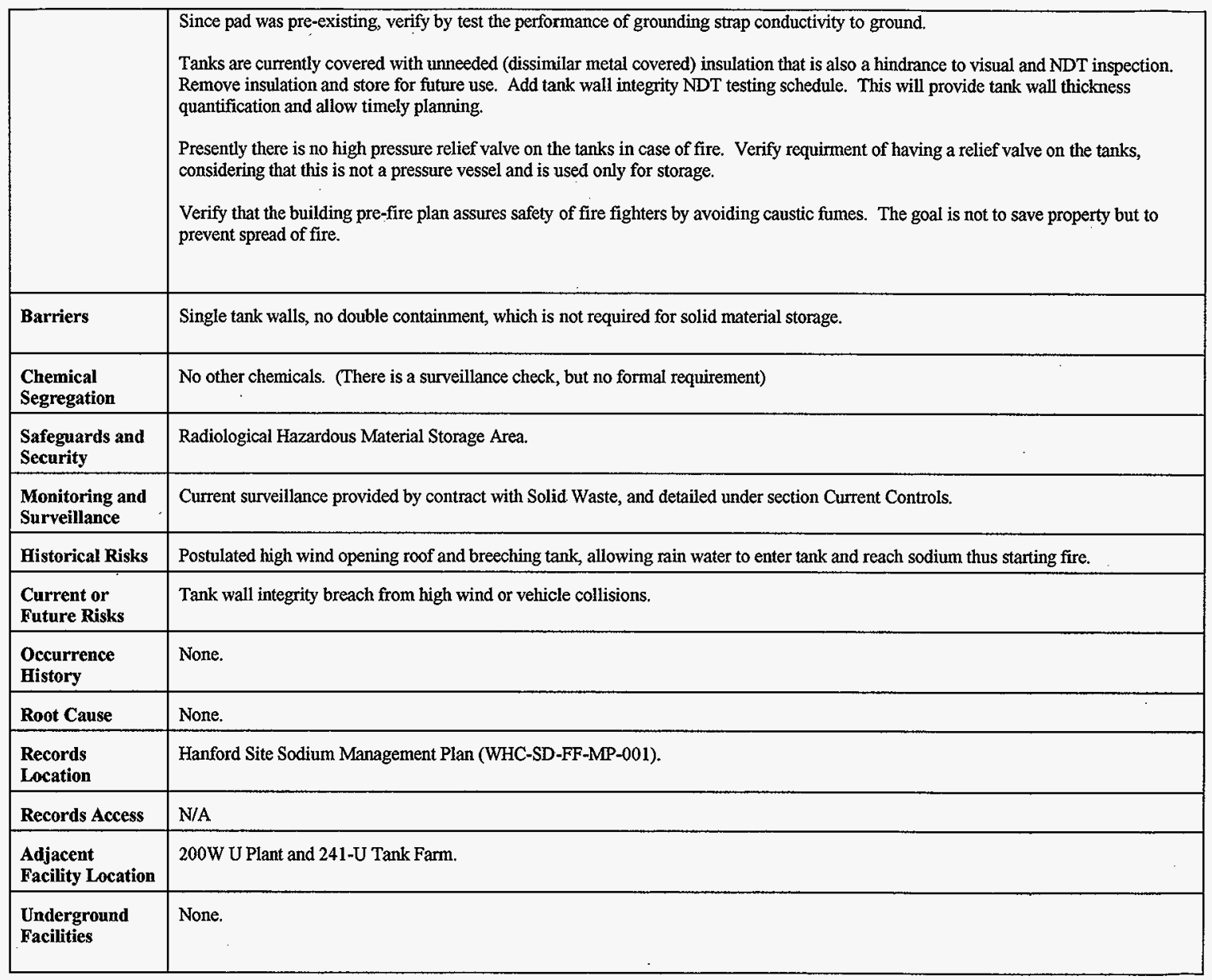




\begin{tabular}{|l|l|}
\hline $\begin{array}{l}\text { Aboveground } \\
\text { Facilities }\end{array}$ & Electrical power connection only. \\
\hline BIO Coverage & $\begin{array}{l}\text { Covered Tank Waste Remediation System, Basis for Interim Operation, HNF-SD-WM-BIO-001, Section 5.3.2 10. The safety analysis } \\
\text { identified only toxicological consequences. No radiological consequences exceeding risk guidelines were discussed. However, the BIO } \\
\text { takes credit for a small metal building in a metal fire, which may not be appropriate. }\end{array}$ \\
\hline FSAR Coverage & Covered in Tank Farms FSAR, HNF-SD-WM-SAR-067, Rev., G, Section 4.4.3. \\
\hline $\begin{array}{l}\text { Information } \\
\text { Sources }\end{array}$ & $\begin{array}{l}\text { Drawing H-2-34084. Brett Barnes for copy of Hanford Site Sodium Management Plan (WHC-SD-FF-MP-001). Mike Aichele for } \\
\text { surveillance routines and review. James E. (Jim) Mitchell for review and nitrogen configuration. Tank Waste Remediation System, } \\
\text { Basis for Interim Operation, HNF-SD-WM-BIO-001, Section 5.3.2 10., and the Tank Farms FSAR, HNF-SD-WM-SAR-067, Rev. G, } \\
\text { Section 4.4.3. Also procedure SW-04-043, Inspect the CWC and Sodium Storage Building and Associated Equipment. }\end{array}$ \\
\hline
\end{tabular}


FACILITY HAZARD PROFILE CHECKLIST

Rev. 0, April 20, 1998

\begin{tabular}{|c|c|c|c|c|c|c|c|c|c|c|}
\hline Facility ID: & \multicolumn{2}{|l|}{ Grout } & \multicolumn{2}{|c|}{ Facility Name: } & \multicolumn{6}{|c|}{ Grout Treatment Facility } \\
\hline Owner/Operator & \multicolumn{2}{|c|}{ Location } & Capacity & $\begin{array}{l}\text { Volume of } \\
\text { Contents }\end{array}$ & $\begin{array}{l}\text { Sludge } \\
\text { Volume }\end{array}$ & $\begin{array}{l}\text { Liquid } \\
\text { Volume }\end{array}$ & Risers & $\begin{array}{l}\text { Active/ } \\
\text { Inactive }\end{array}$ & $\begin{array}{l}\text { Fissile } \\
\text { Content }\end{array}$ & $\begin{array}{l}\text { Rad } \\
\text { Content }\end{array}$ \\
\hline $\mathrm{LMH}$ & \multicolumn{2}{|l|}{$200 \mathrm{E}$} & $\begin{array}{l}\text { Detailed } \\
\text { below }\end{array}$ & $\begin{array}{l}\text { Detailed } \\
\text { below }\end{array}$ & 0 & 0 & 0 & Inactive & $\begin{array}{l}\text { Non- } \\
\text { TRU }\end{array}$ & Low-level \\
\hline Hardware & DMF: & \multicolumn{9}{|c|}{ 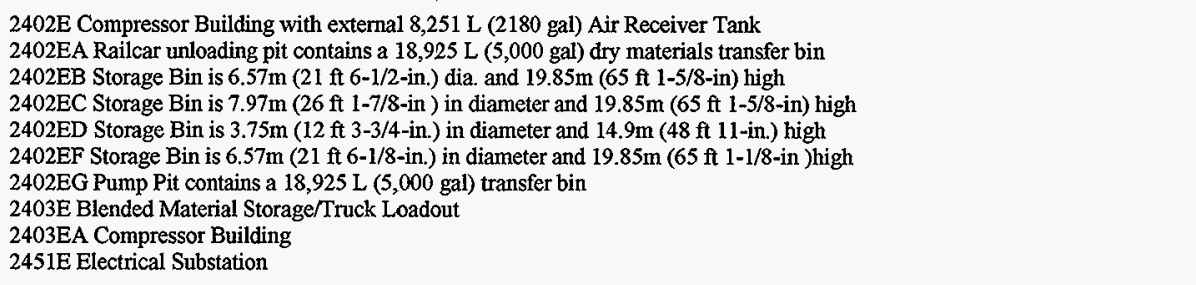 } \\
\hline Hardware Cont. & GPF: & \multicolumn{9}{|c|}{$\begin{array}{l}\text { Control Room, Change Room/Lunch Room, Decon Additive Module, Dry Blend Module, Air Filtration module, Motor Pit, and } \\
\text { adjacent Liquid Collection Tank/Mixer Module. } \\
\text { Decon Additive Module contains } 5 \text { tanks. } \\
\text { Tank R01 is a } 379 \mathrm{~L} \text { ( } 100 \mathrm{gal}) \text { Additive Tank. } \\
\text { Tank } \mathrm{R} 02 \text { is a } 1,893 \mathrm{~L} \text { ( } 500 \mathrm{gal}) \text { Additive Tank. } \\
\text { Tank R03 is a } 946 \mathrm{~L} \text { ( } 250 \mathrm{gal}) \text { Additive Tank. } \\
\text { Tank R04 is a } 757 \mathrm{~L}(200 \mathrm{gal}) \text { Additive Tank. } \\
\text { Tank F01 is a } 1,893 \mathrm{~L} \text { ( } 500 \mathrm{gal}) \text { decontamination solution storage tank. } \\
\text { The Dry Blend Module contains a } 62.3 \text { cu meters }\left(2,200 \mathrm{ft}^{3)} \text { storage bin which is } 3 \mathrm{~m}(10 \mathrm{ft}) \text { in diameter and } 7.93 \mathrm{~m}(26 \mathrm{ft}) \text { high, }\right. \\
\text { and two bag house filters. } \\
\text { The Air Filtration module contains two dual HEPA filter trains. } \\
\text { The Motor Pit contains a small sampling glovebox. }\end{array}$} \\
\hline
\end{tabular}




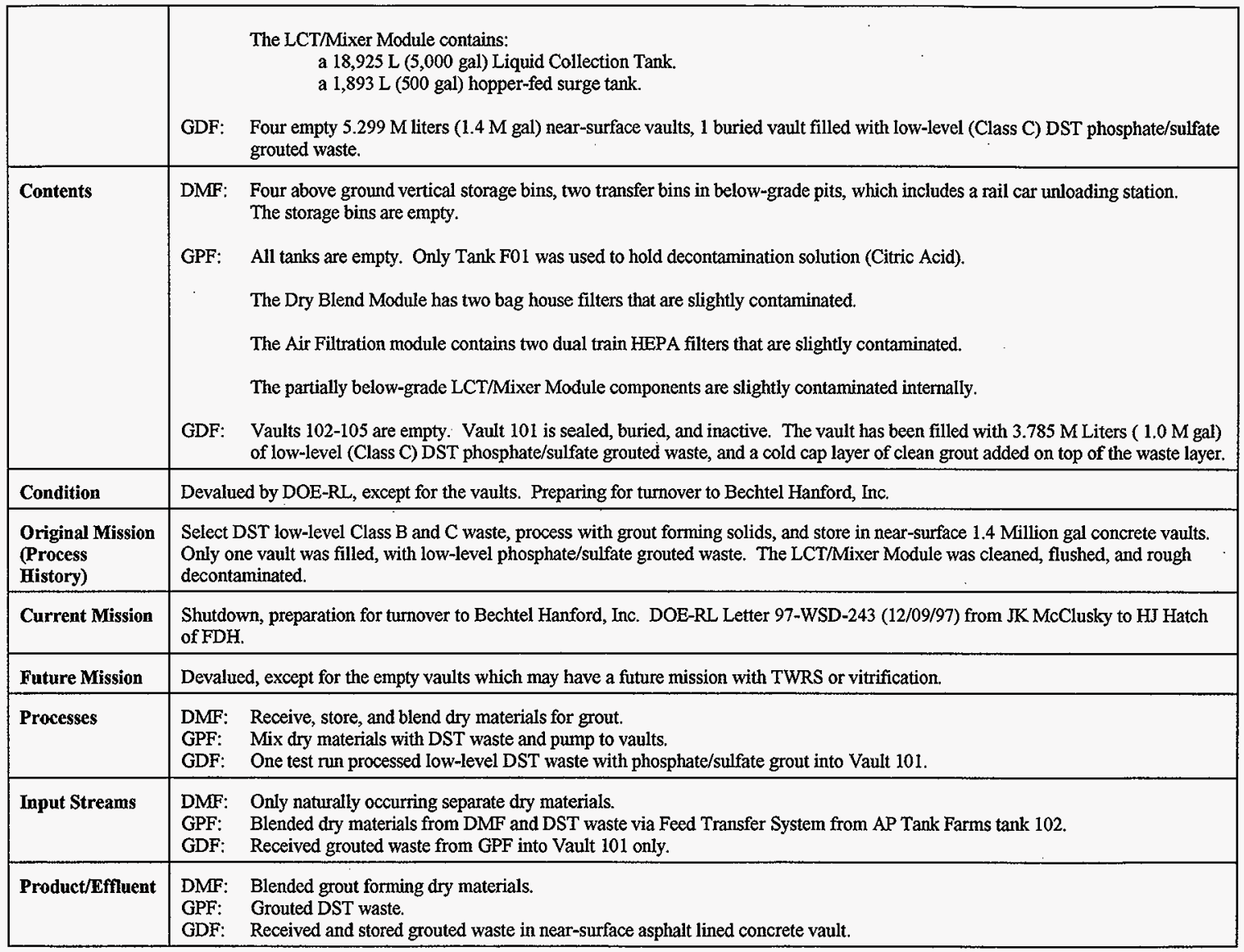




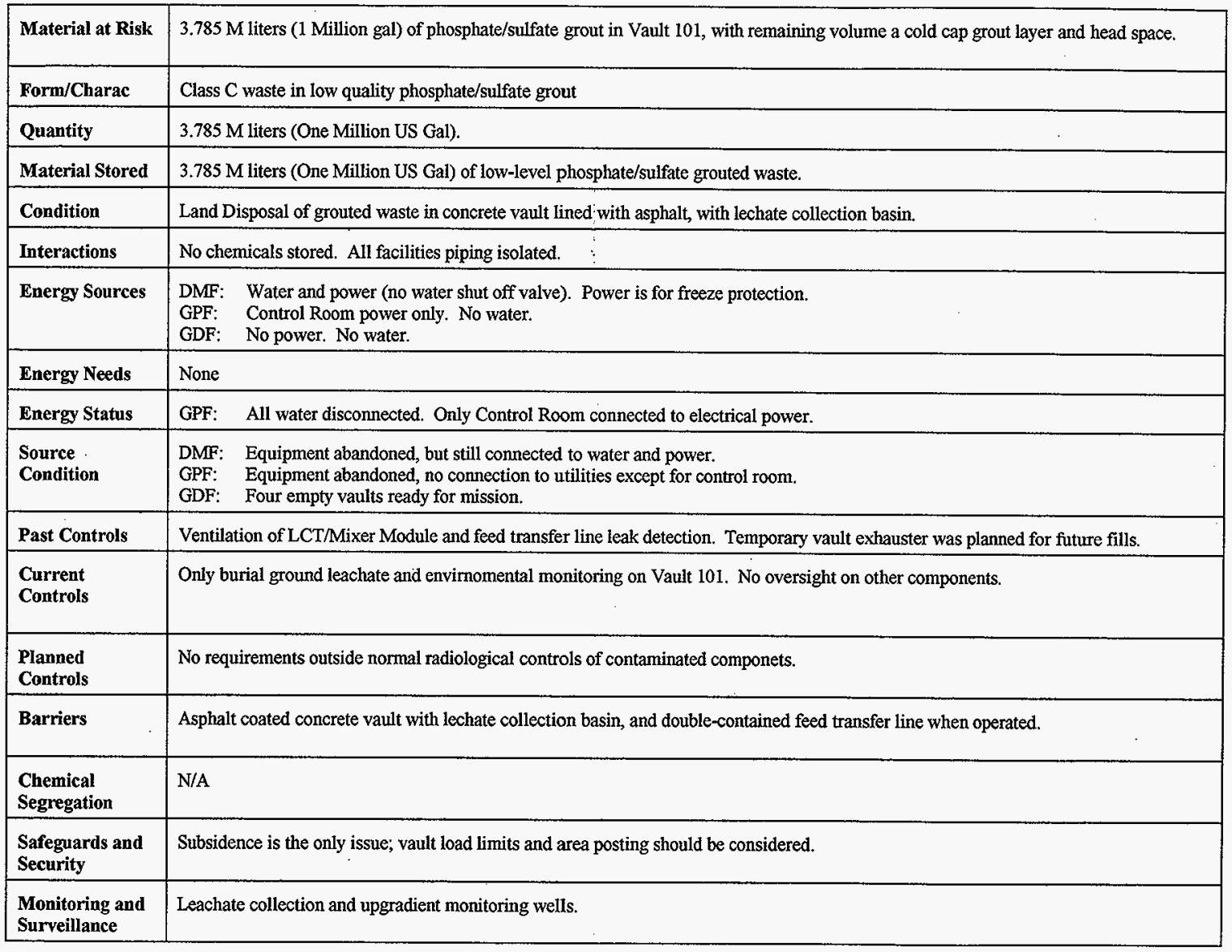




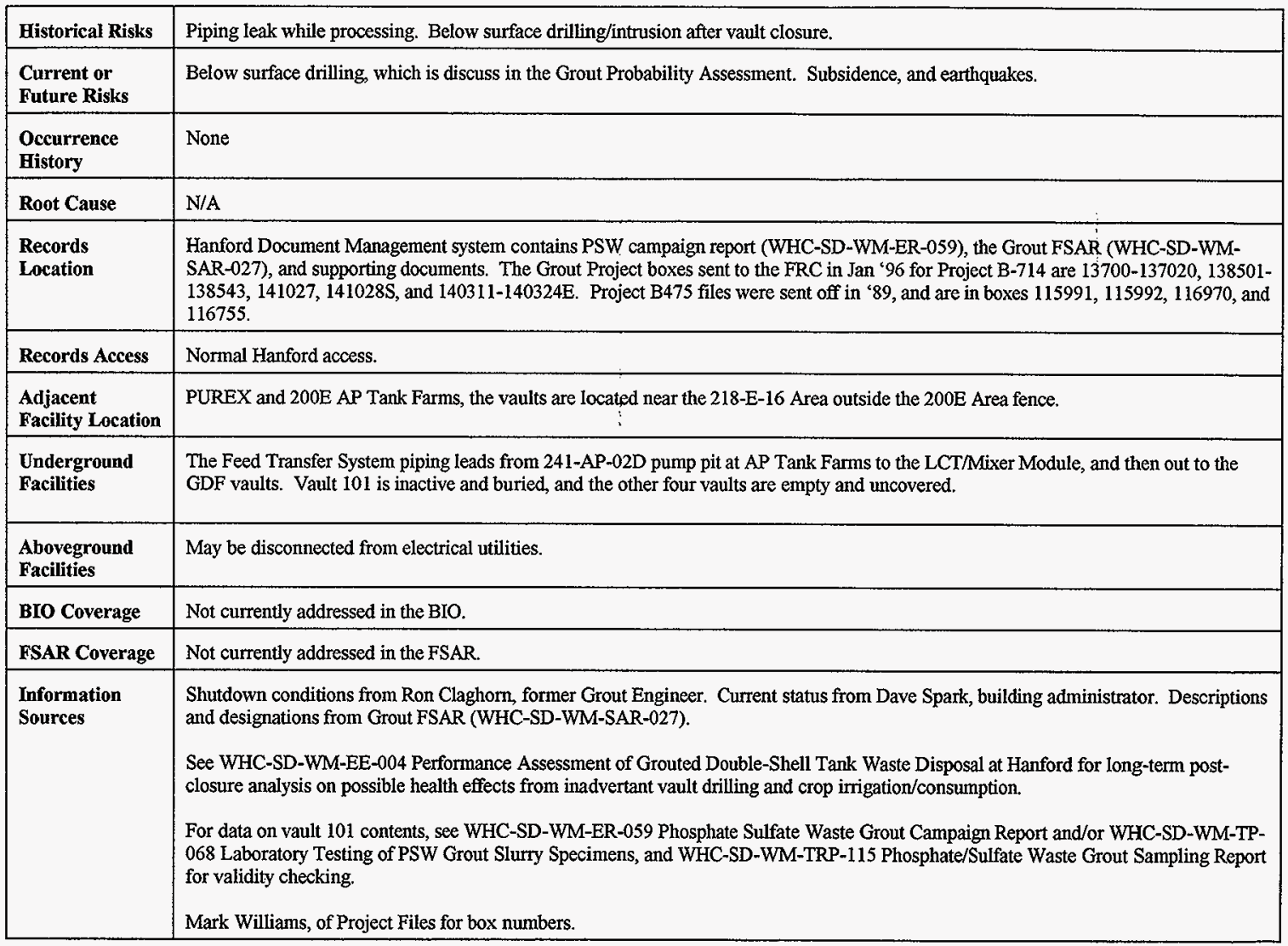


FACILITY HAZARD PROFIL CHECKLIST

Rev. 0, April 20, 1998

\begin{tabular}{|c|c|c|c|c|c|c|c|c|c|}
\hline Facility ID: & 241-BY-ITS-1 & Facility I & ime: & \multicolumn{6}{|c|}{ ITS-1 OFF GAS SYSTEM } \\
\hline Owner/Operator & Location & Capacity & $\begin{array}{l}\text { Volume of } \\
\text { Contents }\end{array}$ & $\begin{array}{l}\text { Sludge } \\
\text { Volume }\end{array}$ & $\begin{array}{l}\text { Liquid } \\
\text { Volume }\end{array}$ & Risers & $\begin{array}{l}\text { Active/ } \\
\text { Inactive }\end{array}$ & $\begin{array}{l}\text { Fissile } \\
\text { Content }\end{array}$ & $\begin{array}{l}\text { Rad } \\
\text { Content }\end{array}$ \\
\hline TWRS & $\begin{array}{l}\text { 200-E Area in 241-BY } \\
\text { Tank Farm }\end{array}$ & $\begin{array}{l}\text { *See } \\
\text { Below }\end{array}$ & $\begin{array}{l}\text { *See } \\
\text { Below }\end{array}$ & $\begin{array}{l}\text { *See } \\
\text { Below }\end{array}$ & $\begin{array}{l}\text { *See } \\
\text { Below }\end{array}$ & $\begin{array}{l}\text { Not } \\
\text { Applicable }\end{array}$ & $\begin{array}{l}\text { Shut } \\
\text { Down } \\
\text { Isolated }\end{array}$ & TBD & TBD \\
\hline Configuration & \multicolumn{9}{|c|}{ The system is isolated from tank farm facilities. Ducting has been removed. Piping is disconnected and capped. } \\
\hline Hardware & \multicolumn{9}{|c|}{ 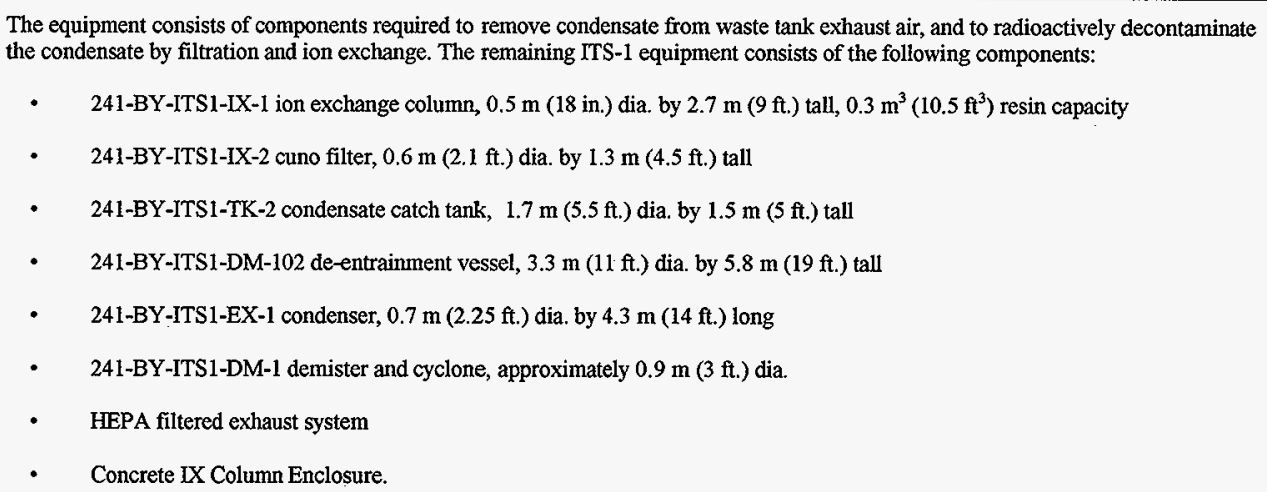 } \\
\hline Contents & \multicolumn{9}{|c|}{$\begin{array}{l}\text { The shutdown plan called for draining all liquids and ion exchange resin to underground tanks. Small amounts of liquid may remain in } \\
\text { vessels. Actual draining of column has not been verified. }\end{array}$} \\
\hline
\end{tabular}




\begin{tabular}{|c|c|}
\hline $\begin{array}{l}\text { Original Mission } \\
\text { (Process History) }\end{array}$ & $\begin{array}{l}\text { The ITS- } 1 \text { offgas system was used in the } 1960 \text { s to treat the offgas from underground radioactive waste storage tanks. Tank contents were } \\
\text { evaporated by sparging heated air through the waste. The offgas system removed and decontaminated condensate, and filtered the dried } \\
\text { air exhaust. }\end{array}$ \\
\hline Current Mission & None. Isolated and awaiting dismantling. \\
\hline Future Mission & None. To be dismantled when BY Farm is brought to Controlled-Clean-Stable status, est. FY2000. \\
\hline Processes & None. In operation or planned. Last operation (condensate removal, cleanup) shutdown more than 30 years ago. \\
\hline Input Streams & None. System is blanked, sealed, and isolated. \\
\hline Product/Effluent & None. Some atmospheric breathing/venting is occurring through the HEPA filtered vent (passive). \\
\hline Material at Risk & None. System is sealed, awaiting dismantling. Small amounts of radiation contamination remains in vessels and piping. \\
\hline Form/Charac & $\begin{array}{l}\text { Small amounts of solid radioactive residue and possible aqueous condensate may remain in vessels and piping. It is also possible that } \\
\text { Zeolite, an ion exchange medium, remains in the ion exchange column. }\end{array}$ \\
\hline Quantity & Liquid - estimated at less than 100 gal. Zeolite may remain in the IX column. \\
\hline Material Stored & Residual condensate (if any), residual waste in demister elements. Zeolite may remain in the LX column. \\
\hline Condition & Material is safely contained. \\
\hline Interactions & None. Facility is sealed and isolated. \\
\hline Energy Sources & $\begin{array}{l}\text { None. Facility is sealed and isolated. There is a slight possibility that hydrogen is present in vessels and piping due to radiolytes decay } \\
\text { in the presence of water. }\end{array}$ \\
\hline Energy Needs & None. No part of system is operating. No part will operate in future. \\
\hline Energy Status & No parts of system are energized. \\
\hline $\begin{array}{l}\text { Source } \\
\text { Condition }\end{array}$ & Source isolation needs to field verified. \\
\hline \multicolumn{2}{|l|}{ Past Controls } \\
\hline $\begin{array}{l}\text { Current } \\
\text { Controls }\end{array}$ & None. Facility is isolated awaiting dismantling. Facility is visually inspected on daily basis by operator rounds. \\
\hline
\end{tabular}




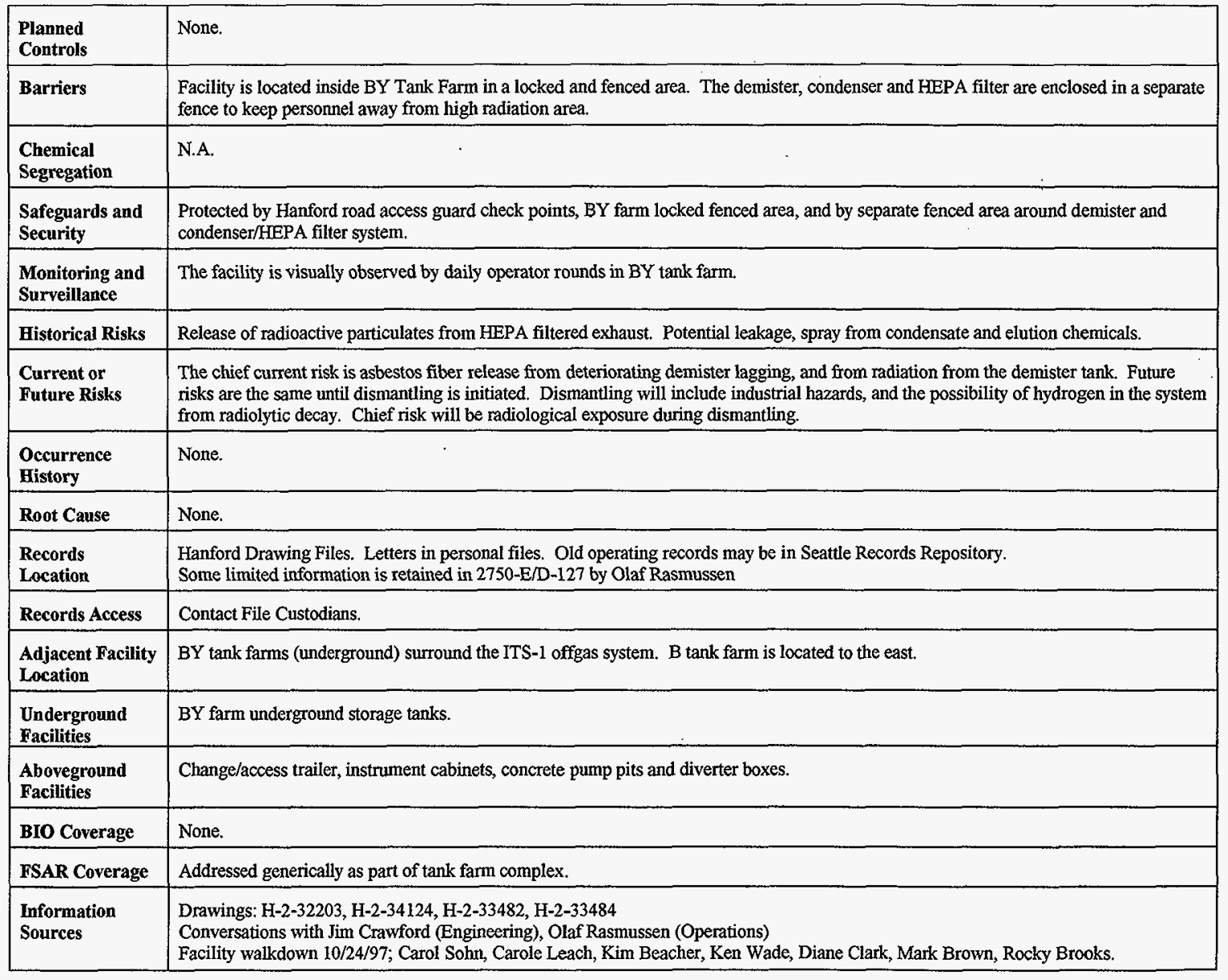


FACILITY HAZARD PROFUE CHECKLIST

Rev. 0, April 20, 1998

\begin{tabular}{|c|c|c|c|c|c|c|c|c|c|}
\hline Facility $\mathbf{D :}$ & 241-BY-ITS2-TK-1 & \multicolumn{2}{|c|}{ Facility Name: } & \multicolumn{6}{|c|}{ 241-BY-ITS2 Condenser Vessel } \\
\hline Owner/Operator & Location & Capacity & $\begin{array}{l}\text { Volume of } \\
\text { Contents }\end{array}$ & $\begin{array}{l}\text { Sludge } \\
\text { Volume }\end{array}$ & $\begin{array}{l}\text { Liquid } \\
\text { Volume }\end{array}$ & Risers & $\begin{array}{l}\text { Active/ } \\
\text { Inactive }\end{array}$ & $\begin{array}{l}\text { Fissile } \\
\text { Content }\end{array}$ & $\begin{array}{l}\text { Rad } \\
\text { Content }\end{array}$ \\
\hline LMHC & 200W BY Tank Farm & $\begin{array}{l}\text { Detailed } \\
\text { below }\end{array}$ & $\begin{array}{l}\text { Detailed } \\
\text { below }\end{array}$ & 0 & 0 & 0 & Inactive & Unknown & Unknown \\
\hline Geometry & \multicolumn{9}{|c|}{ A small vapor condenser, $76.2 \mathrm{~cm}$ (30 in.) in diameter by $2.9 \mathrm{~m}(9.5 \mathrm{ft}$.) in a pit above Tank $241-\mathrm{BY}-112$. } \\
\hline Configuration & \multicolumn{9}{|c|}{ The condenser has been disconnected. } \\
\hline Hardware & \multicolumn{9}{|c|}{ A small, approximately 1,320 Liters (349 gal) vapor condenser. } \\
\hline Contents & \multicolumn{9}{|c|}{$\begin{array}{l}\text { The radiological and chemical contents in the condenser are unknown, assume condensed vapors and carry-over particles. The } \\
\text { condenser was disconnected and no longer in service. }\end{array}$} \\
\hline Condition & \multicolumn{9}{|l|}{ Abandoned in place. } \\
\hline $\begin{array}{l}\text { Original Mission } \\
\text { (Process } \\
\text { History) }\end{array}$ & \multicolumn{9}{|c|}{ Condense vapor from heated in-ground waste storage tank. } \\
\hline Current Mission & \multicolumn{9}{|c|}{ None, component disconnected and inactive. } \\
\hline Future Mission & \multicolumn{9}{|l|}{ None } \\
\hline Processes & \multicolumn{9}{|c|}{ Remove moisture and entrained particles from vapor. } \\
\hline Input Streams & \multicolumn{9}{|c|}{ Waste tank heated vapors, and volatile chemicals. } \\
\hline Product/Effluent & \multicolumn{9}{|c|}{ Deentrained waste tank vapor. } \\
\hline Material at Risk & \multicolumn{9}{|c|}{ Contents unknown, assume condensed waste vapors from in-ground single-shell tank(s). } \\
\hline Form/Charac & \multicolumn{9}{|c|}{ The form of any possibly remaining waste is unknown. } \\
\hline
\end{tabular}

Original Mission

History)

Current Mission

one, component disconnected and inactive.

Future Mission

Remove moisture and entrained particles from vapor

Input Streams 


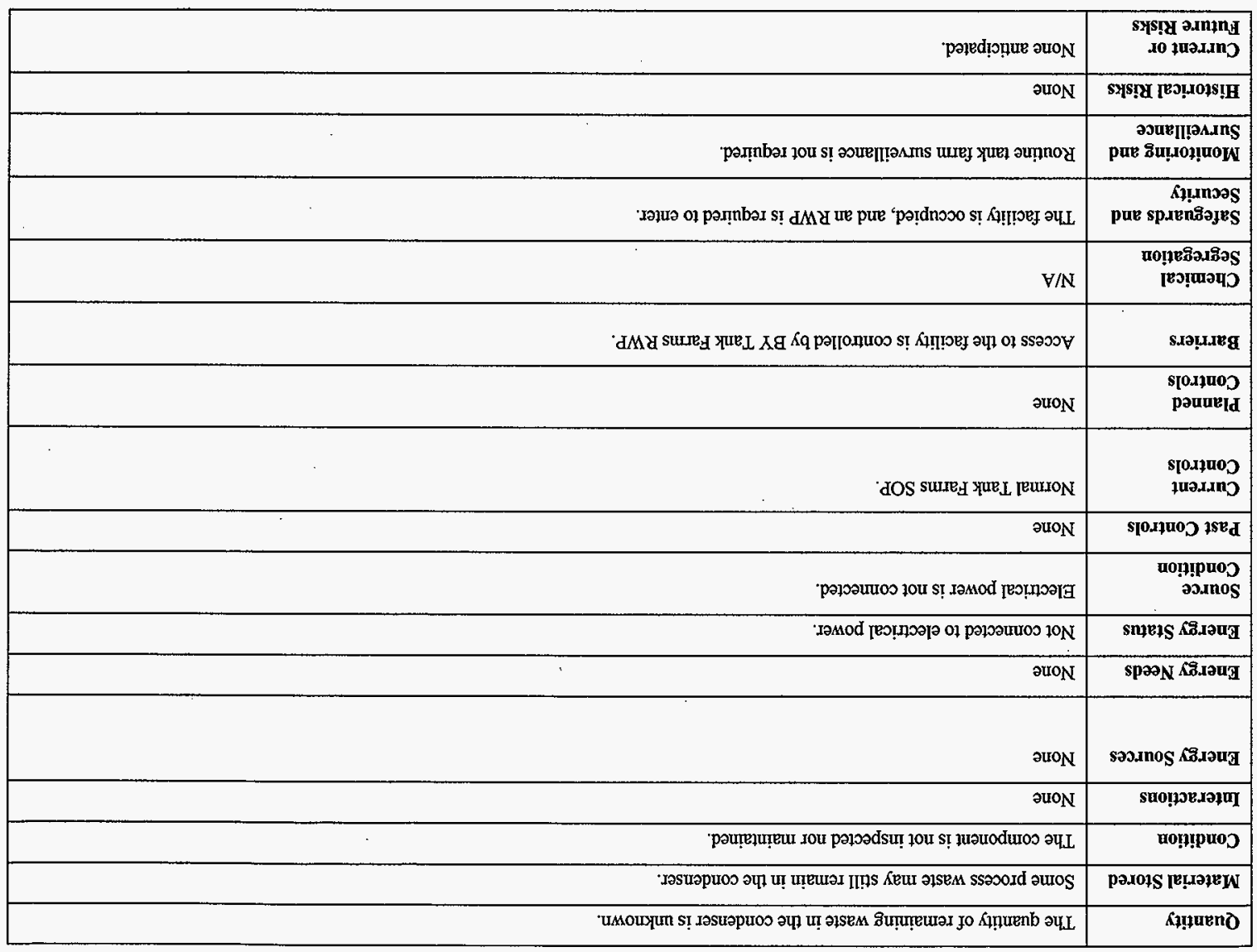




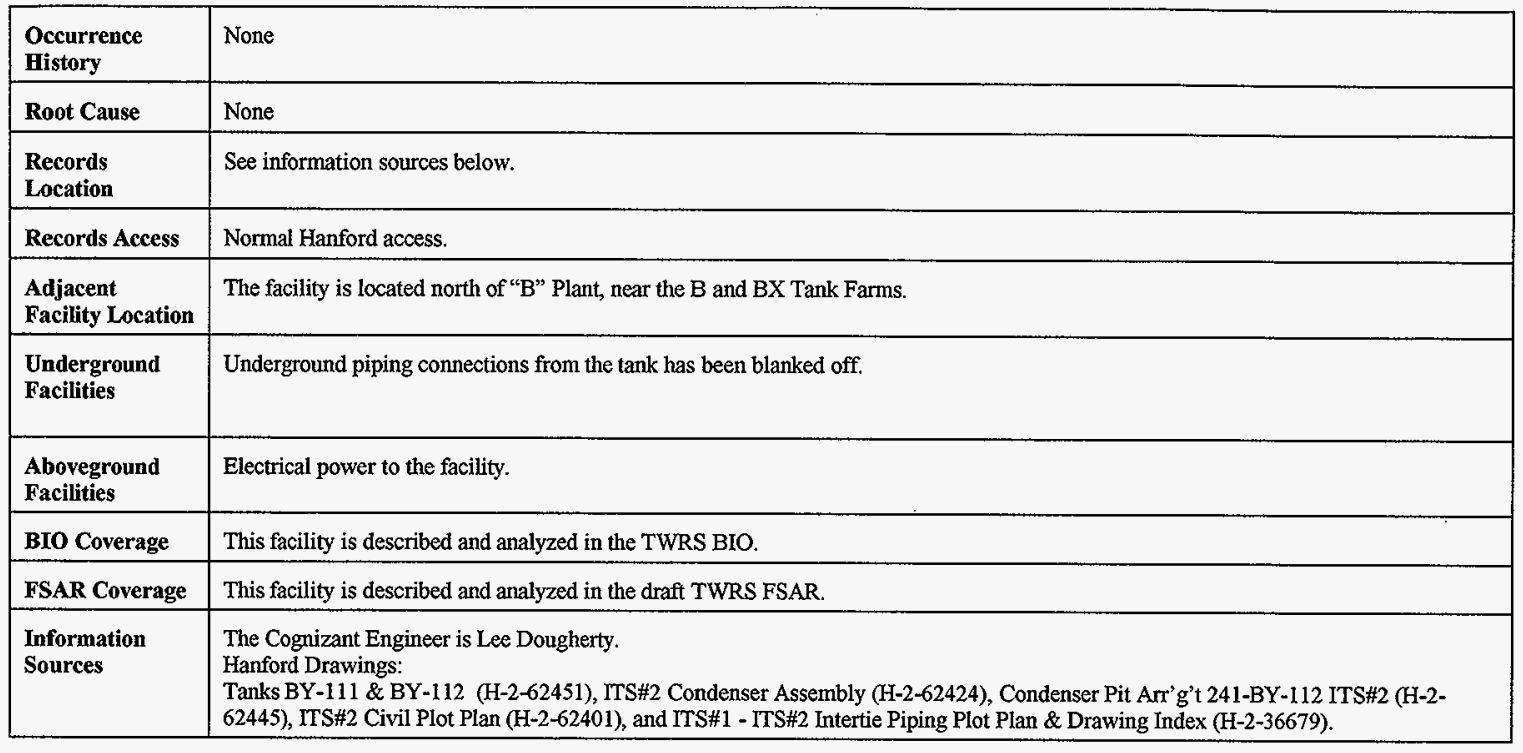




\section{FACILITY HAZARD PROFIL CHECKLIST}

Rev. 0, April 20, 1998

\begin{tabular}{|c|c|c|c|c|c|c|c|c|c|}
\hline Facility W: & 241-BY-ITS2-TK-2 & \multicolumn{2}{|c|}{ Facility Name: } & \multicolumn{6}{|c|}{ 241-BY-ITS2 Heater Flush Tank } \\
\hline Owner/Operator & Location & Capacity & $\begin{array}{l}\text { Volume of } \\
\text { Contents }\end{array}$ & $\begin{array}{l}\text { SIndge } \\
\text { Volume }\end{array}$ & $\begin{array}{l}\text { Liquid } \\
\text { Volume }\end{array}$ & Risers & $\begin{array}{l}\text { Active/ } \\
\text { Inactive }\end{array}$ & $\begin{array}{l}\text { Fissile } \\
\text { Content }\end{array}$ & $\begin{array}{l}\text { Rad } \\
\text { Content }\end{array}$ \\
\hline LMHC & 200W BY Tank Farm & $\begin{array}{l}\text { Detailed } \\
\text { below }\end{array}$ & $\begin{array}{l}\text { Detailed } \\
\text { below }\end{array}$ & 0 & 0 & 0 & Inactive & Unknown & Unknown \\
\hline Geometry & \multicolumn{9}{|c|}{ A vertical in-ground heater flush tank. The flush tank is installed between Tank 241-BY-111 and Tank 241-BY-112. } \\
\hline Configuration & \multicolumn{9}{|c|}{ The flush tank contains a sparger ring and full length flush pipe. The flush tank is not connected to any vessel or piping. } \\
\hline Hardware & \multicolumn{9}{|c|}{$\begin{array}{l}12.8 \mathrm{~m}(42 \mathrm{ft} .) \text { of } 101 \mathrm{~cm}(40 \mathrm{in} .) \mathrm{ID} \text { pipe inside } 13.1 \mathrm{~m}(43 \mathrm{ft} \text {.) of } 118.1 \mathrm{~cm}(46.5 \mathrm{in} \text {.) } \mathrm{ID} \text { caisson on bottom [mated to a } 5.18 \mathrm{~m}(17 \mathrm{ft} \text {.) of } \\
122 \mathrm{~cm}(48 \mathrm{in} \text {.) OD pipe top section]. }\end{array}$} \\
\hline Contents & \multicolumn{9}{|c|}{ The radiological and chemical contents in the approximately 10,379 Liter (2,742 gal) flush tank are unknown. The tank was abandoned. } \\
\hline Condition & \multicolumn{9}{|c|}{ The tank has been inactive since 1977.} \\
\hline $\begin{array}{l}\text { Original Mission } \\
\text { (Process } \\
\text { History) } \\
\end{array}$ & \multicolumn{9}{|c|}{ To decontaminate heater elements used for in-tank heating. } \\
\hline Current Mission & \multicolumn{9}{|l|}{ None, inactive. } \\
\hline Future Mission & \multicolumn{9}{|l|}{ None } \\
\hline Processes & \multicolumn{9}{|c|}{ Dip heater elements in tank. } \\
\hline Input Streams & \multicolumn{9}{|l|}{ None } \\
\hline Product/Effluent & \multicolumn{9}{|l|}{ None } \\
\hline Material at Risk & \multicolumn{9}{|c|}{ Unknown dissolved single-shell waste tank contamination. } \\
\hline
\end{tabular}




\begin{tabular}{|c|c|}
\hline posedpọnue auon & 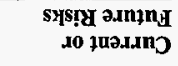 \\
\hline umoursun & 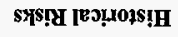 \\
\hline 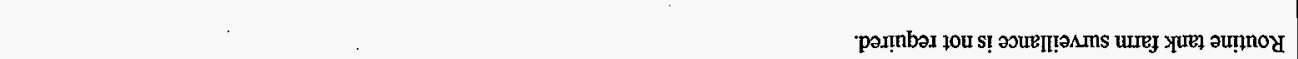 & 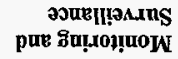 \\
\hline 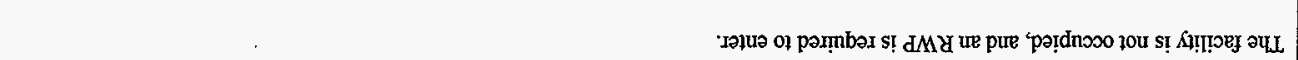 & 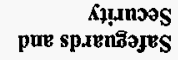 \\
\hline 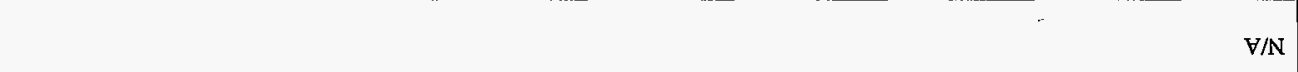 & 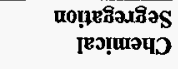 \\
\hline 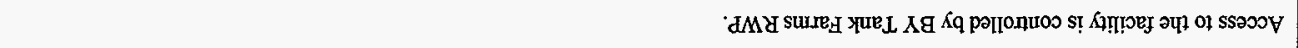 & s.rẹ.ueg \\
\hline aroN & $\begin{array}{l}\text { sponuoj } \\
\text { pəuareld }\end{array}$ \\
\hline 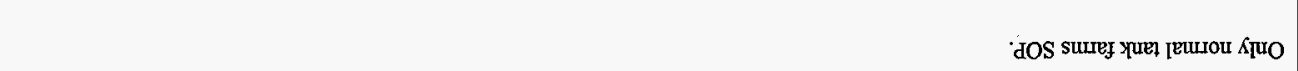 & 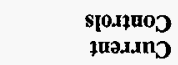 \\
\hline 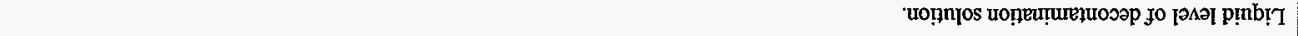 & 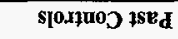 \\
\hline 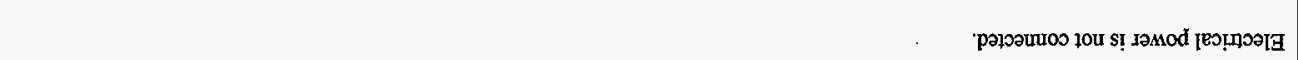 & $\begin{array}{l}\text { noupppos } \\
\text { ә0.nnos }\end{array}$ \\
\hline 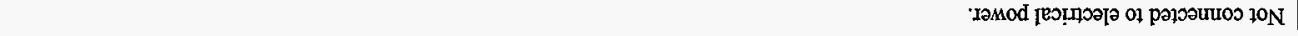 & 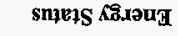 \\
\hline axoN & 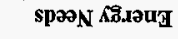 \\
\hline כuoN & 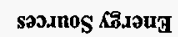 \\
\hline aUON & suo!̣pe.rə\}山I \\
\hline 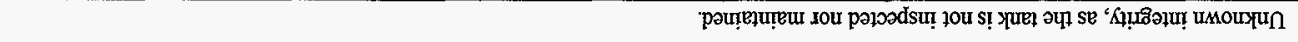 & шо!!!pueग \\
\hline 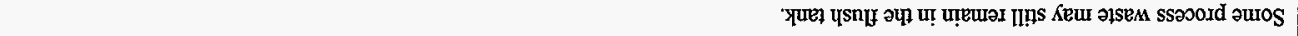 & pax01S je!najeu \\
\hline 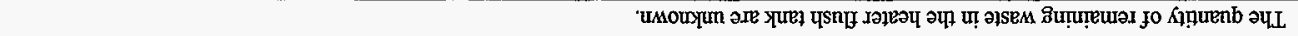 & אұ̣uenò \\
\hline 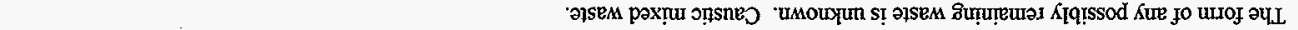 & 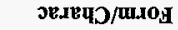 \\
\hline
\end{tabular}




\begin{tabular}{|l|l|}
\hline $\begin{array}{l}\text { Occurrence } \\
\text { History }\end{array}$ & Unknown \\
\hline Root Cause & None \\
\hline $\begin{array}{l}\text { Records } \\
\text { Location }\end{array}$ & See information sources \\
\hline Records Access & Normal Hanford access. \\
\hline $\begin{array}{l}\text { Adjacent } \\
\text { Facility Location }\end{array}$ & The facility is located north of "B" Plant, near the B and BX Tank Farms. \\
\hline $\begin{array}{l}\text { Underground } \\
\text { Facilities }\end{array}$ & No underground piping connections associated with flush tank. \\
\hline $\begin{array}{l}\text { Aboveground } \\
\text { Facilities }\end{array}$ & Electrical power to the facility. \\
\hline BIO Coverage & This facility is described and analyzed in the TWRS BIO. \\
\hline FSAR Coverage & This facility is described and analyzed in the draft TWRS FSAR. \\
\hline $\begin{array}{l}\text { Information } \\
\text { Sources }\end{array}$ & $\begin{array}{l}\text { The Cognizant Engineer is Lee Dougherty. } \\
\text { Hanford Drawings: } \\
\text { Tanks BY-111 \& BY-112 (H-2-62451), ITS Tank Heater Flush Tank (H-2-34383), and Piping Waste Tank 241-BY-111 (H-2-73256). }\end{array}$ \\
\hline
\end{tabular}

